\title{
DOE/NV/12027--2
}

\section{NYE COUNTY NUCLEAR WASTE REPOSITORY PROJECT OFFICE INDEPENDENT SCIENTIFIC INVESTIGATIONS PROGRAM ANNUAL REPORT MAY 1997 - APRIL 1998}

Prepared by:

NYE COUNTY DEPARTMENT OF NATURAL RESOURCES AND FEDERAL FACILITIES

NUCLEAR WASTE REPOSITORY PROJECT OFFICE

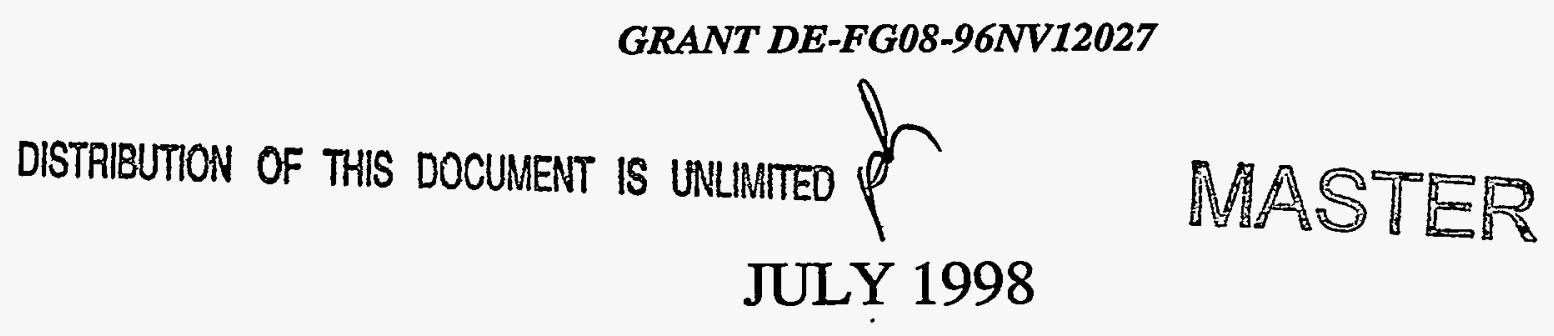




\section{DISCLAIMER}

This report was prepared as an account of work sponsored by an agency of the United States Government. Neither the United States Government nor any agency thereof, nor any of their employees, makes any warranty, express or implied, or assumes any legal liability or responsibility for the accuracy, completeness, or usefulness of any information, apparatus, product, or process disclosed, or represents that its use would not infringe privately owned rights. Reference herein to any specific commercial product, process, or service by trade name, trademark, manufacturer, or otherwise does not necessarily constitute or imply its endorsement, recommendation, or favoring by the United States Government or any agency thereof. The views and opinions of authors expressed herein do not necessarily state or reflect those of the United States Government or any agency thereof. 


\section{DISCLAIMER}

Portions of this document may be illegible electronic image products. Images are produced from the best available original document. 


\section{DISCLAIMER}

The investigations and research reported here have been conducted according to Nye County's Quality Assurance Program Plan manual, which is compliant with NQA-1 standards. However, the results reported here have not been thoroughly checked and compared against the sources of information. Some of the results are preliminary, and the quality assurance for some of the activities has not been completed as of the date of this printing. Therefore, some of the results presented in this report are subject to change and verification. 


\section{TABLE OF CONTENTS}

DISCLAIMER ...ii

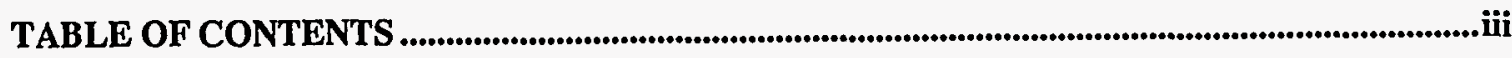

LIST OF FIGURES AND PHOTOGRAPHS................................................................................... vii

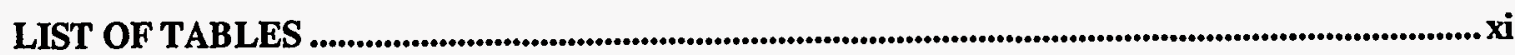

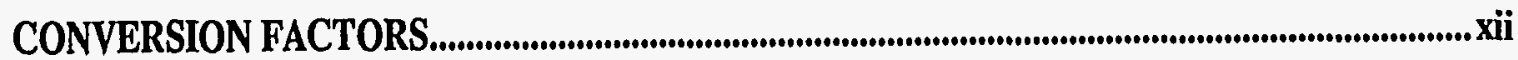

CONTENTS OF THE ACCOMPANYING MEDIA..........................................................................

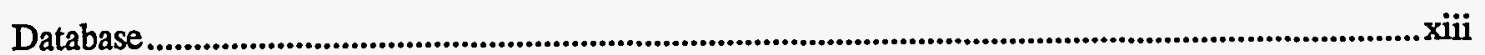

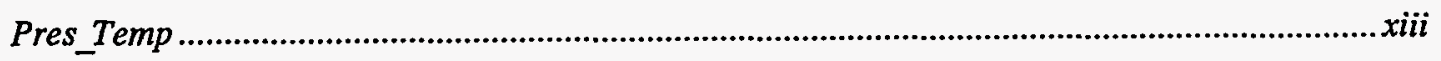

Springs Pumpage and Discharge (NQA) ....................................................................................ii

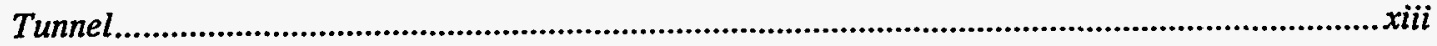

WaterLevel (NQA) ...............................................................................................................

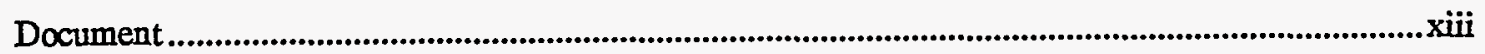

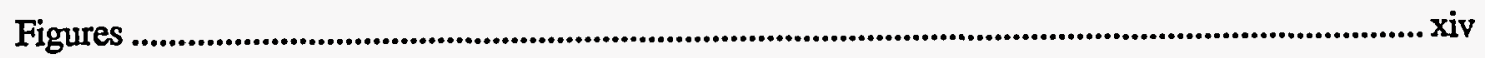

Figures in Text .................................................................................................................

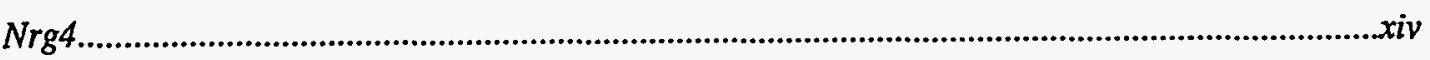

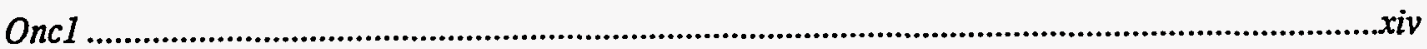

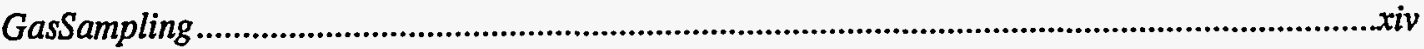

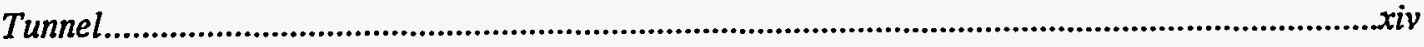

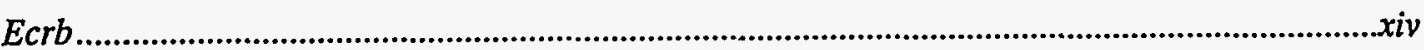

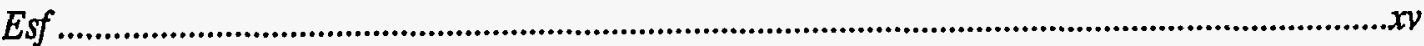

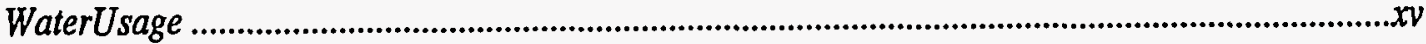

Tables and Graphs..............................................................................................................................

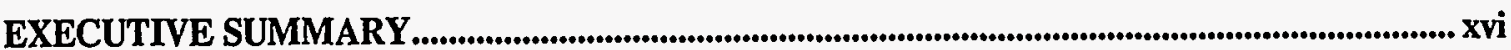

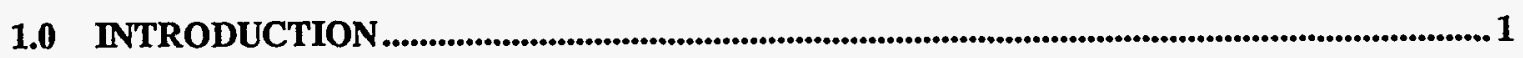

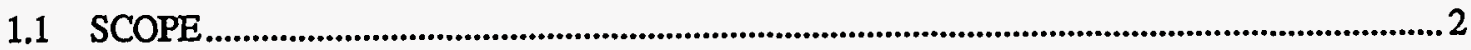

1.2 NYE COUNTY'S BOREHOLE AND TUNNEL MONITORING STUDIES............................... 3

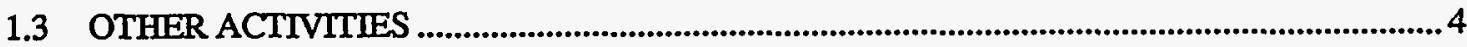

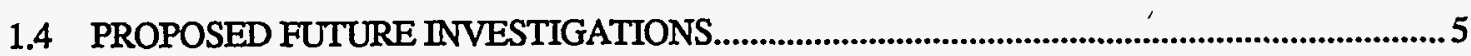


2.0 PETROGRAPHIC STUDIES OF UE-25 ONC\#1 6

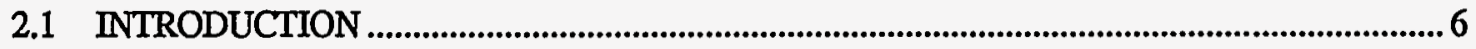

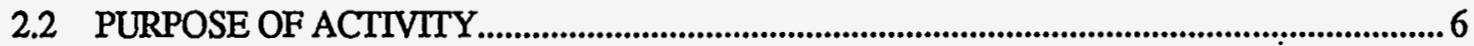

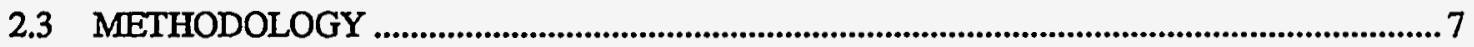

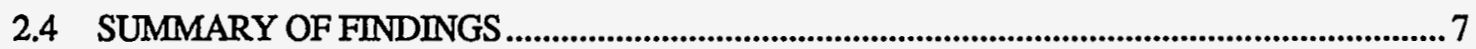

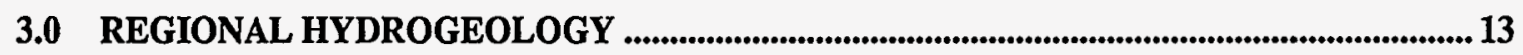

3.1 EVALUATION OF YUCCA MOUNTAIN WATER SUPPLY AND DEMAND ISSUES ......... 14

3.1.1 Definition and Evaluation of Nye County's Water Supply and Demand Issues ................. 15

3.1.1.1 Protection of Drinking Water Supplies and Wildlife Habitats ..................................................... 15

3.1.1.2 Water Use Trends and Future Water Availability..................................................................... 16

3.1.1.2.1 Managed Overdraft................................................................................................. 17

3.1.1.2.2 Carbonate Aquifer Development...................................................................................... 19

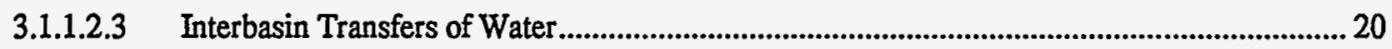

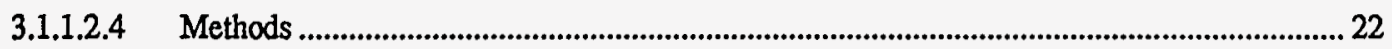

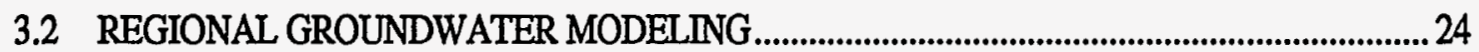

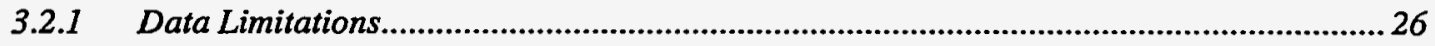

3.2.2 Death Valley Regional Flow System Boundaries.............................................................. 28

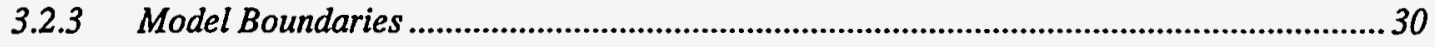

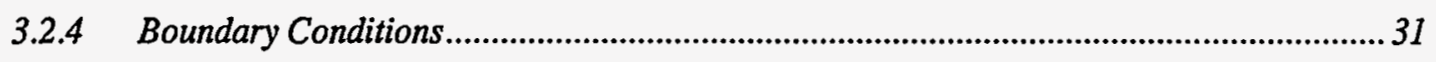

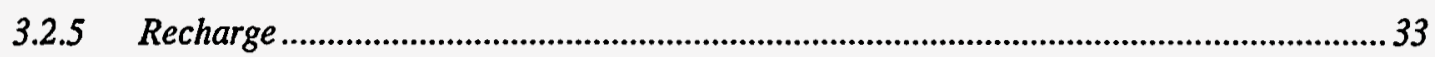

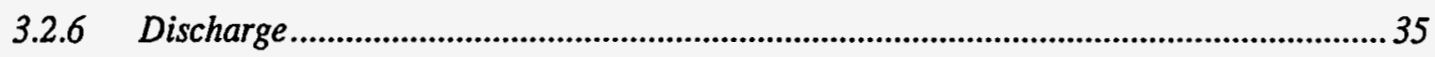

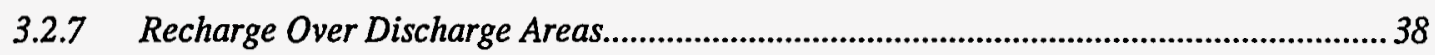

3.2.8 Steady State Versus Transient Conditions ......................................................................... 39

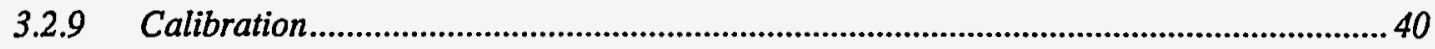

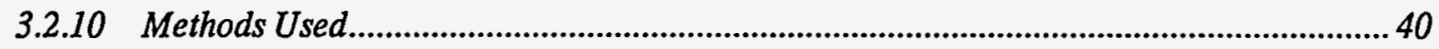

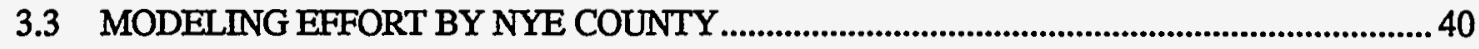

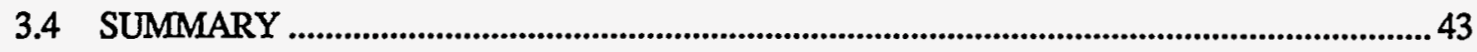

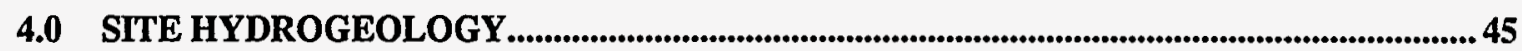

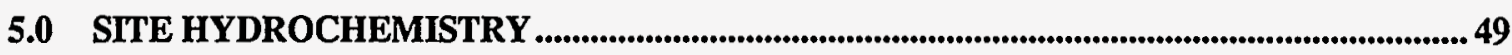

5.1 CHLORINE-36 GEOCHEMISTRY OF CUTTINGS SAMPLES FROM UE-25 ONC\#1 ........... 49

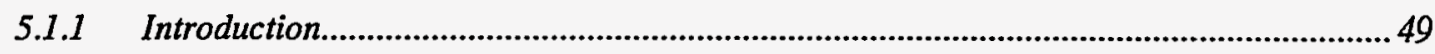

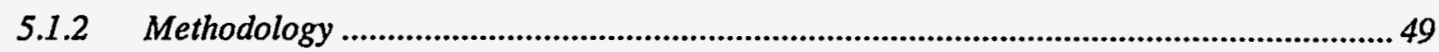

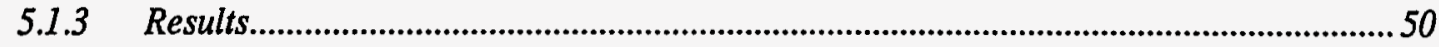

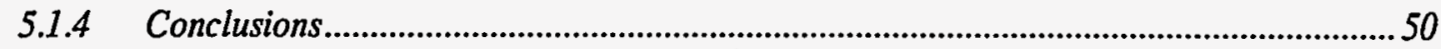




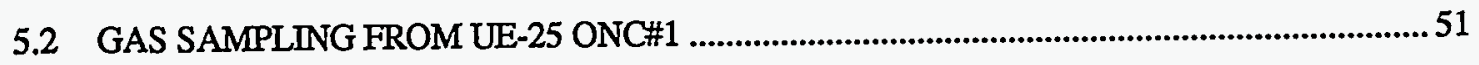

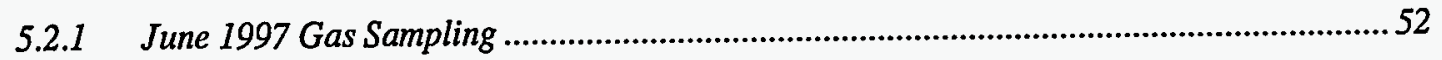

5.2.1.1 Apparatus and Sampling Procedures .............................................................................................. 53

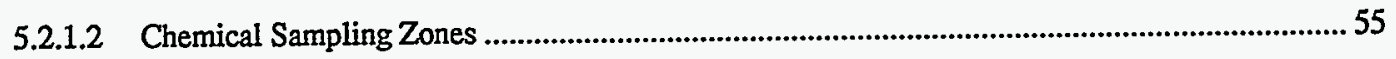

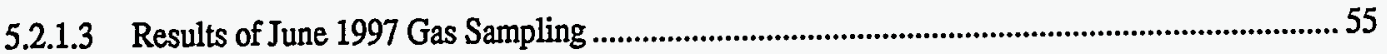

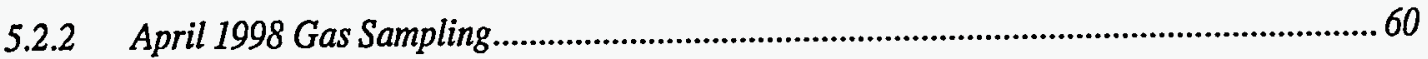

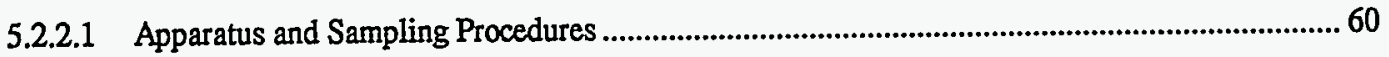

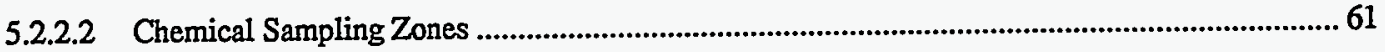

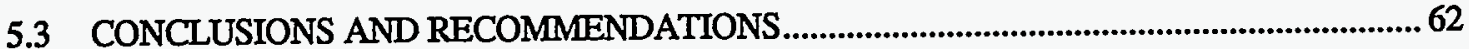

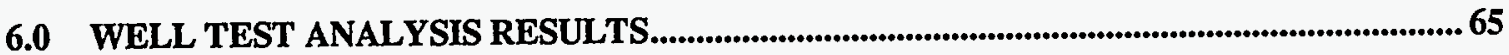

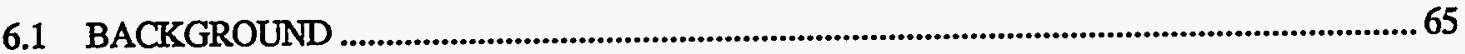

6.2 UE-25 ONC\#1 RESPONSE TO ATMOSPHERIC PRESSURE PULSES .................................65

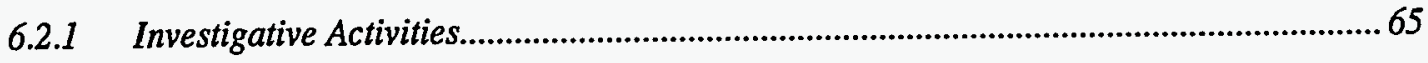

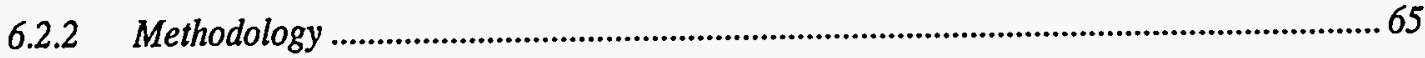

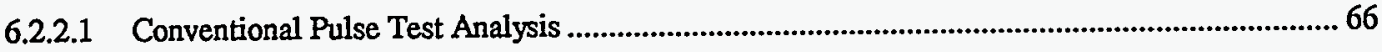

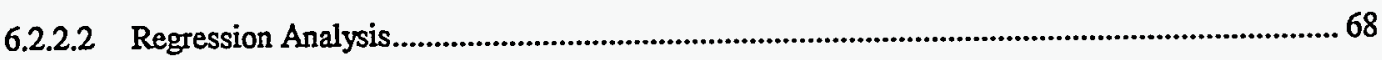

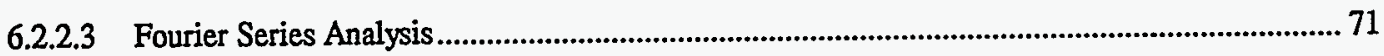

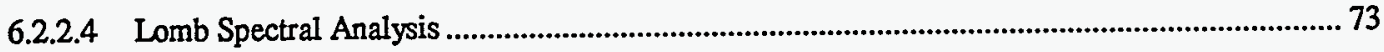

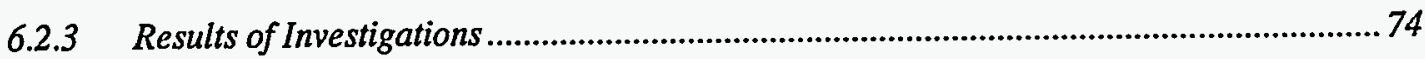

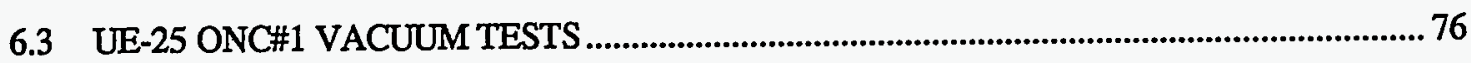

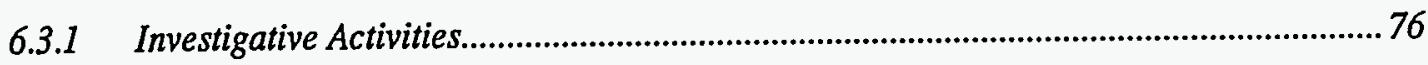

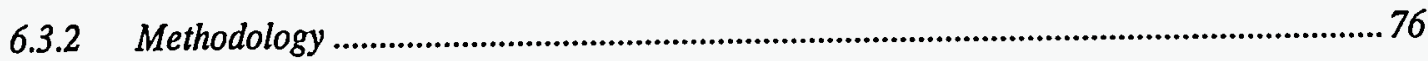

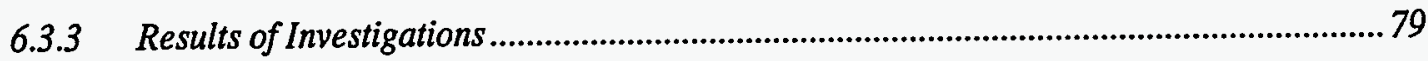

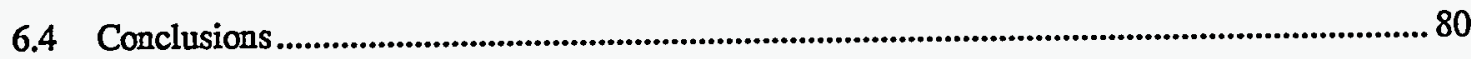

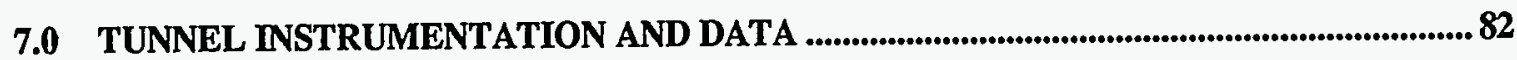

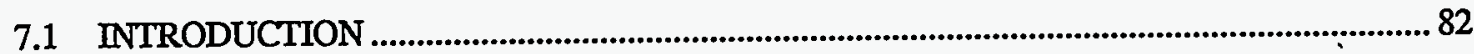

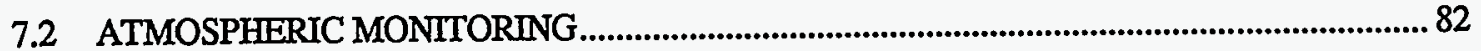

7.3 EVALUATION OF THE USE OF WATER IN THE TUNNEL .............................................. 83

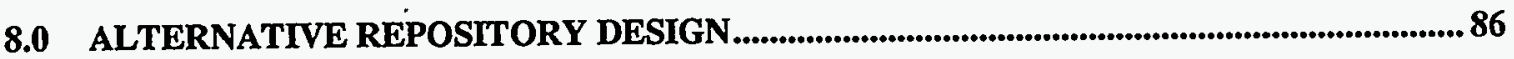

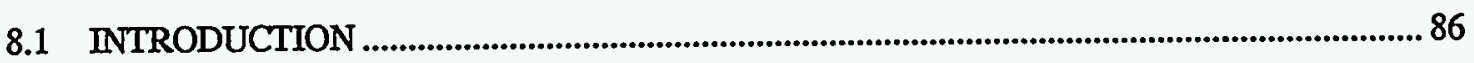

8.2 OBSERVATIONS IN THE YUCCA MOUNTAIN ESF TUNNEL .........................................8 89

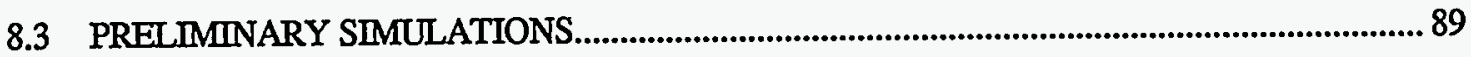

8.4 SIMULATIONS USING THE SITE-SCALE UZ MODEL ......................................................90

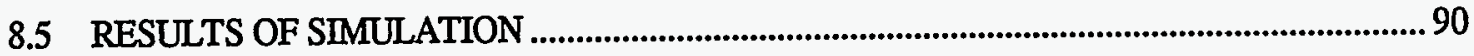

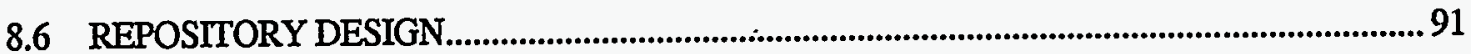




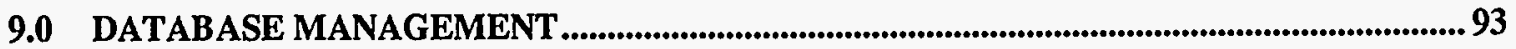

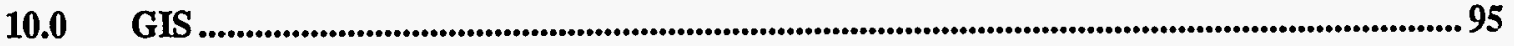

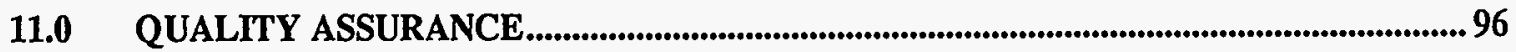

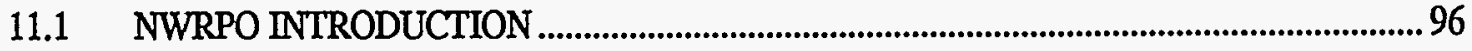

11.2 NYE COUNTY NUCLEAR WASTE REPOSITORY PROJECT OFFICE............................96

11.3 QUALITY ASSURANCE PROGRAM..............................................................................99

11.4 QA ACTIVITES - SUMMARY APRIL 1997 to APRIL 1998 .........................................98

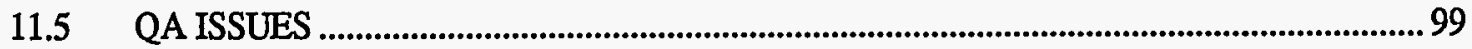

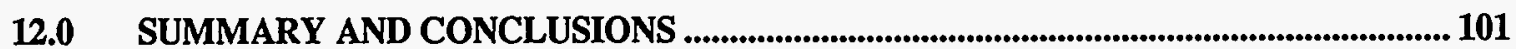

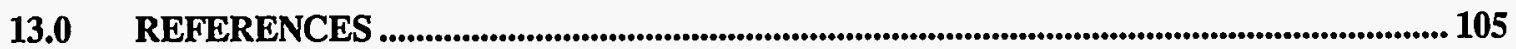




\section{LIST OF FIGURES AND PHOTOGRAPHS}

Figure 1-1

Figure 1-2

Figure 3-1

Figure 3-2

Figure 3-3

Figure 3-4

Figures $3-5 a-i$

Figures 3-6a-j

Figures $3-6 \mathrm{k}-\mathrm{m}$

Figure 3-7a

Figure $3-7 \mathrm{~b}$

Figure $3-7 \mathrm{c}$

Figure 4-1

Figure 4-2

Figure 4-3

Figure 4-4

Figure 4-5

Figure 4-6
Location of Yucca Mountain site in Nye County, Nevada

Topography, location of selected boreholes, ESF centerline and ECRB at Yucca Mountain Site

The "data gap" located down gradient of, and near to Yucca Mountain

The Death Valley flow system as defined by Harrill et al (1988)

Comparison of extent of model domains for the three regional models

Attempted mesh for the regional saturated-zone model

Water level contour maps, ten year intervals

Water level contour maps, entire data collection period

Water level contour maps, entire data collection period, all wells

Water table elevations of selected wells in Pahrump Valley

Water table elevations of selected wells in Amargosa Valley

Water table elevations of selected wells in Inyo County

Schematic profile of instrumentation setup in UE-25 ONC\# 1 and USW NRG4

Temperature variation with time in UE-25 ONC\#1 corrected with interpolation calibration, June 1997

Temperature variation with time in UE-25 ONC\#1 corrected with interpolation calibration, October 1997

Temperature variation with time in UE-25 ONC\#1 corrected with interpolation calibration, March 1998

Absolute pressure for UE-25 ONC\#1 corrected with interpolation calibration, June 1997

Absolute pressure for UE-25 ONC\#1 corrected with interpolation calibration, October 1997 
Figure 4-7

Figure 4-8

Figure 4-9

Figure 4-10

Figure 4-11

Figure 4-12

Figure 4-13

Figure 5-1

Figure 5-2

Figure 5-3

Figure 5-4

Figure 5-5

Figure 5-6

Figure 5-7

Figure 5-8

Figure 5-9

Figure 5-10
Absolute pressure for UE-25 ONC\#1 corrected with interpolation calibration, March 1998

Temperature variation with time in USW NRG4 corrected with interpolation calibration, June 1997

Temperature variations with time in USW NRG4, October 1997

Temperature variations with time in USW NRG4, March 1998

Absolute pressure for USW NRG4 corrected with interpolation calibration, June 1997

Absolute pressure for USW NRG4 corrected with interpolation calibration, October 1997

Absolute pressure for USW NRG4 corrected with interpolation calibration, March 1998

Composite cuttings sample, borehole UE-25 ONC\#1

Schematic diagram of the surface attachments for gas sampling in UE-25 ONC\#1, June 1997

UE-25 ONC\#1 stratigraphy and instrumentation profile, June 1997 gas sampling

Plot of all chemical analyses except for isotopic analyses, UE-25 ONC\#1, June 1997

Concentration of methane and carbon oxides, UE-25 ONC\#1, June 1997

Concentration of chlorinated hydrocarbons with depth, UE-25 ONC\#1, June 1997

Concentration of chlorinated fluorocarbon compounds with depth, UE-25 ONC\#1, June 1997.

Concentration of nitrous oxide with depth, UE-25 ONC\#1, June 1997

Concentration of Deuterium and O-18 ratios with depth, UE-25 ONC\#1, June 1997

O-18 versus Deuterium plot, UE-25 ONC\#1, June 1997 
Figure 5-11

Figure 5-12

Figure 5-13

Figure 5-14

Figure 5-15

Figure 6-1

Figure 6-2

Figure 6-3

Figure 6-4

Figure 6-5

Figure 6-6

Figure 6-7

Figure 6-8

Figure 6-9

Figure 6-10

Figure 7-1

Figure 7-2

Figure 8-1
Carbon-14 apparent age with depth, UE-25 ONC\#1, June 1997

Comparison of 1996 and 1997 sampling with UZ-1, UZ-14 and UZ\#16 values for Carbon-14

Comparison of 1996 and 1997 sampling with UZ-1, UZ-14 and UZ\#16 values for ${ }^{13} \mathrm{C}$

Schematic diagram of the surface attachments for gas sampling in UE-25 ONC\#1, April 1998

UE-25 ONC\#1 stratigraphy and instrumentation profile, April 1998 gas sampling

Correlation between probes 0 and 3 showing response to ESF breakthrough (UE-25 ONC\#1 pressure response)

Comparison between probes 2 and 3, UE-25 ONC\#1

Combined frequency response at UE-25 ONC\#1

Combined frequency response at UE-25 ONC\#1 around 1 day period Combined frequency response at UE-25 ONC\#1 around half day period Probe 0 response from March 28, 1996 to March 24, 1997 (spectral analysis of UE-25 ONC\#1 pressure)

Probe 3 response from March 28, 1996 to March 24, 1997 (spectral analysis of UE-25 ONC\#1 pressure)

Comparison between atmospheric response and probe 1 response from March 28, 1996 to March 24, 1997

UE-25 ONC\#1 vacuum test \#5, spherical flow analysis

UE-25 ONC\#1 well schematic and flow inferences

Configuration of instrumentation frame for 25' diameter ESF, August 1995 through May 1997

Configuration of instrumentation frame for $17^{\prime}$ diameter ECRB

Temperature anomaly caused by a flood lamp near Nye County's instrumentation 
Figure 8-2 Three-dimensional simulated tunnel model and cross-sectional view

Figure 8-3 Oblique view of the modified unsaturated zone mesh

Figure 8-4 Saturation level around ESF after 1000 years

Figure 8-5 Temperature versus time for Datm $=0.01$ with decayed heat load

Figure 8-6 Conceptualization of natural ventilation

Photograph 5-1 View at the UE-25 ONC\#1 sampling and testing setup

Photograph 7-1 View of the climatological monitoring station setup in the ECRB 


\section{LIST OF TABLES}

Table 5-1 Chlorine-36 analyses of leachates from rock cuttings samples

Table 5-2 UE-25 ONC\#1 testing and sampling, June 2 to June 13, 1997

Table 5-3 Results of gas sampling in UE-25 ONC\#1 and ESF tunnel

Table 5-4 Results of carbon isotope sampling in UE-25 ONC\#1, June 1997

Table 5-5 Results of carbon isotope sampling in UE-25 ONC\#1, April 1998

Table 5-6 Results of gas sampling in UE-25 ONC\#1, April 1998

Table 6-1 Summary of regression results (page 70 of the report)

Table 6-2 UE-25 ONC\#1 vacuum test preliminary results (page 79 of the report) 


\section{CONVERSION FACTORS}

\begin{tabular}{lll}
\hline Multiply & By & To obtain \\
\hline & & \\
acre-foot (acre-ft) & 0.001233 & cubic hectometer \\
acre-foot per year (acre-ft/yr.) & 0.001233 & cubic hectometer per year \\
cubic foot per second $\left(\mathrm{ft}^{3} / \mathrm{s}\right)$ & .02832 & cubic meter per second \\
foot (ft) & .3048 & meter \\
inch (in.) & 25.40 & millimeter \\
mile (mi.) & 1.609 & kilometer \\
square mile & 2.590 & square kilometer \\
\hline
\end{tabular}

Temperature: Degrees Fahrenheit $(\mathrm{F})$ may be converted to degrees Celsius (C) by using the formula $\mathrm{C}=0.5556(\mathrm{~F}-32)$ 


\section{CONTENTS OF THE ACCOMPANYING MEDIA}

DATABASE

PRES_TEMP

Nycoun97.mdb

Pressure and temperature data collected at ONC\#1 and NRG4 boreholes and atmospheric monitoring data collected in the ESF tunnel and the ECRB drift

$\underline{\text { Stor } 97 . \mathrm{mdb}}$

Pressure and temperature data collected at ONC\#1 and NRG4 boreholes and atmospheric monitoring data collected in the ESF tunnel and the ECRB drift

\section{SPRINGS PUMPAGE AND DISCHARGE (NQA)}

Discharge.xls

Pumpage.xls

Springs.xls

\section{TUNNEL}

tunldata.mdb

\section{WATERLEVEL (NQA)}

modelUTM.mdb

\section{DOCUMENT}

$$
\text { AnnualRpt97 98.doc }
$$

Estimated evapotranspiration and spring discharge rates by discharge area

Total pumpage rates per year for the Death Valley Regional Watershed

Spring discharge rates for the Death Valley Regional Watershed

Atmospheric monitoring data collected in the ESF tunnel and the ECRB drift

Water Level data for monitoring and agricultural wells located in the Death Valley Regional Watershed

NWRPO Annual Report May 1997 - April 1998 


\section{FIGURES}

\section{FIGURES IN TEXT}

RegionAllWells.ppt

10yr maps.ppt

AllYr maps.ppt

Nrg4Text.ppt

Onc1Text.ppt

TextFiguresA.ppt

TextFiguresB.ppt

\section{NRG4}

Nrg4Press\&Temp.ppt

\section{ONC1}

Onc1Press\&Temp.ppt

GASSAMPLING

Onc1GasChem97.ppt

Onc1GasChem98.ppt

\section{TUNNEL}

\section{ECRB}

ecrbMay20 June25.ppt
Water level contour maps for all hydrographic areas combined

Water level contour maps presented in 10year intervals

Water level contour maps of the entire data collection period

NRG-4 graphs referenced in the text section of the Report

ONC\#1 graphs referenced in the text section of the Report

Additional figures located within the text section of the Report

Additional figures located within the text section of the Report

Pressure and Temperature data collected at the NRG-4 borehole

Pressure and Temperature data collected at the ONC\#1 borehole

Gas Chemistry Results from ONC\#1 - 1997

Gas Chemistry Results from ONC\#1 - 1998

Atmospheric monitoring data from the ECRB drift - 1998 
ecrbJune98.ppt

ESF

ESFInstall.ppt

ESF TBM.ppt

WATERUSAGE

TunnelWaterUse.ppt

\section{TABLES AND GRAPHS}

\section{Cl36RockCuttings.xls}

Onc1GasChem.xls

WaterLevelData.xls

ecrb.xls

$\underline{\text { esf.xls }}$
Atmospheric monitoring data from the ECRB drift - 1998

Atmospheric monitoring data from the onetime installation in the ESF tunnel

Atmospheric monitoring data from the TBM - installation in the ESF tunnel

Water usage data from the ESF tunnel and ECRB drift

Chlorine-36 analyses of leachates from rock cuttings samples

Gas chemistry results in table form from ONC\#1, 1997 and 1998

Precipitation graphs, hydrographs and water level data for the Death Valley region

Site activity and water usage data from ECRB tunnel

Site activity and water usage data from ESF tunnel 


\section{EXECUTIVE SUMMARY}

This annual summary report, prepared by the Nye County Nuclear Waste Repository Project Office (NWRPO), summarizes the activities that were performed during the period from May 1, 1997 to April 30, 1998. These activities were conducted in support of the Independent Scientific Investigation Program (ISIP) of Nye County at the Yucca Mountain Site (YMS).

The Nye County NWRPO is responsible for protecting the health and safety of the Nye County residents. NWRPO's on-site representative is responsible for designing and implementing the Independent Scientific Investigation Program (ISIP). Major objectives of the ISIP include:

- Investigating key issues related to conceptual design and performance of the repository that can have major impact on human health, safety, and the environment

- Identifying areas not being addressed adequately by the Department of Energy (DOE)

Nye County has identified several key scientific issues of concern that may affect repository design and performance which were not being adequately addressed by DOE. Nye County has been conducting its own independent study to evaluate the significance of these issues.

The reader is referred to previous reports (NWRPO, 1995; Multimedia Environmental Technology, Inc. (MET), 1995; 1996, and 1997) for a detailed explanation of these specific concerns.

This report summarizes the results of monitoring from two boreholes and the Exploratory Studies Facility (ESF) tunnel that have been instrumented by Nye County since March and April of 1995. The preliminary data and interpretations 
presented in this report do not consiitute and should not be considered as the official position of Nye County.

The ISIP presently includes borehole and tunnel instrumentation, monitoring, data analysis, and numerical modeling activities to address the concerns of Nye County.

Figure 1-1 shows the regional setting of the Yucca Mountain. Nye County has installed and is currently monitoring pressure and temperature instruments in boreholes UE-25 ONC\#1 and USW NRG4 (Figure 1-2) to evaluate the long-term pneumatic conditions at strategic depths in the subsurface both in response to fluctuations in atmospheric conditions and in response to other possible disturbances resulting from site characterization activities such as the ESF tunnel construction. UE-25 ONंC\#1 was drilled by Nye County as part of its oversight program. Nye County has also installed instruments to measure temperature, pressure, humidity and wind speed within the ESF tunnel and the Enhanced Characterization of the Repository Block (ECRB) drift to characterize the air being used to ventilate the tunnel that could potentially impact the performance of the repository. Additionally, Nye County collected gas samples from the vadose zone in UE-25 ONC\#1 at three different times to establish background conditions and to evaluate changes in the chemical composition of the gases. Changes in the chemical compositions of the gases in the vadose zone with time may be used to evaluate the impact of the ESF construction and obtain transport properties of the rock mass at the site. Finally, Nye County is conducting numerical simulations to evaluate factors (including tunnel ventilation) that might potentially affect both short-term and long-term pneumatic and moisture conditions in the repository host rock.

Nye County has also been evaluating new critical data and information as it becomes available from the DOE's Yucca Mountain Project studies. In the past year, Nye County has observed water usage in the tunnel and its potential impact on the repository horizon and the scientific investigation results. The 
interpretation of the results of the ${ }^{36} \mathrm{Cl}$ and other environmental and geological isotope studies such as ${ }^{14} \mathrm{C},{ }^{13} \mathrm{C}$, and ${ }^{3} \mathrm{H}$ have been the focus of many meetings attended by Nye County which has resulted in several letter reports to DOE during the past year. Some of these communications have resulted in DOE's more focused attention to some of the issues raised by Nye County. Specifically, these issues related to the need for more detailed studies in the ESF tunnel and ECRB drift, limiting the use of construction water, enhanced ventilation studies, and enhanced interpretation of the results of the isotope sampling.

Nye County evaluated procedures and methods used by DOE to conduct airpermeability tests in the unsaturated zone of YMS. As a result of several interactions between Nye County and DOE, satisfactory procedures were developed and used by DOE in more recent testing efforts. The results of these tests were analyzed and reported (Advance Resources International, 1995 and Multimedia Environmental Technology, Inc., 1995, 1996 and 1997).

Water resources of the county are one of its most important assets. Nye County has been conducting research as to the potential impact of the construction and operation of the Yucca Mountain Repository on its water resources. As part of this task, a regional model of the Death Valley Hydrologic Basin was developed and is undergoing refinement. Preliminary results have revealed inadequacies in current models of the Yucca Mountain hydrologic system. As a result of several meetings, DOE has developed plans to alleviate and address these concerns.

Nye County is planning to perform several investigations in the near future to clear some of the issues that were outlined above by installing new wells in both the saturated and unsaturated zones, testing and sampling these wells, and performing data analysis and modeling. These issues are related to the steep gradients in the saturated zone north and west of the site, the potential for dilution in the saturated zone as unsaturated zone moisture enters the saturated zone, the atmospheric and pneumatic boundaries in the Solitario Canyon that might impact the repository 
performance, and the large-scale transport properties of the fractured formations in both saturated and unsaturated zones. Nye County has identified future monitoring well locations and plans to begin installation of these wells in late 1998. 


\section{$1.0 \quad$ INTRODUCTION}

This annual report, prepared by Nye County Nuclear Waste Repository Project Office, summarizes the activities that were performed during the period from May 1, 1997 to April 30, 1998 under a grant (DE-FG08-96NV12027) from U.S. Department of Energy (DOE). These activities were conducted in support of the Independent Scientific Investigation Program (ISIP) of Nye County at the Yucca Mountain Site (YMS). The goal of the grant from the DOE is to provide opportunity for Nye County to conduct independent research and evaluate the potential impact of planned activities by DOE on the health and safety of the county residents and workers as well as on the environment and resources of the county.

The Nye County NWRPO is responsible for protecting the health and safety of the Nye County residents. NWRPO's on-site representative is responsible for designing and implementing the Independent Scientific Investigation Program (ISIP). Major objectives of the ISIP include:

- Investigating key issues related to conceptual design and performance of the repository that can have major impact on human health, safety, and the environment.

- Identifying areas not being addressed adequately by DOE

Nye County has identified several key scientific issues of concern that may affect repository design and performance, which initially were not being adequately addressed by DOE. Nye County has been conducting its own independent study to evaluate the significance of these issues. Many interactions with the Yucca Mountain Project scientists and engineers have proven beneficial in conveying Nye County's concern in these issues. DOE has been very responsive in addressing these issues and Nye County believes that such interactions and responses will lead 
to improved protection of the health and safety of the county residents and workers as well as enhanced protection of the county's environment and resources.

The reader is referred to previous reports (NWRPO, 1995; Multimedia Environmental Technology, Inc., 1995 and 1997) for detailed explanation of these specific concerns.

\subsection{SCOPE}

This report summarizes the results of geologic and hydrologic research conducted in two boreholes, the Exploratory Studies Facility (ESF) tunnel, and the Enhanced Characterization of the Repository Block (ECRB) drift. UE-25 ONC\#1 borehole was drilled in December of 1995. UE-25 ONC\#1 and an existing borehole (USW NRG4) were instrumented by Nye County during March and April of 1996. Characterization of the cuttings from UE-25 ONC\#1 and monitoring and pneumatic testing of both boreholes are ongoing and preliminary results are presented in this report. Petrographic and geochemical analyses of the cuttings from UE-25 ONC\#1 are presented in Sections 2.0 and 5.1 respectively. Pneumatic testing, monitoring and sampling of the boreholes are discussed in Sections 4.0, 5.2 and 6.0. The Regional Hydrogeology of the area surrounding Yucca Mountain is presented in Section 3.0. A discussion of the ESF and ECRB tunnel monitoring activities can be found in Section 7.0. Section 8.0 contains a discussion concerning alternative repository design. Sections 9.0 and 10.0 summarize Nye County's ongoing activities concerning the development and management of a hydrogeologic database and associated GIS files. Finally, Section 11.0 is concerned with the re-establishment and maintenance of Nye County's documented Quality Assurance Program. The preliminary data and interpretations presented in this report do not constitute and should not be considered as the official position of Nye County. 


\subsection{NYE COUNTY'S BOREHOLE AND TUNNEL MONITORING STUDIES}

The ISIP presently includes drilling new boreholes, instrumenting new and existing boreholes, analyzing the geology and geochemistry of drill cuttings, instrumenting tunnels and drifts, monitoring, data analysis, and numerical modeling activities to address the concerns of Nye County.

Figure 1-1 shows the regional setting of the Yucca Mountain. To investigate uncertainties in how water moves from the land surface to the water table and how it moves in the water table, Nye County is conducting extensive tests at drill hole UE-25 ONC\#1. Nye County has installed and is currently monitoring pressure and temperature instruments in boreholes UE-25 ONC\#1 and USW NRG4 (Figure 12) to evaluate the long-term pneumatic conditions at strategic depths in the subsurface both in response to fluctuations in atmospheric conditions and in response to other possible disturbances resulting from site characterization activities such as the ESF tunnel and ECRB drift construction. Nye County has also installed instruments to measure temperature, pressure, humidity and wind speed within the ESF tunnel and ECRB drift to characterize the air being used to ventilate the tunnel which could potentially impact the performance of the repository. Additionally, Nye County has collected gas samples from the vadose zone in UE-25 ONC\#1 at three separate occasions to establish background conditions and to evaluate changes in the chemical composition of the gases. Changes in the chemical compositions of the gases in the vadose zone with time may be used to evaluate the impact of the ESF construction and obtain transport properties of the rock mass at the site. Finally, Nye County is conducting numerical simulations to evaluate factors (including tunnel ventilation) which affect both short-term and long-term pneumatic and moisture conditions in the repository host rock. 


\subsection{OTHER ACTIVITIES}

Nye County has also been evaluating new critical data and information as it becomes available from the DOE's Yucca Mountain Project studies. In the past year, Nye County has observed water usage in the tunnel and its potential impact on the repository horizon and the scientific investigation results. The interpretation of the results of the ${ }^{36} \mathrm{Cl}$ and other environmental and geological isotope studies such as ${ }^{14} \mathrm{C},{ }^{13} \mathrm{C}$, and ${ }^{3} \mathrm{H}$ have been the focus of many meetings attended by Nye County which has resulted in several letter reports to DOE during the past year. Some of these communications have resulted in DOE's increased attention, focusing on some of the issues raised by Nye County. Specifically, these issues related to the need for more detailed studies in the ESF tunnel, limiting the use of construction water, and enhanced interpretation of the results of the isotope sampling.

Nye County evaluated procedures and methods used by DOE to conduct airpermeability tests in the unsaturated zone of YMS. As a result of several interactions between Nye County and DOE, satisfactory procedures were developed and used by DOE in more recent testing efforts. The results of these tests were analyzed and reported (Advance Resources International, 1995).

Water resources of the county are one of its most important assets. Nye County has been conducting research as to the potential impact of the construction and operation of the Yucca Mountain Repository on its water resources. As part of this task, a regional model of the Death Valley Hydrologic Basin has been developed and is undergoing refinement. As a result of these efforts, Nye County has identified data gaps in the regional hydrologic system and specific to the Yucca Mountain Site (YMS). 


\subsection{PROPOSED FUTURE INVESTIGATIONS}

Nye County is planning to perform several investigations in the near future to clear some of the issues that were outlined above by installing new wells in both the saturated and unsaturated zones, testing and sampling these wells, and performing data analysis and modeling. These issues are related to the steep gradients in the saturated zone north and west of the site, the potential for dilution in the saturated zone as unsaturated zone moisture enters the saturated zone, the need for hydrogeologic data in Amargosa Valley downgradient from the YMS, compilation of geologic and geophysical data related to deep aquifers in the vicinity of the YMS, the atmospheric and pneumatic boundaries in the Solitario Canyon that might impact the repository performance, the merits of a naturally-ventilated repository, and the large-scale transport properties of the fractured formations in both saturated and unsaturated zones. 


\subsection{PETROGRAPHIC STUDIES OF UE-25 ONC\#1}

\subsection{INTRODUCTION}

The mechanics of water movement through the fractured volcanic aquifers at Yucca Mountain is an important consideration in assessing the performance of a repository at this site. To reduce the uncertainties in how water moves from the land surface to the water table and how it moves in the water table, Nye County is conducting extensive tests at drill hole UE-25 ONC\#1. These tests include detailed petrographic studies, chemical tests, and well tests. In this section, the results obtained to date from the petrographic studies are presented and discussed.

In a fracture dominated flow system like Yucca Mountain, the pore characteristics and fracture characteristics govern the rates of groundwater flow and transport of radionuclides. With respect to the pore spaces, the contrast in pore space in different volcanic units and the effects of mineralization of the pore spaces can result in considerable variation. For fractures, the number of fractures present, their connectivities, apertures, and degree of fracture filling can have a pronounced affect on the flow of groundwater. One of the methods Nye County is using to investigate the volcanic rock properties are scanning electron microscopic studies of the actual pores and mineral deposits. These studies are focused on defining the pore and fracture characteristics at UE-25 ONC\#1. The results will be used in conjunction with the geochemical and well testing to provide the data needed to support analytical or numerical models of flow and transport processes.

\subsection{PURPOSE OF ACTIVITY}

Analysis of cuttings from drill hole UE-25 ONC\#1 are focused on the petrographic characterization of past and present fluid pathways that support transport from the ground surface through the vadose and saturated zones. The ultimate goal of this study is to acquire a comprehensive understanding of the fluid pathways and 
therefore the stratigraphic distribution and interconnectivity of fracture conduits and matrix pore space through time at the UE-25 ONC\#1 location. The spatial attributes of the pathway system impart a significant knowledge concerning the rate of fluid transport in the system. This understanding includes the characterization of the authigenic mineral history associated with the transport pathways for two distinct purposes: 1) the study of porosity changes as the filling and opening of pore and fracture space is controlled by dissolution and authigenic mineralization; and 2) the study of the potential for radionuclide retardation due to presence of authigenic products in and along these pathways.

\subsection{METHODOLOGY}

Nye County's studies have utilized standard petrographic microscope examination of petrographic thin sections and polished mounts of drill hole cutting samples. In addition to these activities, we examined cutting samples by cathodoluminescence on the scanning electron microscope (Dave Krinsley at University of Oregon, Department of Geology). To the County's knowledge, there are no other cathodoluminescence studies for Yucca Mountain samples. This technique provides us with a unique ability to study paleo-authigenic mineralization events with respect to fluid pathways.

\subsection{SUMMARY OF FINDINGS}

Nye County's petrographic studies have concentrated on welded and poorly welded tuffs, and for the most part, have excluded non-welded tuffs due to drill hole cuttings availability. Consequently, non-welded tuff samples must be obtained through other field situations. For welded and poorly welded tuffs in UE-25 ONC\#1, the dominant mode of fluid transport in the past and in the present is by fracture flow. Transport by matrix porosity had been more dominant in the past than in the present due to the pore filling of authigenic minerals in the past under 
active matrix transport conditions. The findings are summarized in the following topic areas:

1. Authigenic mineralization (neomineralization)

The authigenic minerals recognized as either fracture filling or matrix pore filling material are as follows:
a. quartz
b. opal-CT
c. zeolites dominated by clinoptilolite-heulandite
d. clays

e. manganese oxyhydroxides

f. iron oxyhydroxides

g. calcium carbonate (calcite among other minerals)

2. Dissolution (as a function of present and past transport)

Dissolution of feldspar, cristobalite and tridymite in addition to any matrix glass that was not reorganized during devitrification occurs where previous porosity, either as matrix pore space or as fracture conduits, have supported fluid transport. Dissolution occurs along fracture walls in bleached zones. Neomineralization occurs within these zones generally utilizing material mobilized during dissolution. There is a net change in both mineral species and porosity associated with these reactions. In addition there is a net change in overall volume.

3. Classification of fluid pathways

a. Open fracture pathways in welded and poorly welded tuffs. 
b. Open fracture pathway in non-welded tuffs.

c. Open matrix pore space in welded and poorly welded tuffs. Pore space formed during devitrification events.

d. Open matrix pore space in non-welded tuffs. Pore space formed during devitrification events.

e. Open matrix pore space in welded and poorly welded tuffs. Pore space formed during authigenic mineralization due to past fluid transport events.

f. Open matrix pore space in non-welded tuffs. Pore space formed during authigenic mineralization due to past fluid transport events.

g. Open matrix pore space in welded and poorly welded tuff fracture bleach zones. Pore space formed during authigenic mineralization and tuff dissolution of fracture walls during past transport events.

h. Closed fracture pathways due to authigenic mineralization as a function of past transport events. For welded, poorly welded and non-welded tuffs.

i. Closed matrix pore space due to authigenic mineralization as a function of past transport events. For welded, poorly welded and non-welded tuffs.

j. Pathways that combine one or more of the above situations.

4. Characterization of past fracture filling and opening events

Thus far we have only been able to recognize fracture filling, refracturing, and refilling sequential events in fractures that have been initially filled with quartz. This is likely an artifact of the analytical procedure, which allows us to investigate quartz, opal and calcite by cathodoluminescence, but does 
not support the analysis of oxyhydroxide phases. Nye County has not encountered much calcite fracture and pore filling material in the drill hole studied.

5. Identification of pore space formed as a function of neo-mineralization

Zeolitic morphologies favor the formation of pore space at the boundaries between crystal faces. In many cases this pore space is interconnected, and in some cases, the matrix pore space is associated with fracture conduits, so that there is continuity between fracture flow and zeolitic pore space within the matrix. What has been quite obvious though, is that the zeolitic pore space in welded tuffs is local and not interconnected to other matrix pore space.

6. Interactions between matrix pore space and fracture conduits

There are several situations where we can observe the interconnectivity of matrix pore space with fractures:

a. Interconnectivity of matrix pore space in the fracture walls of bleach zones with the centralized aperture opening of the fracture itself; and

b. Interconnectivity as local inter-crystal zeolite pore space tied to fracture conduits. Fracture conduits are apparently responsible for the transport of reacting fluids to the localized zones that once held glass. This glass has since undergone dissolution as a function of fracture transport of fluids. The precipitation of zeolites dominated by clinoptilolite-heulandite is a function of the ionic components and the stability of these phases after glass dissolution.

7. Fracture bleached zones and their relevance to:

a. Past conditions 
1. Fluid transport by fracture flow has dominated the paleo-transport environment in these areas.

2. Fluid transport was responsible for matrix dissolution within the fracture walls.

3. Authigenic mineralization occurred within these higher porosity zones in response to mobilized ionic species made available by dissolution reactions.

b. Potential retardation by sorption along fracture conduits

1. Bleached zones are dominated by quartz, opal-CT, zeolites (clinoptilolite-heulandite), clay and some manganese oxyhydroxides. The zeolites, clays and manganese oxyhydroxides have the potential to provide radionuclide sorption.

2. Since these authigenic mineral suits occur within the matrix walls of the fractures and are connected to the fracture by matrix porosity, they have all of the prerequisites necessary for providing sorption. This includes access to the transporting fluids. The residence time of fluid within the bleached zone has not been investigated relative to the rate of transport in the open fracture.

3. The bleached zones can be as much as 500 microns thick on either side of a fracture whose original aperture is generally less than a millimeter. Consequently, the bleached zone provides extensive porosity beyond that which is provided by the fracture itself.

c. Spatial distribution of present conductivity

Bleached zones occur in fractures that have been actively transporting fluids. These functioning pathways are tied into the overall transporting fracture flow network, and are therefore part of the main transporting pathway system. 


\section{Unanswered questions}

a. How does the effective porosity at this location (UE-25 ONC\#1) differ from other drill hole locations at Yucca Mountain?

b. How do the pathways change at the stratigraphic boundaries between welded and non-welded tuffs? In other words, what does the authigenic mineralogy show, and what do the interconnectivities look like (for matrix pore space and fracture conduits), at the boundaries of these rock types?

c. From authigenic mineralogy past-events-data along fluid pathways, what are the likely porosity and fracture changes that might occur if: 1) conditions remain the same; 2) temperatures are elevated to repository conditions; 3 ) if there was a net evaporation of water vapor in the nearfield; 4) if there is a climate change to wetter conditions? 


\subsection{REGIONAL HYDROGEOLOGY}

This section presents an overview of Nye County's Fiscal Year 1998 activities related to the hydrogeologic conditions of the region surrounding Yucca Mountain. A thorough understanding of the groundwater conditions of the region is a prerequisite to accurately predicting the long-term performance and impacts of siting a high-level waste repository at Yucca Mountain. Nye County is particularly interested in the losses and damages that have already occurred to the water resources of the region and the additive losses that might result from impacts associated with the location of a repository at Yucca Mountain.

In the Department of Energy's evaluations of the regional groundwater conditions, an emphasis has been placed on the use of numerical models that simulate the hydrologic processes at work so groundwater flow paths and travel times can be predicted. These models are then used to determine the migration of contaminants from pollution sources such as the underground nuclear testing areas on the Nevada Test Site and Yucca Mountain.

Nye County recognizes the need for these modeling efforts and believes that a well-calibrated flow model of the region would provide a powerful tool for use in water resources planning and management. The "ideal" model would provide an accurate predictive capability for managing the County's water development over the coming decades. Such a model would be able to accurately simulate the presence of existing and future contaminant sources and the locations and durations of groundwater withdrawals. The results of models that have been completed to date, while encouraging, indicate that there is still considerable uncertainty and that further refinement is needed before regional groundwater models can provide such tools. However, Nye County recognizes that there should be a balance between the amount of effort placed in development of the groundwater models and the in-situ data needed to support the models. Groundwater models should initially be.used as a guiding tool for collecting data. 
Results of data-collection activities should be used to update the models on a regular basis. The usefulness of the models is primarily dictated by the adequacy and quality of the data.

\subsection{EVALUATION OF YUCCA MOUNTAIN WATER SUPPLY AND DEMAND ISSUES}

In planning for future water demands, Nye County, Nevada is faced with a formidable task. As a result of national demographic trends, Nye County is one of the fastest growing areas in the United States, yet the county is faced with ever diminishing water supplies. Population forecasts that have been made by the county and the state both indicate that rapid growth will continue over the next half-century or more. Meeting the demand for future water supplies is a top priority for the county. Careful evaluations and planning must be done to determine how the proposed repository at Yucca Mountain may affect, or be affected by, future water developments within the region.

Nye County is also the situs county for a number of other facilities. The facilities include the underground nuclear testing areas on the Nevada Test Site, Department of Defense installations and ranges, hazardous and radioactive wastes disposal facilities, an important National Monument, National Forests, and National Wildlife areas. Large areas of Nye County have already suffered the irrevocable and irretrievable loss of natural resources and reduced water resource availability as a result of the presence of these facilities. Careful evaluations must be done to determine the additive losses that will occur should the proposed repository at Yucca Mountain become a reality.

In this section, an overview is presented of Nye County's Fiscal Year 1998 activities related to water supply and demand, land use, and other environmental issues. Nye County's efforts on these issues can be broadly categorized into three areas: 
1. Definition and evaluation of water supply and demand issues

2. Regional groundwater modeling

3. Evaluations of the Total System Performance Assessment, Viability Assessment, and the Environmental Impact Statement for the Yucca Mountain Project.

Another task involves the acquisition, synthesis, analysis, and dissemination of the data needed in conducting studies related to these three areas.

\subsubsection{DEFINITION AND EVALUATION OF NYE COUNTY'S WATER SUPPLY AND DEMAND ISSUES}

In this section, the key issues related to the changing patterns of water supplies in southern Nevada are defined and discussed along with the impacts and constraints imposed by Yucca Mountain on the development of those water supplies. The three key issues related to Yucca Mountain from a water supply point of view are: 1) the protection of the county's drinking water supplies and wildlife habitats; 2) future water availability; and 3) the cumulative impacts of federal actions on water resources.

\subsubsection{PROTECTION OF DRINKING WATER SUPPLIES AND WILDLIFE HABITATS}

Protection of drinking water supplies is, of course, essential to Nye County and is required under the provisions of the Safe Drinking Water Act. Unless remedied, the existing groundwater contamination at the Nevada Test Site and elsewhere in the county poses a significant constraint on the development of new water supplies. It is incumbent upon Nye County to protect the remaining water resources from further contamination. Past actions have polluted the water resources up gradient of populated areas and future pollution of the water resources has been predicted. Actions which will result in the loss of additional 
water resources through contamination must be taken into account in long-term water planning.

Additional constraints on water supply development are imposed by the environmentally sensitive areas at Devils Hole and Ash Meadows where endangered species habitats must be maintained. Federal laws require protection of these areas. Protection afforded to these areas further limits the water resources that are available. A large area of the Amargosa Desert hydrographic basin cannot be considered as a source of water because of concerns related to the continued maintenance of the habitat that supports these species. The continued preservation of these environmentally sensitive areas is also incumbent upon Nye County. It should be noted, however, that such preservation is not without cost to the county. In addition to the effective loss of natural resources for other purposes, socioeconomic impacts have already been demonstrated in employment and productivity.

\subsubsection{WATER USE TRENDS AND FUTURE WATER AVAILABILITY}

In 1996, Nye County completed a baseline water supply and demand study of the southern portion of the county. This study included evaluations of the communities of Beatty, Amargosa Valley, and Pahrump. The study concluded that water supplies are expected to be adequate to meet projected demands in Beatty and Amargosa Valley through the year 2050 but that the available supplies are not adequate to meet the projected growth in Pahrump. However, the study also pointed to the fallibility of predicting growth and noted that Amargosa Valley could begin to experience water supply shortfalls in the Amargosa Desert hydrographic basin prior to that time.

Groundwater withdrawals in Pahrump Valley have exceeded the perennial yield of 19,000 acre feet every year since at least 1983. In 1996 withdrawals of groundwater from Pahrump Valley were just under 27,000 acre feet. In 1997 
almost 29,000 acre feet of groundwater were pumped from the alluvial aquifer in Pahrump, according to the records of the Nevada Division of Water Resources. This 1997 extraction rate represents a 7 percent increase from 1996. The 1997 pumping rate was well ahead of the most recent projections made by Nye County (Buqo, 1996). These projections predicted that groundwater use would not exceed 28,000 acre feet per year until the year 2010. The phenomenal growth of the community of Pahrump is fueling an ever-increasing demand for the limited available water resources. In Fiscal Year 1999, the County will reevaluate their projections based upon the latest water use inventory and growth trends in Pahrump.

Nye County has identified five alternatives for meeting future water demands in Pahrump Valley:

1. A managed overdraft of the basin;

2. Development of the carbonate aquifer that underlies the basin;

3. Importation of water from other basins;

4. Administrative actions; and

5. A combination of any of these alternatives.

The first three options (and the fifth) could potentially be affected by, or affect, the performance of a repository at Yucca Mountain. Thus, these options warrant further consideration.

\subsection{MANAGED OVERDRAFT}

The effects of an overdraft in Pahrump Basin over recent decades has been well documented. The observed effects of the overdraft in the late 1960s through 1975 included water level declines of as much as 60 feet in areas of large water withdrawals and the elimination of spring discharges at two springs. As a result of 
the elimination of these springs, the natural habitat for three subspecies of the Pahrump Killifish was lost.

These observed effects occurred at a time when water withdrawals in Pahrump Valley exceeded 30,000 acre feet. (Water withdrawals peaked at 47,100 acre feet in 1968). The effects of extracting significantly higher volumes of water, estimated at 84,000 acre feet by the year 2050 , have not been evaluated. However, the results of other models of the region suggest that the impacts of a long-term overdraft in Pahrump Valley could reach considerable distances, including the Yucca Mountain area.

To evaluate the plausibility and magnitude of such impacts, the potential areas where hydraulic connections between Pahrump Valley and the basins that border it (Amargosa Desert, Las Vegas Valley, Mercury Valley, Three Lakes Valley South, and Sandy Valley in Nevada and Mesquite Valley, Chicago Valley, California Valley, and Amargosa Desert in California) are being evaluated by Nye County. The areas of most concern with respect to Yucca Mountain, are Stewart Valley, Amargosa Flat, and the area along Highway 95 between Mt. Montgomery and Mt. Sterling. Preliminary evaluations suggest that there may be hydraulic communication between Pahrump Valley and other basins in these areas. Longterm stresses on the aquifer system in Pahrump Valley could result in effects beyond the basin boundaries through these areas. More detailed evaluations are needed to determine if such effects would be of concern with respect to Yucca Mountain.

A first step in addressing the relationship between water withdrawals in Pahrump Valley and water level declines is establishing a comprehensive baseline of information on water wells, water level measurements, water withdrawals, and other related data. Nye County has compiled and is evaluating the water well, water rights, water use, and water level data available from the U.S. Geological Survey and the Nevada Division of Water Resources. In total, these records 
provide basic hydrologic data for the more than 7,200 wells that have been drilled in the Nevada portion of the basin, the major areas of withdrawals, and the quantity of those withdrawals. These data sets are presented in the accompanying media. Based upon the data sets for Pahrump Valley, Nye County prepared large scale maps that show the distribution of wells and water level variations between 1944 and 1997 for each developed section of land within the basin. Nye County is further analyzing these data sets to determine the responses of the water table to historic water withdrawals. These analyses will be used in evaluations of the hydraulic communication between basins, leakance between aquifer systems, and the long-term effects of an overdraft in Pahrump Valley.

\subsection{CARBONATE AQUIFER DEVELOPMENT}

The development of the carbonate aquifer in Pahrump Valley also has the potential to be impacted by, or impact Yucca Mountain. The impacts of large-scale water withdrawals from the carbonate aquifer have not been well defined but the results of some models and long-term aquifer tests suggest that the effects will be widespread. Careful planning of any water withdrawals from this aquifer will be needed to prevent the spread of contamination or adverse impacts on sensitive habitats.

Nye County has conducted preliminary discussions with the Nevada State Engineer concerning the potential for development of the carbonate aquifer in southern Pahrump Valley. Based upon the results of a U.S. Geological Survey evaluation, groundwater pumping from the alluvial aquifer in the community of Pahrump only captures a negligible quantity of water from the carbonate aquifer. A redistribution of water withdrawals from the alluvial aquifer to the carbonate aquifer might be used to mitigate, in part, the impacts of a long-term overdraft of the basin. Alternatively, water could be withdrawn from the carbonate aquifer in the undeveloped portions of Pahrump and injected into the alluvial aquifer in areas 
where the alluvial aquifer is being over-drafted. This approach could be used to mitigate the adverse impacts of over-pumping the alluvial aquifer in the populated areas. However, the quantity of water that could be managed in this method is limited, estimated at 19,000 acre feet per year.

Nye County has discussed the potential for carbonate aquifer development with the Nevada State Engineer. Based upon these discussions, it was concluded that such an approach could only be used if existing water rights from the alluvial aquifer in Pahrump were obtained and transferred to the carbonate aquifer; i.e., no new water rights will be permitted for groundwater withdrawals from the carbonate aquifer. The estimated 19,000 acre feet per year of groundwater that could be "captured" in this manner are inadequate to meet the projected long-term demand in Pahrump. Therefore, it is considered likely that groundwater will ultimately have to be imported to Pahrump from other basins within the Death Valley flow system unless water can be obtained from an external source.

\subsection{INTERBASIN TRANSFERS OF WATER}

Nye County is hardly the first area in the desert southwest to experience water shortfalls. In recent decades, the use of interbasin transfers of water has become an accepted technique for meeting the demand for water in urbanized basins. In this approach, water supplies are developed in "water rich" but largely unpopulated basins and conveyed to the "water poor" basins where cities are located. Prime historic examples of this approach include the development of water resources in Owens Valley, California by the Los Angeles Department of Water and Power and the transfer of water from Avra Valley, Arizona to augment groundwater short falls in metropolitan Tucson.

In southern Nevada, interbasin transfers of water have been limited but large-scale transfers of this type have been considered in the past and some are still actively under consideration. In the early 1970 s, the potential for transferring water from 
Amargosa Valley to metropolitan Las Vegas was considered. In the late 1970s and early 1980s the U.S. Air Force proposed large-scale interbasin transfers to provide water supplies for the proposed MX Missile System racetrack deployment in Nevada and Utah. In the late 1980s, the Las Vegas Valley Water District filed massive water right applications in a number of basins in eastern and central Nevada with the intent of transferring water from the rural areas of Nevada to Las Vegas. This proposal is still under consideration by the Southern Nevada Water Authority but has been "placed on the back burner" while the authority attempts to obtain greater shares of the Colorado River water stored in Lake Mead.

Existing interbasin transfers convey water from the carbonate and alluvial aquifers in the Muddy Springs Area hydrographic basin for power generation at Nevada Power Company's Hidden Valley generating station and for public drinking water supplies in Logandale and Overton. Recent water right filings in this region have been made for power generation and quasi-municipal purposes that could significantly increase the quantities of groundwater being managed through basin transfers.

Given the magnitude of projected water shortfalls in Pahrump Valley by the year 2050, the development of water in other basins for conveyance to Pahrump seems (on the surface at least) to be feasible. If groundwater is to be developed beyond the limits of Pahrump Valley, the closest basins with unappropriated groundwater are Mercury Valley, Rock Valley, and Jackass Flats. Unappropriated groundwater is present in each of these basins and the results of historic water developments in these basins suggest that there are areas where productive water supply wells could be located. As portions of Mercury Valley may be hydraulically up gradient of Devils Hole and the wetland areas at Ash Meadows, it is likely that any future water withdrawals would have to be limited. Such constraints have not been identified for Rock Valley or Jackass Flats. 
The combined perennial yields of Mercury Valley, Rock Valley, and Jackass Flats are 20,000 acre feet per year. It is important to note however, that these perennial yields are not based upon the recharge derived over the basins, but rather on subsurface flow through each of the basins. If it is assumed that the entire perennial yields of these three basins could be captured and transferred to Pahrump, then the projected shortfall in water availability in Pahrump in the year 2050 could be reduced from 65,000 acre feet to 45,000 acre feet. The remaining shortfall could be addressed through managed overdrafts of the three basins or by importing water from more distant basins or from sources beyond the boundaries of Nye County.

Nye County recognizes that there are a myriad of issues associated with interbasin transfers of water in this manner. Careful evaluations are needed to identify source areas and to determine the impacts of implementing such an approach. However, given the overall water supply situation in southern Nevada, transfers of water between basins may be the only internal source of water available to the county.

\subsection{METHODS}

The methods used in identifying the water supply and demand issues related to Nye County and Yucca Mountain included the review of literature and program documents germane to the topic and both formal and informal discussions with a number of agencies and the public. Nye County has consulted with the Nevada State Engineer, the Nevada State Water Planner, the Pahrump Regional Planning Commission, and Inyo County, California. Discussions have been held with the U.S. Department of Energy, the U.S. Department of Defense, the National Park Service, the U.S. Fish and Wildlife Service, the U.S. Department of Justice, farm representatives from Amargosa Valley, and interested parties and individuals from the general public.

In April 1998, Nye County hosted the Devil's Hole Workshop. A half-day field trip to Nye County's well UE-25 ONC\#1 was made to introduce participants to 
the County's important data collection activities at this monitoring site. The workshop also included a full day of formal presentations. These presentations were invited from farm organization representatives from Amargosa Valley, the Nevada State Engineer and State Planner, the National Park Service, the U.S. Department of Justice, the U.S. Geological Survey, and U.S. Department of Energy contractors. The focus of the workshop presentations was on water issues in southern Nye County. Nye County presented the preliminary results of their modeling efforts and the specific issue of preservation of the sensitive habitats at Devil's Hole and Ash Meadows in light of the projected water supply shortfalls for the southern part of the county. The workshop was well attended with more than 85 participants. The 1998 Devil's Hole Workshop provided an important venue for the sharing of ideas between many of the groups involved in planning and use of the water resources of the region.

Nye County has also been an active participant in the Citizens Advisory Board. At the request of this board, a formal presentation was made in January 1998. This presentation was on Nye County's Perspective on Nevada Test Site Programs and identified the key water supply issues along with the County's concerns. The focus on this presentation was on the existing contaminated groundwater at the Nevada Test Site and the issues associated with that contamination including the continuing loss of natural resources, future water demands and resource availability, and other actions taken by federal agencies, including Yucca Mountain.

Nye County has taken a proactive approach in working with other groups and interested parties. The County has informally helped coordinate the flow of information between the farm interests in Amargosa Valley, county and city planners, and federal and state agencies. For example, when the U.S. Geological Survey announced their intent to expand their monitoring program in Amargosa Valley, the County facilitated a meeting with interested farmers in the area. The County provided both parties with comprehensive lists of water wells in the basin, 
identified areas for conducting aquifer tests, and planned future cooperative efforts. The County has also been a participant at Town Boards, Regional Planning Commissions, and other local meetings. Nye County maintains a presence at these meetings to provide information concerning Yucca Mountain and to explain its ongoing programs and data collection efforts. The county's involvement in these meetings has helped to define the issues that are important to planners and the public.

\subsection{REGIONAL GROUNDWATER MODELING}

Numerical models are being used to simulate and define flow paths and travel times between existing and future contaminant sources, such as the Nevada Test Site (NTS) and Yucca Mountain, and potential receptor populations. The results of these simulations are then used in estimating the risk associated with that contamination. The Department of Energy has recently published the results of two models, one for the Yucca Mountain Program (D'Agnese et al, 1997), and one for the Nevada Test Site Environmental Restoration Program (U.S. Department of Energy, 1997). Previously, the U.S. Geological Survey, published the results of their regional model of the carbonate rock province which encompasses a large area in Nevada and Utah and which includes the areas modeled by the Department of Energy (Prudic, Harrill, and Burbey, 1993).

Nye County is developing its own numerical models of the groundwater flow regime in the vicinity of Yucca Mountain. A necessary first step in this effort is the evaluation of the regional models that have already been developed by the Department of Energy and the U.S. Geological Survey. These evaluations are aimed at identifying the strengths and weaknesses of the modeling approaches that were used and identifying the areas where more data are needed. The three models being evaluated are:

1. The U.S. Geological Survey Death Valley regional groundwater flow system model developed by D'Agnese et al, (1997). This model was developed to 
assist in the characterization of the hydrologic regime in the region surrounding the proposed high-level nuclear waste repository at Yucca Mountain. This model is hereafter referred to as the Yucca Mountain Project (YMP) regional model.

2. The Nevada Test Site underground test area (UGTA) regional groundwater flow and tritium transport model (U.S. Department of Energy, 1997). The purpose of this model was to identify groundwater pathways and travel times to aid in the assessment of the effects of underground nuclear weapons testing at the Nevada Test Site and the risk associated from the release of tritium during the tests. This model is hereafter referred to as the UGTA regional model.

3. The U.S. Geological Survey's regional carbonate aquifer-system model developed by Prudic, Harrill, and Burbey (1993). The purpose of this model was to provide a mathematical simulation of the regional aquifer system to serve as the basis for the conceptual evaluation of regional groundwater flow in the carbonate-rock province of Nevada and Utah. This model is hereafter referred to as the NTS regional model.

By carefully examining these models, Nye County's scientists are identifying the relative strengths and weaknesses of each model. The predictive capability of these models rests in large part upon two key factors: 1) the ability of numerical models to be reliably used in lieu of data; and 2) the database and assumptions that were used in developing the computer simulation. In areas where data are lacking, assumptions must be made concerning the key hydraulic parameters that govern the output from the models. No numerical model is able to reliably predict the response of a hydrologic system at all locations. They are merely tools to evaluate the gaps in data and to provide means of estimating potential responses of a portion of the system to various changes in the boundary conditions in the system. 
Numerical models simply provide a mathematical representation of the basic processes of a groundwater flow regime. The reliability of a calibrated model is dependent to a large extent on the data used and assumptions made to arrive at the results. The groundwater models under review are constrained by the precision to which the basic hydrologic processes can be measured or estimated. For example, transmissivity values calculated using aquifer test data and accepted analytical procedures still only offer order-of-magnitude estimates. The recharge to the aquifer systems is the driving force behind all models, yet it is one of the least understood hydrologic processes. Over the last two decades, new methods for estimating evapotranspiration have helped reduce the uncertainty of this process, the largest source of discharge in the Death Valley flow system. Because of the importance being placed on the numerical models, Nye County is identifying the need for further analysis of existing data and the collection of new data concerning the basic hydrologic processes that are known to occur in the region. These evaluations are aimed at increasing the predictive capability of the models by reducing the uncertainty in the underlying factors that control all groundwater flow models.

\subsubsection{DATA LIMITATIONS}

The existing numerical models of the Yucca Mountain region and the Death Valley flow system are limited in their capability to portray the groundwater regime. Evaluations are underway by Nye County that are comparing the published models and identifying those areas where additional data or evaluations are needed. The models that have been developed to date only include portions of the Death Valley flow system and disregard the contribution of water from basins north, south, and west of Death Valley. Nye County is conducting a preliminary evaluation of the western most portions of the Death Valley flow system. This evaluation includes the compilation and synthesis of published materials and data sets, and reconnaissance level surveys of the hydrographic basins located west of Death Valley. Nye County, in cooperation with Inyo County, is also investigating springs 
in the Funeral Range to determine their sources and the potential contribution of water from this recharge area to Desith Valley. The data collected during these evaluations is being used to determine if the contributions of groundwater to Death Valley from the west are truly negligible, as assumed in the numerical models.

The models are based upon limited data sets, especially in the region immediately down gradient of Yucca Mountain. Figure 3-1 shows the locations of wells and the available data for southern Jackass Flats and Rock Valley and the northern part of Amargosa Desert. A large gap exists between the southern limit of Yucca Mountain characterization wells and boreholes and the water supply wells located on the Nevada Test Site and to the south, in the community of Amargosa Valley. The data for this gap is primarily limited to that collected using non-intrusive techniques such as detailed mapping of surficial units and geophysical methods. Even in areas to the south, where public and private water wells are present, very little primary hydrologic data is available and is generally limited to Well Drillers Reports, water level measurements, and water chemistry data for the uppermost part of the top aquifer in the groundwater system. Aquifer test data is lacking, as is information on the aquifers present, their extent, and their hydraulic properties. As a consequence, the models that have been developed have had to rely upon assumed, rather than measured aquifer properties for the entire area down gradient of Yucca Mountain.

Although deep subsurface data is generally lacking, the data that are available indicate that the models do not provide the level of detail necessary to simulate the groundwater flow paths between the proposed repository site and potential receptor populations. The published results for an oil and gas exploration test holes and geophysical surveys indicate that the valley-deposits down gradient of Yucca Mountain are not just alluvial gravels, sands, and clays, but also include basalts, volcanic tuffs and ash deposits, lacustrine limestones, and carbonate boulder breccias. Each of these units may be expected to exhibit differing hydraulic characteristics with respect to groundwater storage and flow. 
Other data gaps are located between the proposed repository site and the nearest populated areas in Oasis Valley and Pahrump Valley. Nye County is currently evaluating geophysical data and interpretations for Oasis Valley and has entered into a cooperative agreement with the U.S. Geological Survey to conduct additional geophysical surveys and to conduct detailed geologic mapping of portions of Pahrump Valley. These cooperative efforts will provide important new data sources that will be used in characterizing the hydrogeologic conditions between Yucca Mountain and these populated areas.

\subsubsection{DEATH VALLEY REGIONAL FLOW SYSTEM BOUNDARIES}

The boundary conditions selected play a major role in setting the controls on a mathematical simulation of groundwater flow within a basin. The basis for the boundary conditions varies for each of the three models. These variations are based in part upon the purpose of the model, and in part on the assumptions made in developing the model grids and boundary conditions. As a consequence, the differences between the actual flow system boundaries and the model boundaries warrant further consideration. Because of the thickness of the aquifers and complexity of the hydrogeologic system, the boundary conditions are different for various hydrogeologic units. The surface-water hydrologic basin boundaries may be a reasonable no-flow boundary for the shallow aquifers, but may not apply to aquifers that are at depths of 1000 feet or more. The carbonate aquifers in the region have a very complex structural configuration. Their extent and thickness vary from place to place depending on the proximity to faults which may be normal or thrust faults. Overturned sections of the carbonates are not uncommon in the area. Major faults and fracture zones in the area play an important role in controlling the hydrologic boundaries of the system.

The Death Valley flow system, as discussed by Harrill et al (1988), comprises 15,800 square miles and 30 individual hydrographic basins. The extent of the flow 
system and the hydrographic basins within it are graphically presented in Figure 32. The boundaries shown on this map have come to be the accepted extent of the Death Valley flow system.

Although the boundaries of the flow system have become accepted, there are questions about the hydraulic characteristics of those boundaries. In defining the Death Valley flow system boundary, Harrill et al (1988) noted that "the character of the northeast boundary is not well understood" and these workers characterized the flow system boundary from Tikaboo Valley to the Las Vegas Valley as uncertain. The basis for defining the western boundary of the flow system is not well documented. Plume and Carlton (1988) state that the Great Basin regional aquifer system is bounded on the west by the Sierra Nevada and on the south by the Mojave Desert. These workers defined the boundary of the aquifer system as the mountain divide immediately east of Death Valley (the Panamint Range).

Further, there may be areas beyond the flow system boundaries which contribute water, via subsurface flow, into the Death Valley flow system. D'Agnese et al (1997 pp. 59, 60-61) note that there are at least eleven locations where regional inflows cross the flow system boundaries, and state that good estimates of these inflows are not available except for flow from Pahranagat Valley (east of Tikaboo Valley). However, Pal Consultants, Inc. (1995) provided flux estimates for other areas including flows from Saline Valley (and potentially Panamint Valley), Soda Lake Valley, and Las Vegas Valley into the Death Valley flow system (Pal Consultants, Inc., 1995, Appendix B, pp. 87, 89-91).

Pal Consultants, Inc. (1995, p., 89) conducted an evaluation of water budgets for the flow system and concluded that "the concentration of discharge in Mesquite Flat [in northwestern Death Valley] could be best explained by subsurface inflow of about 8,000 acre feet per year from Saline Valley (some of this inflow may be from Panamint Valley)". Flow from Las Vegas Valley into the flow system was estimated at 5,000 acre feet per year (Pal Consultants, Inc., 1995, p. 91). A lesser 
contribution was estimated for inflow from Soda Lake Valley, about 450 acre feet per year, but it was noted that "additional information will be needed to develop a more credible quantitative estimate" (Pal Consultants, Inc., 1995, p. 90).

To further evaluate these inflows, additional analyses are being performed as part of Nye County's model reviews. Water level data for Inyo County, California was obtained from the U.S. Geological Survey District Office in San Diego (see tables in database provided on the accompanying media package). These data must be considered qualified insofar as they are provisional. Nonetheless, it is the best available water level data set that was identified. This data set is being used in conjunction with water level data for some portions of the flow system in Nevada basins to evaluate the need for further data collection in these areas. An important aspect of this data is the significant fluctuations in water levels over the last fifty years (1944-1997). This observation indicates that there are short-term transient conditions that may discredit the steady-state assumption. Furthermore, data from the spring deposits in the area indicate that flow of the springs continued for several thousands of years after retreat of Pleistocene glaciation. This would indicate that there are long-term delays between recharge and discharge in the groundwater system. This would also emphasize the transient nature of the groundwater system in the area.

\subsubsection{MODEL BOUNDARIES}

Figure 3-3 shows the Death Valley flow system and the extent of the three modeled areas. It is interesting to note that none of the regional models include the entire Death Valley flow system as defined by Harrill et al (1983).

The NTS model (Prudic, Harrill, and Burbey, 1993) is by far the most extensive model and includes almost the entire carbonate aquifer system stretching from the Idaho border on the north to westernmost California on the south and from Lander and Esmeralda counties in Nevada on the west to the Great Salt Lake in Utah on the east. With respect to the Death Valley flow system, the NTS model includes 
all of the flow system except for the area southwest of the Death Valley saltpan. The model includes Pahrump Valley in Nevada as well as Lower Amargosa Valley, Chicago Valley, Valjean Valley, and Shadow Valley in California.

The UGTA regional model domain is much smaller, encompassing a large portion of the Death Valley flow system. As with the regional NTS model, the UGTA model does not include the area southwest of the Death Valley saltpan. The UGTA regional model does not include Pahrump Valley nor Chicago, Valjean, and Shadow valleys in California.

The Yucca Mountain regional model domain is intermediate between the NTS model and the UGTA model. The YMP model includes most of the Death Valley flow system but excludes Shadow and Valjean valleys. As with the other two models, the YMP model does not include the area to the southwest of the Death Valley saltpan.

Although these models cover somewhat different areas, it is interesting to note that none of the models include the portions of the flow system to the southwest of the Death Valley saltpan. As discussed previously, recent published evaluations suggest that there may be considerable contributions of groundwater from the areas to the southwest of the regional hydraulic sink that is present in Death Valley. The effects of excluding such contributions could include unnecessary adjustments of key model parameters during calibration to achieve acceptable water balances or to achieve some level of fit with observed water levels. Nye County, in coordination with Inyo County, is evaluating the significance of disregarding potential contributions from other areas toward the sink at Death Valley.

\subsubsection{BOUNDARY CONDITIONS}

This discussion is limited to the areas located hydraulically down gradient of Yucca Mountain, the key area of concern to Nye County. 
The NTS model includes two types of boundary, no-flow boundaries and generalhead boundaries. In the Death Valley area, the head-dependent boundaries were set to coincide with the Death Valley salt pan (Prudic et al, 1995, p. 18-20).

Conversely, the UGTA regional model includes a no-flow boundary condition around almost the entire model domain including the entire area down gradient of Yucca Mountain. These no flow boundaries were implicitly defined between active and inactive cells along the entire model boundary except at a few locations where other boundary types were used to simulate wells, inflow from Pahrump Valley across the Resting Springs Range, and discharge near Eagle Mountain (U.S. Department of Energy. 1997, p 7-11 - 7-12).

The Yucca Mountain regional model uses yet a third approach and sets a constant head boundary that coincides with the Death Valley saltpan and Sarasota Springs (D'Agnese et al, 1997, p.76- 77). Constant head boundary in this area is not justified over a long period of time. Fluctuations in the water level in the saltpan are well known. The connection between the shallow aquifers and the deep carbonate aquifer in this area is not well known. Therefore, the fact that there is a controlling head boundary near ground surface in this area does not translate into a corresponding head boundary in the deeper aquifers. The recharge to the deeper aquifers may be lagged by geologic times as opposed to short-term lag between recharge and discharge of the shallower aquifers.

All three models, through the selection of boundary conditions, were developed in a manner that mathematically simulates heads in the Death Valley sink on the basis of the recharge derived solely in Nevada. Thus, the majority of this recharge is via subsurface flow through Nye County. The effects of selecting the boundary conditions that exclude the contribution of groundwater from areas west of the Death Valley regional groundwater sink could include unnecessary adjustments of key model parameters during calibration. 


\subsubsection{RECHARGE}

Groundwater recharge is a dominating parameter in the development of any numerical model. The treatment of recharge in the NTS model is described by Prudic et al (1995, p. 23 \& 25). The recharge was estimated by first determining the areas within precipitation zones in the mountainous regions where recharge was believed to be a significant process. The estimated recharge over the mountainous areas was then further evaluated and revised to be consistent with the estimated recharge for individual hydrographic basins or groups of areas. (Presumably, this comparison was with Maxey-Eakin recharge estimates in some areas, but this is not explicitly stated by the authors.) The totaled recharge to the model was about 1.5 million acre feet which represented about three percent of the precipitation.

Recharge in the UGTA regional model was treated differently. A modified Maxey-Eakin method was used that is described in some detail by the U.S. Department of Energy (1997, p. 5-22 - 5-30). The recharge rates used in the model were developed by first reevaluating the precipitation data with data that has become available since the Maxey-Eakin method was developed. Surprisingly, this reevaluation did not find any large difference between total precipitation using the new data sets when compared to similar estimates presented by Scott et al (1971) using the older data sets.

Based upon the revised precipitation distribution, the recharge to each cell in the model was initially estimated using Maxey-Eakin derived coefficients for areas with more than 11.8 inches of rainfall. For the zone with between 7.9 inches and 11.8 inches of rainfall, the Maxey-Eakin coefficient was reduced by 33 percent. This reduction resulted in a lower overall recharge rate than that estimated using the Maxey-Eakin method.

The next step in the approach to recharge in the UGTA model consisted of the redistribution of recharge from the upland areas to canyon wash recharge areas 
such as along Fortymile Wash. The issue of whether recharge along stream beds and canyons should be additive to recharge over mountainous areas is being evaluated by Nye County.

The Yucca Mountain regional model uses a third approach to recharge that is described in detail by D'Agnese et al (1997, p.51-56). In brief, this approach used a digital terrain model to classify altitude zones and slope-aspect zones, defined vegetation zones, and used small-scale geologic maps to define parent material zones. After these zones were defined, recharge ratings were selected for each zone. These ratings serve as weighting factors. Maps of the recharge potential were then made for the four factors and overlain and the results reclassified to derive a "refined" recharge potential map for the Death Valley region.

In developing the recharge potential map, no recharge was assigned to any areas below an altitude of 5,000 feet. Further, no recharge was assigned to any area that was not vegetated with coniferous forests, pinon-juniper or mixed shrub. This may have resulted in a reduction in recharge over the Spring Mountains and other highaltitude areas where the vegetation was unclassified because little or none is present. Recharge is not excluded in such areas and further evaluation of the model is needed to determine if this was indeed the case. More information on the specific methodology used in converting from a pixel-based vegetative classification to a model cell-based recharge value is needed for such an evaluation.

The net result of this approach varied little from the Maxey-Eakin approach. The only difference was in areas above altitudes of 9,000 feet where the recharge factor was increased by about 17 percent. Without further evaluation, the effects that may have resulted from eliminating areas above 5,000 feet and that do not have one of the three vegetative assemblages cannot be ascertained. Reductions of recharge in such areas may have effectively offset the use of the increased recharge coefficients in the areas above 9,000 feet elevation, thereby reducing the differences with the Maxey-Eakin method. 


\subsubsection{DISCHARGE}

Each model simulated discharge from natural processes (evapotranspiration processes by plants, springs, and underflow out of the model). The Yucca Mountain model also included consumptive use of water discharge via water wells. Because of the differences in areas, a direct comparison of the total discharge rate of each model is of little utility. It is interesting to note, however, the implications of the approaches that were used both in terms of the distribution of discharge and the discharge rates.

The NTS simulated evapotranspiration as a head-dependent flow boundary in the upper model layer which essentially relies on the extinction of evapotranspiration as a function of depth (Prudic et al, 1993, p. 20). A modified function was used to reduce the number of numerical simulations and adjustments were made to transmissivities and leakance rates to reduce evapotranspiration in areas where the model simulated springs that were considered unrealistic. Without information concerning the specific model cells that were affected, it is not possible to evaluate the overall effect of these adjustments. It should be noted however, that the initial model results may not have been in error. The initial results may have been indicating that appreciably more discharge occurs under true steady-state conditions.

The UGTA model was simulated using the drain package of the model code as described in U.S. Department of Energy (1997, p. 7-16 - 7-19). Estimated and target discharge ranges were establish based on published estimates and on a single measurement of spring discharge at Indian Springs. That the simulated evapotranspiration so closely matched the target rates suggests that this approach may have resulted in effective constant discharge boundaries wherein unnecessary adjustments are needed in some model parameters to force a high level of calibration. That is not to say that the approach used is incorrect or inaccurate. The previously discussed problems encountered with the NTS model may have 
been eliminated using this approach. The drain package may have a better ability to simulate evapotranspiration estimates. If so, the accuracy of the simulation may hinge totally upon the accuracy of those estimates.

The Yucca Mountain regional model used an extinction-based algorithm to simulate evapotranspiration in some areas. The extinction rate varied according to the plant type and ranged from 0 to about 50 feet; the basis for assigning these values was not provided.

Of particular note is the unusual treatment of the evapotranspiration in Death Valley where the model approach abandoned evapotranspiration in favor of a constant head boundary (D'Agnese et al, 1997, p. 78). This approach needs further evaluation as it suggests that simulated values of discharge of a portion of a flow system can be used in lieu of measured and estimated evapotranspiration rates for the entire flow system.

Also of note is the treatment of evapotranspiration in Pahrump Valley. The Yucca Mountain regional model distributed evapotranspiration in a few isolated cells rather than across a large area and then used pumping wells to simulate water withdrawals from the basin. The use of this novel approach in a steady-state simulation is noted; further evaluations of this approach are being conducted by Nye County. D'Agnese (1997, p 84) noted that different well parameters were used for Pahrump Valley versus the rest of the model and then went on to state:

"These parameters were not estimated [using a coded parameter estimator within the model] because their inclusion created an unrealistic source of recharge to the model. That is, when regression was applied, the wells became a source of water instead of discharge locations."

Of further note is the manner in which these well withdrawals were simulated. The overall final water budget for the model includes a simulated discharge of 88,000 $\mathrm{m} 3 / \mathrm{d}$ (with return flow included). This simulated value corresponds with an 
annual extraction rate of only 26,000 acre feet per year for the entire flow system. This value is compared to an estimated value of $89,400 \mathrm{~m} 3 / \mathrm{d}$ or about 26,500 acre feet per year. A comparison with the conceptualization for this model indicates that the pumping rates in just Pahrump Valley ranged from about 65,000 to $162,000 \mathrm{~m} 3 / \mathrm{d}$ between 1962 and 1992 (19,000 to 48,000 acre feet per year). These rates were reduced by fifty percent to calculate an overall average annual rate (D'Agnese et al, 1997, p. 47). More recent water use data indicates annual water withdrawal rates from Pahrump Valley now exceed that simulated for the entire flow system.

Comparing the simulated value of $88,000 \mathrm{~m} 3 / \mathrm{d}$ with an estimated value of 89,400 $\mathrm{m} 3 / \mathrm{d}$ leads to additional questions insofar as the estimated value is based upon the removal of groundwater from storage rather than as pumping wells. (See D'Agnese et al. 1997, Table 17, p. 112; and Table 13, p. 71.) The basis for this value is not given but the uncertainty associated with the estimate is characterized as "considerable" (D'Agnese et. 1997, p. 71).

The Yucca Mountain regional model uses changes in storage under transient conditions to simulate discharge from the Pahrump basin rather than simulating evapotranspiration under steady-state conditions as is done for the rest of the model. As such, the quantity of water removed from storage should be additive to the natural evapotranspiration rate, estimated at 10,000 to 14,000 acre feet per year (Harrill, 1986, Table 7, p. 46). It is not surprising, therefore, that the regression based parameter estimation technique required that wells become sources of water rather than as points of discharge. The overall effect of using a constant head boundary or wells to model the removal of storage in lieu of using the extinction approach on the model results is not clear at this point. Additional evaluation is needed along with an evaluation of the manner in which crop evapotranspiration rates should be factored into the approach used in the Yucca Mountain model. 


\subsubsection{RECHARGE OVER DISCHARGE AREAS}

None of the models account for the natural phenomenon of rainfall over discharge areas or evapotranspiration losses over recharge areas. The NTS model report does recognize that recharge may occur over discharge areas and states that rivers and lakes that border the carbonate province, as well as the Death Valley playa may be either a source of recharge or a source of discharge (Prudic et al, 1993, p. 92). The report notes that this is one of the simplifying assumptions of the model although it could as easily be characterized as a complicating factor.

Hunt (1975, pp. 15 and 30-35) provides an excellent discussion of discharge in Death Valley and a 1969 flood event. This author also noted that while the potential evaporation rate is 150 inches per year, the actual evaporation rate depends upon the water that is available in a given year and "there is no deficit spending". Any runoff of surface waters or precipitation directly over the Death Valley saltpan is likely to provide direct recharge to the hydrologic system through two processes, direct infiltration into storage, and through the replacement of evapotranspiration losses of groundwater with evaporation losses of surface water. The significance of the long-term interactions between the coupled groundwatersurface water processes in Death Valley needs further evaluation.

Similarly, rainfall over other discharge areas such as Ash Meadows and areas of shallow groundwater in southern Amargosa Valley may be contributing recharge directly into discharge areas. Further evaluation is needed to determine the significance of such recharge in numerical simulations. If recharge must equal discharge for a model to be considered calibrated, then it is important that the recharge and discharge components be differentiated so that it is not assumed that all discharge from an area is solely derived from distant regional recharge areas. 


\subsubsection{STEADY STATE VERSUS TRANSIENT CONDITIONS}

At the Devil's Hole workshop, the issue of steady-state versus transient conditions was identified by Nye County. In essence, this issue stems from the implied assumption in each of the models that steady-state conditions prevail across the model domain. This assumption may be in error as climatic conditions and the development of water by man have significantly altered the hydrologic regime and that the period over which these changes have occurred represent transient conditions rather than steady-state.

True steady-state conditions probably last occurred during the Pleistocene. During Pleistocene time, more precipitation resulted in more runoff and more recharge. As a result, there were large lakes present in Pahrump Valley, Death Valley, and a smaller lake in the Amargosa Flat area. The Pleistocene environment over much of the Amargosa Desert basin was marshland with water at, or near, the land surface over much larger areas than today. As more arid conditions prevailed, corresponding declines in water levels and spring discharge rates occurred. These changes represented transient conditions that should be accounted for in regional models.

The error that arises from the assumption of steady state during calibration is significant. If a particular basin is in a transient rebound mode, that is water levels are rising due to reduced pumping activity (which may be the case in Pahrump Valley), calibration assuming a steady state condition generates erroneous results in estimating the hydraulic conductivity values. In this case, the estimated hydraulic conductivity values from steady state would be smaller than the actual values. 


\subsubsection{CALIBRATION}

Nye County notes that none of the models have been shown to meet the calibration requirements under ASTM Standard D 5490-93 (ASTM, 1994).

\subsubsection{METHODS USED}

In conducting the review of the three models, the methods used included literature review, discussions with some of the authors of the models, and direct comparisons between the published reports of the three models. Additional water level data sets for Inyo County and Nye County were reviewed along with published information for oil and gas wells, water wells, and the published and preliminary results of geophysical surveys that have been made in the region.

\subsection{MODELING EFFORT BY NYE COUNTY}

In the reporting period, Nye County focused on development of a saturated zone model for the Death Valley Region (Multimedia Environmental Technology, 1998) in an effort to mitigate some of the concerns outlined in the previous subsections. The initial effort entailed re-creation of the Yucca Mountain regional model by D'Agnese et al, 1997. In this effort, T2VOC (Falta et. al., 1995) was used for the simulations. T2VOC is based on TOUGH2 (Pruess, 1991). TOUGH2 is a robust code that allows simulation of multiphase flow of fluids coupled with energy transport. The domain of discretization can be one, two, or three dimensional in irregularly spaced grid system. A variably-saturated system can be simulated using various capillary pressure and permeability characteristic curves. Simulation of the Yucca Mountain Site-Scale unsaturated-zone has been performed using this code (Bodvarsson et al, 1996). T2VOC is an extension of TOUGH2 which allows simulation of transport of a chemical component dissolved in air, water, or as a free non-aqueous phase fluid. Adsorption and interchange between the phases is allowed based on the thermodynamic state of the computational cells (nodes). T2VOC's gridding system is fully compatible with TOUGH2. Therefore, 
integration of the unsaturated zone model with the saturated zone model can be done relatively easily. The ventilation model, which will be discussed in Section 8.0 of this report, is performed using T2VOC and the modified unsaturated zone site-scale input file (Multimedia Environmental Technology, 1998a).

The attempted mesh for the regional saturated-zone model developed by Nye County is shown in Figure 3-4. This mesh has 39744 nodes (108 wide, 92 long, and 4 layers). The mesh is finer around Yucca Mountain, Amargosa Valley, and Pahrump Valley. The initial attempt was to evaluate the calibrated parameters of the YMP regional model. All boundary conditions, sources and sinks were set identical to the YMP model. The initial conditions were set as the steady-state results of the YMP model. The only difference in the Nye County Death Valley Basin Model (NCDVB) was that it was set to run in transient mode. The storage properties were set based on typical values for the rock types. Values from pumping tests were used where possible, but only a very small portion of the model has storage property data. T2VOC was set to run in saturated, isothermal mode only. In this mode, the results of T2VOC should closely match those of MODFLOWP (the code used for simulation of YMP regional model) because the basic equations solved are identical (darcy and continuity equations).

Many attempts were made to achieve steady state with T2VOC by running the model for a long period of time. Convergence in calculated pressures was not possible after a maximum period of 100 years. This is because, in transient simulations, the code (T2VOC) attempts to calculate pressure head distributions based on the calibrated hydraulic conductivity values. Storage coefficients were changed to allow for variations in the transient effects. It was concluded that the steady-state calibration results were not suited for a transient run because of the time lag necessary for the model to equilibrate the inflow and outflow. In steady state simulations, because the change in storage is set to zero, equilibration is instant in the model. In transient simulations, depending on the storage properties, the time lag between the inflow and outflow dictates the equilibration process. 
Because of long time lags between the recharge (inflow) and discharge (outflow) points, in the transient runs, the model supplies water from the nodes nearest to the discharge points. These nodes tend to desaturate until the effect of recharge is detected by the model. Either unrealistically large storage coefficients had to be assumed to provide large amounts of water near the discharge points or very small storage coefficients had to be assumed to minimize the time required for the inflow-outflow equilibration. Neither one of these assumptions could be justified based on the observations and the known values of the storage properties of the aquifers involved. Therefore, it was concluded that the hydraulic conductivity values calibrated to the transient conditions must be incorrect.

Observations in the basin support the conclusion that the lag-time between recharge and discharge are too large to assume equilibrium conditions. The most significant evidence is the discharge from paleosprings. The paleosprings in the Amargosa Valley flowed at least three thousand years after the retreat of the Pleistocene glaciation. This means that the system has a storage capacity to supply water to the springs for at least three thousand years, once recharged. The current water level beneath some of these spring deposits exceed 300 feet, which means that there must have been additional time required for the water table to drop another 300 feet after the springs ceased to flow.

Water level data available for the Death Valley Hydrologic Basin for the past fifty years was compiled into a database. Hydrographs and selected contour maps for this data are provided in the attached electronic media package (see WaterLevelData.xls, RegionAllWells.ppt, 10yr_maps.ppt and AllYr_maps.ppt). The series of figures beginning with Figures 3-5a through 3-5i shows the contour maps of the water levels combined for 10-year intervals. Figures 3-6a through 3-6j show contour maps for water levels combined for the entire 50-year time interval. Figures 3-6k through $3-6 \mathrm{~m}$ are water elevation contour maps for all the hydrographic areas combined for the entire data collection period. Selected hydrographs are shown in Figures 3-7a through 3-7c. From these figures, it is 
evident that in the time period for which data is available, the piezometric levels have been fluctuating in excess of 100 feet. It is particularly interesting that the fluctuations to the north (the recharge areas) are not synchronous with the water levels in the south. This indicates that there is a short-term time lag between the recharge and discharge, as well as the long-term lag deducted from the paleohydrological records.

The initial modeling exercise indicated that the present steady-state calibration is not representative of the Death Valley groundwater system. Transient calibration of such a complex system is not practical at this time. Therefore, it was concluded that smaller model domains should be used in Nye County's future modeling efforts.

\subsection{SUMMARY}

The water resources available for use in southern Nye County are constrained by a number of environmental, regulatory, and economic factors. The development of new water supplies will have to be planned in a manner that protects the rights of senior water right holders and the important wildlife values at Ash Meadows, Devils Hole, and Death Valley National Monument, while continuing to provide reliable supplies of safe drinking water. These planning efforts must also take into account the legal availability of water and the location of contaminated area and waste disposal units at the Nevada Test Site, the U.S. Ecology site near Beatty, and other potential point sources of contamination. The interrelationships with a proposed repository at Yucca Mountain must then be taken into consideration as a new constraint. These evaluations must be done in a manner that recognizes the fast-changing nature of water demand and allocations within the region and the likelihood that the demand for water in the region will significantly alter the current hydrologic conditions over the next fifty years, or less.

As existing numerical models of the Yucca Mountain and the Death Valley flow system are limited in their capability to portray the groundwater regime, Nye 
County is developing its own saturated zone model for the Death Valley Region. Based on an initial modeling exercise, it was determined that smaller model domains should be used in future modeling exercises 


\subsection{SITE HYDROGEOLOGY}

This section briefly describes the results of monitoring pressure and temperature in UE-25 ONC\#1 and USW NRG4. A more comprehensive presentation of the results of monitoring is presented in Multimedia Environmental Technology, Inc. (1996) and is posted on a monthly basis on the Internet (www.nyecounty.com). The UE-25 ONC\#1 borehole was drilled and both UE-25 ONC\#1 and USW NRG4 boreholes were instrumented to support the following data collection activities:

1. To monitor the long-term variation of pressure and temperature in hydrogeologic units that may be impacted by the construction of the ESF.

2. To perform vacuum and/or injection pneumatic testing to evaluate the horizontal and, to some extent (unknown), vertical pneumatic conductivity values of the hydrogeologic units packed off by the Westbay Instruments.

3. To sample intervals isolated by packers for environmental isotopes to evaluate the residence time of the gases in the hydrogeologic formations.

Nye County borehole locations were selected primarily to establish baseline conditions before penetration of the repository host rock by the ESF tunnel and to monitor the effects of the mine ventilation system used in the ESF tunnel on the ambient pneumatic and moisture conditions of the unsaturated zone in the vicinity of the north and south ramps of the ESF tunnel. UE-25 ONC\#1 is situated southeast of the repository block and is in the path of the future South Ramp of the ESF tunnel (Figure 1-2). It was also strategically located to be along the main trace of the Bow Ridge Fault system and close enough to DOE's C Well Complex (approximately 800 meters) to serve as a monitoring well during aquifer testing. It was drilled by Nye County in late 1994 and early 1995 using dual wall reverse circulation technology to demonstrate an alternative drilling and sampling method to DOE (NWRPO, 1995). 
USW NRG4 is located northeast of the repository block (Figure 1-2) and is situated aboul $1100 \mathrm{~m}$ from the North Ramp (NR) portal of the ESF tunnel. It was previously drilled by DOE. The ESF tunnel passed within approximately 15 meters of USW NRG4 in the middle of June 1995. The effects of the tunnel excavation on pneumatic conditions in this instrumented borehole, as well as in UE-25 ONC\#1, will be discussed in the following sections.

Nye County instrumented UE-25 ONC\#1 and USW NRG4 in early 1995 with Westbay Corporation's MOSDAX MP55 system. The MP-55 is a multilevel monitoring device that consists of an access casing with multiple ports or valves that can be opened to the formation. A multilevel packer system integrated into the access tube serves to isolate access ports and retrievable temperature/pressure measurement probes that connect to these access ports. An above ground data logger is used to monitor the temperature/pressure probes. A complete description of this downhole monitoring system and installation procedures in these boreholes is presented in NWRPO (1995).

Fifteen downhole packers were used to isolate major stratigraphic units, a fault zone, and two isolated zones below the water table in UE-25 ONC\#1. Figure 4-1 shows the location of 15 packers and 31 measurement ports in relation to stratigraphic units, the Bow Ridge fault zone, and the water table. MOSDAX temperature/sensor probes were installed in 9 of the 31 measurement ports available. It should be noted that the two bottom-most probes in UE-25 ONC\#1 are situated below the water table and are monitoring the piezometric potential.

Seven downhole packers and 7 measurement ports were strategically installed in major stratigraphic units in USW NRG4 as shown in Figure 4-1. MOSDAX temperature/sensor probes were installed in all 7 measurement ports.

The pressure and temperature in UE-25 ONC\#1 and USW NRG4 have been monitored since April 1995. Figures 4-2 through 4-13 are graphical representations of the pressure and temperature readings for the months of June 
1997, October 1997, and March 1998 for each borehole. Graphs for the time period of April 1997 through May 1998 are presented in the accompanying media package (see Onc1Press\&Temp.ppt and Nrg4Press\&Temp.ppt). Temperatures reported for all downhole instruments are fairly stable with occasional deviations from the norm. The atmospheric probe (Probe 0 ) in each borehole records a wide range of daily and seasonal temperature fluctuations typical of a desert environment. Comparison of the temperature data from atmospheric probes in USW NRG4 and UE-25 ONC\#1 indicates very consistent atmospheric temperature patterns at the two borehole sites.

Pressure fluctuations with time for UE-25 ONC\#1 and USW NRG4 show that pressure responses exhibit trends versus depth that are expected in layered geologic media. That is, there is a general dampening of the magnitude as well as an increasing time-lag in the peaks and valleys of barometric pressure fluctuations as depth increases. The only exception to these trends are data collected from April to August 1995 in UE-25 ONC\#1 when the upper portion of the borehole was opened to the atmosphere and in both boreholes after the tunnel penetrated the proposed repository horizon.

Two of the probes in UE-25 ONC\#1 (Probes 8 and 9) are below the water table. These probes monitor variation of piezometric level with time.

Comparison of Probe-0 pressure responses at USW NRG4 and UE-25 ONC\#1 indicate nearly identical responses over time when corrected for elevation differences.

Nye County has also received data from unsaturated zone boreholes monitored by U. S. Geological Survey's. These data were analyzed and graphed to compare the data collected by the Yucca Mountain Project (U.S. Geological Survey) with those collected by Nye County. These graphs show that, despite the significant difference in the data collection techniques, there is a close agreement between the averages of the data. The slight differences in the trends and magnitudes are 
expected due to the position of the boreholes with respect to the natural and manmade boundary conditions. 


\subsection{SITE HYDROCHEMISTRY}

\subsection{CHLORINE-36 GEOCHEMISTRY OF CUTTINGS SAMPLES FROM UE-25 ONC\#1}

\subsubsection{INTRODUCTION}

Nye County's first borehole (Stellavato, 1996; Stellavato et al., 1995) for oversight purposes was drilled in December 1994, using dual-wall, reverse circulation technology. This borehole is located approximately $793 \mathrm{~m}$ northwest of the "C" well complex, southwest of Midway Valley, and between boreholes UE25UZ-16 and UE-25p\#1. Composite cuttings samples were collected over every five-foot interval of the borehole; we utilized mostly a $25 \%$ split of these composite samples. Emphasis for this study was placed on characterizing potential rapid transport pathways for radionuclides to the biosphere and determining if any such transport occurred at this location.

\subsubsection{METHODOLOGY}

Our subcontractor, Dr. Marek Zreda of the Department of Hydrology and Water Resources, University of Arizona, prepared the samples by the following procedure. Samples for ${ }^{36} \mathrm{Cl}$ were leached three times in 18-megaohm water, roughly in the proportion of 1 part of sample to 1 part of water. All leachate waters were transferred to a large beaker and combined into one sample. Then, 1 $\mathrm{ml}$ of chlorine isotopic spike $\left(99 \%{ }^{35} \mathrm{Cl}\right.$ and $\left.1 \%{ }^{37} \mathrm{Cl}\right)$ was added to produce enough $\mathrm{Cl}$ for the analysis of ${ }^{36} \mathrm{Cl}$. Chloride was then precipitated as $\mathrm{AgCl}$ by addition of $20 \mathrm{ml}$ of $0.1 \mathrm{M} \mathrm{AgNO}_{3}$ and purified of sulfur using standard methods (Zreda et al, 1991). The ratio of ${ }^{36} \mathrm{Cl}$ to $\mathrm{Cl}\left({ }^{36} \mathrm{Cl} / \mathrm{Cl}\right.$ ) was measured using accelerator mass spectrometry (Elmore et al., 1979) at the Prime Laboratory, Purdue University. 


\subsubsection{RESULTS}

Table 5-1 lists the results to date of chlorine-36 analyses of leachate from rock cuttings samples from UE-25 ONC\#1. There are some duplicate analyses for quality assurance purposes (labeled " $A$ " and " $B$ " in Table 5-1). For several samples (labeled "coarse" and "fine" in Table 5-1), the coarse and fine fractions were separated from the composite cuttings and analyzed separately. The coarse fraction always had the higher ${ }^{36} \mathrm{Cl} / \mathrm{Cl}$ ratio suggesting that the finer fraction had relatively less ${ }^{36} \mathrm{Cl}$ due to rupturing of fluid inclusions and exposure of broken mineral grains (during drilling). Both of these processes present in-situ chlorine to the laboratory leaching solutions which is "older", and thus more decayed, than that deposited by more recent infiltrating waters.

Figure 5-1 includes all of the data collected to date plus unpublished data (personal communication, Dr. June Fabryka-Martin, Los Alamos National Laboratory, 1998). Data are plotted at the top of the five-foot interval for that composite cuttings sample. In fact, the highest measured ${ }^{36} \mathrm{Cl} / \mathrm{Cl}$ ratio (about $825 \mathrm{E}-15$ ) for cuttings from this borehole is one of Dr. Fabryka-Martin's samples at about 1,400 feet depth in the upper Prow Pass (labeled "PP" on Figure 5-1).

\subsubsection{CONCLUSIONS}

The first leachate water produced from coarse samples gave ${ }^{36} \mathrm{Cl} / \mathrm{Cl}$ values in the range from $290 \mathrm{E}-15$ to $686 \mathrm{E}-15$. This is typical of the natural ${ }^{36} \mathrm{Cl} / \mathrm{Cl}$ background expected in precipitation in this region during the last 10,000 years (FabrykaMartin et al., 1997) and the measured value of $\sim 500 \mathrm{E}-15$ in pore water at this location (Fabryka-Martin et al., 1996). The observed range is due to natural temporal variability of ${ }^{36} \mathrm{Cl} / \mathrm{Cl}$ in precipitation and dry fallout. This variability is caused by the variable strength of the geomagnetic field, which results in corresponding changes in the production rates of ${ }^{36} \mathrm{Cl}$ and other cosmogenic isotopes. 
No bomb-pulse chlorine has been detected thus far, but we are awaiting results of ${ }^{36} \mathrm{Cl}$ analyses on more cuttings samples.

\subsection{GAS SAMPLING FROM UE-25 ONC\#1}

The purpose of the gas sampling is to:

- Estimate the ages of the gases in the vadose zone in UE-25 ONC \#1 and their relationship with the ages of the water obtained from other boreholes at Yucca Mountain that could help evaluate the percolation and recharge at the site.

- Understand the transport mechanism governing gaseous migration in the vadose zone at this site.

- Evaluate the effect of tunneling on the repository horizon.

The Exploratory Studies Facility (ESF) tunnel has been approaching the area of UE-25 ONC\#1. It broke through at the South Portal on May 20, 1997. The tunnel is a boundary condition for temperature, pressure, humidity, and environmental isotopes. As the tunnel penetrated the rocks in the repository horizon, the air in the tunnel became an avenue for communication between the air in the geologic formations at the repository horizon and the atmosphere outside the tunnel. Diurnal variations in temperature and pressure observed in the tunnel correspond with the outside atmospheric fluctuations. Pressure and temperature responses that have been observed in various unsaturated zone boreholes, including UE-25 ONC\#1, can be attributed to the presence of the ESF tunnel. It is suspected that if air pressure responses are detected at relatively long distances away from the tunnel, fracture pathways for migration of gases may exist. Therefore, it may be possible to detect existing gaseous chemicals in the atmospheric air introduced into the repository horizon through the tunnel. 
Gas samples have been collected three times from UE-25 ONC\#1. The first sampling was performed in October 1996 and consisted of sampling for carbon 14, tritium, and chlorinated fluorocarbons (CFC). The detection limit for the CFC was selected at too high a value in the first preliminary sampling effort. In June 1997, a second set of samples were collected for the same compounds but pertinent environmental gases were analyzed for at a much lower detection limit. During the third sampling event that took place in April 1998, the same set of environmental gases were analyzed for. In this third sampling effort, only two zones near the fault zone were selected for time-dependent carbon-14 sampling. The timedependent carbon-14 sampling was performed to resolve issues that were raised in previous sampling efforts.

The results of the first sampling effort were presented in previous reports (Multimedia Environmental Technology, Inc., May 1997, this is the last annual report and Multimedia Environmental Technology, Inc. February 1997, this is the gas sampling report) and will not be repeated here except for comparison purposes. The results of the last two sampling reports are discussed below.

\subsubsection{JUNE 1997 GAS SAMPLING}

The samples collected in June 1997 were intended to complete the background sampling of compounds that could not be sampled during the October 1996 sampling and also to verify some of the values that were reported in the earlier report (Multimedia Environmental Technology, Inc., February, 1997). The current plan is to repeat the environmental gas sampling on an annual basis to monitor the changes in environmental chemicals in UE-25 ONC\#1 that could potentially be attributed to the introduction of these chemicals to the repository horizon by the ESF tunnel. The results of these sampling rounds and subsequent analysis of data will be used to evaluate the conductive nature of the repository host rock. Gastransport parameters may be estimated from analysis of the data and may be used in evaluation of the potential for transport of gaseous radionuclides from the 
repository to the accessible environment. These data will also be used to evaluate the ability of a naturally ventilated repository to perform safely and adequately. Sampling and testing of UE-25 ONC\#1 air is expected to provide information about the pneumatic and thermal conductivity as well as the diffusive and dispersive nature of the rock.

Environmental chemicals such as fluorocarbons and isotopes such as ${ }^{14} \mathrm{C},{ }^{13} \mathrm{C}$, and ${ }^{3} \mathrm{H}$ are introduced through the tunnel air as a constant source. The tunnel air has near atmospheric chemical composition. These chemical species and isotopes enter the unsaturated zone (UZ) with advection of the atmospheric air caused by the changes in the air pressure of the tunnel. These gases are transported in the $\mathrm{UZ}$ by the advective, dispersive, and diffusive processes.

Once the pre-excavation conditions are established at the UE-25 ONC\#1 site, the changes in the chemical composition of the pore gas with time may be analyzed to evaluate the arrival of these environmental tracers in UE-25 ONC\#1. With adequate data, transport properties of the rock mass between the tunnel and UE25 ONC\#1 may be evaluated. The volume of rock affected by this test is the largest that has ever been tested at the Yucca Mountain site.

\subsubsection{APPARATUS AND SAMPLING PROCEDURES}

The sampling apparatus is schematically shown in Figure 5-2 (also see Photograph 5-1). Detailed sampling procedures are outlined in Nye County's Technical Procedure 9.40 entitled "Gas Sampling Procedure of UE-25 ONC\#1 and other Westbay Instrumented Wells". A brief description follows.

The Westbay access tube was fitted with a vacuum-tight plug (Figure 5-2) during sampling. By applying vacuum in the access tube through this plug, sampling was performed at selected depth intervals. The surface attachments consisted of:

1. Tritium sampling unit (TSU). 
2. The CFC and organic compound canister.

3. The Tedlar bag vacuum purging and sampling (TBVPS) unit.

4. Flow metering unit (FMU).

5. Temperature probe.

6. Vacuum pump (VP).

The first four units had by-pass valves that were used during purging of the sampling zone. Flow rates in excess of $2 \mathrm{ft}^{3} / \mathrm{min}\left(0.06 \mathrm{~m}^{3} / \mathrm{min}\right)$ were used during purging for 1.5 to more than 12 hours. The duration of flow was calculated to be sufficient to evacuate the entire string, the entire annulus between the packers, and a radius of at least 2.5 feet into the formation, based on an average air-filled porosity of 10 percent. Assuming air-filled porosity of 10 percent is very conservative. Actual air-filled porosity is less than 1 percent for the formations sampled. Therefore, in some cases the formation may have been purged to a radial distance of up to 25 feet around the borehole prior to sampling.

In addition to the sampling apparatus, the down-hole Westbay MOSDAX probes were set as monitoring ports at various intervals during purging. The pressure and temperature data were used to calculate pneumatic conductivity of the formations sampled.

As soon as the purging process was completed, the by-pass valve for the CFC canister was closed and the valve to the canister opened. Because the canister was already under vacuum from the laboratory, it automatically filled with the gas from the line. Then the Tedlar bags were filled (depending on the zone of interest, one or two 10 liter bags were filled), the by-pass valve for the TSU was shut and air was allowed to flow through the Tritium Microsieve Sampling Cylinder (TMSC). All the TMSCs were weighted, prepared, and sealed in the laboratory prior to field sampling. The by-pass valve at the FMU was also closed to allow for monitoring 
of the flow rate. A minimum of one hour of flow was allowed to occur through the TMSCs at an approximate rate of $1 \mathrm{ft}^{3} / \mathrm{min}\left(0.03 \mathrm{~m}^{3} / \mathrm{min}\right)$. This time duration allowed entrapment of between 50 and 70 grams of water in the molecular sieve.

Once Tritium sampling was completed, the TMSC was disconnected and shipped to the laboratory in a cooler.

\subsubsection{CHEMICAL SAMPLING ZONES}

The Westbay access tube can be opened at nine locations in UE-25 ONC\#1 (Figure 5-3) using sliding sleeves that, once opened, expose slotted sections of the access tube. Each of the six vertical slots in a section is 1.75 in $(4.5 \mathrm{~cm})$ long and 0.5 in $(1 \mathrm{~cm})$ wide. By opening each one of the sliding sleeves, a packed-off section of the borehole can be sampled by applying a vacuum to the inside of the access tube.

Seven of the nine access tube port locations were used for sampling during testing performed from June 3 through June 12, 1997. The locations of four of these screens are identified by a "GS- "prefix in Figure 5-3. Samples GS-1, GS-2 and GS-2A were selected to be near the fault zone. GS-5 was selected to be in the Tiva Canyon Welded Unit (TCWU) above the Paintbrush Tuff Nonwelded Unit (PTNU). Additionally, samples were taken from access tube screen 8 in the PTNU and screens 1 and 2 below the water table. Samples of the atmosphere just above the top surface of UE-25 ONC\#1 were also collected.

\subsubsection{RESULTS OF JUNE 1997 GAS SAMPLING}

A summary of the tests and sampling performed in UE-25 ONC\#1 during June of 1997 is shown in Table 5-2. Table 5-3 tabulates the results of all the chemical analyses excluding Carbon-14. Figure 5-4 is a plot of all the chemical analyses except for the isotopic analyses. Figures 5-5 through 5-8 show individual groups of chemicals. Figures 5-9 and 5-10 are the results of 0-18 and Deuterium analyses. The tunnel data are also shown in these figures when available at depths 
of 100 and 200 feet. These depths were arbitrarily chosen to show the tunnel data because there are no sampling ports in UE-25 ONC\#1 at these depths.

Figure 5-5 shows the distribution of methane and carbon oxides. Concentrations of both methane and carbon dioxide are similar for the atmosphere and the tunnel. Methane is depleted at a depth of 1225 feet in UE-25 ONC\#1. On the other hand, carbon dioxide shows an increasing trend to a depth of 700 feet. A sharp decline is observed near the fault zone below which an increase in carbon dioxide is observed. The increase in carbon dioxide with depth has been observed in other boreholes at Yucca Mountain. However, the decrease at the fault zone seems to be an anomaly that requires explanation.

A plot of the chlorinated hydrocarbons with depth is shown in Figure 5-6. Trichloroethane (TCA) concentration appears to be only elevated in the tunnel and absent in the fault zone. Its presence below the fault zone is attributed to the sample container. Tedlar bags allow slight diffusion of some gases (especially volatile organic compounds) through their plastic wall. Therefore, TCA is believed to be absent in the vadose zone of UE-25 ONC\#1 and is considered to be a good candidate tracer for monitoring any tunnel air interaction with the subsurface environment. However, TCA is a compound that is highly sorbed on other organic matter in the vadose zone and may not be a conservative tracer.

Figure 5-7 is a plot of the concentration of chlorinated fluorocarbon compounds (CFCs) with depth. Concentrations in the tunnel are similar to the atmospheric concentrations as expected. A decrease in concentration with depth has also been observed elsewhere at Yucca Mountain. The increase in F11 and F12 at a depth of 1225 feet, which is below the fault zone, is attributable to the Tedlar bag as can be seen by comparison with the results of the sample in the canister from the same zone. However, in the upper part of the fault zone, slight deviation from the linear trend can be seen in all three compounds. 
Figure 5-8 presents the concentration of nitrous oxide with depth. The concentration levels of nitrous oxide in the tunnel are slightly lower than the atmospheric concentration levels; however, they are similar to the concentration levels in UE-25 ONC\#1 at Topopah Springs horizon. Concentration values of nitrous oxide appear to increase noticeably near the fault zone. The decline in the Tedlar bag sample below the fault zone is attributable to sample contamination with atmospheric air by diffusion through the wall of the bag. Nitrous oxide is present in the atmosphere and is believed to be present in elevated levels in groundwater due to biological activities. Its elevated concentration in the fault zone is currently under investigation. One possibility is diffusion from the water table.

Figure 5-9 is a plot of Deuterium and 0-18 ratios with depth and Figure 5-10 is a plot of their correlation. The bottom two samples are groundwater samples and the remainder is the results from condensation collected from the vadose zone. Both isotopes appear to be lighter in the vadose zone; this is attributed to potential fractionation of these isotopes during flow of the air from deeper zones. Figure 510 shows that the water samples are very similar in their composition of these isotopes to the perched waters at the site.

Table 5-4 lists the results of Carbon-14 isotope sampling. Testing was performed to measure the age of the Carbon-14 isotope in the unsaturated zone and in the groundwater of UE-25 ONC\#1. A plot of the apparent age of the groundwater based on this isotope versus depth is shown in Figure 5-11. Although these ages are corrected for ${ }^{13} \mathrm{C}$ ratios, they are not corrected for the dead carbon in the groundwater. Personal communication with Ed Kwicklis of the U.S. Geological Survey indicates that the groundwater ages may be 2000 to 4000 years overestimated. However, the activities reported from UE-25 ONC\#1 compare very well with the Yucca Mountain database. Carbon-14 apparent ages support a systematic trend for the ages in the unsaturated zone as expected. The age gradually increases until the fault zone is reached. At this point, the age of the 
Carbon-14 drops roughly more than 1000 years. Through the fault zone and until the water table is reached, the age progressively increases again. The ages for both measurements taken from the groundwater are about the same.

Based on ${ }^{13} \mathrm{C}$ values, atmospheric contamination of all other samples is minimal, if any. The only time that atmospheric air may have contacted the samples is during removal from the TBVPS; however, the inlet into the bag is very small and the amount of atmospheric air that can be accidentally introduced into the bag is less than 0.1 percent of the volume of the sample.

Figures 5-12 and 5-13 compare UE-25 ONC\#1 sampling in 1996 and 1997 with UZ-1, UZ-14 and UZ\#16 values for Carbon-14 and ${ }^{13} \mathrm{C}$ (Yang et al., 1996). Comparison of the data from UE-25 ONC\#1 in June 1997 sampling with those from UZ-1 reveals significant differences and some similarities in the carbon isotope signatures. The isotopic signatures in TCWU are not similar between the UE-25 ONC\#1 and the other boreholes. In UE-25 ONC\#1, the ${ }^{14} \mathrm{C}$ activity is about 20 to 40 percent less than that of the other boreholes at the same vertical distance from the top of the TCWU. Carbon-14 activity in UZ-1 is 33 percent lower than the activity at an equivalent depth in UE-25 ONC\#1 (GS-4 sample). If the value of GS-4 is representative of the conditions in UE-25 ONC\#1, the apparent age of the gas at this level would be about 500 years. This is considerably younger than any apparent age reported for UZ-1 borehole below a depth of 100 feet $(30 \mathrm{~m})$. Conversely, the activity of C-14 in the Topopah Springs through the fault zone is about the same as that in UZ-1. The activity of GS-2A sample is less than 10 percent lower than that of the equivalent horizon in UZ-1. This sample is not likely to have been contaminated with the atmosphere due to its much heavier ${ }^{13} \mathrm{C}(-6.0)$ ratio as compared with the atmospheric ${ }^{13} \mathrm{C}$ (about -9 at Yucca Mountain). However, it is possible that fractionation may have occurred as a result of preferential diffusion of lighter carbon isotope through the wall of the 
Tedlar bag. The C-14 activity in Calico Hills unit is similar for UE-25 ONC\#1 and UZ\#16.

GS-1 sample is in the Calico Hills Nonwelded Unit and is on the hanging wall of the fault zone. The apparent younger age of this sample in October 1996 could not be confirmed and a much older age was reported in the June 1997 sample from the same zone. This younger age contradicts the data from other boreholes and the conceptual model of Montazer and Wilson (1984). However, the high value of ${ }^{13} \mathrm{C}(-3.6)$ in October 1996 was confirmed with values of -5.7 and -6.0 in the June 1997 sampling event. Such ranges of ${ }^{13} \mathrm{C}$ have not been reported anywhere else at Yucca Mountain. These values are usually associated with the presence of carbonates of marine origin. The reason for their presence at the fault zone is not clear at this time. According to Al Yang of the U. S. Geological Survey (personal communication, 1997), the Calico Hills Unit is not known to have an abundance of carbonates. Because of the heavy signature of the ${ }^{13} \mathrm{C}$, atmospheric contamination of the samples is ruled out. A possible explanation for the discrepancy between the results of the two sampling events is postulated to be the difference in the zone of influence. In the June 1997 sampling event, a larger volume of air was purged and, therefore, the sample represents a larger area around the borehole. The October 1996 sample was taken only after 2.5 hours of purging. The smaller purged volume may represent the fault characteristic better than the larger sample. Therefore, it may be possible that the ${ }^{13} \mathrm{C}$ signature of the June 1997 sample is due to mixing of air from the fault zone with the air from the surrounding formation, which has a much lighter ${ }^{13} \mathrm{C}$ signature. The Carbon-14 activities also represent an average between the fault zone and the overall formation characteristics. If this postulation is assumed correct, the October 1996 Carbon-14 activity of the fault zone may be interpreted to indicate the presence of a younger water in the fault zone. Sampling using incremental increases in volume of purged air performed in April 1998 has clarified this uncertainty (see the following section). 


\subsubsection{APRIL 1998 GAS SAMPLING}

Background conditions had been established at the UE-25 ONC\#1 site during previous sampling events. Therefore, the sampling in April 1998 was focused on detecting changes in the chemical composition of the gas with time needed to evaluate the arrival of these environmental tracers in UE-25 ONC\#1 from the ESF tunnel. The second objective of this sampling effort was to evaluate the cause of discrepancy between the results of the two previous sampling events in carbon-14 ages. Samples collected during April 1998 were analyzed for CFC/organic chemicals and ${ }^{14} \mathrm{C}$ only.

\subsubsection{APPARATUS AND SAMPLING PROCEDURES}

The sampling apparatus used during the April 1998 sampling event is schematically shown in Figure 5-14. This apparatus was slightly different from the previous sampling setup as briefly described in the following.

The Westbay access tube was fitted with a vacuum tight plug (Figure 5-14) during sampling. By applying vacuum in the access tube through this plug, sampling was performed at selected depth intervals. The surface attachments were slightly different as compared to previous sampling events. They consisted of:

1. The CFC and organic compound canister.

2. The Tedlar bag vacuum purging and sampling (TBVPS) unit (used for ${ }^{14} \mathrm{C}$ sample collection).

3. Vacuum pump (VP).

The first two units had by-pass valves that were used during purging of the sampling zone. Flow rates in excess of $2 \mathrm{ft}^{3} / \mathrm{min}\left(0.06 \mathrm{~m}^{3} / \mathrm{min}\right)$ were used during 
purging for 0.5 to more than 16 hours for ${ }^{14} \mathrm{C}$ samples and for 4 hours for $\mathrm{CFC}$ samples.

In addition to the sampling apparatus, the down-hole Westbay MOSDAX probes were set as monitoring ports at various intervals during purging conducted on April 22 and 23. Pressure and temperature data were collected on the $22^{\text {nd }}$ and on the subsequent day, April $23^{\text {rd }}$, during sampling at screen \#4. These data were used to calculate pneumatic conductivity of the formation sampled.

As soon as the purging process was completed, the by-pass valve for the CFC canister was closed and the valve to the canister opened. Because the canister was already under vacuum from the laboratory, it automatically filled with the gas from the line. The same process was used during collection of ${ }^{14} \mathrm{C}$ samples. Tedlar bags were purged three times before filling (one 10-liter Tedlar bag was filled for each ${ }^{14} \mathrm{C}$ sample collected).

\subsubsection{CHEMICAL SAMPLING ZONES}

As described in the previous section concerning the June 1997 gas sampling event, the Westbay access tube can be opened at nine locations in UE-25 ONC\#1 (Figure 5-15) using sliding sleeves that, once opened, expose slotted sections of the access tube. Seven of the nine access tube port locations (screens) were used for sampling during testing performed from April 20 th through April 30 1998. Sample collection locations or pumping ports (screens \#3 through \#9) are indicated in Figure 5-15. Samples collected at screens \#3, \#4 and \#5 were selected to be near the fault zone. Samples collected at screens \#6 and \#7 were selected to be in the Topopah Springs Unit. The sample collected from access tube screen \#9 was selected to be in the Tiva Canyon Welded Unit (TCWU) above the Paintbrush Tuff Nonwelded Unit (PTNU). Additionally, a sample was taken from access tube screen \#8 in the PTNU. CFC samples were collected at all seven of the screen locations after purging the borehole for four hours for each screen sampled. An atmospheric CFC sample was also collected just above the top surface of UE-25 
ONC\#1. ${ }^{14} \mathrm{C}$ samples were collected at only screen \#3 and screen \#7. A total of six ${ }^{14} \mathrm{C}$ samples were collected at each of these screens. ${ }^{14} \mathrm{C}$ samples were collected at different time intervals over a period of 16 hours during which purging of the borehole continued. These samples were collected at the following intervals: $1 / 2$, $1,2,4,8$ and 16 hours. The ambient temperature was also recorded periodically during this sampling round.

A summary of the sampling and testing performed at UE-25 ONC\#1 during April of 1998 is shown in Tables 5-5 and 5-6. After sample collection, samples were packed in coolers and sent to the appropriate laboratories with accompanying Chain of Custody forms.

\subsection{CONCLUSIONS AND RECOMMENDATIONS}

Preliminary results from all three sampling events indicate that the sampling method used for obtaining gas samples from UE-25 ONC\#1 is very efficient and produces results that seem to be comparable with results of other UZ sampling techniques that have been used at the Yucca Mountain Site. Tritium sampling results from October 1996 are confirmed with the results of the June 1997 sampling results. No bomb pulse tritium was found in the gases of the unsaturated zone. This demonstrates that there has not been a pervasive recharge event in the vicinity of UE-25 ONC\#1 during the past 50 years. This is confirmed by the results of the chlorine-36 sampling of the drill cuttings (see Section 5.1). However, because the gas sampling method used averages the concentration of the isotopes from the purged volume, small and discrete fluxes in fractures may not be detectable. The young carbon-14 ages, observed in the October 1996 sampling round, were not repeatable in either one of the subsequent sampling events. In variable-time interval sampling of April 1998, it was concluded that the young ages detected in October 96 samples must have been due to preferential diffusion of the lighter carbon isotopes through the Tedlar bags. Therefore, the range of the ages 
in the vadose zone at and below the TSWU is between 5000 to 8000 years. These ages represent the residence time of the pore water and not the gas ages.

Sampling of CFCs and organic compounds must be done using special canisters. No further sampling and analysis of tritium seems to be necessary.

The groundwater ages need to be corrected; however, it is not certain whether any further correction in the vadose zone $\mathrm{C}-14$ ages needs to be performed. If no corrections in the vadose zone ages are made and the ages of groundwater are corrected to be 8000 to 10000 years old, then there seems to be a consistent trend in the ages from the ground surface to the groundwater in the area of the UE-25 ONC\#1.

The results of the three sampling events indicated that TCA and CFC are good tracers for atmospheric diffusion of gases in the vadose zone of the Yucca Mountain. These compounds, along with the other compounds such as nitrous oxide, will be monitored in future sampling efforts. No further carbon-14 and tritium sampling seem to be necessary from UE-25 ONC\#1. However, general chemistry samples from groundwater may be needed to verify the original results obtained from samples collected immediately after drilling in the saturated zone.

The fact that the diffusion of the modern gases (CFCs) into the vadose zone to depths of greater than 1200 feet is observed indicates that the Yucca Mountain vadose zone is a pneumatically open system in direct communication with the atmospheric air. The fact that the $\mathrm{C}-14$ samples show depleted modern $\mathrm{C}-14$ concentrations indicates that the carbon dioxide in the air of the vadose zone is in an equilibrium state with the aqueous-phase carbonates. Therefore, the C-14 activities are believed to be representative of the activities of the moisture in the rocks that are in equilibrium with the air in the vadose zone. The absence of bomb pulse tritium and chlorine- 36 also supports this conclusion. If water had moved as 
fast as the gases, bomb pulse tritium and chlorine-36 would have been detected. The reason that this concept may appear to contradict the observations of the bomb pulse chlorine-36 in the ESF is that the samples collected in UE-25 ONC\#1 are averages of large volumes of the formation air. If discrete percolation pathways exist at this site, such as those found in the ESF tunnel, they could not be detected with this method. In any case, the results show that such discrete percolation flux pathways, if present, are very isolated and not pervasive (otherwise the systematic sampling would have detected some anomaly). It is also recommended that the results and interpretation of the chlorine-36 samples from the ESF be more carefully and thoroughly analyzed to evaluate other possible explanations for the presence of the bomb pulse at the ESF level. In general, it may be concluded that the percolation in the area of UE-25 ONC\#1 is not fast despite the presence of the Bow Ridge Fault Zone.

Comparison of the CFC results from the two sampling events in April 1998 and June 1997 indicates some significant differences between the concentration of the F-12 and F113 that may be reflective of changes of chemistry in the vadose zone. However, because the analytical laboratory for the organic chemicals was different between the two events, the significance of the difference is not considered conclusive until further verification and quality assurance comparison between the two laboratories are conducted.

A preliminary observation and interpretation of the differences between the last two sampling events indicates that the fault zone must have had a significant influence in transport of the CFC to a depth of 1200 feet. Comparison between the data for the two sampling periods does not show detectable differences between the two time periods. 


\subsection{WELL TEST ANALYSIS RESULTS}

\subsection{BACKGROUND}

Well test analysis by the Nye County Nuclear Waste Repository Project Office during the period May 1, 1997 to May 1, 1998, consisted of the following activities:

1. An analysis of the pressure response of Well UE-25 ONC\#1 to atmospheric pressure pulses through natural and man-made pathways, and

2. An analysis of vacuum tests conducted in Well UE-25 ONC\#1

These activities are discussed in detail in the following sections.

\subsection{UE-25 ONC\#1 RESPONSE TO ATMOSPHERIC PRESSURE PULSES}

\subsubsection{INVESTIGATIVE ACTIVITIES}

The Nye County Nuclear Waste Repository Project Office installed instruments in borehole UE-25 ONC\#1 to monitor the pressure at various levels at Yucca Mountain, and to identify the response to atmospheric conditions and activities at the project. The well has ten probes to monitor pressure and temperature at various depths. The pressure response from March 28, 1996 through March 24, 1997 was analyzed.

\subsubsection{METHODOLOGY}

The original objective of the analysis was to determine whether pressure transients in UE-25 ONC\#1 caused by the Exploratory Studies Facility (ESF) could be analyzed using conventional. pulse test analysis techniques. The ESF 
tunnel broke through the non-welded unit on June 18, 1996. After reviewing the observed response, it was determined that the effect of the tunnel could not be accounted for with a one-dimensional linear or radial flow model (Section 6.2.2.1).

Because the various zones at Yucca Mountain are in pressure communication with each other through a complex system of natural fractures and/or faults or other features, the pressures recorded by the different probes were compared using linear regression between the pressure response of adjoining probes to evaluate the degree of similarity in the pressures (Section 6.2.2.2).

To more clearly identify the various components associated with the atmospheric pressure changes, a Fourier analysis was also conducted to separate the parts of the data that are caused by each particular frequency. The basic consideration in Fourier analysis is that the function or data being analyzed is made up of a series of sinusoidal terms (sine and cosine functions) of various frequencies and strengths. The frequency refers to how often each particular term repeats, as for example daily, hourly, or yearly. The strength, or amplitude, of each term refers to the magnitude of its contribution to the total. Terms with large amplitude contribute a large amount to the pressure, while terms with small amplitudes have little effect. Two methodologies focusing on different aspects of the periodic functions were used for the Fourier analysis: a standard Fourier series expansion of the data (Section 6.2.2.3), and a Lomb analysis (Section 6.2.2.4).

\subsubsection{CONVENTIONAL PULSE TEST ANALYSIS}

A pulse test consists of producing (or injecting) into one well for a period, then stopping for a while, then resuming production, then halting, etc. The response is monitored at an adjacent observation well. From the time lag between the pulsing of the active well and the time and magnitude of the observation well response, it is possible to determine the permeability and storage constant $(\phi c h)$ of the porous 
medium (Earlougher, Jr., 1977). Atmospheric pressure changes provide a "natural pulse test" at Yucca Mountain.

Originally, it was thought that the effect of the ESF tunnel breaking through the non-welded unit might be analyzed in this fashion. Figure 6-1 shows the atmospheric pressure and Probe 3 response around the time of tunnel breakthrough. Probe \#3 in UE-25 ONC\#1 is located at a depth of 1029 feet in the Topopah Springs Unit below the Paintbrush Nonwelded Unit (the PTn). The response of Probe \#3 changed after the ESF tunnel breakthrough. Prior to breakthrough, Probe \#3 responded to the atmospheric pressure changes (recorded by Probe $\# 0$ at the surface) with a time lag of about 1 day. About half of the overall atmospheric pressure changes were evident in Probe \#3, except the higher frequency (short period) daily spikes were "smoothed out" by their passage through 1029 feet of rock. After the tunnel broke through the PTn, the time lag shortened slightly, and the daily pressure variations became more obvious at Probe \#3, indicating a more direct connection had been established between Probe \#3 and the atmosphere via the ESF.

Because UE-25 ONC\#1 responds to both vertical flow from the surface through the mountain, and horizontal flow from the tunnel, it does not meet the constraints for conventional pulse test analysis. (There may also be horizontal effects from the sides of the mountain.) To determine the effect of tunnel breakthrough on the UE25 ONC\#1 pressures, it would be necessary to remove the effects of the pulsing from the pre-breakthrough pathways, because conventional pulse test analysis techniques are based on one-dimensional, horizontal, cylindrical flow into a well. Inasmuch as the response after breakthrough was similar to the response prior to breakthrough, the inherent inaccuracies involved in trying to remove the prebreakthrough response from the pressure data would make the pulse test analysis unreliable. Accordingly, the pressure data were reviewed to determine whether other analysis techniques could be applied. 


\subsubsection{REGRESSION ANALYSIS}

Regression analysis is a technique for identifying the degree of correlation, if any, between two or more variables (Draper and Smith, 1981). In this case, the pressures for successive probes in UE-25 ONC\#1 were compared. Previous well testing and other analyses of Yucca Mountain had indicated high permeabilities are present, so it was expected that there would be a high degree of correlation between the pressures at adjacent probes. This was found to be true.

Analysis graphs were prepared to evaluate the correlation between successive adjacent probes in UE-25 ONC\#1 for the period from March 28, 1996 through March 24, 1997. This period was selected for review because it was after known mechanical or operational problems with the probes had been solved, and it constitutes a period of one year of continuous data readings. Each graph contained three plots:

1. A plot of the pressure from each probe versus time. Different pressure scales were used for each probe to show the similarity between the timing of the pressure changes.

2. A linear regression plot of the pressure from the shallower probe on the $x$ axis, versus the pressure from the deeper probe on the $y$-axis. If the pressures from the two gauges are perfectly correlated, the data follow a perfect straight line, while if they are poorly correlated, the data are highly scattered.

3. A pressure residual plot showing the residual pressure change in the deeper probe after removing the effect of the correlation to the shallower probe. This plot shows whether there were other changes in the system beside the correlation between the pressures measured at the two probes. Such changes might include for example, seasonal effects, or the effect of continued work on the ESF. 
In general, a slope of 1.0 on the correlation plot between pressures means the same pressure changes were observed on both gauges, a slope greater than 1.0 implies the lower gauge saw greater pressure change than the upper gauge, and a slope less than 1.0 implies the lower gauge saw less pressure change than the upper gauge. The correlation coefficient shows how strongly the two readings depend on each other, with a value of 1.0 implying perfect agreement, while a value of 0.0 implies no correlation. The correlation between successive probes accounted for almost all the pressure variability, except between Probe 7 above the water table, and Probe 8 in the saturated section.

The linear regression analysis plots for the correlation between Probes 2 and 3 are shown in Figure 6-2. (Similar analysis graphs were prepared between each pair of successive gauges.) Probe 2 measures the pressure in the Topopah Springs at a depth of 778 feet, while Probe 3 is located in the Topopah Springs unit at a depth of 1029 feet. There was a strong correlation between the pressure at Probe 3 and Probe $2\left(\mathrm{r}^{2}=0.9599\right)$. The slope of the best-fit line was 1.0993 , which suggests that the pressure changes observed at Probe 3 were greater than those at Probe 2. This implies a more direct communication between atmospheric pressure and Probe 3 than Probe 2, which might be indicative of greater horizontal permeability or connecting faults. As well, the correlation was better between Probe 3 and Probe 2 than it was between Probe 1 and Probe 2, suggesting Probe 2 may be receiving more impetus from below than from above. The residuals after accounting for the correlation between the probes were negligible. 
The results of the linear regression are summarized below:

Table 6-1: Summary of Regression Results

\begin{tabular}{|c|c|c|c|c|c|}
\cline { 3 - 6 } \multicolumn{2}{c|}{} & \multicolumn{2}{c|}{$\begin{array}{c}\text { Linear Correlation } \\
\text { Between Pressures }\end{array}$} & \multicolumn{2}{c|}{$\begin{array}{c}\text { Residual Correlation } \\
\text { with Time }\end{array}$} \\
\hline $\begin{array}{c}\text { Upper } \\
\text { Probe }\end{array}$ & $\begin{array}{c}\text { Lower } \\
\text { Probe }\end{array}$ & $\begin{array}{c}\text { Slope, } \\
\text { psi/psi }\end{array}$ & $\begin{array}{c}\text { Correlation } \\
\text { Coefficient, } r^{2}\end{array}$ & $\begin{array}{c}\text { Slope, } \\
\text { psi/day }\end{array}$ & $\begin{array}{c}\text { Correlation } \\
\text { Coefficient, }\end{array}$ \\
\hline 0 & 1 & 0.8891 & 0.9272 & 0.00000 & 0.0000 \\
1 & 2 & 0.4379 & 0.5328 & 0.00009 & 0.1214 \\
2 & 3 & 1.0993 & 0.9599 & -0.00001 & 0.0043 \\
\hline 3 & 4 & 0.9827 & 0.9592 & 0.00002 & 0.0641 \\
4 & 5 & 0.8808 & 0.8540 & -0.00001 & 0.0087 \\
5 & 6 & 1.0732 & 0.2436 & 0.00008 & 0.0104 \\
\hline 6 & 7 & 0.9352 & 0.9727 & -0.00010 & 0.0184 \\
7 & 8 & -0.0418 & 0.0002 & -0.00080 & 0.6843 \\
8 & 9 & 1.1020 & 0.9930 & -0.00002 & 0.0290 \\
\hline
\end{tabular}

The regression analyses between the different gauges indicated Probes 1 through 7 responded to atmospheric pressure changes, which may also have affected to a much lesser degree Probes 8 and 9 below the water table. The gauges showed greater variability from Nov. 1996 through March 1997 than the previous 7 months, which was probably a seasonal effect. There is an indication that Probe 3 has a more direct connection with atmospheric pressure than Probe 2, either through greater horizontal permeability carrying the ESF tunnel effects more efficiently, or through faults. The pressure response at Probe 4 indicated possible changes in the flow paths affecting the gauge around Nov. 1, 1996 and Dec. 20, 1996 , or perhaps changes in the gauge sensitivity or measurements around those times. There was a similar indication that Probe 6 may have become better connected to the tunnel around Nov. 1, 1996; if so, the improved connection did not extend to Probes 5 or 7 . Alternatively, there may have been a change in the mechanical response of the gauge in Probe 6 at that time. Finally, Probes 8 and 9 below the water table appear to be responding more to other signals than the atmospheric pressure changes. These other factors are presumably associated with 
water level changes, which can be much larger in magnitude than atmospheric pressure changes communicated to such depths.

\subsubsection{FOURIER SERIES ANALYSIS}

A Fourier series is a mathematical formula to express an arbitrary periodic function as a series of sinusoidal terms (sines and cosines). The Fourier coefficients ( $a_{n}$ and $b_{n}$ ) for an arbitrary function $f(x)$ with period $2 L$ are computed from standard equations (Menzel, 1960) as:

$$
\begin{aligned}
& f(x)=a_{0}+\sum_{n=1}^{\infty} a_{n} \cos \left(\frac{n \pi x}{L}\right)+b_{n} \cos \left(\frac{n \pi x}{L}\right) \text {, where } \\
& a_{n}=\frac{1}{L} \int_{0}^{2 L} f(x) \cos \left(\frac{n \pi x}{L}\right) d x, n=0 \text { to } \infty \\
& b_{n}=\frac{1}{L} \int_{0}^{2 L} f(x) \sin \left(\frac{n \pi x}{L}\right) d x, n=1 \text { to } \infty
\end{aligned}
$$

In this case, the measured data were unevenly spaced, and there are some periods with absent data. To adjust for this, it was assumed for the calculation of the Fourier coefficients that pressure was a linear function of time between measured points. A period of 360 days was used. To avoid having the difference between the first and last data points influence the results, a linear trend from the beginning to end was removed prior to computing the Fourier coefficients.

For plotting purposes, the standard forms were converted to an amplitude $\left(c_{n}\right)$ and phase angle $\left(\theta_{n}\right)$ as shown below:

$$
\begin{aligned}
& f(x)=a_{0}+\sum_{n=1}^{\infty} c_{n} \cos \left(\frac{n \pi x}{L}+\vartheta\right), \text { where } \\
& c_{n}=\sqrt{a_{n}^{2}+b_{n}^{2}}, \quad \vartheta_{n}=\tan ^{-1}\left(-\frac{b_{n}}{a_{n}}\right)
\end{aligned}
$$


The Fourier coefficients $c_{\mathrm{n}}$ for the pressure response for Probes 0 through 9 are plotted together in Figure 6-3. From this figure, it was inferred that the coefficients for Probes 0 through 7 all have similar magnitude, with some appearance of anomalous values at $1,1 / 2$ and $1 / 3$ day periods (frequencies of 1,2 and 3 days $\left.^{-1}\right)$. Probes 8 and 9 have much larger coefficients. The coefficients in all cases are greatest for the low frequencies, and decline rapidly at higher frequencies.

The Fourier coefficients around a period of one day are plotted in Figure 6-4, and around one-half day in Figure 6-5. These figures confirm that there are daily and semi-daily pressure variations, and that they are largest for Probes 0 (atmospheric response), 1 and 6. This may indicate a more direct communication between Probe 6 and the atmosphere either through faults or through the tunnel and subsequent horizontal pressure transients. If the latter explanation is true, it could be an indicator of higher horizontal permeability between the tunnel and Probe 6 than the other probes.

The Fourier coefficients $c_{\mathrm{n}}$ and phase angles $\theta_{\mathrm{n}}$ for each probe were computed, and one day and fractional day periods were evident at all probes. The Fourier coefficient and phase angle as a function of frequency were generally similar functions for all probes except Probes 4 and 6, which had much greater scatter in their plots, possibly indicating they were responding to some factors that were different than the other probes.

The Fourier series identifies the components that have a particular frequency, regardless of whether the flow is horizontal, vertical, radial, linear, or through combined flow paths. Unfortunately, the method also may identify false results, either through statistical noise in the data, or through "aliasing", whereby terms with a frequency of one day may falsely appear at frequencies that are multiples of one day. This appears to be the case with the terms at one-half day, one-third day, etc. 


\section{2:2.4 LOMB SPECTRAL ANALYSIS}

Another method for analyzing periodic data is the Fast Fourier transform (or "FFT") technique. The FFT allows a direct computation of the power spectrum, corresponding to the Fourier coefficients, based on a discrete Fourier transform of the data. The FFT methodology requires evenly spaced data. For unevenly spaced data, a variant of the FFT known as the Lomb method is used instead (Press, et al., 1992). In addition to computing the spectral power, the Lomb algorithm also provides a computation of the statistical significance of the results. The use of this technique is best described by reference to one of the figures showing the results. Figure 6-6 shows the computed power spectrum for Probe 0, which measures atmospheric pressure changes. There are numerous frequencies of less than 2.25 days $^{-1}$ (corresponding to periods greater than 0.4 days) that would be expected to arise by chance from noise less than one time in ten thousand. Accordingly, those frequencies are considered statistically significant. The largest factors are those in the upper left corner of the plot, which correspond to longer-term cycles of 30 days period or more. A plot for Probe 3, which measures pressure response in the Topopah Springs unit at a depth of 1029 feet, is shown in Figure 6-7. The Probe 3 response was similar to the Probe 0 (atmospheric) response.

Using similar plots for all probes, it was found that higher frequency data, corresponding to periods of 0.6 days or less, were not significant for Probes 2 through 9. The power spectrum for Probe 6 had a distinctly different shape than the other probes, possibly indicating different flow paths. One possible interpretation for the power spectrum for Probe 6 might be that it is responding to multiple flow paths, with the pressure waves canceling out certain frequencies and reinforcing other frequencies. Only low frequency components, with periods greater than 1.5 days, were significant for Probes 8 and 9, which are below the water table. This implies the daily variations in those two probes are probably not real, but are aliasing effects from other, lower frequency terms. 
To provide a better comparison between the power spectrum for the various probes, the results were plotted against each other. In other words, the computed spectral power for each frequency for one probe was plotted against the computed spectral power for another probe at the same frequency. Figure 6-8, for example, is a cross-plot between the Probe 0 and Probe 1 power spectra, indicating these probes respond similarly to each other. (Only the values greater than 10 on this plot are statistically significant.)

\subsubsection{RESULTS OF INVESTIGATIONS}

The analysis of the UE-25 ONC\#1 atmospheric pressure response led to the following conclusions:

\section{Pulse Test Analysis Results}

1. Conventional pulse test analysis techniques were not applicable, because there are both horizontal and vertical flow effects.

2. A more detailed, multidimensional analysis (such as the Multimedia Environmental Technology, Inc. model) is necessary for complete analysis of the pressure response.

\section{Regression Analysis}

3. Probes 1 through 7 clearly responded to atmospheric pressure changes, which had little or no effect on Probes 8 and 9 below the water table.

4. Greater pressure variability from Nov. 1996 through March 1997 was probably a seasonal effect.

5. Probe 3 has a more direct connection with atmospheric pressure than Probe 2, either through greater horizontal permeability carrying the ESF tunnel effects more efficiently, or through faults. 
6. The flow paths affecting Probe 4 apparently changed around Nov. 1, 1996 and Dec. 20, 1996.

7. Probe 6 may have become better connected to the tunnel around Nov. 1, 1996; if so, the improved connection did not extend to Probes 5 or 7.

8. Probes 8 and 9 below the water table responded more to other signals (presumably water level changes) than the atmospheric pressure changes.

\section{Fourier Series Results}

9. Daily pressure variations were evident for all probes, and were largest for Probes 0 (atmospheric pressure), 1 and 6.

10. This may indicate the presence of a relatively direct communication between Probe 6 and the atmosphere, either through faults or through the tunnel and subsequent horizontal pressure transients.

11. Probes 4 and 6 have much greater scatter in their plots, possibly indicating they are responding to some factors that are different than the other probes.

\section{Lomb Spectral Analysis}

12. The most significant terms were those corresponding to cycles of 30 days or more. Data for periods of 0.6 days or less were not significant for Probes 2 through 9, which implies the high frequency terms were "damped out" by their passage through the mountain.

13. Probe 1 had a response similar to the Probe 0 (atmospheric) response. No other Probe correlated as strongly with Probe 0.

14. Strong correlation was seen between Probes 2 and 3,2 and 5, and 2 and 7, indicating more similar flow paths or connections for these than the other probes. 
15. None of the probes correlated with Probe 4 or 6 , implying those two probes are responding to different flow paths.

16. Probe 6 has a power spectrum that is distinctly different from the other probes, possibly indicating different flow paths and pressure interference, with the pressure waves canceling out certain frequencies and reinforcing other frequencies.

17. Probes 8 and 9 below the water table were strongly correlated to each other, and the only significant terms for those probes were the low frequency components (periods $>1.5$ days).

\subsection{UE-25 ONC\#1 VACUUM TESTS}

\subsubsection{INVESTIGATIVE ACTIVITIES}

In June, 1997, vacuum tests were conducted in UE-25 ONC\#1 to obtain air samples for laboratory measurements. The pressures recorded during these tests were analyzed using a prolate spheroidal (elliptical) flow analysis technique.

\subsubsection{METHODOLOGY}

The analysis of the UE-25 ONC\#1 vacuum tests was based on the recognition of the presence of wellbore storage, skin, and both cylindrical and spherical flow. When the port connecting to a zone is opened, flow is initially influenced by wellbore storage as air moves from the open region in the annulus between the pipe and the wall of the hole. After the air volume stored in the well is produced, the pressure drop associated with flow from the formation becomes the dominant factor in the pressure response. The flowing pressure drop is caused by two main factors:

- The pressure drop in the region immediately around the well, corresponding to the skin effect. 
- The pressure drop further out in the reservoir, which depends on the level of permeability present.

The skin pressure drop and the reservoir pressure drop are often of comparable magnitude, so it is not generally possible to separate their effects from the steady-state response flow alone. Once the zone is shut in, the rate of flow from the formation to the well decreases to a minimal level. During that "late time" period, reservoir effects dominate. Because the flow rate at that time is negligible, so is the skin factor, and it is therefore feasible to separate the effects of the reservoir permeability from the skin effects. The late-time pressure buildup is very small, and care must be taken to minimize wellbore storage, flow rate variability and temperature variability in order to see the spherical flow response.

The test analysis involved constructing spherical flow plots for the buildup (Figure 69). After wellbore storage effects die out, the late-time dimensionless response for spherical flow is (Joseph, et al, 1985)

$$
P_{D}=1+S-\frac{1}{\sqrt{\pi t_{0}}}
$$

\section{Equation 1}

$$
\text { where } \quad \begin{aligned}
& P_{D}=\text { dimensionless pressure } \\
& S=\text { skin factor } \\
& t_{D}=\text { dimensionless time }
\end{aligned}
$$

The dimensionless response is normally given for continuous production. The permeability is one of the proportionality constants in the definition of the dimensionless pressure (and also dimensionless time). For this reason, it is not generally possible to separate the effects of permeability and skin effect from the production portion of the test alone.

For the late-time buildup portion of the test, after wellbore storage effects have died out, the corresponding equation is (Joseph, et al., 1985): 


$$
P_{F(\text { bullowp })}=\left[1+S-\frac{1}{\sqrt{\pi\left(t_{0}+\Delta t_{0}\right)}}\right]-\left[1+S-\frac{1}{\sqrt{\pi \Delta t_{0}}}\right]=\frac{1}{\sqrt{\Delta t_{0}}}-\frac{1}{\sqrt{\pi\left(t_{0}+\Delta t_{0}\right)}}
$$

\section{Equation 2}

Hence, if the buildup pressure is plotted against a function equal to the difference between two reciprocal square roots of time, a straight line should be obtained. The equation of the applicable straight line is:

$$
P[p s i a]=P_{I}-2454.26 \frac{q[b p d][[b b l / s t b] \mu[c p]}{k^{3 / 2}[m d]} \sqrt{\phi[-] \mu[c p] c\left[\left[p s i^{-1}\right]\right.}\left(\frac{1}{\sqrt{\Delta t[h r]}}-\frac{1}{\sqrt{t+\Delta t[h r]}}\right)
$$

\section{Equation 3}

After substituting typical average values for air viscosity $(0.018 \mathrm{cp})$, temperature

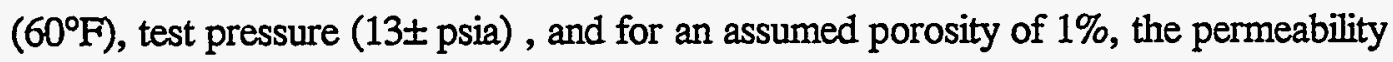
is computed from the injection rate $(q)$ and slope of the spherical flow plot $(m)$, as follows:

$$
k[m d]=\left(33.11 \frac{q[M c f d]}{m[p s i \sqrt{h r}]}\right)^{3 / 2}
$$

\section{Equation 4}

The intercept of the line is equal to the extrapolated reservoir pressure.

The skin factor is evaluated from the difference between the final injection pressure and the extrapolated reservoir pressure, by neglecting the time dependent term in Equation 1 , and converting to conventional units and rearranging as follows: 


$$
S=\frac{k[m d] r_{w e}[f t]\left(P_{t r j}-P_{i}\right)[p s i a]}{70.627 q[b p d] \mu[c p][1[b b / / s t b]}-1
$$

Equation 5

The approximate equivalent spherical wellbore radius was estimated using a published formula for prolate spheroidal or elliptical flow (Raghavan and Clark, 1975).

$$
r_{\mathrm{w \theta}}=\frac{h}{\ln \left[\frac{0.5+\sqrt{.25+\left(\frac{r_{w}}{h}\right)^{2} \frac{k_{z}}{k_{h}}}}{-0.5+\sqrt{.25+\left(\frac{r_{\mathrm{w}}}{h}\right)^{2} \frac{k_{z}}{k_{h}}}}\right]}
$$

Equation 6

\subsubsection{RESULTS OF INVESTIGATIONS}

Preliminary results indicate the following permeability and skin factors were present:

Table 6-2: UE-25 ONC\#1 Vacuum Test Preliminary Results

\begin{tabular}{|c|c|c|c|c|}
\hline Test No. & Test Port & $\begin{array}{c}\text { Permeability if } \\
\text { Skin were Zero, } \\
\text { darcies }\end{array}$ & $\begin{array}{c}\text { Corrected Permeability for } \\
\text { Non-zero Skin, } \\
\text { darcies }\end{array}$ & Skin Factor \\
\hline 1 & 5 & 0.87 & 5.2 & 5.0 \\
\hline 2 & 4 & 0.065 & 0.31 & 3.7 \\
\hline 3 & 6 & 0.33 & 3.0 & 8.3 \\
\hline 4 & N/A & NA & NA & NA \\
\hline 5 & 2 & 0.019 & 0.22 & 11 \\
\hline
\end{tabular}

The final results will differ slightly (estimated to be within $\pm 20 \%$ ) from the preliminary results after a more rigorous derivation of the equivalent spherical radius is prepared. These results confirm the presence of high permeability at Yucca Mountain, and are similar to values computed from the SD-12 tests. 
The presence of significant skin factors is inferred to occur as a result of incomplete connection to the natural fracture system. Especially in a long test interval such as is present at UE-25 ONC\#1, only a few of the existing natural fractures communicate directly to the well. Thus, there is a pressure drop near the well as flow converges into the fractures that do directly communicate with the well, which leads to a so-called skin factor. This topic will be addressed in future work.

\subsection{CONCLUSIONS}

1. Well UE-25 ONC\#1 shows quasi-periodical pressure changes as a result of atmospheric pressure changes. The atmospheric pressure changes show repeated highs and lows corresponding to daily pressure changes, local weather, and seasonal changes.

2. A regression analysis of adjacent gauges showed the existence of preferential pathways for flow in the system. Probes 1 through 7 (above the water table) responded to atmospheric pressure changes, which had little or no effect on Probes 8 and 9 below the water table. Probes \#3 and \#6 in particular had more direct connection to the atmospheric pressure changes than most of the other probes.

3. Methods for the analysis of sinusoidal functions were applied to evaluate the pressure changes in UE-25 ONC\#1. Using Fast Fourier Transform (FFT) methods and the Lomb spectral analysis technique, it was found that the connection between Probe 1 and the surface is mainly the result of vertical flow from the surface. Probe 2 was affected by other factors, probably resulting from horizontal flow through permeable layers below it. Probes 3, 5 and 7 have similar responses to Probe 2. This might indicate fault connection or other conduits for flow between these intervals. Probes 4 and 6 are apparently affected by flow through other pathways. Probe 6 in particular may be seeing the effects of constructive and destructive pressure wave interference that 
could be the result of multiple pathways for pressure communication to that probe. Probes 8 and 9 in the saturated zone are largely affected by changes in the water table. These results are shown graphically in Figure 6-10. Although the results are qualitative in that the reservoir properties could not be computed from this approach, preferred flow paths and changes in flow paths were delineated.

4. The pressure data from the vacuum tests were of sufficient quality to allow computation of permeability and skin factor in four horizons. Preliminary analysis results indicated permeability ranging from 0.2 to 5.2 darcies, and skin factors between +3.7 and +11 were present. The presence of significant skin factors is inferred to occur as a result of incomplete connection to the natural fracture system. 


\subsection{TUNNEL INSTRUMENTATION AND DATA}

\subsection{INTRODUCTION}

Nye County, in an effort to demonstrate the importance of the climatological monitoring in the exploratory test facility and its potential application to alternative repository design, has continued monitoring barometric pressure, temperature, humidity, and air flow velocity in various locations and schemes within the underground workings of the ESF. Nye County has also been analyzing the data collected periodically to evaluate the need for additional data and implications of the results on the performance and operation of the repository.

\subsection{ATMOSPHERIC MONITORING}

Nye County has installed instruments to measure temperature, pressure, humidity and air flow velocity within the ESF tunnel to understand and evaluate the interaction of the ventilation air in the tunnel and its potential impacts on the performance of the repository. An underground climatological monitoring station was installed in August 1995 behind the ESF tunnel boring machine (TBM) to measure the temperature, pressure, and relative humidity of the ventilation air. Figure 7-1 is a schematic drawing that shows the relative position of the instruments. This monitoring station moved with the tunnel boring machine frame. As the TBM broke through at the South Portal on May 20 instrumentation was disassembled and monitoring was discontinued. In November of 1997 another monitoring station was setup along the wall of the ESF tunnel approximately located at Station $35+63$, near Niche 1 . In addition to temperature, pressure and relative humidity, an anemometer was used to measure the air flow velocity in the tunnel. Also, soil moisture probes were installed at two locations in the rock along the wall of the tunnel at this location. Data was collected at this monitoring station for a period of a month and was then analyzed to determine how atmospheric conditions in the tunnel may be affected by ventilation. 
Variations in the water content of the rock were also observed and this data was analyzed in relation to changes in atmospheric conditions in the tunnel. In December of 1997 construction commenced on the Enhanced Characterization of the Repository Block (ECRB) drift. This drift is in approximately an east-west direction and traverses across the ESF main loop at ESF sta. 31+00.

A climatological monitoring station was set up in the ECRB in May of 1998 at ECRB sta. 1+00 (Figure 7-2 and Photograph 7-1). This station was designed to be easily disassembled, so that it could be relocated at another position within the ECRB. As the TBM bores through the rock during the construction of the ECRB, Nye County plans to relocate the monitoring station approximately every 500 feet as the TBM progresses through the rock. Results of Nye County's monitoring in the ESF are presented in a series of graphs in the enclosed media (see ESFInstall.ppt and ESF_TBM.ppt).

Both temperature and relative humidity data show a period of almost chaotic perturbations followed by a smooth recovery. The perturbations coincide with the tunnel operating days (Monday through Friday). The smooth recoveries correspond to the weekends and holidays when the ventilation is not in operation. It is noticeable that the values of the temperature and relative humidity of Probe 2, which is in the center of the tunnel, are almost always smaller than the values of the other two probes.

\subsection{EVALUATION OF THE USE OF WATER IN THE TUNNEL}

As reported previously (Multimedia Environmental Technology, Inc., 1997), Nye County's Nuclear Waste Repository Project team visited the Exploratory Studies Facility (ESF) tunnel in 1996. One of the observations made by the team was related to the water usage in the tunnel. Nye County has observed on several occasions standing water throughout the entire length of the tunnel boring machine 
(TBM) and its attachments. Also it was noted that water spraying with a highpressure hose is routinely being used by the miners to wash the walkways and other seemingly unnecessary areas. In fact, in May of 1998 a DOE Stop Work Order was issued to the mining sub-contractor due to inadequate management of water usage and measurement/accountability for water use in the main tunnel and the ECRB. Nye County has developed a database (refer to the media attached, ecrb.xls and esf.xls) containing information on site construction activities which includes water usage data. This database is updated continuously and is based upon water usage logs and site activity reports provided to Nye County through YMP subcontractors. Furthermore, recent evaluation of the report on chlorine 36 $\left({ }^{36} \mathrm{Cl}\right)$ has revealed that the majority of the samples were contaminated with the J13 water (tagged with lithium bromide) which is the main source of the ESF tunnel water. It is noteworthy that these samples have been taken at least 4 inches into the rock and from the walls of the tunnel, which are not subjected to standing water and are only sprayed for cleaning purposes. Also, Nye County has noted that, in some of the closely-space ${ }^{36} \mathrm{Cl}$ sampling locations in the South Ramp, ${ }^{36} \mathrm{Cl}$ was detected only in some of the samples. Considering the highly fractured nature of the rock, it is conceivable that the traces of ${ }^{36} \mathrm{Cl}$ have been washed away by washing the walls for geologic mapping purposes. Nye County has also learned that the lithium bromide has been detected up to several tens of feet in some of the boreholes drilled by DOE for the purpose of investigating the extent of the construction water invasion. Most of these boreholes show at least a few feet of invasion of the construction water.

Nye County has recently performed preliminary mass balance calculations to evaluate the water usage in the tunnel. These calculations augment Nye County's previous work on the impact of ventilation on water removal from the ESF.

In order to demonstrate the significance of the wet surfaces in the tunnel, a simple conceptual numerical model of the situation was setup. The conceptual model was 16.4 feet wide by 82 feet deep. A vertical fracture zone of about 1.6 feet thickness 
was placed in the middle of the model. The properties of this fracture zone are equivalent to a broken Topopah Springs Welded Unit. The surrounding rock has the properties of the matrix of this unit. The floor of the tunnel was kept wet (at a 95\% saturation) for the entire duration of simulation. Evaporation equivalent to that induced by the ventilation was imposed at the tunnel floor. The rock matrix was initially set at $65 \%$ saturation and that of the fracture zone was set at $20 \%$ saturation (to simulate a drained fracture). The wetting (saturation) front in the fracture travels a distance of $30 \mathrm{ft}$ in about 0.003 days ( 4 minutes). After this time, the wetting front travels at a relatively slower rate. However, after 8 days it reaches the lower boundary of this model which is at 6 feet below the floor of the tunnel. Although this model is very simplified, it demonstrates the potential for propagation of even a slight wetness in a fractured zone.

It is Nye County's position and recommendation that the water use during the tunnel construction be minimized to the extent possible without compromising the safety of the workers. 


\subsection{ALTERNATIVE REPOSITORY DESIGN}

\subsection{INTRODUCTION}

Thermal and moisture conditions of the repository are two of the most important processes that may influence containment of the radionuclides. To contain the radionuclides, the current concept is to seal (or backfill) the repository with crushed tuff or similar material after 100 years. Although some considerations have been given to the design with no sealing of the repository, the results have not been satisfactory in the past due to the predicted high temperature levels (above 100 degree Celsius). The uncertainty in water flux through the repository, the long-term hydrological, chemical, and mechanical effects of the elevated rock temperatures, and the long-term geochemical effects of concrete lining have been some of the most investigated subjects and probably the least resolved issues in the HLRW projects. Because of the large heat load, waste packages must be spaced far apart from each other, requiring a relatively large acreage. Natural ventilation may be used to alleviate some of these problems.

The heat generation rate by each canister of high-level radioactive waste is not substantial and is on the order of about 8 kilowatt. This amount of heat is equivalent to the amount of heat generated by about ten 1000-watt light bulbs. This amount of heat can be removed with a relatively small amount of ventilation. To demonstrate this, an observation from one of Nye County's instrumentation is presented in Figure 8-1.

In this figure, the temperature in probe 1 was noticed to behave anomalously during the time when tunnel forced ventilation was not active (11/6/97 to 11/11/97 and during weekends beginning on $11 / 17$ and 11/24). The reason for this anomaly was determined to be the presence of a flood light less than four feet away from the probe. The flood light is a 500-watt halogen lamp. The amount of heat it generates is approximately 400 watts. During active ventilation period, there is no 
noticeable deviation from the normal trend. This is because the small (approximately $1.6 \mathrm{ft} / \mathrm{s}$ ) air flow rate is sufficient to dissipate the heat generated from this lamp. During inactive ventilation periods, the air flow is too small to dissipate the heat near probe 1 . Once the lamp was removed, this anomaly was alleviated. This observation indicates that a relatively small amount of air movement is required to remove heat generated from objects in the tunnel. Calculations have shown that a $3.3 \mathrm{ft} / \mathrm{s}$ air flow can remove 16 mega watts of heat in a 25-ft diameter tunnel connected to a $10 \mathrm{ft}$ diameter shaft (Multimedia Environmental Technology, Inc., 1997). The amount of heat generated from the canisters is estimated to be about 64 mega watts. Therefore, four shafts connected to a $25 \mathrm{ft}$ diameter tunnel may be sufficient to remove the entire heat generated by the waste.

Long-term ( 1000 yrs) forced ventilation may not be practical in terms of cost and maintenance. One of the advantages of Yucca Mountain claimed by DOE is its open and well-drained host rock. Numerous studies, including Nye County's (Multimedia Environmental Technology, Inc. 1995, 1996, 1997), have indicated that the air permeability of the host rock is large which promotes air movement in the host rock. This open system combined with an engineered underground structure can be taken advantage of to provide natural ventilation to remove the heat from the radioactive waste. The underground structure may consist of a series of interconnected tunnels and shafts that provide a chimney-like configuration where the heat from the radioactive-waste decay promotes natural ventilation. This natural ventilation removes the heat from the canisters. The air movement in the emplacement drifts removes moisture from the host rock. By removing moisture from the host rock the capillary pressure will be increased (more negative) in the host rock. This reduction in capillary pressure will produce a strong potential gradient toward the emplacement tunnel. Moisture removal is enhanced by the movement of the air, which is nearly saturated with water vapor, through the fractures in the host rock into the tunnel. 
The overall results are:

- The heat from the canisters gradually dissipates through ventilation in the tunnels.

- The liquid flow in the host rock moves toward the emplacement tunnels.

- This liquid is removed by evaporation as soon as it reaches the tunnel and will never contact the canisters.

- Radionuclide migration (if any) will be toward the tunnels and not away from the tunnels. That is, even if there is an accidental release in a portion of the tunnel, the migration will be toward another section of the tunnel and not in the direction that may intersect the pathway to the groundwater.

Recent observations in the Exploratory Studies Facility (ESF) tunnel at Yucca Mountain by Nye County staff, have indicated that ventilation can remove substantial amounts of moisture and heat from the tunnel host rock in a very short period of time. Therefore, by naturally ventilating the repository and taking advantage of the thermal drive of the waste packages, the repository host rock may be kept dry for over 10,000 years. The amount of moisture removed from the rocks during this time will create a thick low-saturation skin around the drifts that will require thousands of years to re-saturate. Ventilation can also remove large amounts of heat generated by the waste canisters.

Based on the present accumulation of the spent-fuel rods, it is estimated that more than 63000 kilo watts of heat can be generated from the spent fuel rods. Computer simulations have shown that this amount of heat can generate a substantial amount of air flow if properly placed in a tunnel connected to a shaft or any compartment that is connected to a chimney. 


\subsection{OBSERVATIONS IN THE YUCCA MOUNTAIN ESF TUNNEL}

An underground climatological monitoring station was installed in August 1995 behind the Exploratory Studies Facility (ESF) tunnel boring machine (TBM) to measure the temperature, pressure, and relative humidity of the air. Several other measurement stations have been recently installed by DOE, following the recommendation of Nye County, along the main axis of the tunnel and in radial alcoves to characterize the spatial variation of these parameters in the underground tunnel system.

The data indicated substantial heat and moisture loss from the rock as a result of forced ventilation air.

\subsection{PRELIMINARY SIMULATIONS}

Simulations were made to evaluate the effect of ventilation on removal of moisture and heat from the repository host rock. The coupling of the atmospheric processes with the rock was simulated using A-TOUGH (Multimedia Environmental Technology, Inc. 1994 and Multimedia Environmental Technology, Inc. 1995), a numerical code which was developed for simulation of coupled atmospheric-soil processes.

Figure 8-2 shows the model that was used to calculate the amount of air flow generated from a small portion of the fuel rod assemblies. The simulated tunnel has a diameter of about 25 feet. A ventilation shaft, 1000 feet high and 10 feet in diameter was connected to the main tunnel. An equivalent heat provided by 52 waste packages (445 kilo watts) was applied with a packing density of one per 25 feet of tunnel length. The main driving force for the air movement in the tunnel and along the shaft was the buoyancy caused by the temperature of the waste package and the host rock. The initial pressure conditions were the same as a 
static atmosphere. A temperature of $15^{\circ} \mathrm{C}$ and relative humidity of 10 percent was assumed for the atmosphere.

\subsection{SIMULATIONS USING THE SITE-SCALE UZ MODEL}

The site-scale unsaturated zone (UZ) model (Bodvarsson, 1997) was modified to perform simulations presented here. The mesh was reduced by removing layers from the bottom of the model (the saturated zone section). The area of the model was also reduced. A series of nodes representing the ESF and a conceptual repository were introduced. Four shafts were introduced into the model. The overall dual-porosity node configuration consisted of 40000 nodes (from original 72000 nodes of the LBL UZ model).

The oblique view of the modified mesh is shown in Figure 8-3. The first set of simulations that were completed in this reporting period included an experimental simulation. In this experimental simulation, the heat source was placed in the ESF tunnel only. The placement of the canisters in the shaded conceptual repository area is currently underway.

\subsection{RESULTS OF SIMULATION}

The results of the preliminary simulations are presented in Multimedia Environmental Technology, Inc. (1997) and Montazer (1998) and will not be repeated here. The results of the experimental simulation using the modified $\mathrm{UZ}$ mesh are shown in Figures 8-4 and 8-5 for eddy diffusivity of $.01 \mathrm{~m}^{2} / \mathrm{s}$. The hot spot in the tunnel near the waste package reaches a maximum of $45^{\circ} \mathrm{C}$ in a few days. The rock temperature near the tunnel continues to drop to below $10^{\circ} \mathrm{C}$ until after about 20 years when it rises back to approach $15^{\circ} \mathrm{C}$. Only the first 200 years of simulation are shown here. An infiltration rate of .16 inches/yr was used for this simulation. Air flows at about $60,000 \mathrm{cfm}$. 
These results show that conceptually such a design would be beneficial in maintaining the temperature of the host rock within the ambient conditions while drying the host rock in the vicinity of the waste.

\subsection{REPOSITORY DESIGN}

Application of natural ventilation aided by heat source generated by the fuel-rod assembly may provide a cool and dry host rock with a capillary-pressure gradient toward the emplacement tunnels during the first 10,000 years.

A few shafts may be required to implement a full-scale naturally-ventilated repository. These shafts may be designed to have their exit into the Solitario Canyon as conceptually shown in Figure 8-6

Engineering of an open repository could be complicated and would need special studies. The emission of the gaseous radionuclides do not seem to be of major concern at this time because the large amount of flow will dilute any accidental release of gaseous radionuclides. Particulate matter can be trapped by creating large diameter rooms along the shafts. These rooms will serve as velocity traps and eliminate the need for filters. Filters would reduce the efficiency of the ventilation system.

The complex underground system may not readily lend itself to efficient air circulation in all areas of the system. In these areas, forced ventilation can be used potentially powered by the electricity generated from natural ventilation. According to Montazer (1998) there will be ample electricity that can be generated from the natural ventilation.

Because the heat can be removed readily, the canisters may be much more closelyspaced than current design allows. With high density of packing, a much smaller area (about $1 / 4$ ) will be required for disposal. This will also provide the opportunity 
to select the best part of the available area for disposal. The cost savings for reduced area is considerable and should be studied further.

The potential for intrusion is an aspect that will need to be studied further. The entrance to the repository can be blocked by bars and by providing raises that could only be accessed by special equipment. For example, the bars can be electrified or the entrance can be through a $100 \mathrm{ft}$ shaft only accessible by special equipment.

The invasion of the underground opening by biological activity such as plants and animals is unlikely to a great distance. However, traps can be placed along the way to minimize such potential invasions.

There are many other issues such as stability due to geological activities, flooding, and other issues that need to be thoroughly investigated before such a design is accepted. However, it appears that such a repository would increase safety and reduce uncertainty to such a degree that makes it worth further investigation.

It is not Nye County's position to recommend such a design. The purpose of presenting such a potential change in the repository design is merely to encourage DOE to more carefully look at this alternative and provide more detailed information to be evaluated by the affected communities. 


\subsection{DATABASE MANAGEMENT}

Nye County has been developing a hydrogeologic database for the Death Valley Hydrologic Basin that includes information about all the wells, springs, and other pertinent hydrologic features in the basin (referred to as Nye County Database or NCD in this report). Nye County has made every effort to transfer the existing databases and geographical information systems (GIS), DOE maintained, into the NCD to minimize the duplication effort. The sources of the majority of the data transferred to the NCD were D'Agnese, et. al. (1997), DOE (1997), and the Technical Data Management Geographic Information Systems of DOE (1997). Additional data from the Nevada State Engineers Office and various published reports were entered into NCD and integrated with the GIS.

The NCD uses SATURN GEIS ${ }^{\oplus}$ which is a Microsoft ${ }^{\oplus}$ Access $^{\oplus}$ based software system. The NCD SATURN GEIS allows querying the well and spring information based on sub-basins, groups of wells and springs, regional grouping, ranges of dates, types, and categories of data. Once a query is completed, the selected range of data can be visualized in two- or three-dimensional graphs and renderings. Geologic cross-sections, fence diagrams, and models can be visualized in either still or animated views as desired. The NCD is currently being used to prepare the input needed for the regional groundwater model by Nye County.

The attached media (compact disk) Nycoun97.mdb contains pressure and temperature data for UE-25 ONC\#1 and USW NRG4 as well as data for continuous monitoring of the ESF climatic conditions during ESF construction. This database can be opened directly with Access version 2.0. Data access and sorting can be done with user-friendly menus. Tuneldata.mdb contains temperature, pressure, humidity, and air velocity data for various locations within the ESF and ECRB after November 1997. This database can be viewed using the Access program. 
The file modelUTM.mdb contains a Saturn database with all the water level data. This database is preliminary and is undergoing quality assurance review. Also, not all the available data have been entered into this database yet. 


\subsection{GIS}

The geographic information system activity has been limited to transfer of the coverages from the DOE Technical Data Management GIS into the SATURN database. No modification of the original graphic files has been made. Several hydrological and demographic coverages have been regrouped and reorganized into a SATURN compatible electronic file structure. The Nye County GIS files are not included in the media because the compilation and integration with the ongoing effort under the Oversight Program of Nye County has not been completed yet. 


\subsection{QUALITY ASSURANCE}

\subsection{NWRPO INTRODUCTION}

The Nuclear Waste Policy Act of 1982 (NWPA) defined a process whereby the Nation would site, construct, operate, and decommission a geologic repository for spent nuclear fuel and high-level radioactive waste. In its 1987 amendments to the Act, Congress designated Yucca Mountain, located in Nye County, Nevada, as the sole candidate site for a repository.

The NWPA assigned three roles to separate agencies of the executive branch. The Environmental Protection Agency is directed to promulgate generally applicable standards for protection of the general environment from off-site releases from radioactive material in repositories; the Department of Energy (DOE) is directed to characterize Yucca Mountain for its suitability for a repository, as well construct, operate and decommission the facility, if licensed; and the Nuclear Regulatory Commission (NRC) was charged with the role of establishing technical requirements and criteria for licensing, first the construction, then the operation, and ultimately, the closure and decommissioning, of a repository. The NRC is also responsible for evaluating DOE's license application and awarding a license, if appropriate.

DOE's site characterization program includes surface-based testing and the construction of an exploratory studies facility (ESF) to facilitate the study of underground site features. DOE's primary mission is to collect sufficient data to determine site suitability and to support a license application.

\subsection{NYE COUNTY NUCLEAR WASTE REPOSITORY PROJECT OFFICE}

Nye County has responded to Yucca Mountain being designated the Nation's 
candidate site for disposal of spent nuclear fuel and high-level nuclear waste by organizing the Nuclear Waste Repository Project Office (NWRPO). NWRPO's purpose is to investigate the potential impact a repository at Yucca Mountain might have on the health, safety, environment and overall well being of the residents of Nye County.

To achieve this purpose, NWRPO administers a program of monitoring, oversight, independent scientific investigations, impact assessment and impact mitigation. In particular, NWRPO and its contractors/subcontractors (1) monitor DOE activities, (2) critically review and analyze plans, reports, data, and analysis from DOE and other sources, (3) conduct such independent investigations as may be needed to (a) evaluate and validate DOE data, assumptions, conclusions, and designs and (b) establish NWRPO's own database and analysis for potential licensing and impact mitigation proceedings.

\subsection{QUALITY ASSURANCE PROGRAM}

It is the policy of Nye County that the NWRPO establish and maintain a documented Quality Assurance Program. The purpose is to assure that NWRPO will continually achieve quality of performance in all areas of its responsibilities through the application of effective management systems, in conformance with its mission. This Program is designed to meet the requirements of ANSI/ASME NQA-1 and the criteria of 10CRF50 Appendix B.

All NWRPO personnel and its contractors/subcontractors who perform or manage quality-affecting functions work to the procedures that implement the Quality Assurance Program. The NWRPO Project Manager is responsible to assure that all quality-affecting work performed under his cognizance complies with the requirements of the Quality Assurance Program. The Project Quality Assurance Officer is responsible for the establishment, implementation, and verification of the Quality Assurance Program's compliance with this policy. 
The intent of the QA Program is not merely to produce documentation, but more importantly, to provide assurance that the data derived from NWRPO's oversight and investigation program are of the highest quality. Furthermore, it is intended to assure that the NWRPO's scientific activities are conducted in a systematic manner using documented instructions and procedures that will ensure the validity, integrity, preservation, and retrievability of the data generated.

The NWRPO Quality Assurance Program is based upon the interpretation of Federal requirements (that is, ANSI/ASME NQA-1, 10CFR50, Appendix B) for nuclear power plants adapted for waste repository research and is designed to establish procedures for controlling activities that ultimately affect the final product of NWRPO oversight and investigation. The extent to which this Quality Assurance Program deals with $\mathrm{QA}$ and the responsibilities among the various NWRPO activities is consistent with their individual importance.

\subsection{QA ACTIVITES - SUMMARY APRIL 1997 TO APRIL 1998}

The current embodiment of the NWRPO QA Program was restarted in March 1997 after a suspension since October 1996. The primary focus this past year has been the establishment of several fundamental elements of the QA Program; specifically, the creation of the measuring and test equipment (M\&TE) control system and the refinement of the QA records management system.

In addition to the development of the M\&TE system and the records management system, ongoing work has included:

- The review, approval and issuance of various QA documents including Quality Administrative Procedures (QAPs), Work Plans, and Technical Procedures (TPs).

- The generation of a revised version of the NWRPO QA Program Plan.

- Ongoing communication with staff to determine areas where the QA 
Program needs to be strengthened or new areas in need of coverage.

- $\quad$ Review of DOE, NRC, YMP QA audit reports and consideration of impact on NWRPO.

- Performance of two internal surveillances and one audit on technical and QA Program activities.

- Development of a QA Action database to track outstanding QA items and issues of concern.

- Initiation and disposal of a Nonconformance Report and related Suggested Corrective Action related to calibration of environmental monitoring probes. This included the securing of an independent technical review of the questionable probe data.

- Meeting with the Nuclear Regulatory Commission On-Site Representative to discuss the NCR's informal evaluation of the NWRPO QA Program.

- Assumption of the position of NWRPO Quality Assurance Officer by the contractor in March 1998.

- Increase of QA scrutiny of procurement activities involving analytical laboratory services and calibrated equipment.

- Holding continuing discussions with technical staff concerning the quality and traceability of hydrogeologic data.

- Preparation of monthly progress reports.

\subsection{QA ISSUES}

The primary issue facing the NWRPO QA Program is assuring the traceability and validity of data gathered by the program. The QA applied to the gathering and analysis of these data must be sufficient to ensure their conformance to regulatory controls.

The NWRPO QA Program also faces the following issues:

- The broad question of data pedigree and data quality as concerns data being used in models by the NWRPO. 
- The probable increase of data gathering activities in the field associated with the drilling of new boreholes.

- The need for a more complete evaluation of vendor supplied items and services by the QA Program.

- The increase in the level of technical program activity will necessitate a concurring increase in QA audits, surveillances, and evaluation actions.

- As additional technical and administrative staff are added, there is a necessity that their QA responsibilities are clearly communicated and that they properly perform necessary QA. 


\subsection{SUMMARY AND CONCLUSIONS}

Nye County Nuclear Waste Repository Project Office's (NWRPO) Independent Scientific Investigation Program (ISIP) is concerned with several key scientific issues that may impact the repository design and performance. The ISIP presently includes borehole and tunnel instrumentation, monitoring, data analysis, and numerical modeling activities to address some of these concerns.

Nye County has installed and is currently monitoring pressure and temperature instruments in boreholes UE-25 ONC\#1 and USW NRG4 to evaluate the longterm pneumatic conditions at strategic depths in the subsurface both in response to fluctuations in atmospheric conditions and in response to other possible disturbances resulting from site characterization activities such as ESF tunnel construction. Nye County has also installed instruments to measure temperature, pressure, humidity, and air flow velocity within the ESF tunnel to characterize the air being used to ventilate the tunnel which could potentially impact the performance of the repository. Finally, Nye County is conducting numerical modeling simulations to evaluate factors (including tunnel ventilation) which affect both short-term and long-term pneumatic and moisture conditions in the repository host rock.

A summary of activities undertaken by ISIP during the past year are as follows:

- Evaluation of critical data and information as it became available from the DOE's YMP Site Characterization Office.

- Observed water usage in the tunnel and its potential impact on the repository horizon and the scientific investigation results.

- Prepared detailed review of procedures and methods used for in-situ air permeability tests and evaluated the results of some of these tests. 
- Completed several letter reports to DOE on the interpretation of the results of the ${ }^{36} \mathrm{Cl}$ and other environmental and geological isotope studies. These communications have resulted in DOE giving more focused attention to the need for more detailed studies in the ESF tunnel, limiting the use of construction water, and enhanced interpretation of the results of the isotope sampling.

- Analysis of cuttings from bore hole UE-25 ONC\#1 and focus on the petrographic characterization of past and present fluid pathways that support transport from the ground surface through the vadose and saturated zones. In addition, cutting samples have been analyzed for ${ }^{36} \mathrm{Cl} / \mathrm{Cl}$ ratio.

- Analyzed pressure response of UE-25 ONC\#1 to atmospheric pressure pulses through natural and man-made pathways.

- Monitored responses to vacuum tests that were conducted in UE-25 ONC\#1 to obtain gas samples for laboratory analysis.

- Collected gas samples in the vadose zone in UE-25 ONC\#1 and analyzed the samples for fluorocarbons, tritium, and carbon isotopes.

- Estimated the apparent ages of the gas samples from UE-25 ONC\#1 and compared with the results of samples obtained from other boreholes at Yucca Mountain Site.

- Conducted research as to the potential impact of the construction and operation of the Yucca Mountain Repository on the County's resources. Developed and are in the process of refining a regional model of the Death Valley Hydrologic Basin.

- Establishment of several fundamental elements of the QA Program; specifically, the creation of the measuring and test equipment (M\&TE) 
control system and the refinement of the QA records management system.

As a result of the evaluation of the ESF tunnel climatological data collected, Nye County concluded that substantial moisture was being removed from the rocks penetrated by the tunnel ventilation. In response to issues raised by Nye County, DOE assigned a task force to conduct observations in the ESF and perform numerical simulations for interpretation of the results in parallel with Nye County's effort. Nye County provided data, preliminary analytical and simulation results, and input for developing the proposal to this task force. Nye County data indicated that in addition to moisture, a substantial amount of heat is being removed by the ventilation. Nye County performed additional simulations using A-TOUGH, a computer code designed to simulate coupled-open air with geologic formations and discovered that there is a tremendous potential for natural ventilation at the site due to its climate and its physiographic setting. Simplified simulations using A-TOUGH were performed to evaluate the potential of a naturally ventilated repository. One conclusion is that it is possible to design a repository that is naturally ventilated with peak rock temperatures of less than 30 degrees Celsius over a 10,000-year period. These simulations also showed that the capillary pressure distribution would promote a strong gradient for water flow towards the emplacement tunnels during the entire 10,000 years. Nye County, believes that long-term waste containment implications of a naturally-ventilated repository warrants additional analysis.

Nye County is planning to perform several investigations in the near future to understand some of the issues that were outlined above, by installing new wells in both the saturated and unsaturated zones, testing and sampling these wells, and performing data analysis and modeling. These issues are related to the steep gradients in the saturated zone north and west of the site, the potential for dilution in the saturated zone as unsaturated zone moisture enters the saturated zone, the atmospheric and pneumatic boundaries in the Solitario Canyon that might impact 
the repository performance, and the large-scale transport properties of the fractured formations in both saturated and unsaturated zones. 


\subsection{REFERENCES}

Advance Resources International, 1995, Analysis of permeability tests at Yucca Mountain, Nevada.

Ambos, D.S. et al., 1995, Precipitation data for water years 1992 and 1993 from a network of nonrecording gages at Yucca Mountain, Nevada: USGS Open-File Report 95-146.

American Society for Testing Materials, 1994, Standard Guide for Comparing Ground-Water Flow Model Simulations to Site-Specific Information, Philadelphia, PA

Avon, L. and Durbin, T.J., 1992, Evaluation of the Maxey-Eakin method for calculating recharge to ground-water basins in Nevada", Las Vegas Valley Water District, Cooperative Water Project, Series Report No. 7, 44 p.

Bodvarsson, G.S. and Bandurraga, T.M., Eds., 1996, Development and calibration of the three-dimensional site-scale unsaturated zone model of Yucca Mountain, Nevada, Earth Sciences Division, Ernest Orlando Lawrence Berkeley National Laboratory.

Buscheck, T.A., J.J. Nitao, and L. Ramspot, 1995, Localized dry-out: An approach for managing the thermo-hydrological effects of decay heat at Yucca Mountain, Material Research Society Symposium on Scientific Basis for Nuclear Waste Management, 1995 Fall Meeting, Boston, Massachusetts.

Buqo, T.S., 1996, Baseline water supply and demand evaluation of southern Nye County, Nevada, Nye County Nuclear Waste Repository Office.

Claassen, H.C., 1985, Sources and mechanisms of recharge for ground-water in the west-central Amargosa Desert, Nevada - A Geochemical Interpretation: USGS Professional Paper 712-F. 
Czarnecki, J.B., 1984, Finite-element simulation of ground-water flow in the vicinity of Yucca Mountain, Nevada-California: USGS, Water Resources Investigation Report 84-4349.

Czarnecki, J.B., 1990, Geohydrology and evapotranspiration at Franklin Lake Playa, Inyo County, California: USGS Open-File Report 90-356.

Czarnecki, J.B., 1985, Simulated effects of increased recharge on the groundwater flow system of Yucca Mountain and vicinity, Nevada-California: USGS, Water Resources Investigations Report 84-4344.

D'Agnese, F.A., C.C. Faunt, A.K. Turner, and M.C. Hill, Hydrogeologic evaluation and numerical simulation of the Death Valley regional ground-water flow system, Nevada and California: U.S. Geological survey, Water Resources Investigations Report 96-4300, Denver, Colorado, prepared in cooperation with the Nevada Operations Office, U.S. Department of Energy.

Dettinger, M.D. et al., 1995, Distribution of carbonate- rock aquifers and the potential for their development, southern Nevada and adjacent parts of California, Arizona, and Utah: USGS Water-Resources Investigations Report 91-4146.

Draper, N.R. and Smith, H., 1981, Applied regression analysis: John Wiley and Sons, New York.

Eakin, T.E. and Maxey, G.B., et al., 1952, Contributions to the hydrology of eastern Nevada: State of Nevada, Water Resources Bulletin No. 12.

Earlougher, R.C., Jr., 1977, Advances in well test analysis: Society of Petroleum Engineers, Dallas, Monograph 5, p. 105-122

Elmore, D., Fulton, B.R., Clover, M.R., Marsden, J.R., Gove, H.E., Naylor, H., Purser, K.H., Kilius, L.R., Beukins, R.P., and Litherland, A.E., 1979, Analysis 
of $36 \mathrm{Cl}$ in environmental water samples using an electrostatic accelerator: Nature, v. 277, p. 22-25.

Fabryka-Martin, J.T., A.L. Flint, D.S. Sweetkind, A.V. Wolfsberg, S.S. Levy, G.J.C. Roemer, J.L. Roach, L.E. Wolfsberg, and M.C. Duff, 1997, Evaluation of flow and transport models of Yucca Mountain, based on chlorine-36 studies for FY97: YMP Milestone Report SP2224M3, Los Alamos National Lab. Rpt. LA-CST-TIP-97-010.

Fabryka-Martin, J.T., P.R. Dixon, S. Levy, D. Liu, H.J. Turin and A.V. Wolfsberg, 1996, Summary report of chlorine-36 studies: systematic sampling of chlorine36 in the exploratory studies facility: Level 4 Milestone Report 3783AD, Los Alamos National Lab., pp. 53.

Falta, R.W., et al., 1995, TVOC User's Guide: LBL-36400, supported by the WIPP Project, Sandia National Laboratories, under Document No. 129847, March 1995.

Flint, L.E. and Flint, A.L., 1995, Shallow infiltration processes at Yucca Mountain, Nevada - Neutron logging data 1984-93: USGS Water Resources Investigations Report 95-4035.

Fischer, Jeffrey M., Sediment properties and water movement through shallow unsaturated alluvium at an arid site for disposal of low-level radioactive waste near Beatty, Nye County, Nevada.

Gee, G.W., and Wierenga, B.J. et al., 1994, Variations in water balance and recharge potential at three western desert sites: Soil Science Society of America Journal, Vol. 58, No.1.

Harrill, J.R., 1986, Ground-water storage depletion in Pahrump Valley, NevadaCalifornia, 1962-75: U.S. Geological Survey, Water-Supply Paper 2279. 
Harrill, J.R., A.H. Welch, D.E. Prudic, J.M. Thomas, R.L. Carman, R.W. Plume, J.S. Gates, and J.L. Mason, 1983, Aquifer systems in the great basin region of Nevada, Utah, and adjacent states; A study plan: U.S. Geological Survey, Open-File Report 82-445.

Harrill, J.R., J.S. Gates, and J.M. Thomas, 1988, Major ground-water flow systems in the great basin region of Nevada, Utah, and adjacent states: U.S. Geological Survey, Hydrologic Investigations Atlas HA-694-C.

Hunt, C.B., 1975, Death Valley - Geology, ecology, archaeology: University of California Press, Berkeley, California.

IT Corporation, Underground test area project phase 1 data analysis task, volume III, draft", Las Vegas, Nevada, March 1996.

Joseph, J.A. and Koederitz, L.F., 1985, Unsteady-state spherical flow with storage and skin: Society of Petroleum Engineers Journal, Dec., p. 804-822.

Kane, T.G., Bauer, D.J., and Martinez, Clair M., 1994, Streamflow and selected precipitation data for Yucca Mountain region, southern Nevada and eastern California, Water Years 1986-90: USGS Open-File Report 94-312.

Kearl, P.M., 1982, Water transport in desert alluvial soil: Desert Research Institute, University of Nevada System.

Kilroy, Kathryn C., Ground-water conditions in Amargosa Desert, NevadaCalifornia, 1952-87: USGS Report 89-4101.

Kolm, K.E. and Downey, J.S., 1994, Diverse flow patterns in the aquifers of the Amargosa Desert and vicinity, Southern Nevada and California: Bulletin of the Association of Engineering Geologists, Vol. XXXI, No. 1, pp.33-47. 
Lichty, R.W. and McKinley, P.W., 1995, Estimates of ground-water recharge rates for two small basins in central Nevada: USGS Water Resources Investigations Report 94-4104.

Lyles, B. and Mihevec, T., 1994, Potential hydrologic characterization wells in Amargosa Valley: Desert Research Institute, Water Resources Center, Publication 45129.

Malmberg, G.T., 1967, Hydrology of the valley-fill and carbonate-rock reservoirs Pahrump Valley Nevada-California: USGS Water Supply Paper 1832.

Menzel, D.H., 1960, Fundamental formulas of physics: Dover Publications, New York, p. 74.

Montazer, Parviz, 1994, A-TOUGH, A computer code for simulation of atmospheric interface with fractured rocks: International High-Level Radioactive Waste Conference, Las Vegas, Nevada.

Montazer, Parviz, 1998, Generating electriciy, keeping repository cool, dry, and reducing acreage requirement: International High-Level Radioactive Waste Conference, Las Vegas, Nevada, May 1998.

Montazer, Parviz, and Wilson, W.E., 1984, Conceptual hydrologic model of flow in the unsaturated zone, Yucca Mountain, Nevada: U.S. Geological Survey, Water Resources Investigation Report 84-4345.

Montazer et. al. 1987, Characterization of unsaturated flow through fractured rocks: Groundwater Monitoring Review.

Montazer, Parviz and Stellavato, Nick, 1996, Simulation and observation of ESF tunnel effects on barometric conditions: International High-Level Radioactive Waste Conference, April 1996, Las Vegas, Nevada. 
Montazer, Parviz and Stellavato, Nick, 1996, Moisture removal from the repository by ventilation and impacts on design: International High-Level Radioactive Waste Conference, April 1996, Las Vegas, Nevada.

Montazer, Parviz, 1982, Permeability of unsaturated fractured metamorphic rocks near an underground opening: Golden, Colorado School of Mines, Ph.D. Thesis, $630 \mathrm{p}$.

Multimedia Environmental Technology, Inc., 1995, User's manual for A-TOUGH, an atmospheric interface model based on V-TOUGH.

Multimedia Environmental Technology, Inc., 1995, Interim report on results of instrumentation and monitoring of UE-25 ONC\#1 and USW NRG4 boreholes, Yucca Mountain, Nevada: Nye County Nuclear Waste Repository Office, Nye County, Nevada.

Multimedia Environmental Technology, Inc., 1996, Annual report of the Nye County Nuclear Waste Repository Project Office Independent Scientific Investigations Program.

Multimedia Environmental Technology, Inc., 1997, Results of first gas sampling from UE-25 ONC\#1.

Multimedia Environmental Technology, Inc., 1997, Summary annual report May 1996 - April 1997 Nye County Nuclear Waste Repository Project Office Independent Scientific Investigations Program.

Multimedia Environmental Technology, Inc., 1997, Results of gas sampling from UE-25 ONC\#1, June 1997.

Multimedia Environmental Technology, Inc., 1998, Numerical model of the Death Valley groundwater system, in preparation. 
Multimedia Environmental Technology, Inc., 1998a, Simulation of ventilation effects using the modified UZ model, in preparation.

NOAA Coop. Stations \& USDA-NRCS SNOTEL Stations (www.wrcc.dri.edu/summary)

NWRPO, 1995, Borehole UE-25 ONC\#1 and USW NRG4 drilling and instrumentation report, Yucca Mountain, Nevada: Prepared by the Nuclear Waste Repository Project Office, Nye County Nuclear Waste Repository Program.

Naff, R.L., 1973, Hydrogeology of the southern part of Amargosa Desert in Nevada: Master of Science Thesis, University of Nevada Reno.

Naff, R.L. and Maxey, G.B. at al., 1974, Interbasin ground-water flow in southern Nevada: Report 20, Mackay School of Mines, University of Nevada Reno.

National Climatic Data Center Internet Site (www.ncdc.noaa.gov/pub/data/coopprecip/Nevada.txt).

Nevada Bureau of Mines, 1964, Mineral and water resources of Nevada: Bulletin 65, Mackay School of Mines, University of Nevada Reno.

Nichols, W. D., 1987, Geohydrology of the unsaturated zone at the burial site for low-level radioactive waste near Beatty, Nye County, Nevada: USGS WaterSupply Paper 2312.

Nichols, W.D., Laczniak, R.J., DeMeo, G.A., and Rapp, T.R., 1997, Estimated ground-water discharge by evapotranspiration, Ash Meadows area, Nye County, Nevada: USGS, Water Resources Investigations Report 97-4025.

Oatfield, W.J. and Czarnecki, J.B., 1989, Hydrogeologic inferences from driller's logs and from gravity and resistivity surveys in the Amargosa Desert, southern Nevada: USGS Open-File Report 89-234. 
Pal Consultants, Inc., 1995, A conceptual model of the Death Valley ground-water flow system, Nevada, California: Prepared for: U.S. Department of Interior, National Park Service.

Pal Consultants, Inc., 1995, Evaluation of scientific literature pertaining to the conceptualization of the Death Valley ground-water flow system Nevada \& California: San Jose, CA, prepared for the National Park Service.

Plume, R.W. and S.M. Carlton, 1988, Hydrogeology of the Great Basin region of Nevada, Utah, and adjacent states: U.S. Geological Survey, Hydrologic Investigations Atlas HA-694-A.

Press, W.H., Teukolsky, S.A., Vetterling, W.T. and Flannery, B.P., 1992, Numerical recipes in Fortran: Cambridge University Press, p. $569 \mathrm{ff}$.

Prudic, D.E., J.R. Harrill, and T.J. Burbey, 1993, Conceptual evaluation of regional ground-water flow in the carbonate-rock province of the Great Basin, Nevada, Utah, and adjacent states: US. Geologic Survey, Open-File Report 93-170 (revision of Open-File Report 90-560), Carson City, Nevada.

Prudic, D.E., 1994, Estimates of percolation rates and ages of water in unsaturated sediments at two Mojave Desert sites, California-Nevada: USGS WaterResources Investigations Report 94-4160.

Prudic, D.E., Harrill, J.R., and Burbey, T.J., 1995, Conceptual evaluation of regional ground-water flow in the carbonate-rock province of the Great Basin, Nevada, Utah and adjacent states: USGS Professional Paper 1409-D.

Pruess, K. and Wang, J. S. Y., 1984, TOUGH - A numerical model for nonisothermal unsaturated flow to study waste canister heating effects: in Mat. Res. Soc. Symp. Proc., in G.L. McVay (editor), Vol. 26, Scientific Basis for Nuclear Waste Management, North Holland, New York, New York; pp. 1031-1038. 
Pruess, K. and Narasimhan, T.N., 1985, A practical method for modeling fluid and heat flow in fractured porous media: Society of Petroleum Engineers Journal, February; pp. 14-26.

Pruess, K., 1987, TOUGH user's guide; Earth Sciences Division, Lawrence Berkeley Laboratory, University of California, Berkeley, California, LBL20700; 78 pp.

Pruess, K., 1988, SHAFT, MULKOM, TOUGH: A set of numerical simulators for multiphase fluid and heat flow: Earth Sciences Division, Lawrence Berkeley Laboratory, University of California, Berkeley, California, LBL-24430; 25 pp.

Pruess, K., 1990, Editor, Proceedings of the TOUGH Workshop: Earth Sciences Division, Lawrence Berkeley Laboratory, LBL-29710, September; 157 pp.

Pruess, K., 1991, TOUGH2 - A general-purpose numerical simulator for multiphase fluid and heat flow: Earth Sciences Division, Lawrence Berkeley Laboratory, LBL-29400; 102 pp.

Pruess, K., and OSullivan, M., 1992, Effects of capillary and vapor adsorption in the depletion of vapor-dominated geothermal reservoirs: 17th Workshop on Geothermal Reservoir Engineering, Stanford University, January 29-31; 10 pp.

Raghavan, R. and Clark, K.K., 1975, Vertical permeability from limited entry flow tests in thick formations: Trans., AIME, v. 259, p. 65-73.

Rautman, Christopher A. and Engstrom, D.A., Geology of the USW SD-7 drill hole Yucca Mountain, Nevada.

Rautman, Christopher A. and Engstrom, D.A., Geology of the USW SD-9 drill hole Yucca Mountain, Nevada"

Rautman, Christopher A. and Engstrom, D.A:, Geology of the USW SD-12 drill hole Yucca Mountain, Nevada. 
Rice, W.A., 1984, Preliminary two-dimensional regional hydrologic model of the Nevada Test Site and vicinity: Pacific Northwest Laboratory, Richland, WA.

Roseboom, E.H., 1983, Disposal of high-level nuclear waste above the water table in arid regions: U.S. Geological Survey Circular 903, 21p.

Rush, F.E., 1971, Regional groundwater systems in the Nevada Test Site area, Nye, Lincoln and Clark Counties, Nevada: State of Nevada, Department of Conservation and Natural Resources, Water Resources Reconnaissance Series, Rpt. No. 54, 1971.

Savard, C.S., Selected Hydrologic Data from Forty Mile Wash in the Yucca Mountain Area, NV, Water Years 1993-94.

Schaffer, D.H. and Harrill, J.R., 1995, Simulated effects of proposed ground-water pumping in 17 basins of east-central and southern Nevada: USGS Water Resources Investigations Report 95-4173.

Scott, B.R., Smales, T.J., Rush, F.E., and Van Denburgh, A.S., 1971, Water for Nevada: Planning Report 3 - Nevada's Water Resources, Nevada Department of Conservation and Natural Resources, Division of Water Resources, State of Nevada, Carson City, Nevada.

Spaulding, W. G., 1985, Vegetation and climates of the last 45,000 years in the vicinity of the Nevada Test Site, South-Central Nevada: USGS Professional Paper 1329.

Stellavato, Nick, 1996, Borehole UE-25 ONC\#1 drilling at Yucca Mountain, Nevada: High Level Radioactive Waste Management, Proc. Seventh Annual International Conf., Las Vegas, Nevada, April 29-May 3, 1996, p. 166-7.

Stellavato, Nick, Sims, S., Perry, J., Housel, M., Moyer, J., and McMaster, L., 1995, borehole UE-25 ONC\#1 and USW NRG4 drilling and instrumentation 
report, Yucca Mountain, Nevada: Nye County Nuclear Waste Repository Project Office Rpt., 9/1/95.

TRW, 1995, Total System Performance Assessment -1995, An evaluation of the potential Yucca Mountain repository.

U.S. Department of Energy, 1997, Yucca Mountain Site Characterization Project Site Atlas.

U.S. Department of Energy, 1997, Regional groundwater flow and tritium transport modeling and risk assessment of the underground test area, Nevada Test Site: DOE/NV-477, UC-700, DOE Nevada Operations Office, Las Vegas Nevada.

U.S. Department of Energy, 1997b, Summary of public scoping comments related to the environmental impact statement for a geologic repository for the disposal of spent nuclear fuel and high-level radioactive waste at Yucca Mountain, Nye County, Nevada: U.S. Department of Energy, Yucca Mountain Site Characterization Office.

Waddell, R. K., 1982, Two-dimensional, steady-state model of ground-water flow, Nevada Test Site and vicinity, Nevada-California: USGS, Water Resources Investigations 82-4085.

Westenburg, G.L. and La Camera, R.J., Selected ground-water data for Yucca Mountain region, southern Nevada and eastern California, through Dec. 1994: USGS.

Witter, C. et al, Preliminary development of the LBL/USGS three-dimensional site-scale model of Yucca Mountain, Nevada.

Wittmeyer, G.W., Klar, R., Rice, G., and Murphy,W., 1995, The CNWRA regional hydrogeology information system database, NRC -02-93-005. 
Wittmeyer, G.W. and Turner, D.R., 1996, Regional hydrologic processes of the Death Valley region: NRC High Level Radioactive Waste Research at CNWRA July-December 1995. B. Sagar (ed.), San Antonio, Texas, Center for Nuclear Regulatory Analysis, CNWRA 95-02S, 8-1 through 8-18.

Wood, J.L. and Andraski, B.J., 1995, Selected meteorological data for an arid site near Beatty, Nye County, Nevada, calendar years 1990-1991: USGS OpenFile Report 94-489.

Yang, C., et al, 1996, Interpretation of chemical and isotropic data from boreholes in the unsaturated zone at Yucca Mountain, Nevada: USGS.

Zelinski, W. P. and Clayton, R.W., A 3D geologic framework and integrated site model of Yucca Mt.: Version ISM1.0 (Appendix A)

Zreda, M.G., Phillips, F.M., Elmore, D., Kubik, P.W., P., S., and Dorn, R.I., 1991, Cosmogenic chlorine-36 production rates in terrestrial rocks: Earth and Planetary Science Letters, v. 105, p. 94-109. 


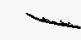

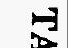

!

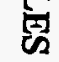


Table 5-1 Chlorine-36 Analyses of Leachates From Rock Cuttings Samples

Both total $\mathrm{Cl}$ and the $\mathrm{Cl}$ ratio were determined by AMS; the $\mathrm{Cl}$ ratio was corrected for the $35 \mathrm{Cl}$ spike.

\begin{tabular}{|c|c|c|c|c|}
\hline 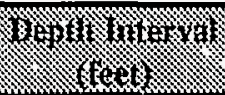 & Hog & 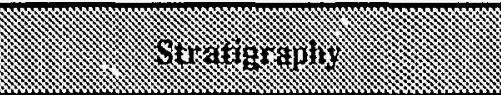 & \% & W \\
\hline $608-613$ & first & bedded tuff, Paintbrush Tuff & 4.36 & 686 \\
\hline $613-618$ & first & bedded tuff, Paintbrush Tuff & 4.05 & 628 \\
\hline $618-623$ & first & non-welded Topopah Springs & 2.71 & 465 \\
\hline $918-923$ & $\overline{\text { coarse }}$ & u. lithophysal, Topopah Springs & 0.93 & 479 \\
\hline $918-923$ & fine & u. lithophysal, Topopah Springs & 0.26 & 194 \\
\hline $923-928$ & coarse & u. lithophysal, Topopah Springs & 0.99 & 426 \\
\hline $923-928$ & fine & u. lithophysal, Topopah Springs & 0.21 & 145 \\
\hline $928-933$ & coarse & u. lithophysal, Topopah Springs & 0.99 & 504 \\
\hline $928-933$ & fine & u. lithophysal, Topopah Springs & 0.19 & 220 \\
\hline 933-938 & coarse & u. lithophysal, Topopah Springs & 1.73 & 380 \\
\hline $933-938$ & fine & u. lithophysal, Topopah Springs & 0.31 & 217 \\
\hline $1,058-1,063$ & first & m. lithophysal. Topopah Springs & 1.19 & 290 \\
\hline $1,153-1,158$ & first, A & Topopah Springs fault zone & 0.32 & 344 \\
\hline $1,153-1,158$ & second & Topopah Springs fault zone & 0.5 & 101 \\
\hline $1,158-1,163$ & second & Topopah Springs fault zone & 0.28 & 118 \\
\hline $1,158-1,163$ & first & Topopah Springs fault zone & 1.16 & 345 \\
\hline $1,278-1,283$ & first & Calico Hills & 3.2 & 387 \\
\hline $1,283-1,288$ & first & Calico Hills & 0.22 & 474 \\
\hline $1,288-1,293$ & first, $A$ & Calico Hills & 1.37 & 656 \\
\hline $1,288-1,293$ & first, $B$ & Calico Hills & 2.09 & 641 \\
\hline $1,333-1,338$ & first & Calico Hills & 2.09 & 599 \\
\hline $1,358-1,363$ & first & Calico Hills & 4.3 & 405 \\
\hline $1,368-1,373$ & first & Calico Hills & 7.67 & 401 \\
\hline $1,378-1,383$ & first & Prow Pass member, Crater Flat tuff & 2.38 & 469 \\
\hline $1,403-1,408$ & first, $A$ & Prow Pass member, Crater Flat tuff & 0.87 & 424 \\
\hline $1,403-1,408$ & first, $B$ & Prow Pass member, Crater Flat tuff & 2.07 & 393 \\
\hline
\end{tabular}

Note: letter after leach indicates a sample split; second leach is after additional crushing. Coarse and fine refer to the two size fractions of a cuttings sample as received.

(coarse + fine size fractions $=$ whole sample) 


\section{Table 5-2 ONC\#1 Testing and Sampling}

\section{June 2 to June 13, 1997}

\begin{tabular}{|c|c|c|c|c|c|c|c|c|}
\hline VACUUM TEST NUMBER & Ground Walor & Ground Water & CFC - Atmosphere & 1 & 2 & 3 & 4 & 5 \\
\hline TEST START DATE & 3ปJun-97 & 3-Jun- -97 & 3-Jun-97 & 4VJun-97 & 9 Jun-97 & 10-Jun-97 & 11-Jun-97 & 12-Jun-97 \\
\hline DEPTH (toot) & 1500 & 1428 & 0 & 1195 & 1164 & 1225 & 575 & 638 \\
\hline \multicolumn{9}{|c|}{ ZONE TESTED } \\
\hline Screon & - & - & ATMOS & $4($ GS-2) & $5(G S-2 A)$ & 3 (as-1) & 9 (QS-5) & 8 \\
\hline Test Port & Port 15.2 & Port 14.1 & - & Port 5 & Port 4 & Port 6 & NONE & Port 2 \\
\hline Serial \# & - & - & - & 1814 & 1812 & 1815 & None & 1810 \\
\hline \multicolumn{9}{|c|}{ MONITORING PORTS } \\
\hline ABOVE & - & - & - & Port 4 & Port 3 & Port 5 & None & Port 1 \\
\hline Serlal \# & - & - & - & 1812 & 1811 & 1814 & None & 1818 \\
\hline BELOW & - & $\dot{-}$ & $\cdot$ & Port 6 & Port 5 & Port 7 & None & None \\
\hline Serial \# & - & $\cdot$ & 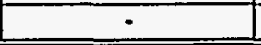 & 1815 & 1814 & 1816 & None & $\cdot$ \\
\hline \multicolumn{9}{|c|}{ HANGING MOSDAX PROBES } \\
\hline Sorlal \# & - & - & 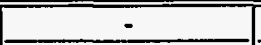 & 1818 & 1818 & 1818 & None & 1811 \\
\hline Serlal \# & - & $\cdot$ & $\cdot$ & 1810 & 1810 & 1810 & None & - \\
\hline Serlal \# & - & $\cdot$ & - & 1811 & $\cdot$ & 1811 & None & 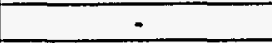 \\
\hline Serlal \# & - & - & $\cdot$ & $\cdot$ & - & 1812 & None & - \\
\hline DATALOGGER USED & None & None & None & ONC1 & NRG4 & ONC1 & None & ONC1 \\
\hline \multicolumn{9}{|c|}{ SAMPLES COLLECTED } \\
\hline CFC Stainless Cylinder & - & 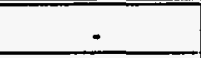 & \#WE-4 & D-112, ONC1-CFC-2,060597-2 & R-18, ONC1-CFC-2,060997-2A & 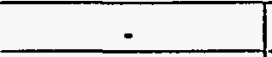 & - & - \\
\hline CFC bag & . & . & $\cdot$ & - & 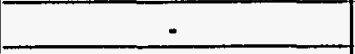 & ONC1-CFC-3, 6/11/97 & ONC1-CFC-9-1,6/12/97 & ONC1-061397-CFC \\
\hline $\mathrm{C}-14$ & 060397b2.wat & 060397b7.wat & - & ONC1-C14-2,6/5/97 & ONC1-C14-2A,6/9/97 & ONG1-C14-3, 6/11/97 & ONC1-C14-9-1, 6/12/97 & ONC1-C14-8-3, 6/13/97 \\
\hline Tritlum. Slove & - & - & - & \#543, ONCH1-TRI-2, 6/5/97 & $\cdot$ & - & - & \#739, ONCH1-061397T1 \\
\hline Tritium Condensate & - & $\cdot$ & $\cdot$ & $\cdot$ & ONC1-ZN5-GS-2A-OD-2 & - & - & ONCW1-061397-T2 \\
\hline 0.18 Condensate & $\begin{array}{l}\text { 060397b3.wat, } \\
\text { 060397b4.wat }\end{array}$ & $\begin{array}{l}\text { 06039766.wat, } \\
\text { 06039765.wat }\end{array}$ & - & 060597b1.wat & ONC1-ZN5-GS-2A-OD-1 & 061197b1.wat & ONC1-O18-9-1,6/12/97 & ONC1-061397-OD.1 \\
\hline
\end{tabular}




\begin{tabular}{|c|c|c|c|c|c|c|c|}
\hline \multicolumn{8}{|c|}{ Table 5-3 Results of Carbon Isotope Sampling In ONC \#1, June 1997} \\
\hline $\begin{array}{c}\text { Sample I.D. for 14- } \\
\text { C }\end{array}$ & Sample \# & $\& 0-13$ & \%Modern & $+\%$ & $\begin{array}{c}14-\mathrm{C} \\
\text { Corrected } \\
\text { Age (yrs BP) }\end{array}$ & $\begin{array}{r}\text { Range } \\
(+/ \mu)\end{array}$ & Depth \\
\hline ONC1-C14-9-1 & Scr\#9Port4 & -11.8 & 51.83 & 0.34 & 5280 & 50 & 575 \\
\hline ONC1-C14-8-3 & Scr\#8Port3 & -11.3 & 36.38 & 0.33 & 8120 & 75 & 638 \\
\hline ONC1-C14-ZN5 & GS-2A & -6 & 44.54 & 0.34 & 6495 & 60 & 1164 \\
\hline ONC1-C14-2 & Scr\#2 & -5.7 & 38.27 & 0.31 & 7715 & 65 & 1195 \\
\hline ONC1-C14-3 & Scr\#3 & -10.3 & 35.97 & 0.28 & 8215 & 60 & 1225 \\
\hline 060397B7.WAT & Port 14.1 & -7.4 & 15.85 & 0.27 & 14800 & 140 & 1428 \\
\hline 060397B2.WAT & Port 15.1 & -8.8 & 16.91 & 0.21 & 14275 & 95 & 1501 \\
\hline
\end{tabular}




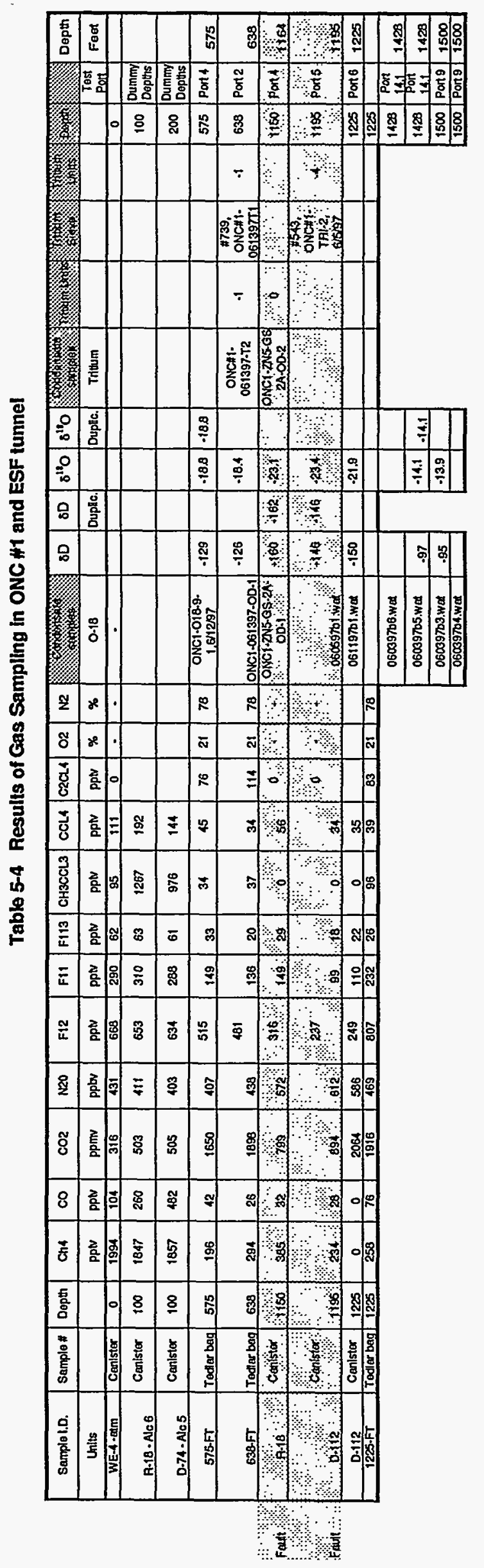




\begin{tabular}{|c|c|c|c|c|c|c|c|}
\hline \multicolumn{8}{|c|}{ Table 5-5 } \\
\hline Sample I.D. for $14 m C$ & Sample \# & $\& C-13$ & \%Modern & $+h$ & $\begin{array}{c}14-\mathrm{C} \\
\text { Corrected } \\
\text { Age (yrs BP) }\end{array}$ & Range $(+/-)$ & Depth \\
\hline ONC1-C14-3-1-042198 & $G X-24134$ & -14.4 & 34.53 & 0.2 & 8540 & 50 & 1225 \\
\hline ONC1-C14-3-2-042198 & $G X-24135$ & -14.6 & 34.99 & 0.2 & 8440 & 50 & 1225 \\
\hline ONC1-C14-3-3-042198 & $G X-24136$ & -14 & 35 & 0.2 & 8430 & 50 & 1225 \\
\hline ONC1-C14-3-4-042198 & GX-24137 & -13.7 & 34.98 & 0.2 & 8440 & 50 & 1225 \\
\hline ONC1-C14-3-5-042198 & $G X-24138$ & -18.4 & 79.35 & 0.37 & 1860 & 40 & 1225 \\
\hline ONC1-C14-3-6-042198 & $G X-24139$ & -13.1 & 35.83 & 0.21 & 8250 & 50 & 1225 \\
\hline ONC1-C14-7-1-042898 & $G X-24140$ & no gas & - & - & - & - & 911 \\
\hline ONC1-C14-7-2-042898 & $G X-24141$ & -14.2 & 36.23 & 0.21 & 8150 & 50 & 911 \\
\hline ONC1-C14-7-3-042898 & $G X-24142$ & -6.2 & 58.15 & 0.29 & 4350 & 40 & 911 \\
\hline ONC1-C14-7-4-042898 & $G X-24143$ & -14.3 & 36.9 & 0.21 & 8010 & 50 & 911 \\
\hline ONC1-C14-7-5-042898 & $G X-24144$ & -14.3 & 36.2 & 0.21 & 8160 & 50 & 911 \\
\hline ONC1-C14-7-6-042898 & GX-24145 & -14.1 & 35.98 & 0.21 & 8210 & 50 & 911 \\
\hline
\end{tabular}


Table 5-6 Results of Gas Sampling in ONC\#1, April 1998

\begin{tabular}{|c|c|c|c|c|c|c|c|c|c|c|c|c|c|c|c|}
\hline Sample ID & Sample & Depth & $F 12$ & F113 & F114 & $\begin{array}{c}\text { Chlorotorm } \\
(\mathrm{CHCl})\end{array}$ & $\begin{array}{c}1,1,1_{*} \\
\mathrm{TCA} \\
\left(\mathrm{C}_{2} \mathrm{H}_{3} \mathrm{Cl}_{3}\right)\end{array}$ & $\mathbf{C C l}_{4}$ & $\begin{array}{l}\text { TCE } \\
\left(\mathrm{C}_{2} \mathrm{HCL}_{3}\right)\end{array}$ & co & $\mathrm{CH}_{4}$ & $\mathrm{CO}_{2}$ & $\mathrm{~N}_{2} \mathrm{O}$ & $\begin{array}{c}\text { Octafluoro } \\
\text { toluene }\end{array}$ & Toluene-d8 \\
\hline Unlts & & fi. & ppmv & ppmy & ppmy & pptv & ppty & pptv & pptv & $\%$ & $\%$ & $\%$ & $\%$ & \% Recoven & \% Recovery \\
\hline ONC1-CFC-9-1-043098 & $9805033 \mathrm{~A}-04 \mathrm{~A}$ & 575 & 300 & 82 & ND & ND & ND & 63 & ND & 0.0003 & ND & 0.15 & ND & 102 & 91 \\
\hline ONC1-CFC-8-1-042998 & $9805033 \mathrm{~A}-03 \mathrm{~A}$ & 633 & 160 & ND & ND & ND & ND & ND & ND & ND & ND & 0.18 & ND & 91 & $55 Q$ \\
\hline ONC1-CFC-7-1-042898 & $9805033 \mathrm{~A}-02 \mathrm{~A}$ & 811 & 200 & 39 & ND & ND & ND & ND & ND & ND & ND & 0.17 & ND & 91 & $55 Q$ \\
\hline ONC1-CFC-6-1-042798 & $9805033 \mathrm{~A}-01 \mathrm{~A}$ & 1019 & 200 & ND & ND & ND & ND & ND & ND & 0.0006 & ND & 0.17 & ND & 90 & 103 \\
\hline ONC1-CFC-5-1-042498 & $9805011 B-04 A$ & 1157 & 260 & ND & ND & ND & ND & 43 & ND & ND & ND & 0.16 & ND & 110 & $60 Q$ \\
\hline $\begin{array}{l}\text { ONC1-CFC-4-1-042398 } \\
\text { ONC1-CFC-4-1-042398 }\end{array}$ & $9805011 \mathrm{~B}-02 \mathrm{~A}$ & 1198 & 260 & 62 & ND & ND & ND & 43 & ND & 0.0006 & ND & 0.16 & ND & 92 & $50 Q$ \\
\hline . Dup & $9805011 \mathrm{~B}-02 \mathrm{~A}$ & 1198 & 310 & 69 & ND & ND & ND & $41 \mathrm{~J}$ & ND & $\cdot$ & - & - & - & 100 & $58 Q$ \\
\hline ONC1-CFC-3-1-042198 & 9805011B-01A & 1225 & 320 & 63 & ND & 600 & 36 & 130 & 81 & 0.0007 & ND & 0.14 & ND & 99 & 90 \\
\hline $\begin{array}{c}\text { ONC1-CFC-TRIP BLANK } \\
\text { ONC1-CFC-ATMO. }\end{array}$ & $9805033 A-05 A$ & N/A & & ND & ND & & & & ND & ND & ND & 0.0001 & ND & 108 & 88 \\
\hline 042498 & $9805011 B-03 A$ & N/A & 460 & 72 & ND & ND & 56 & 46 & ND & 0.0003 & 0.0003 & 0.038 & ND & 85 & $59 \mathrm{Q}$ \\
\hline Lab Blank & $9805011 B-05 A$ & N/A & ND & ND & ND & ND & ND & ND & ND & ND & ND. & ND & ND & & - \\
\hline Lab Blank & 9805011B-05B & N/A & ND & ND & ND & ND & ND & ND & ND & - & - & - & - & - & - \\
\hline Lab Blank & $9805033 \mathrm{~A}-06 \mathrm{~A}$ & $N / A$ & ND & ND & ND & ND & ND & ND & ND & ND & ND & ND & ND & 107 & 92 \\
\hline Lab Blank & $9805033 \mathrm{~A}-06 \mathrm{~B}$ & N/A & ND & ND & ND & ND & ND & ND & ND & - & - & - & - & 107 & 93 \\
\hline
\end{tabular}

$Q=$ Exceeds Quality Control Limits

$\mathrm{J}=$ Below Detection Limit, but Supported by Duplicate Analysis

ND = Below Detection Limit 



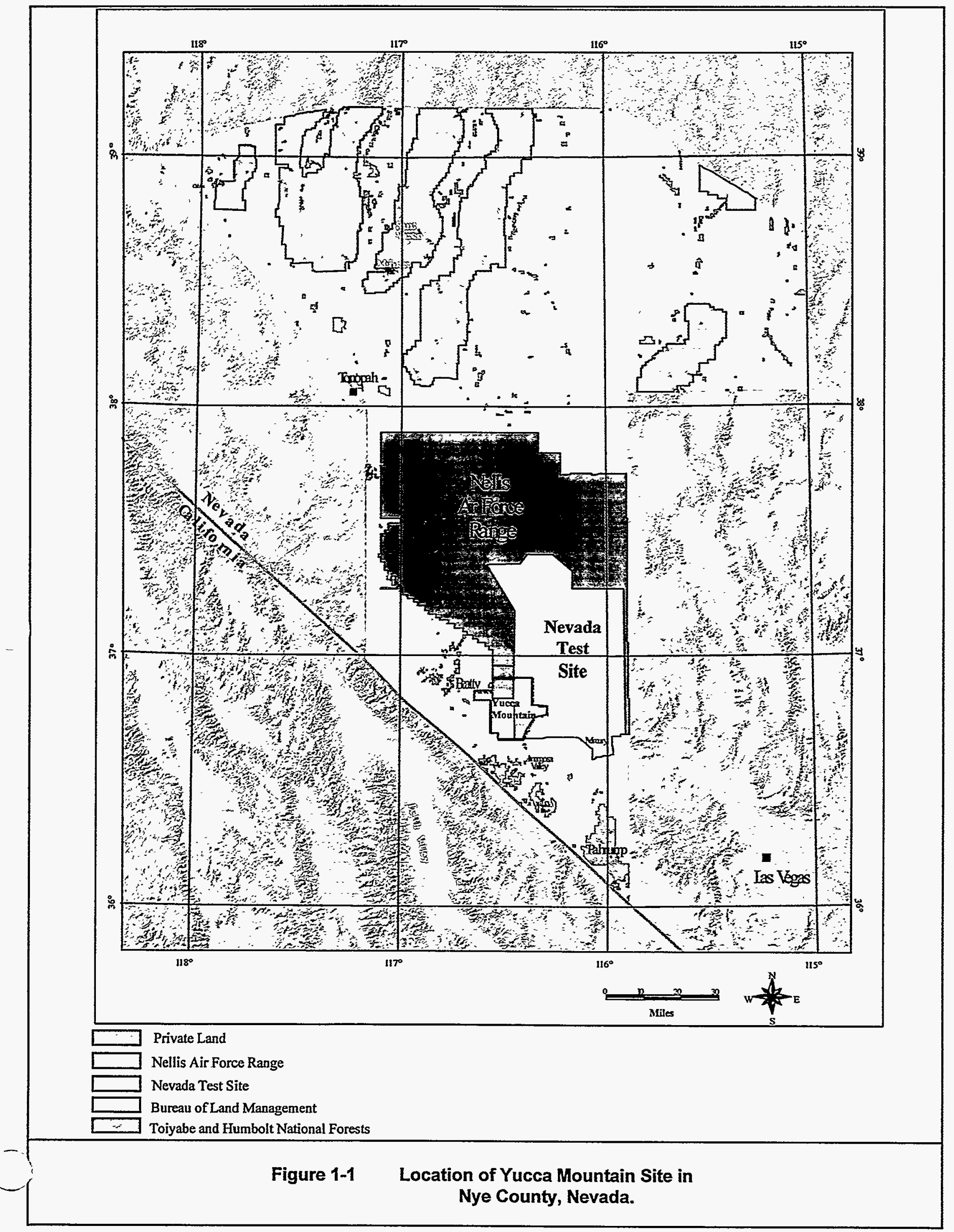





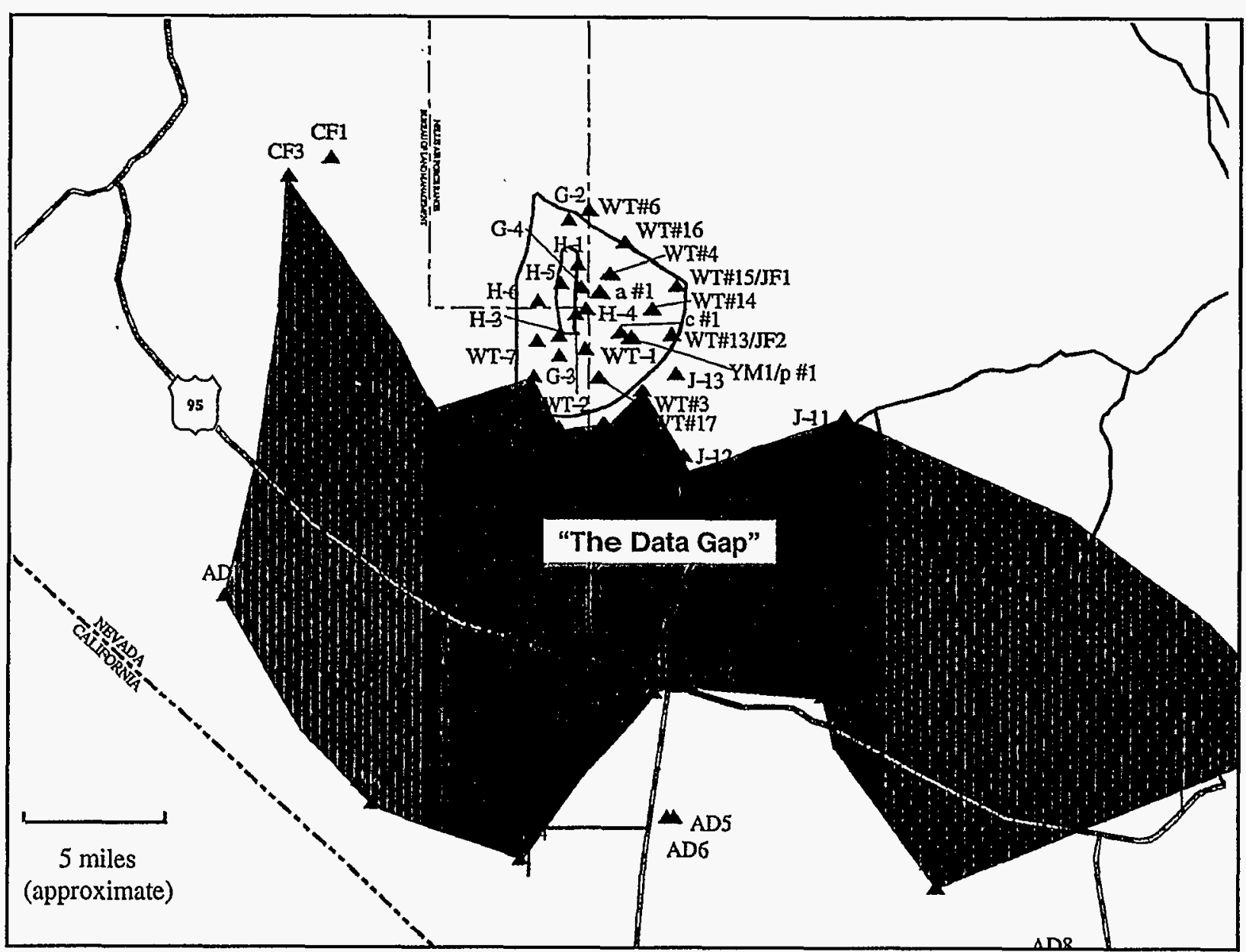

The labeled symbols represent springs and wells that are monitored as part of the Department of Energy's monitoring efforts for Yucca Mountain. Where the map is shaded, information on a primary hydrologic monitoring data (depth to groundwater) is entirely lacking as is information concerning the number and types of aquifers and their properties. The boundaries for the gap will vary somewhat for different data parameters. For example, the data gap would be much larger for aquifer test data. Modified from Map YMP97-05-04 of the U.S. Department of Energy's Yucca Mountain Site Atlas (Rev. 12/31/97). 


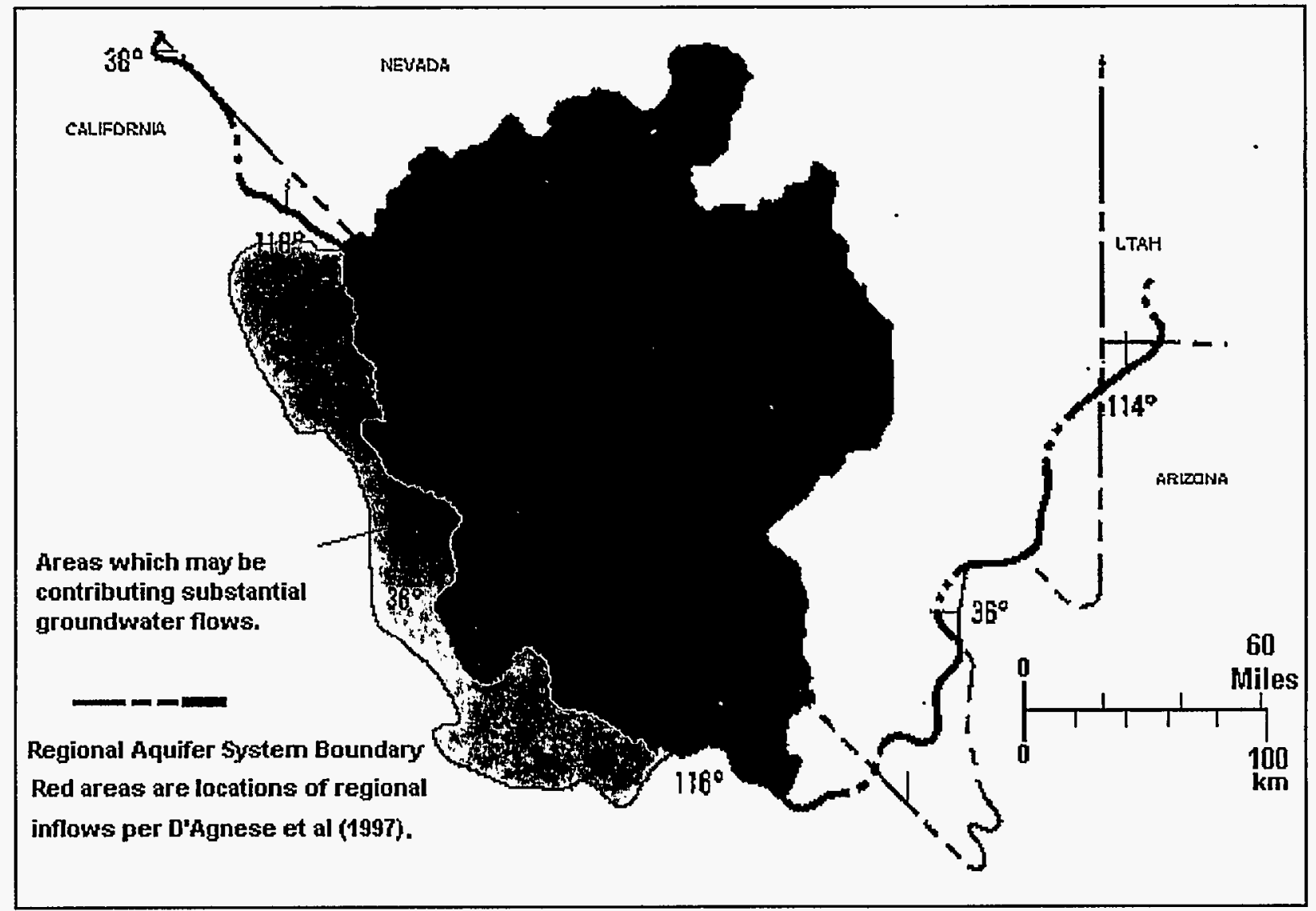

The boundaries of this flow system are indefinite in some areas. A large area to the southwest, including Saline and Panamint valleys, may be contributing appreciable quantities of recharge, via subsurface flow, into the system. In other areas along the north and eastern boundaries, subsurface recharge may also be entering the flow system. Although the recharge from these areas has not been quantified, it may total a significant amount that is not accounted for in the mass balance comparisons of recharge and discharge for the regional models. Failure to account for this recharge may result in unnecessary adjustments to other model parameters to achieve an acceptable level of calibration.

Note: All boundaries and locations shown are approximate.

Figure 3-2 The Death Valley flow system as defined by Harrill et al (1988). 


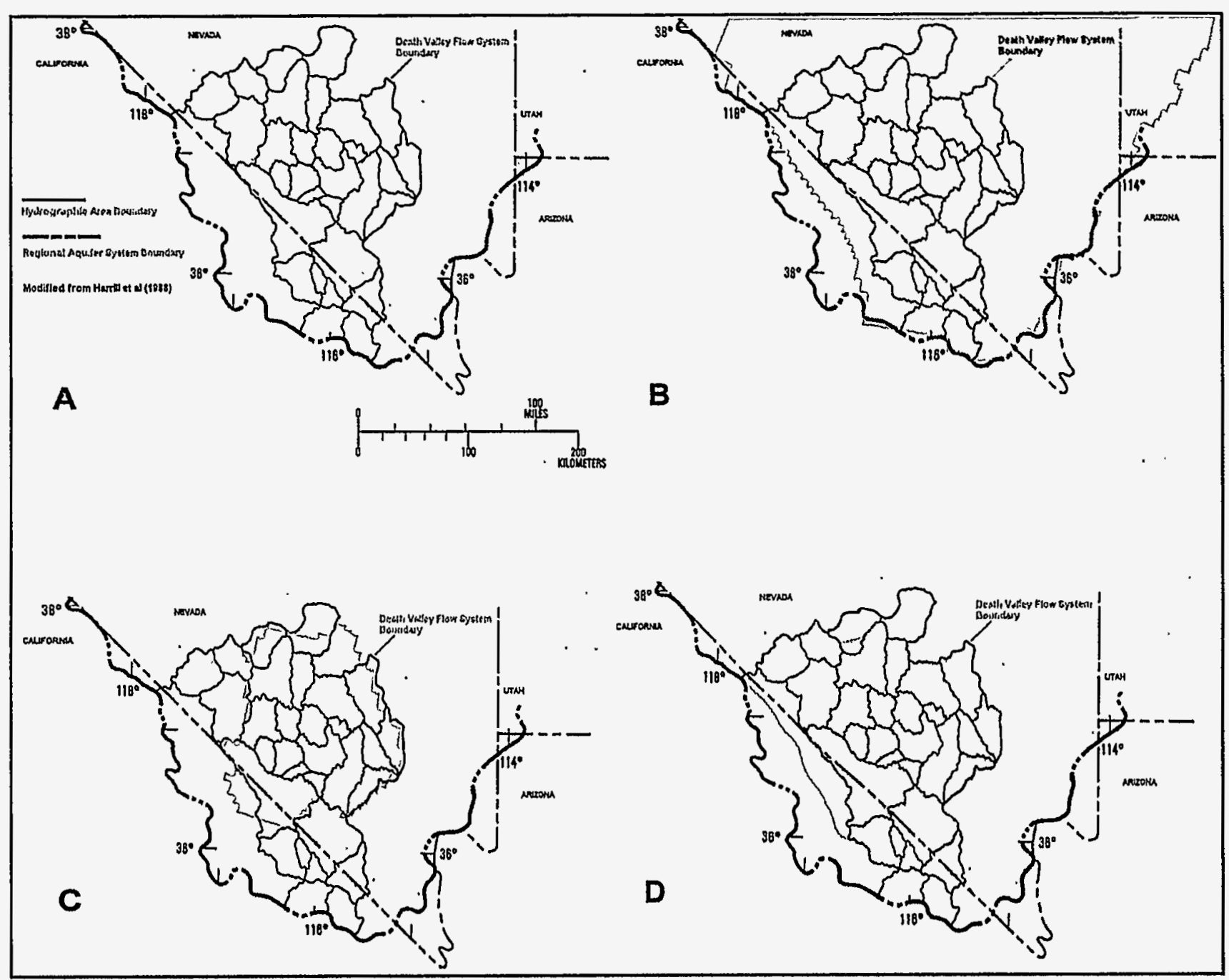

Map A shows the Death Valley flow system boundaries as defined by Harrill et al (1988). Map B shows the southern extent of the regional carbonate model (NTS regional model). The domain for this model extends more than 200 miles to the north of the area shown. Map C shows the domain for the UGTA regional model. Map D shows the extent of the Yucca Mountain regional model. As shown, none of the models include the entire Death Valley flow system.

Note: All model boundaries shown are approximate. 


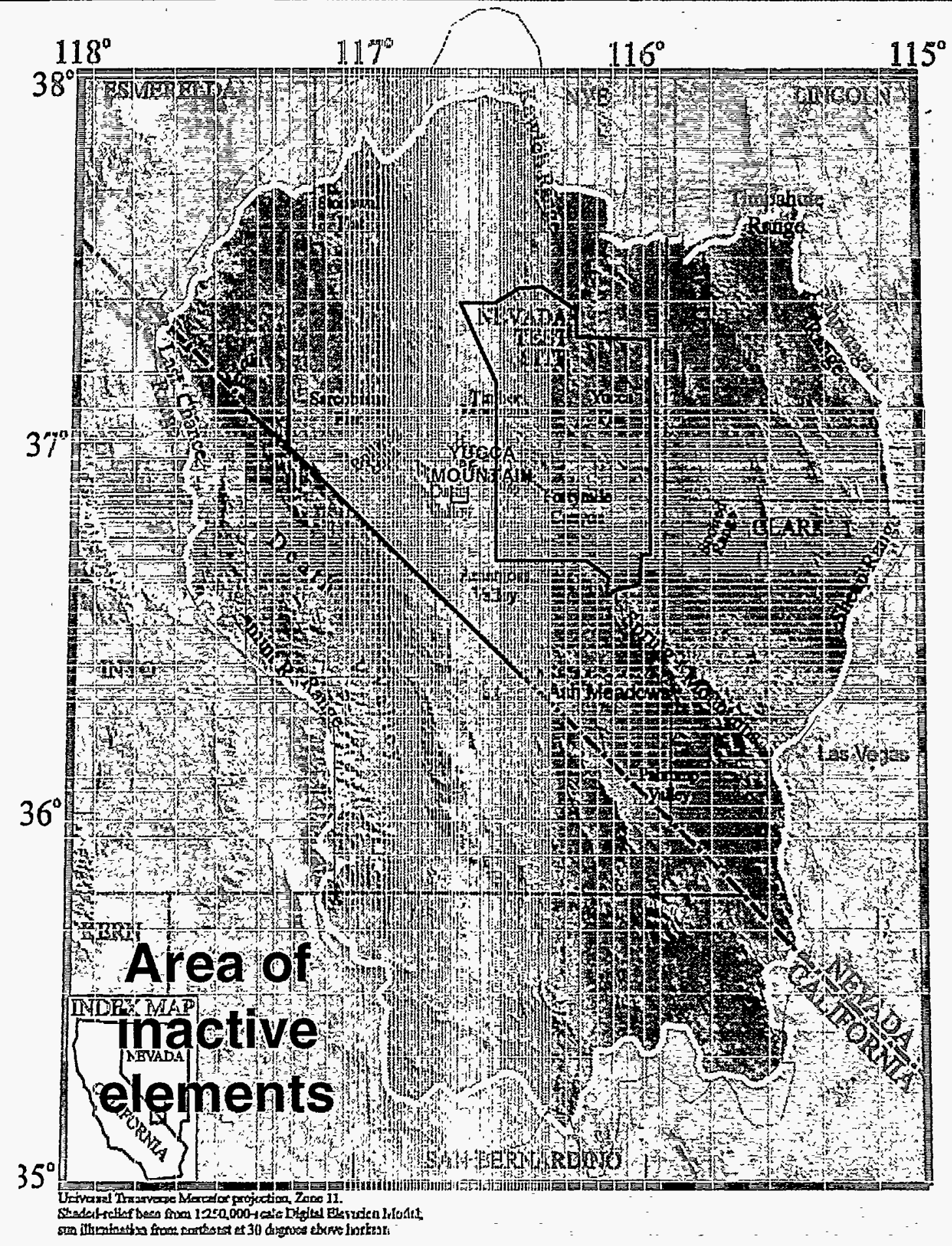

25

$25 \quad 0 \quad 25 \quad 50$ KILOMETERS

Figure 3-4 Attempted mesh for the regional saturated-zone model. 


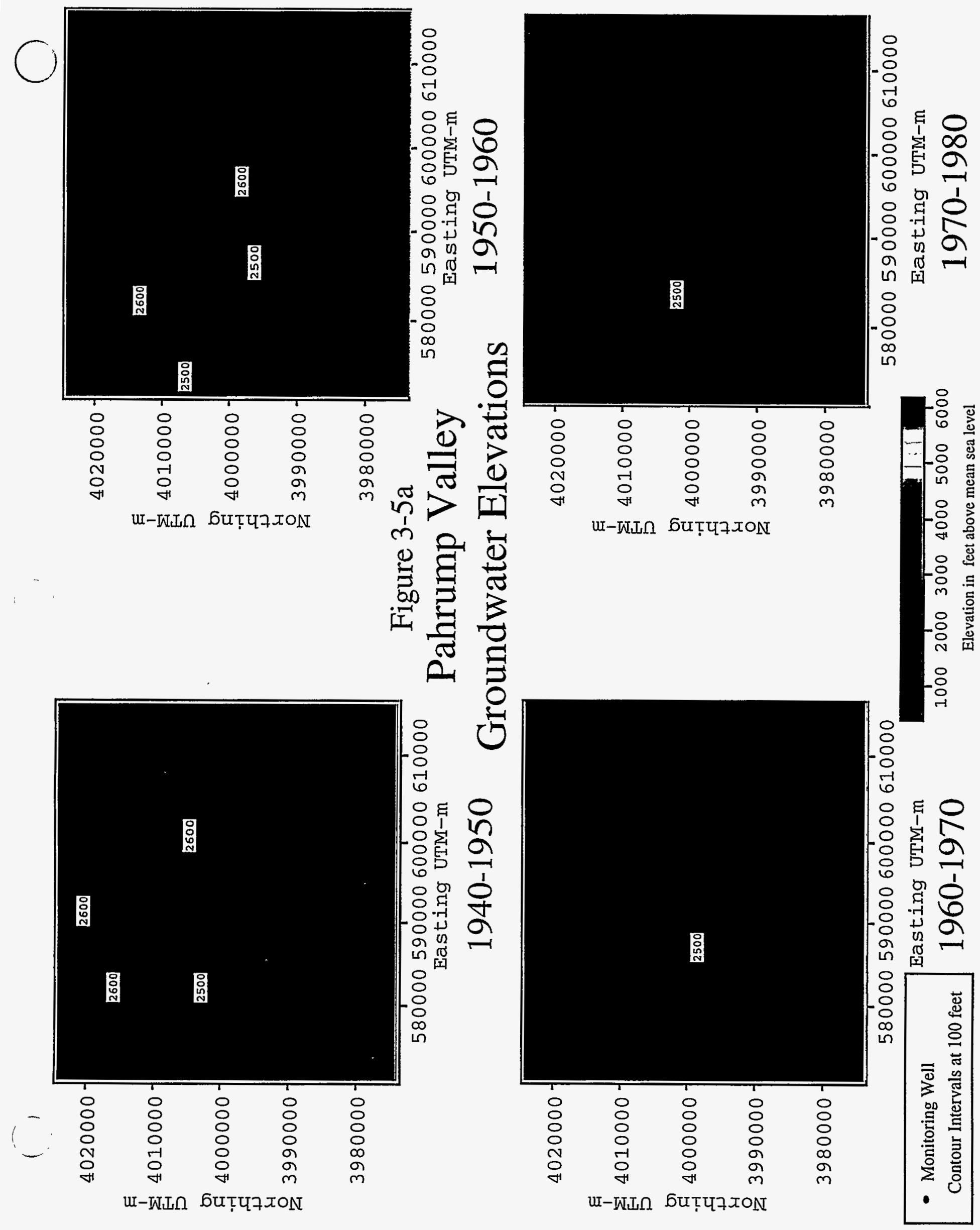


Figure 3-5b

\section{Pahrump Valley Groundwater Elevations}

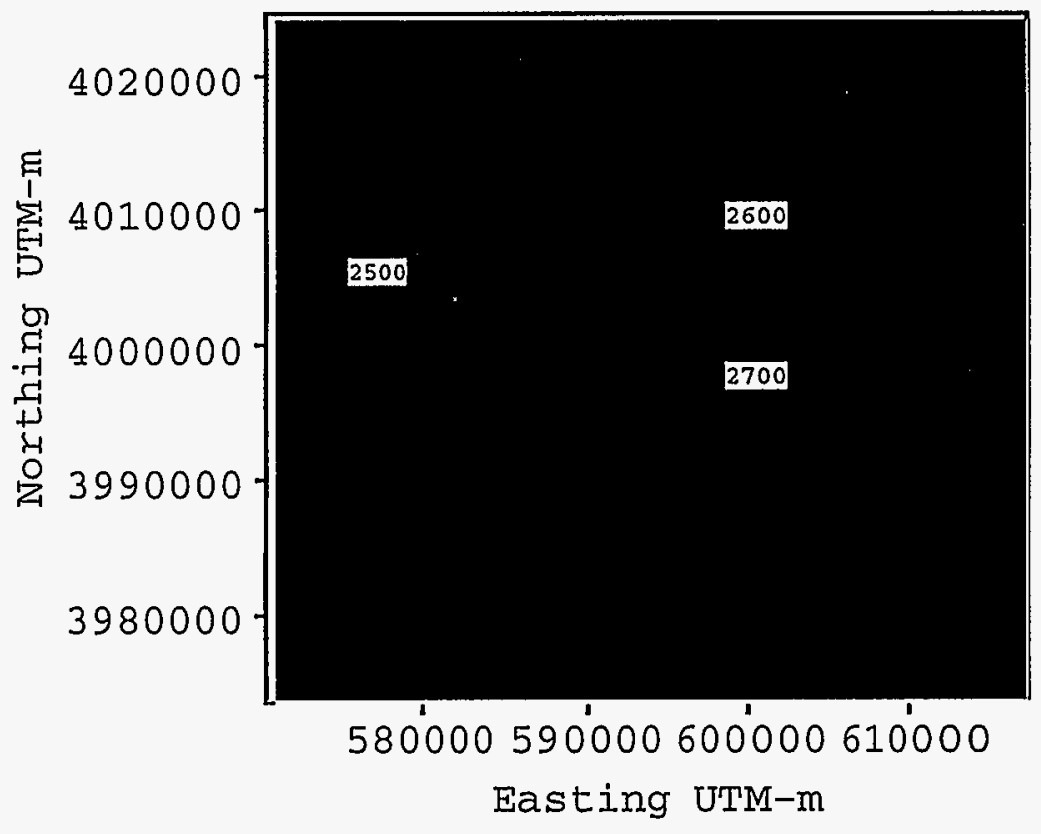

1980-1990

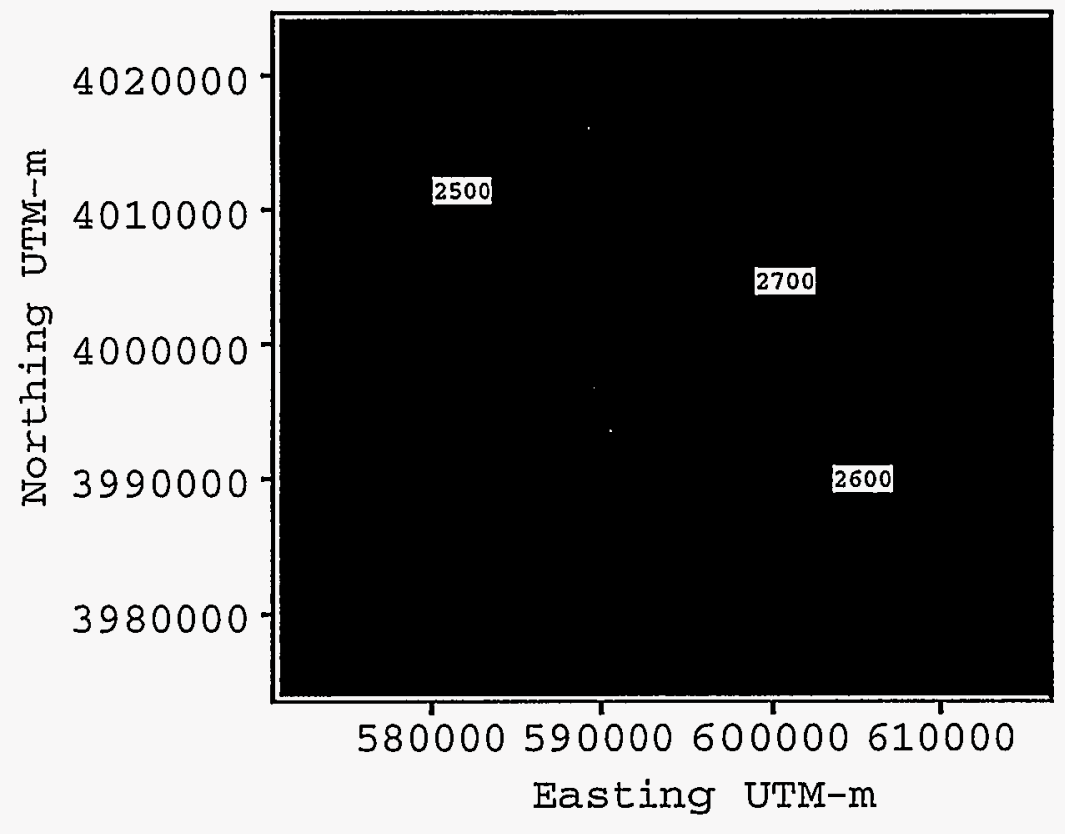

1990-1997
- Monitoring Well Contour Intervals at 100 feet
$10002000 \quad 3000 \quad 4000 \quad 5000 \quad 6000$

Elevation in feet above mean sea level 

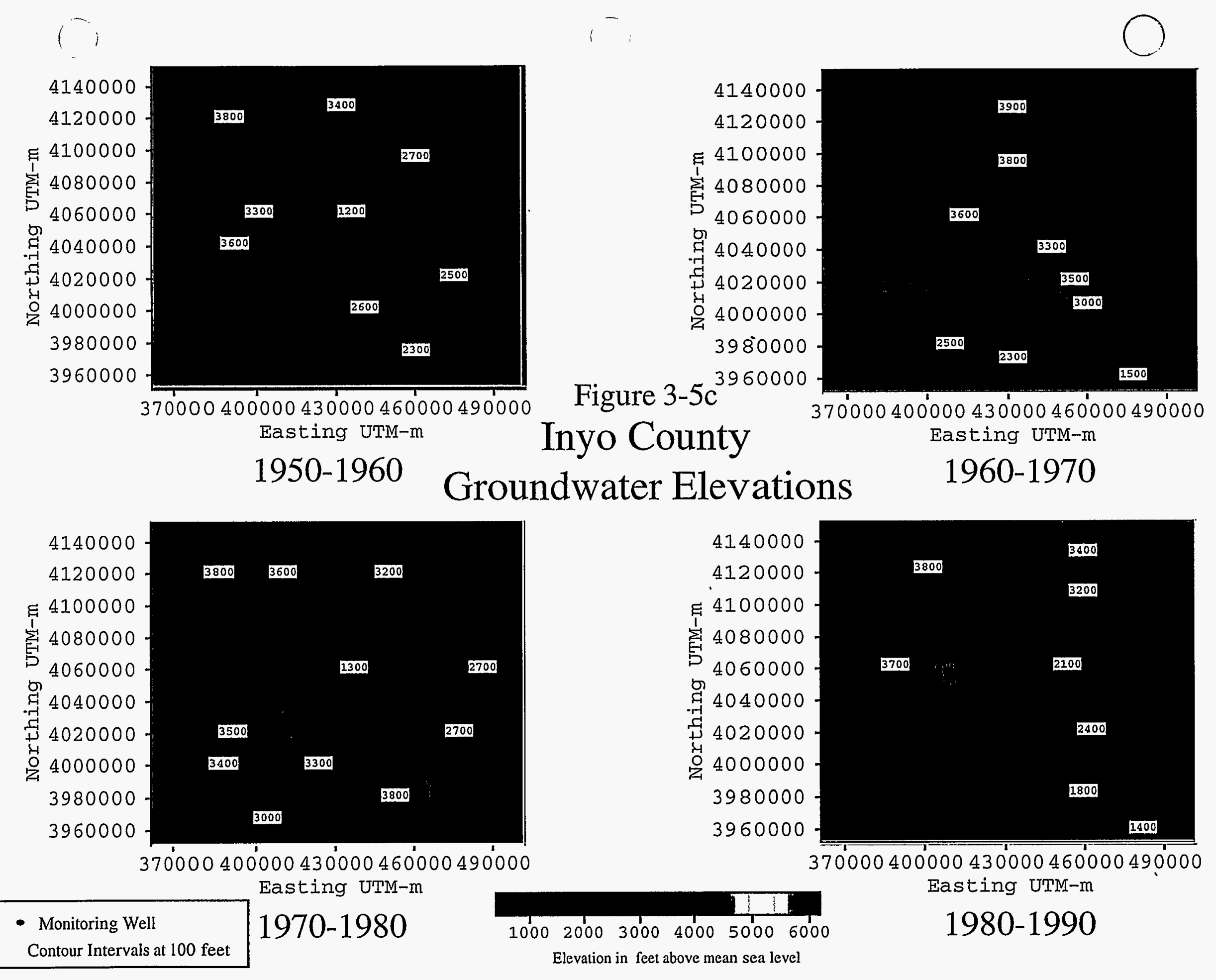


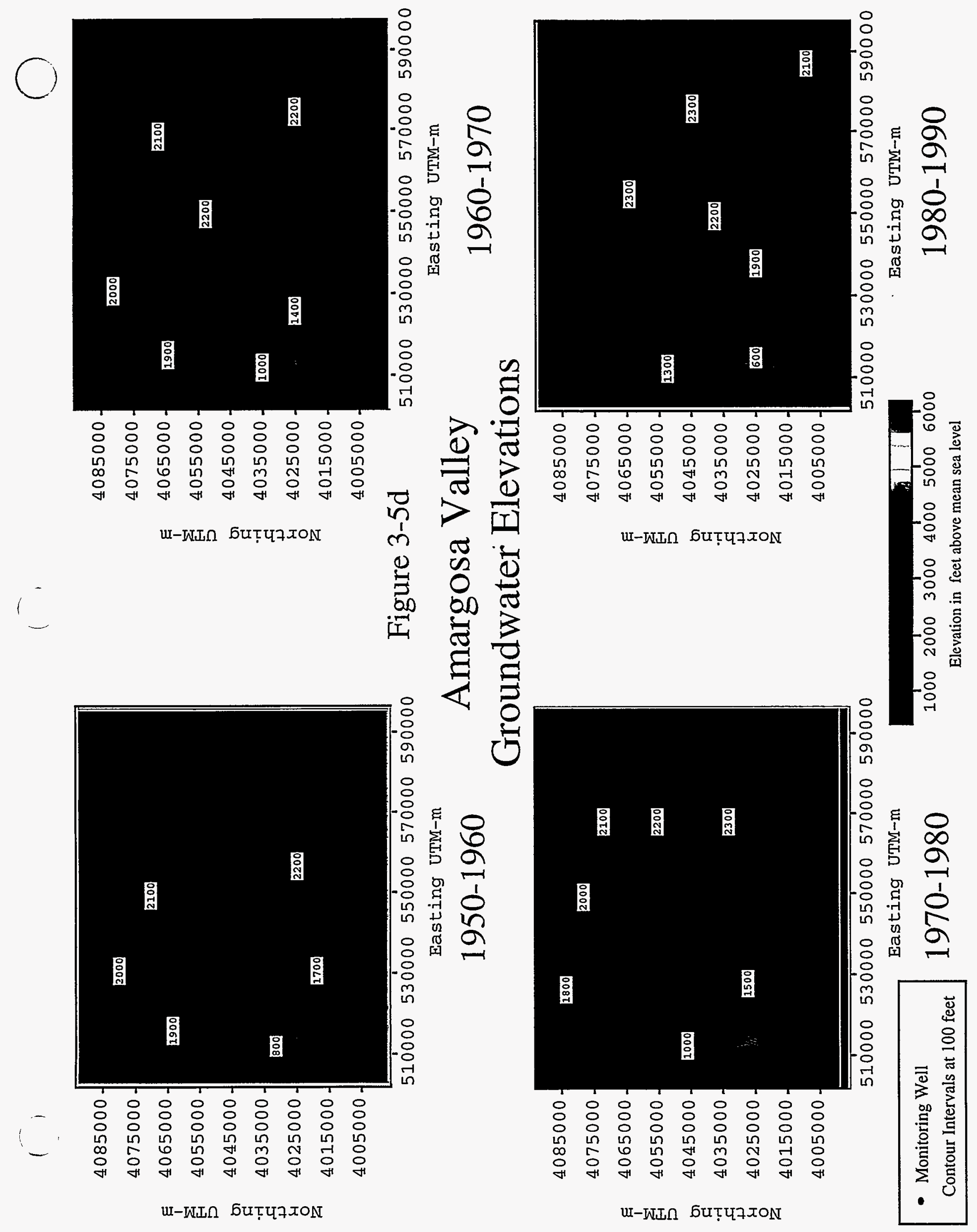




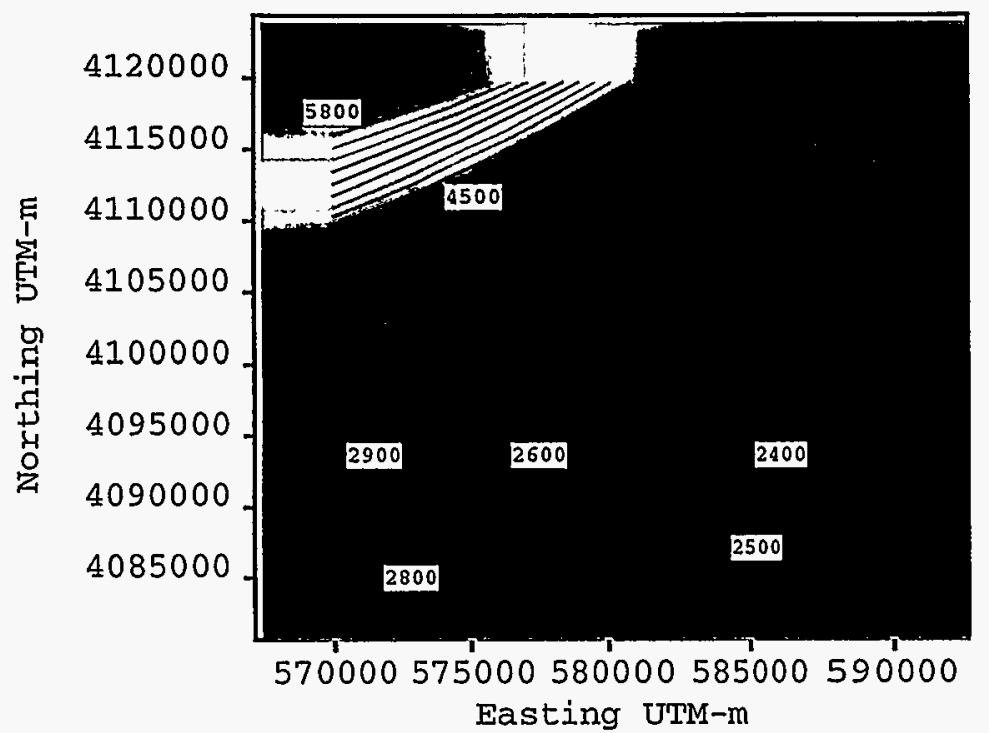

1950-1960

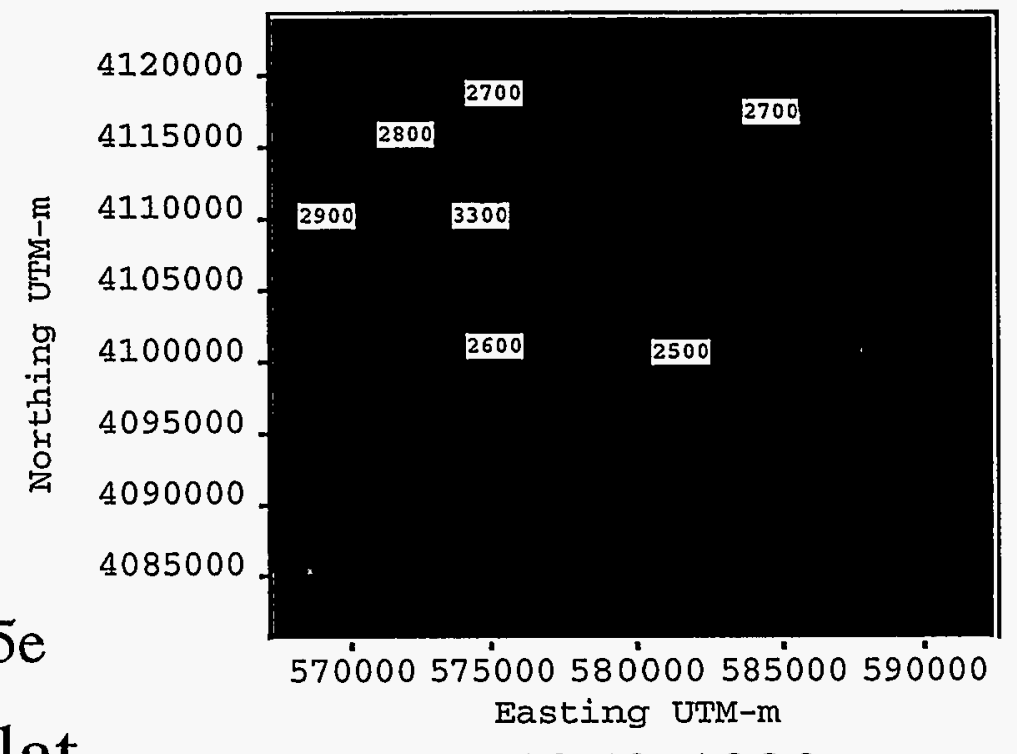

Yucca Flat

\section{Groundwater Elevations}

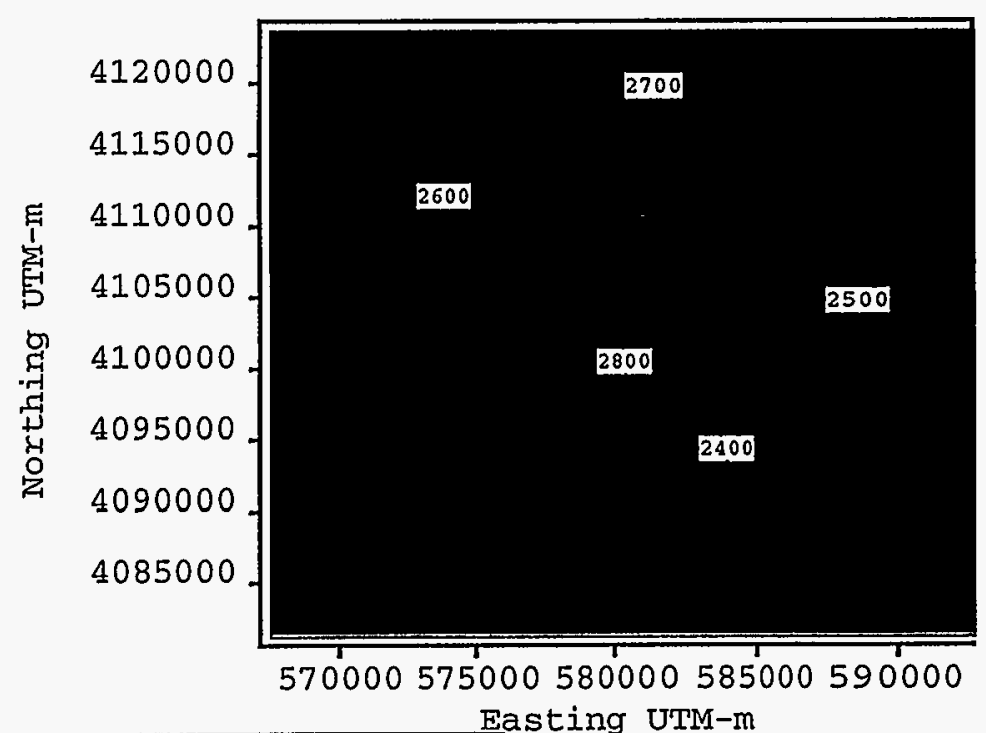

$\begin{aligned} & \text { - Monitoring Well } \\ & \text { Contour Intervals at } 100 \text { feet }\end{aligned} 1980-1990$
Figure 3-5e

Easting UTM-m

1970-1980

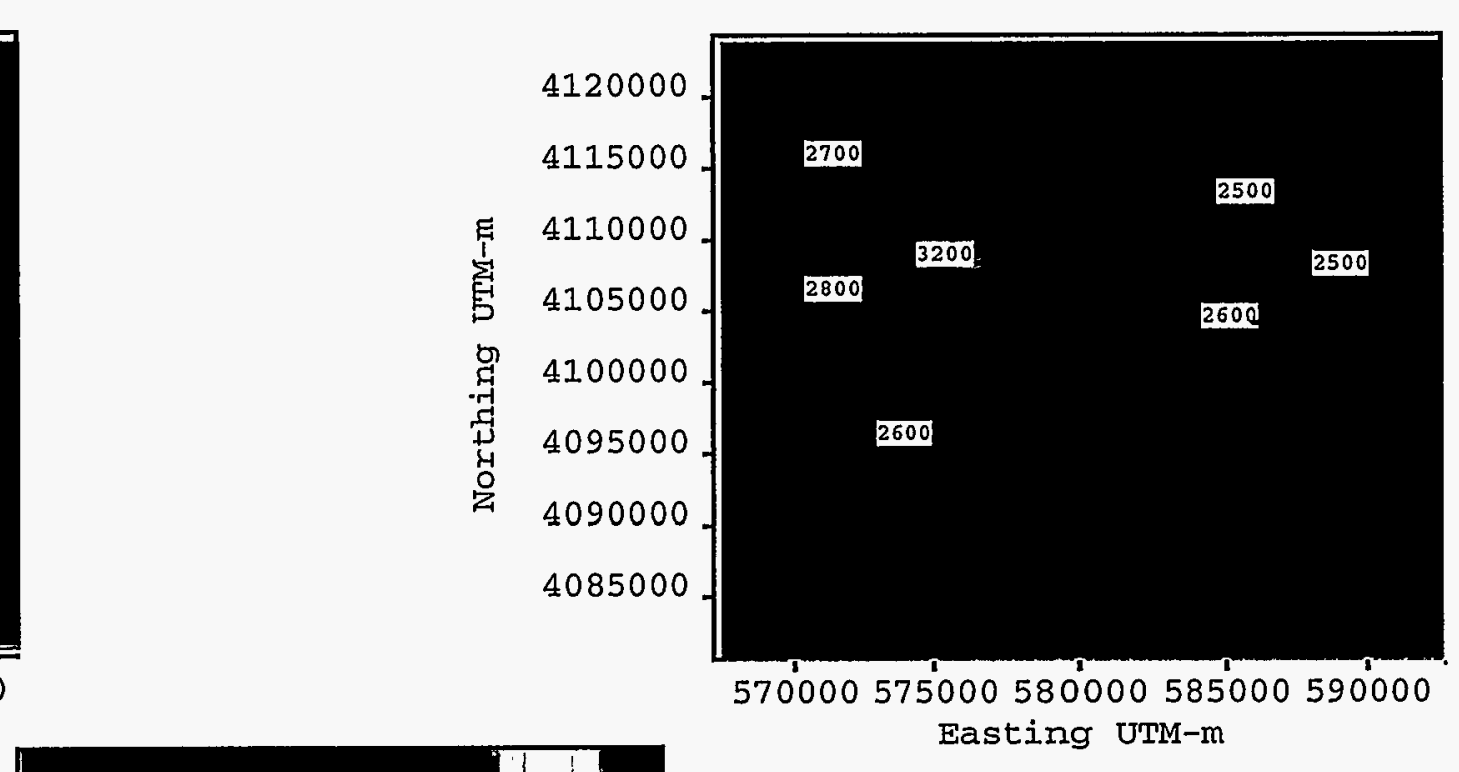

$10002000 \quad 3000 \quad 4000 \quad 5000 \quad 6000$

1990-1997 
u-kiL бuțวseg

u-WLO 6uțaeg

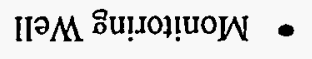

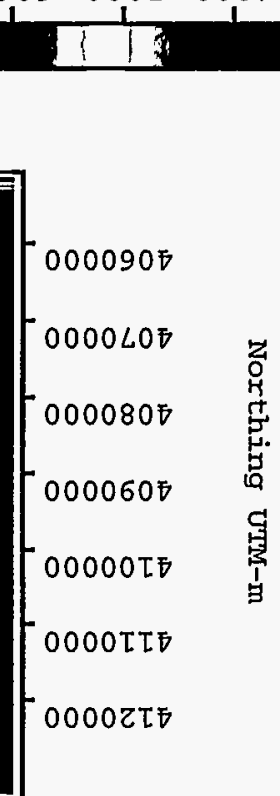

0000LS 000S9S 00009S 000SSS 0000SS

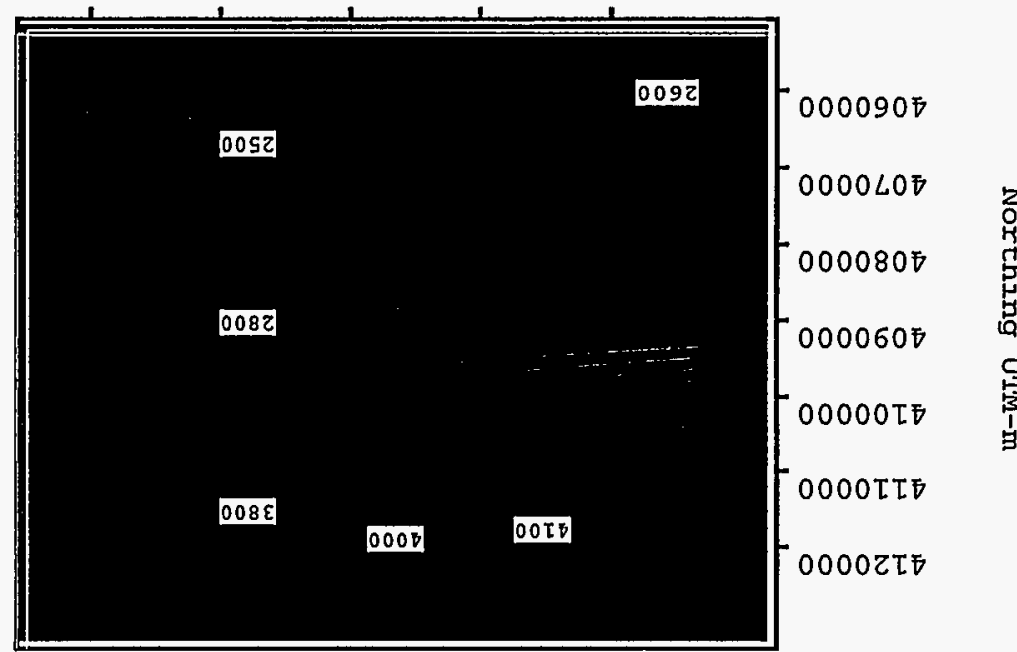

0000LS 00059S 00009S 000SSS 0000SS

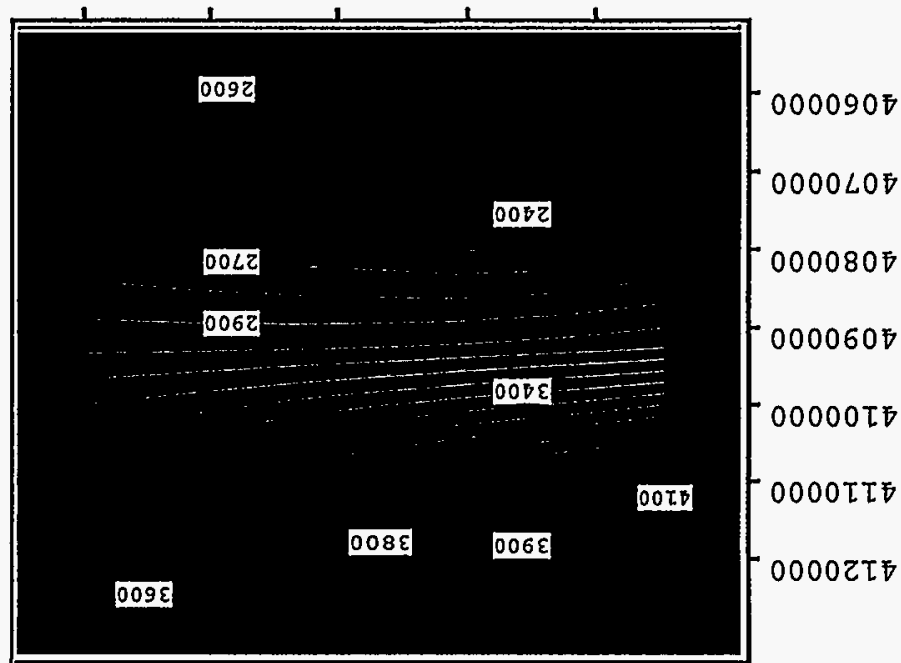

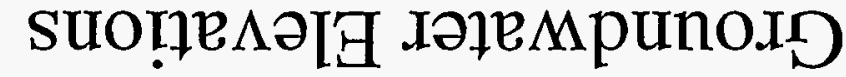

086 I-0L6I uoКUP

0L6 [-096I

u-Iun burtaser

$0000 L 5000599000095000559000059$

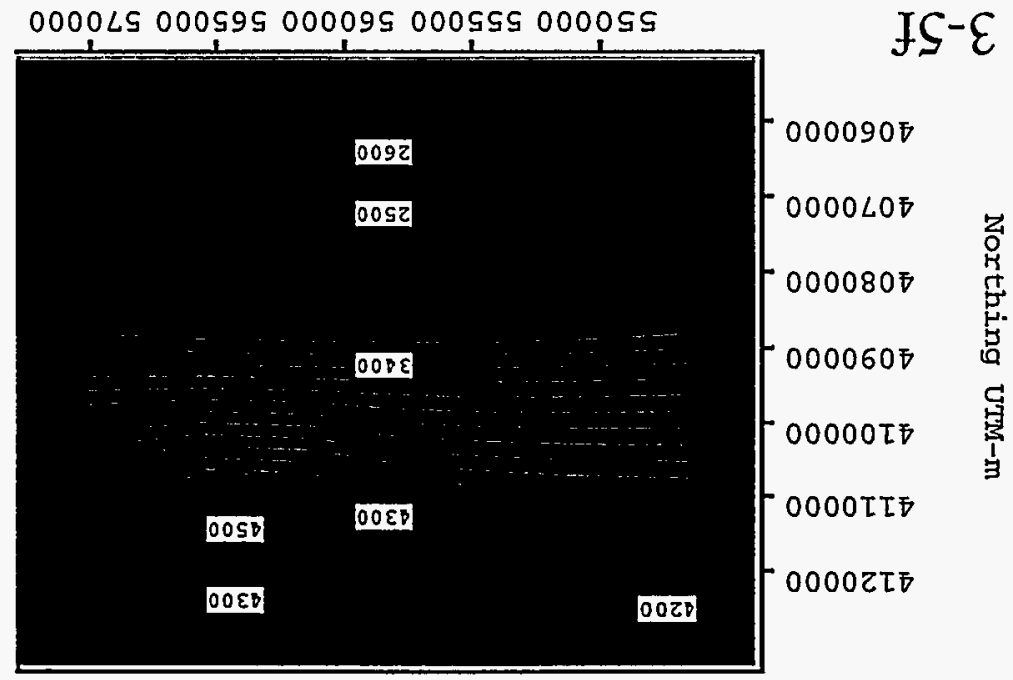

W-WLO 6uT75eg

$000025000999000095000 \$ 99000095$

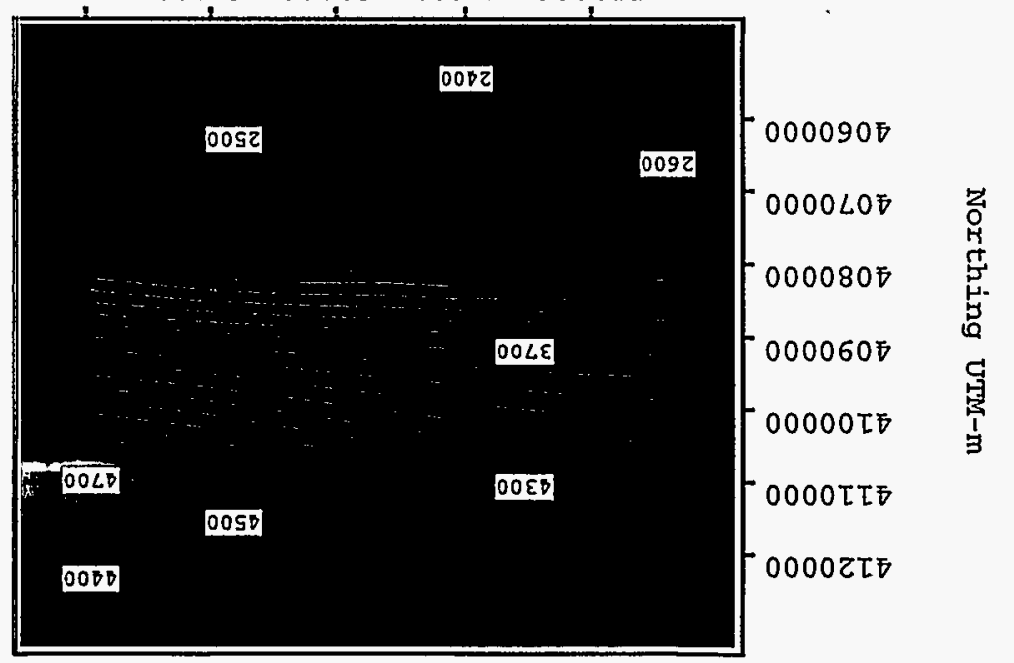




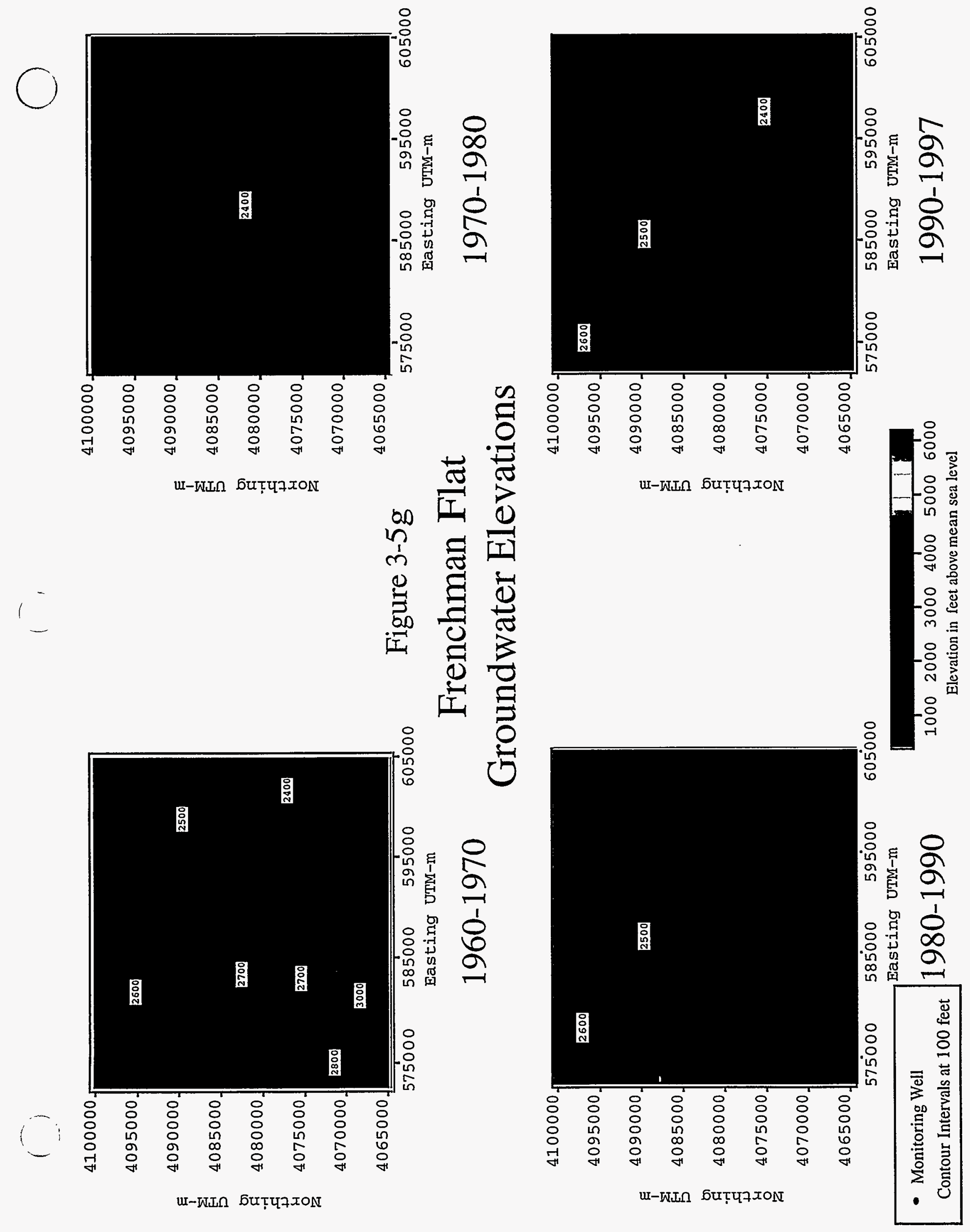


Figure 3-5h

\section{Crater Flat}

\section{Groundwater Elevations}

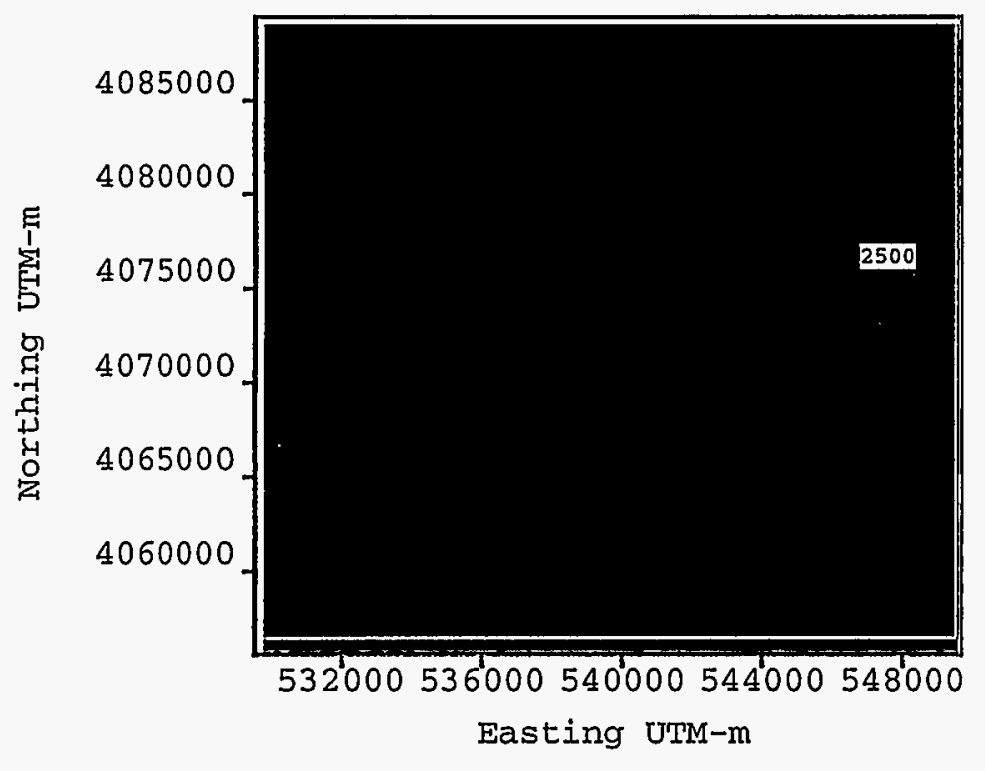

1980-1990

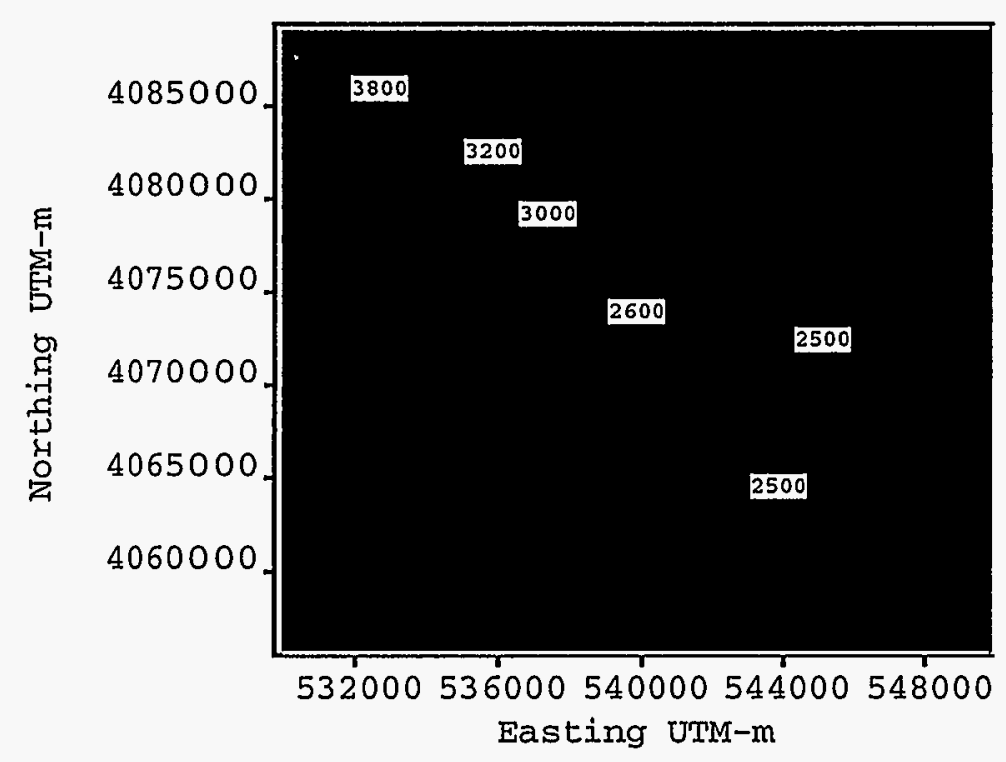

1990-1997
- Monitoring Well

Contour Intervals at 100 feet

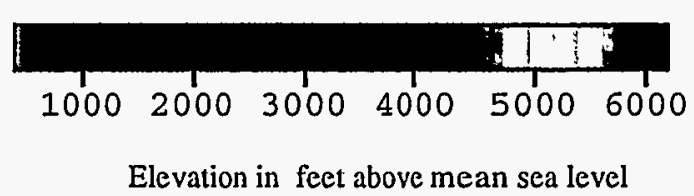

Elevation in feet above mean sea level 


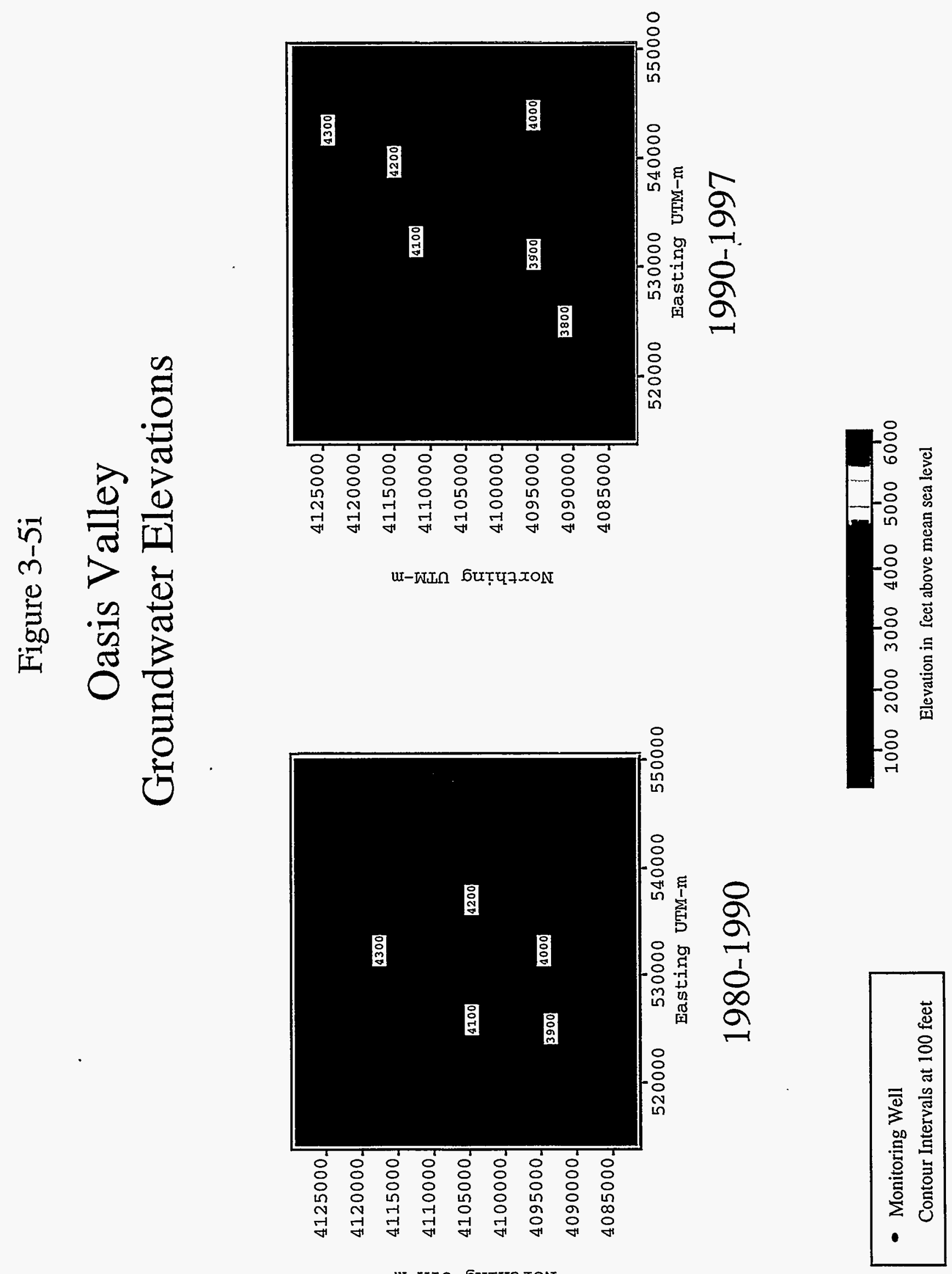




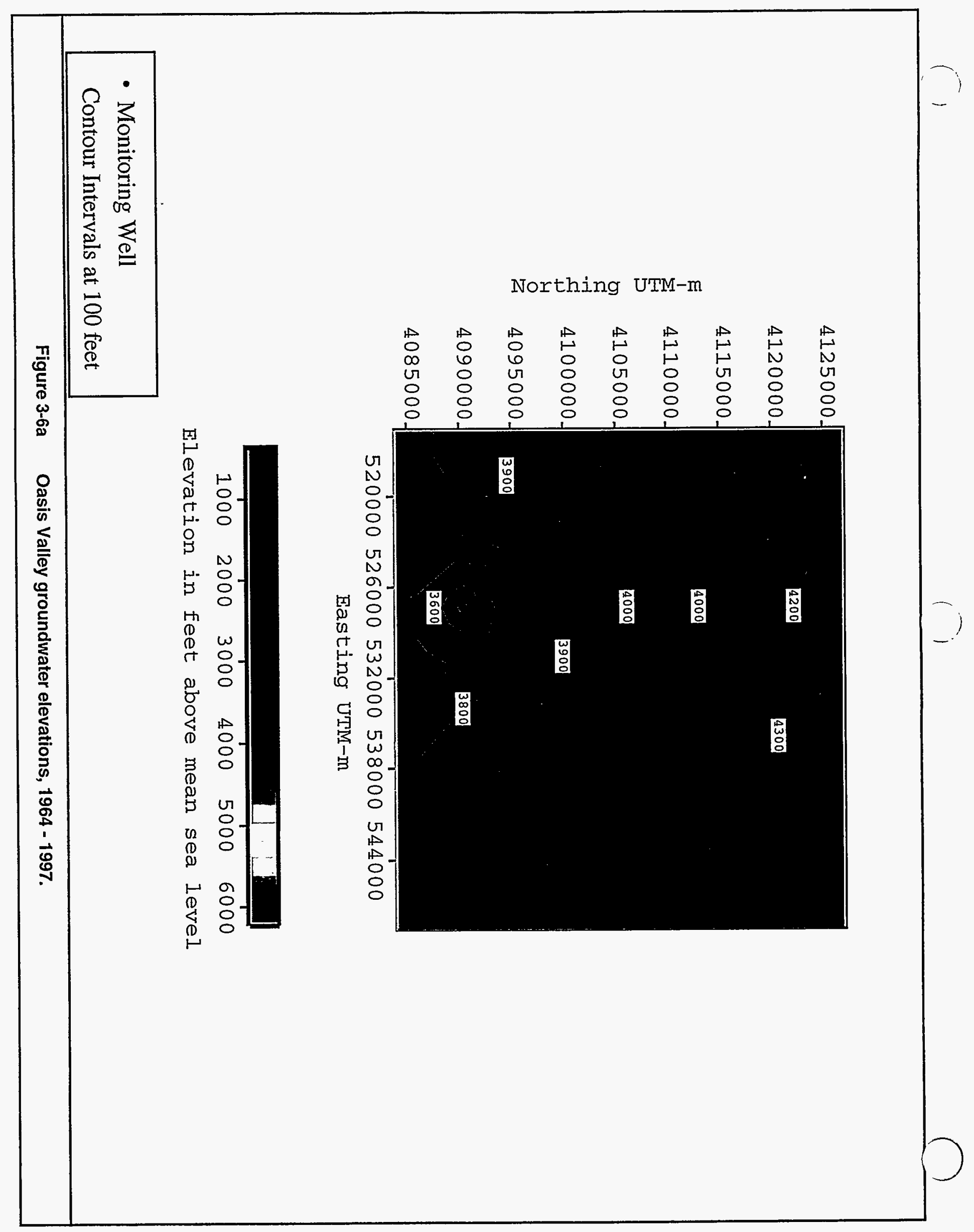




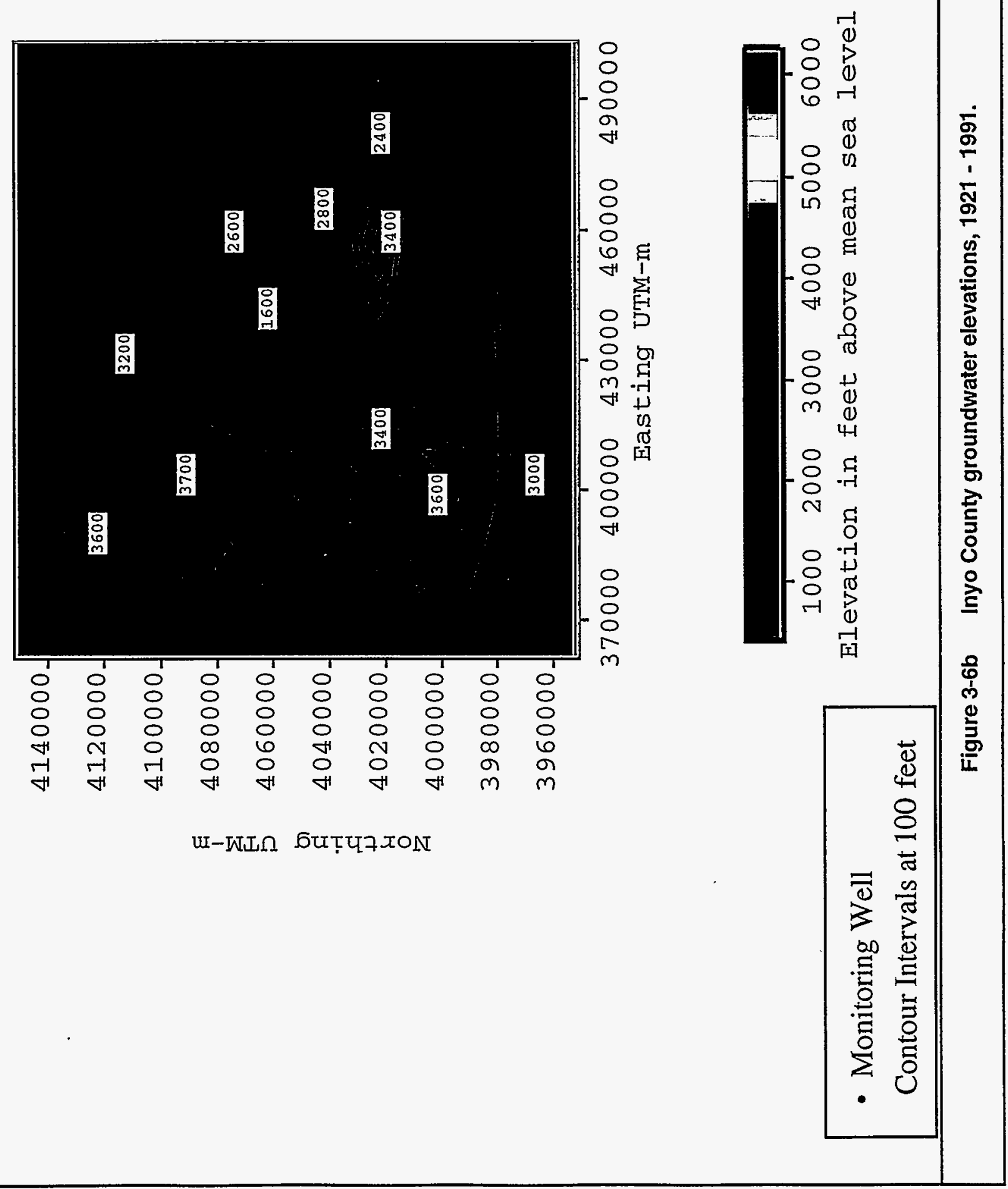




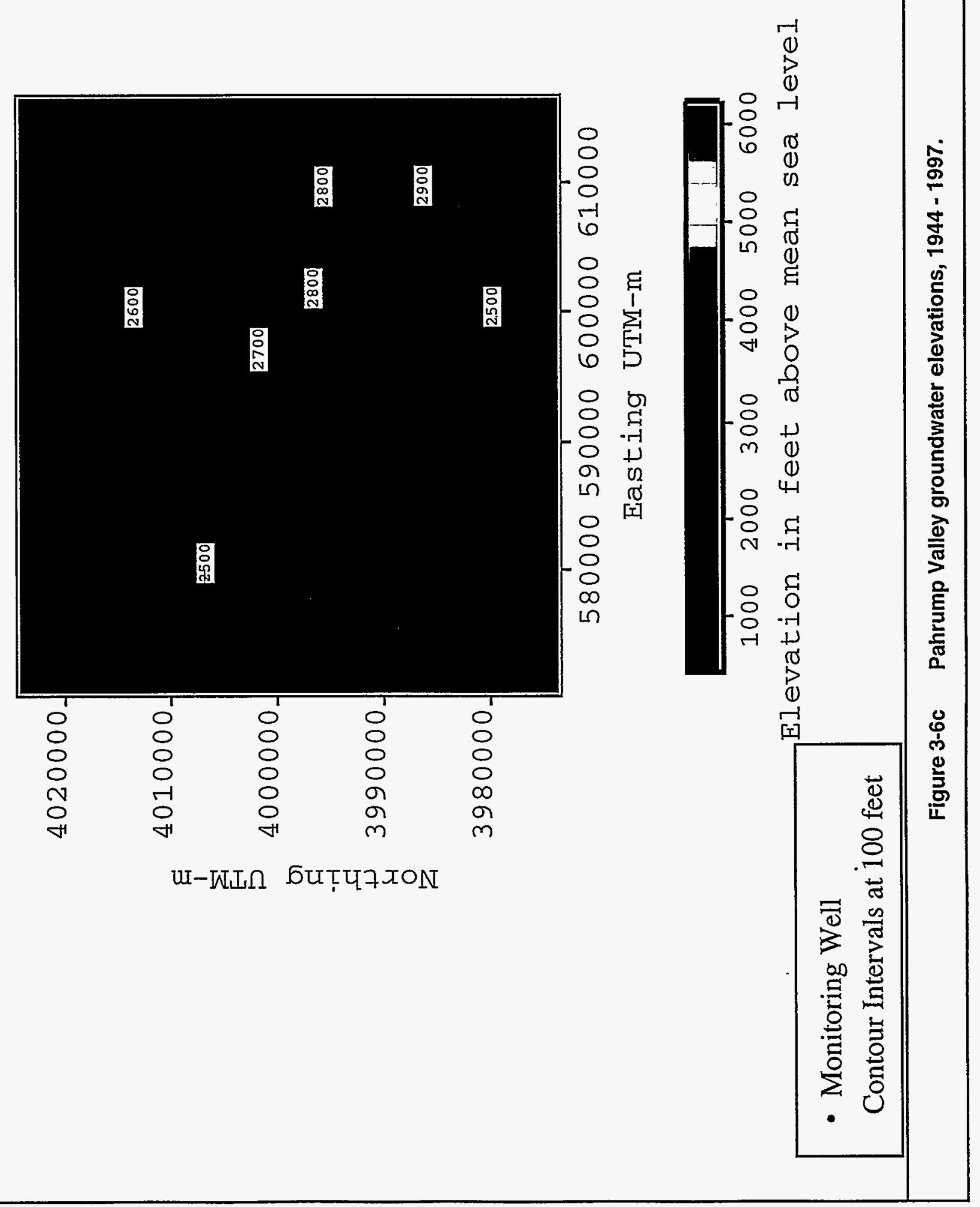



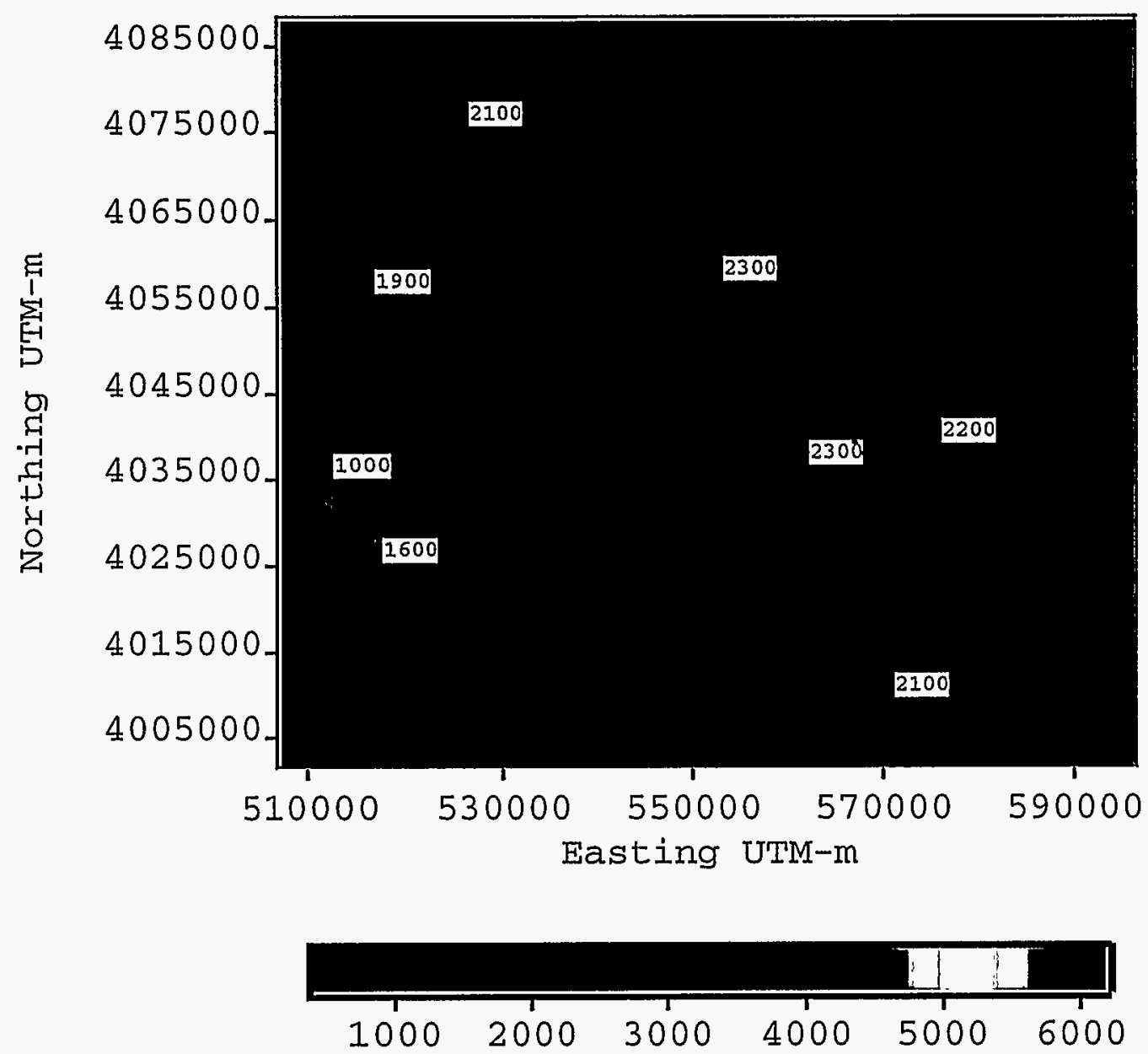

Elevation in feet above mean sea level

- Monitoring Well

Contour Intervals at 100 feet

Figure 3-6d Amargosa Valley groundwater elevations, 1952 - 1997. 


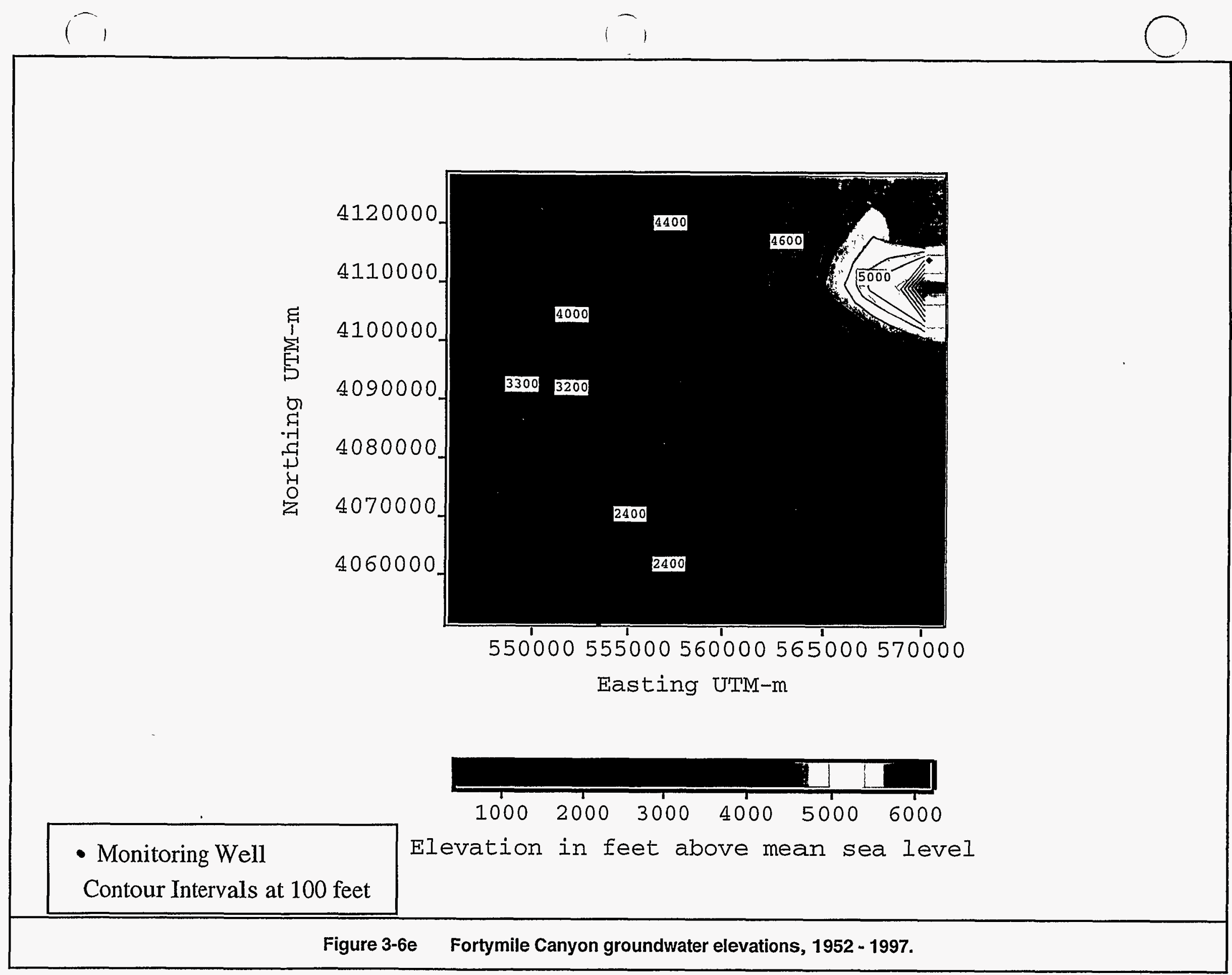


圆

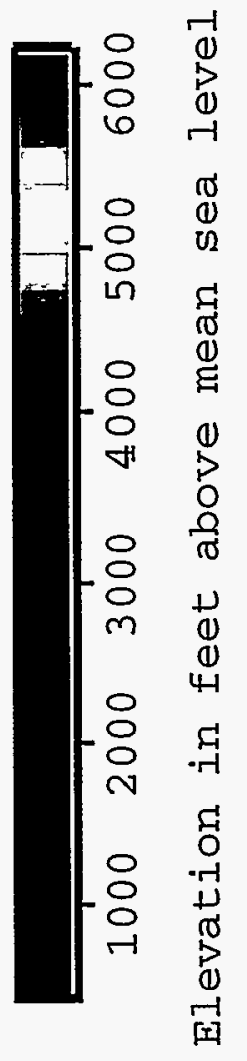

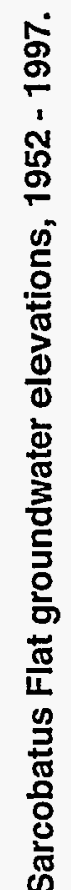
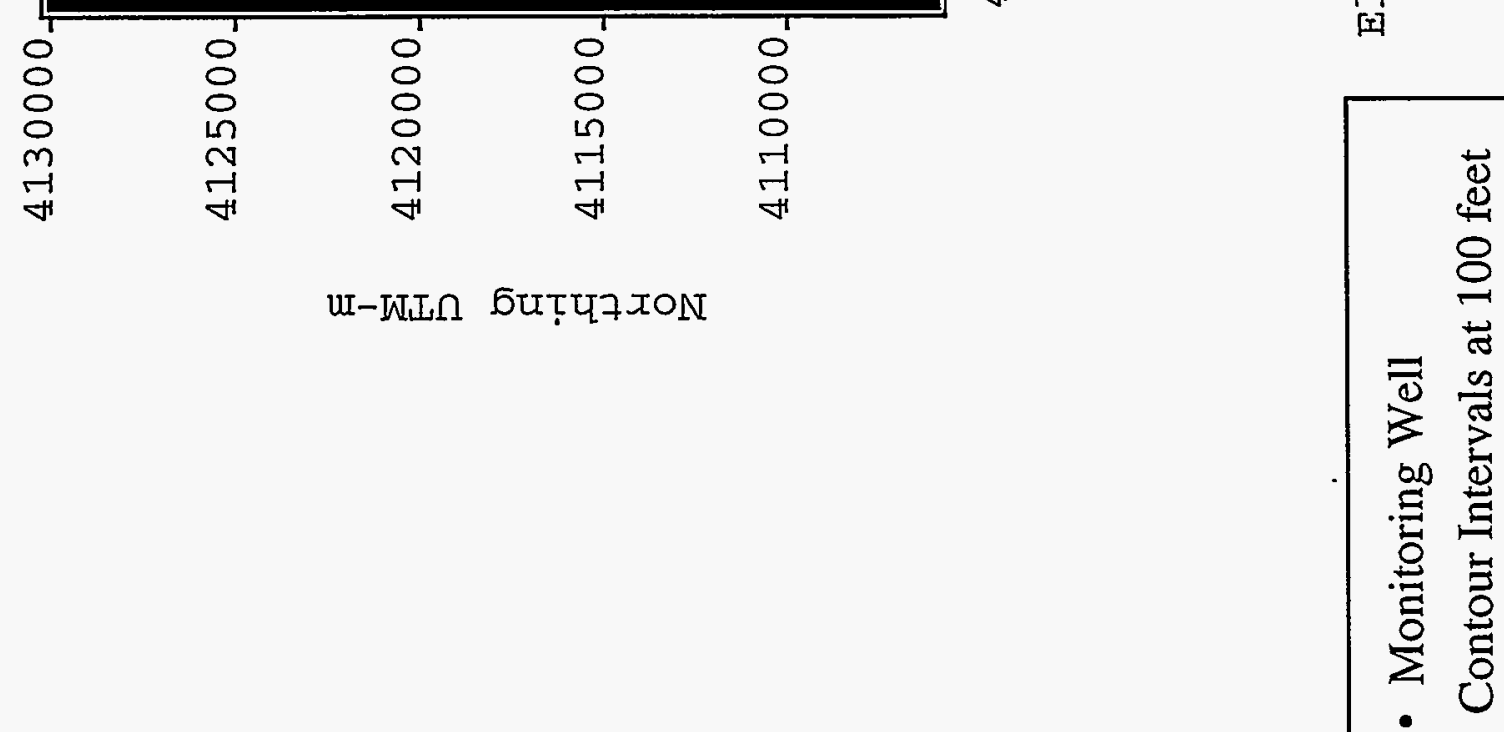

U-KII БUTุบTON 


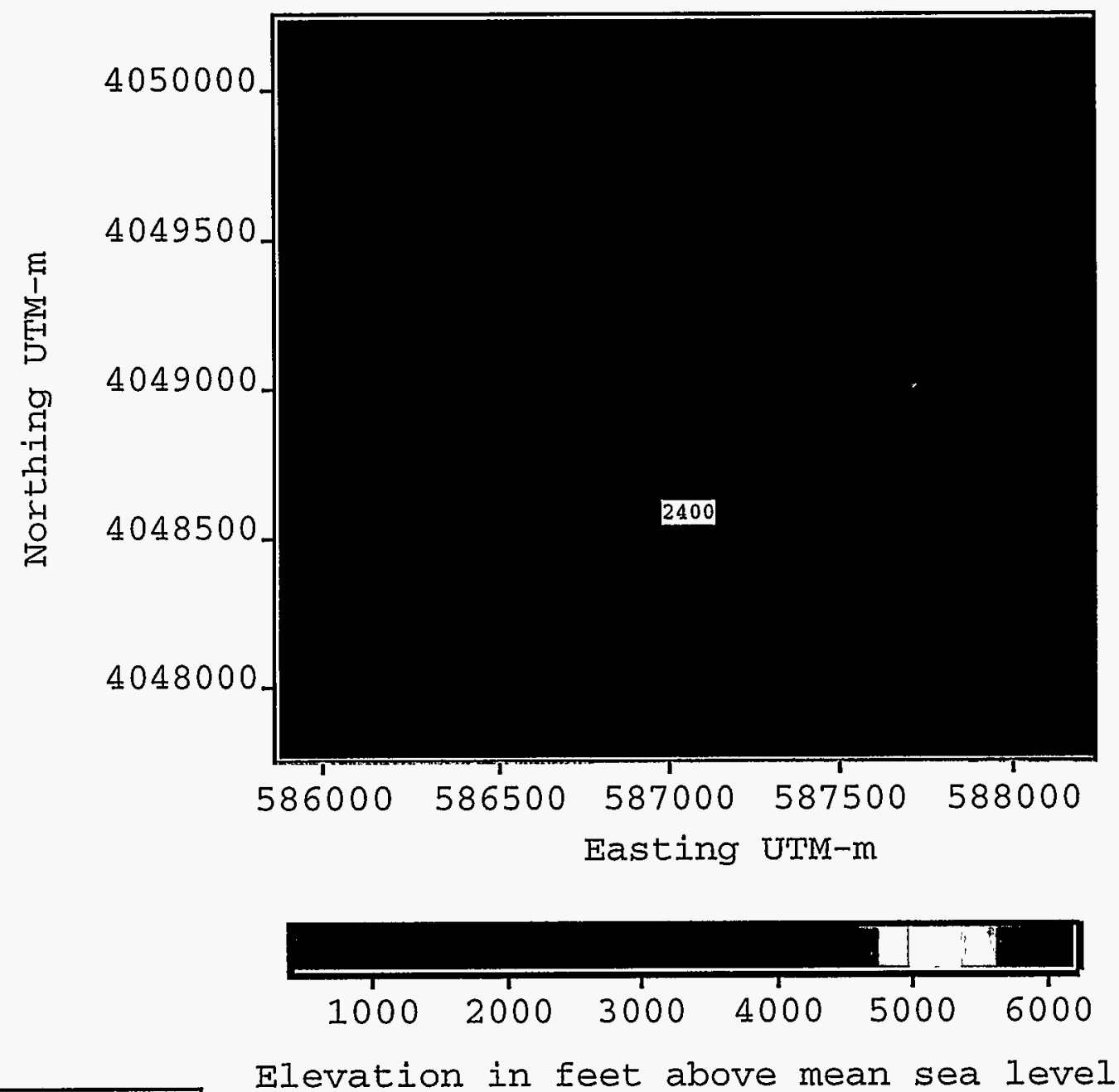

- Monitoring Well

Contour Intervals at 100 feet

Figure 3-6g Mercury Valley groundwater elevations, 1958 -1997. 


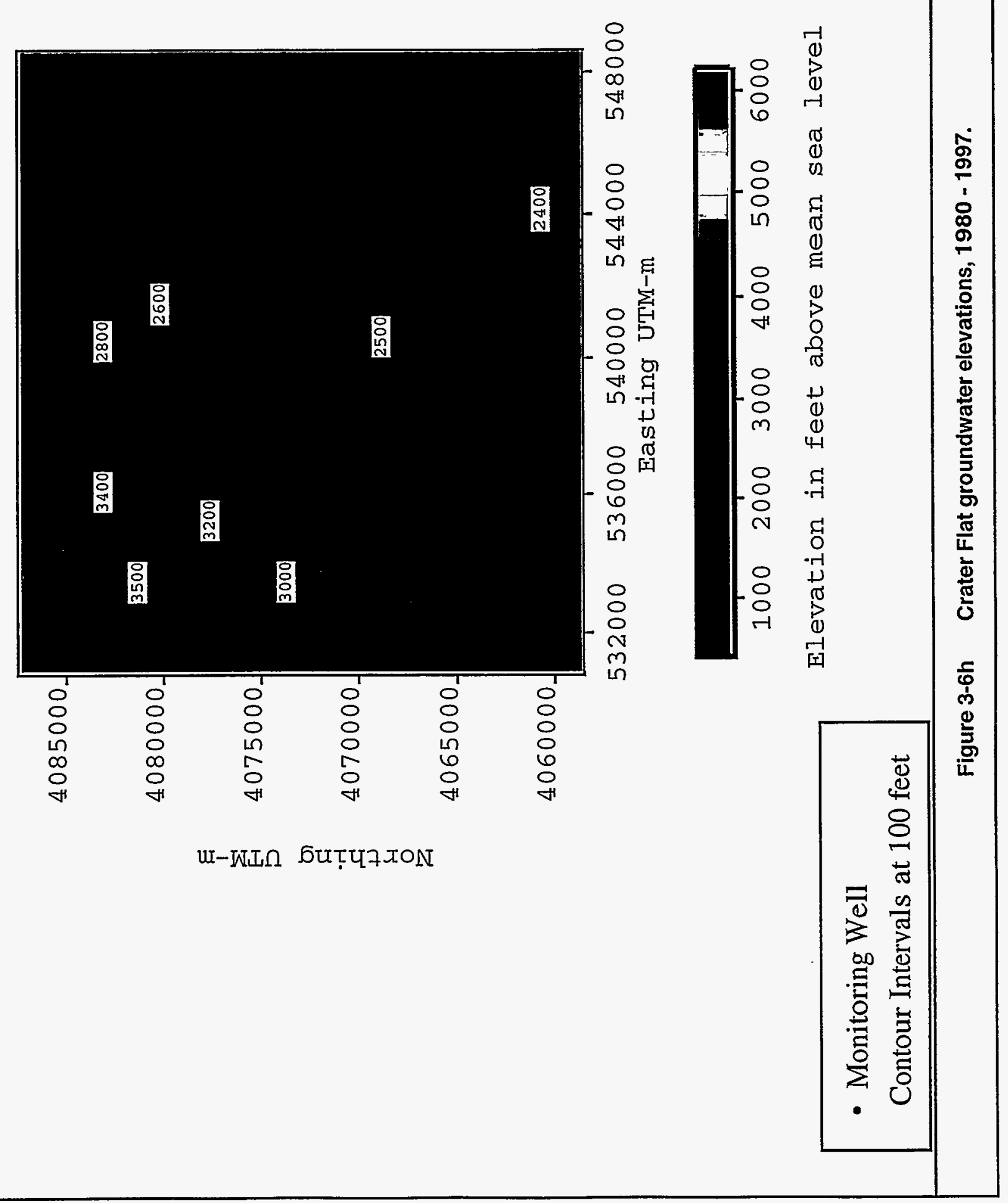




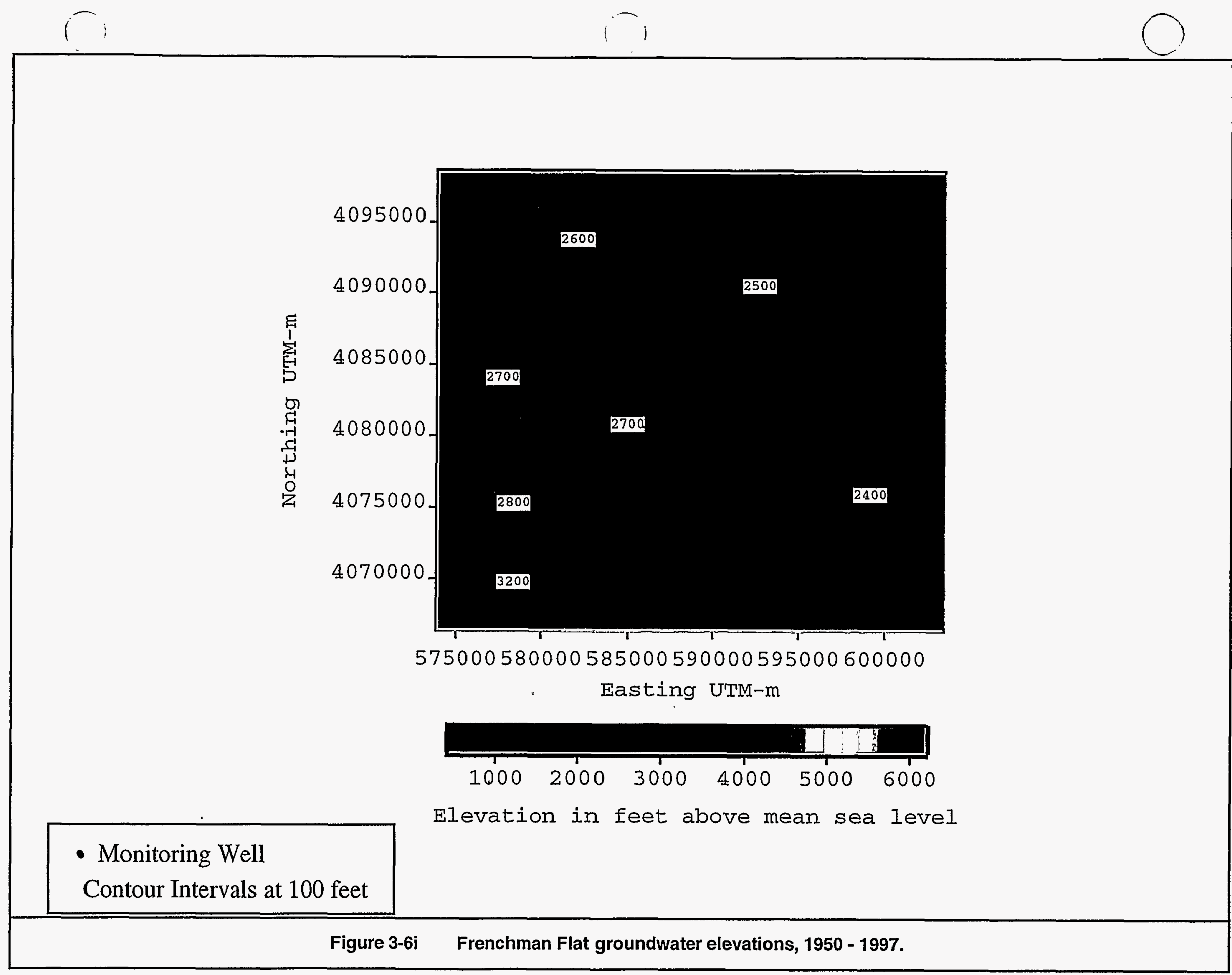



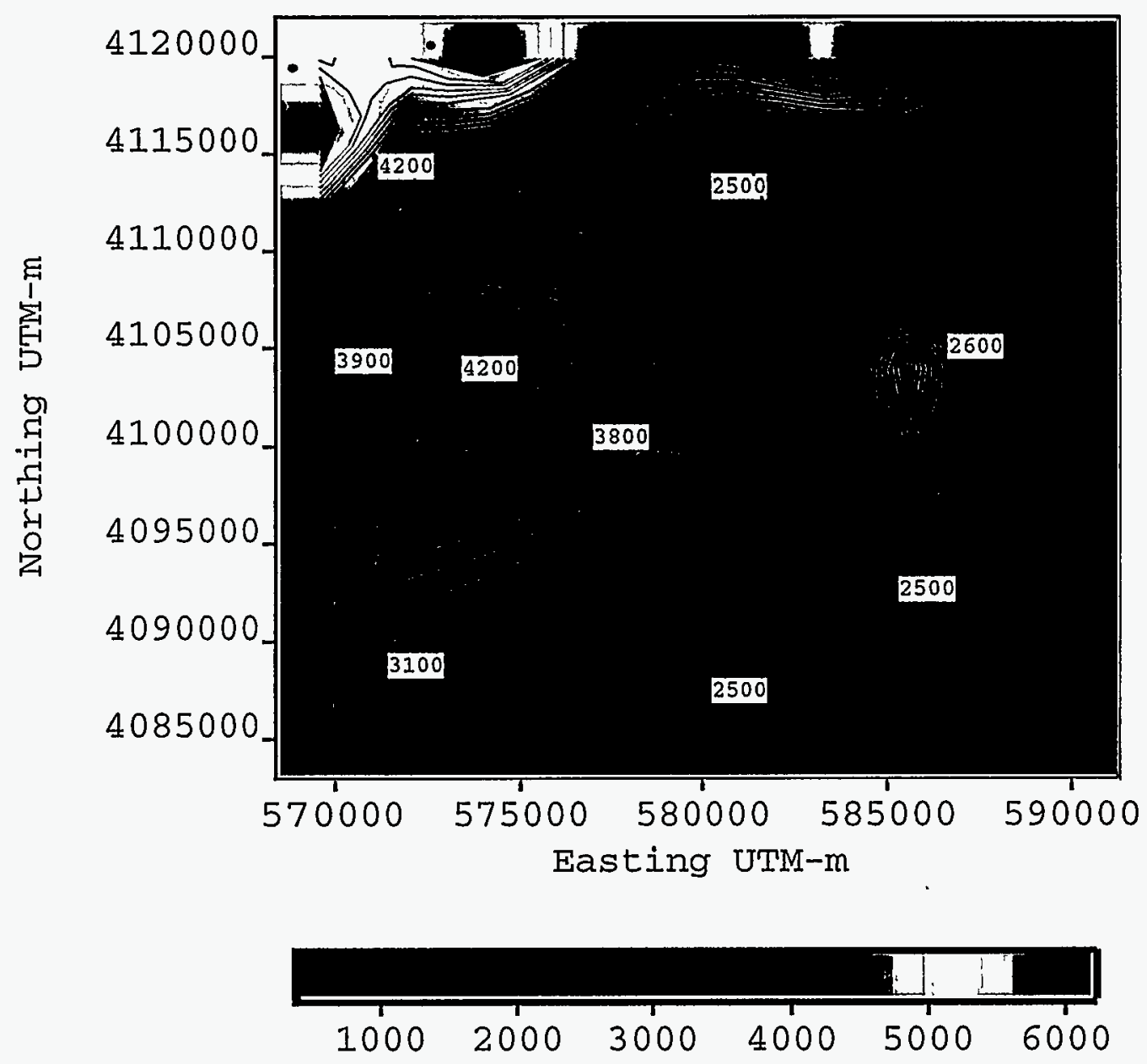

Elevation in feet above mean sea level

- Monitoring Well

Contour Intervals at 100 feet

Figure 3-6j Yucca Flat groundwater elevations, 1958 -1997. 


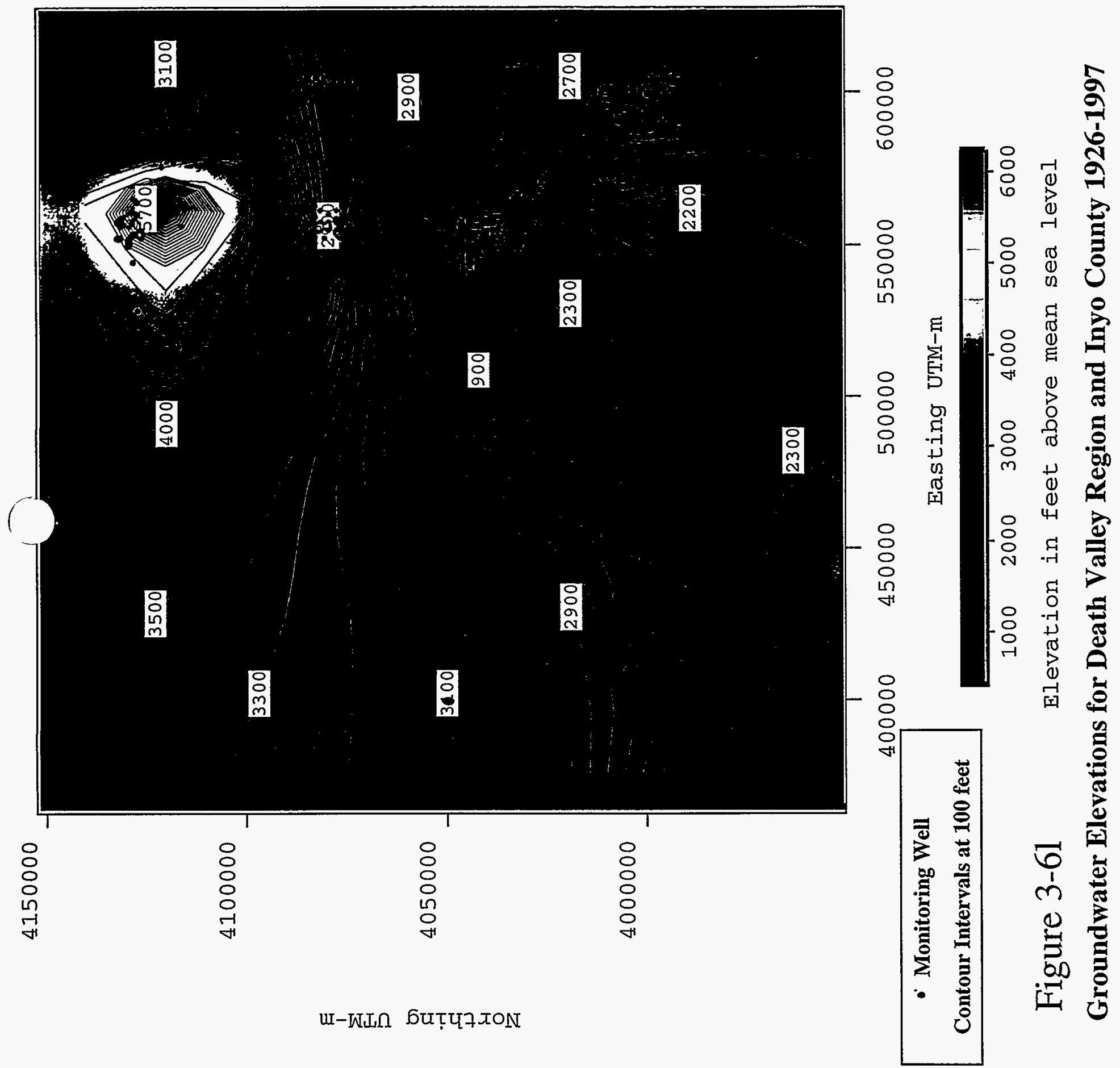




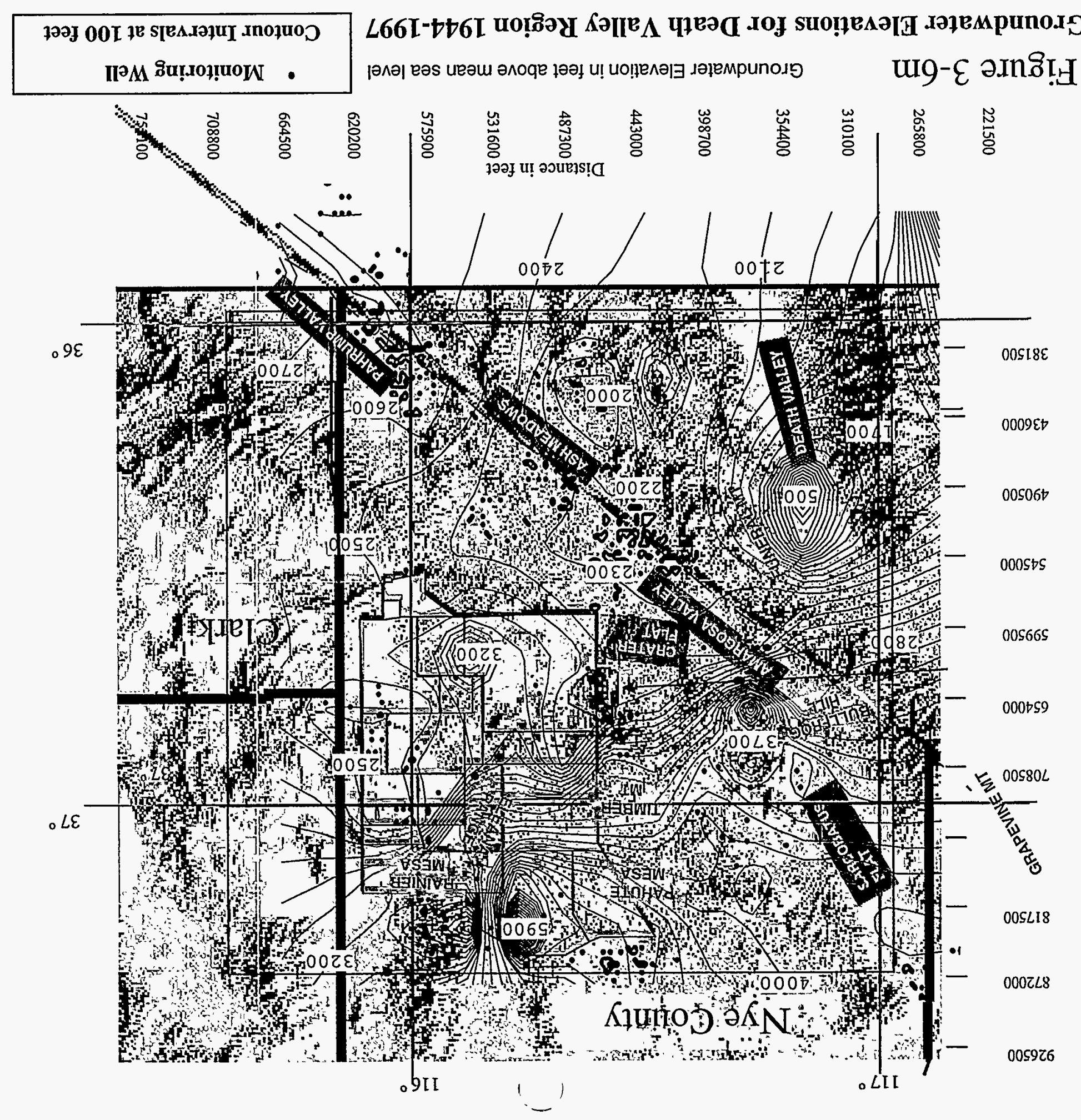


E.S. Bowman
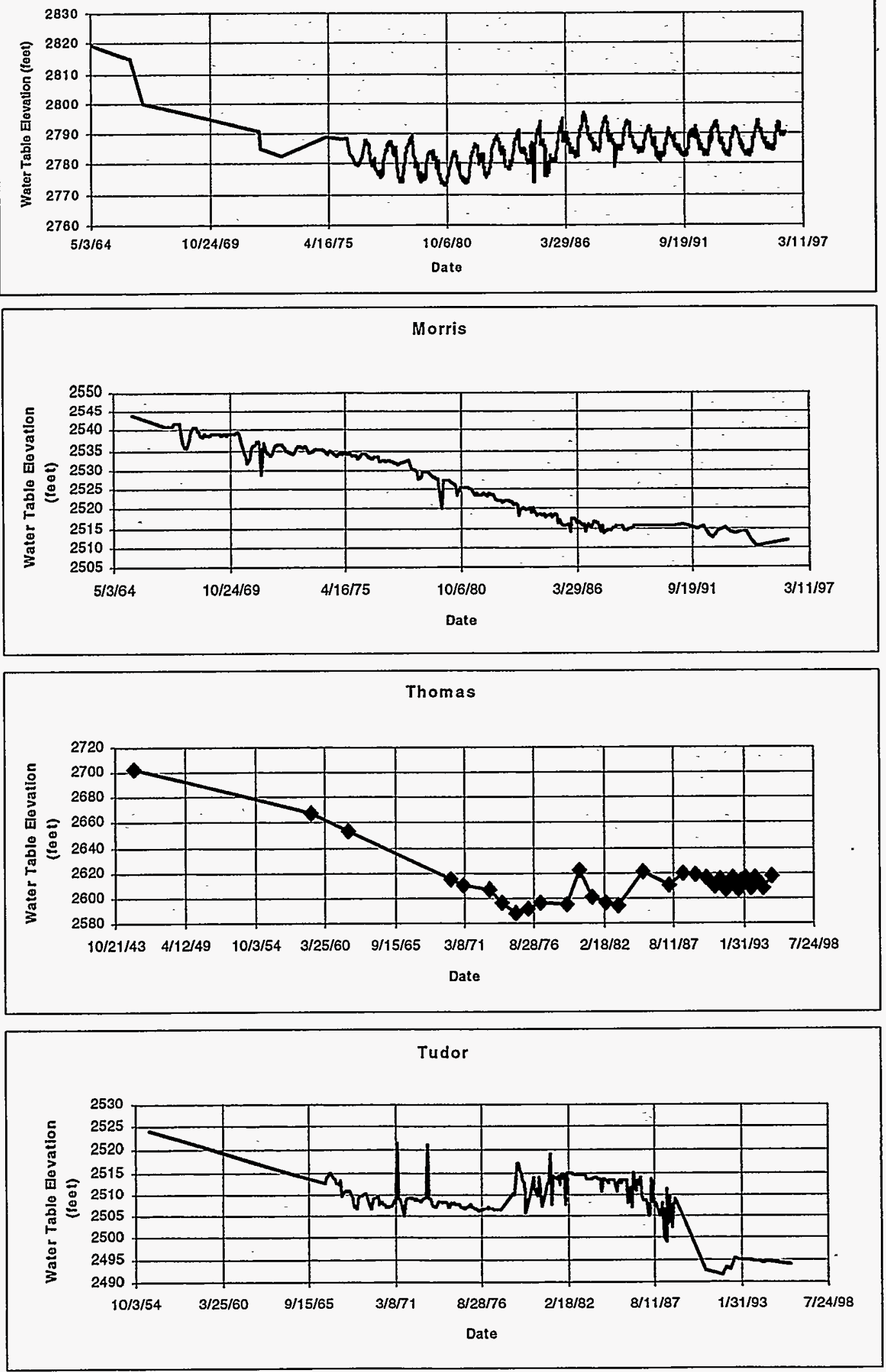

Figure 3-7a Water table elevations of selected wells in Pahrump Valley. 

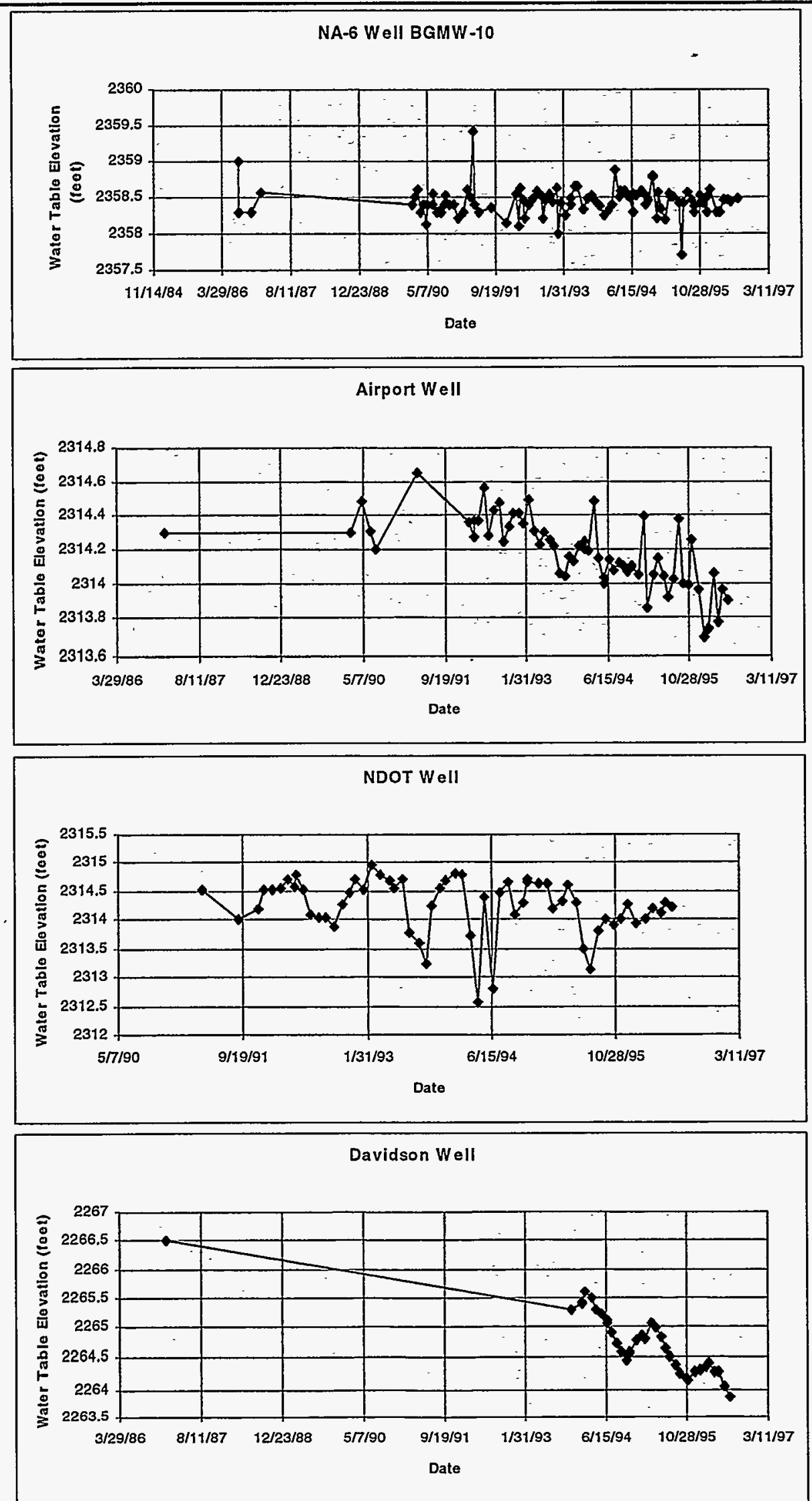

Figure 3-7b Water table elevations of selected wells in Amargosa Valley. 

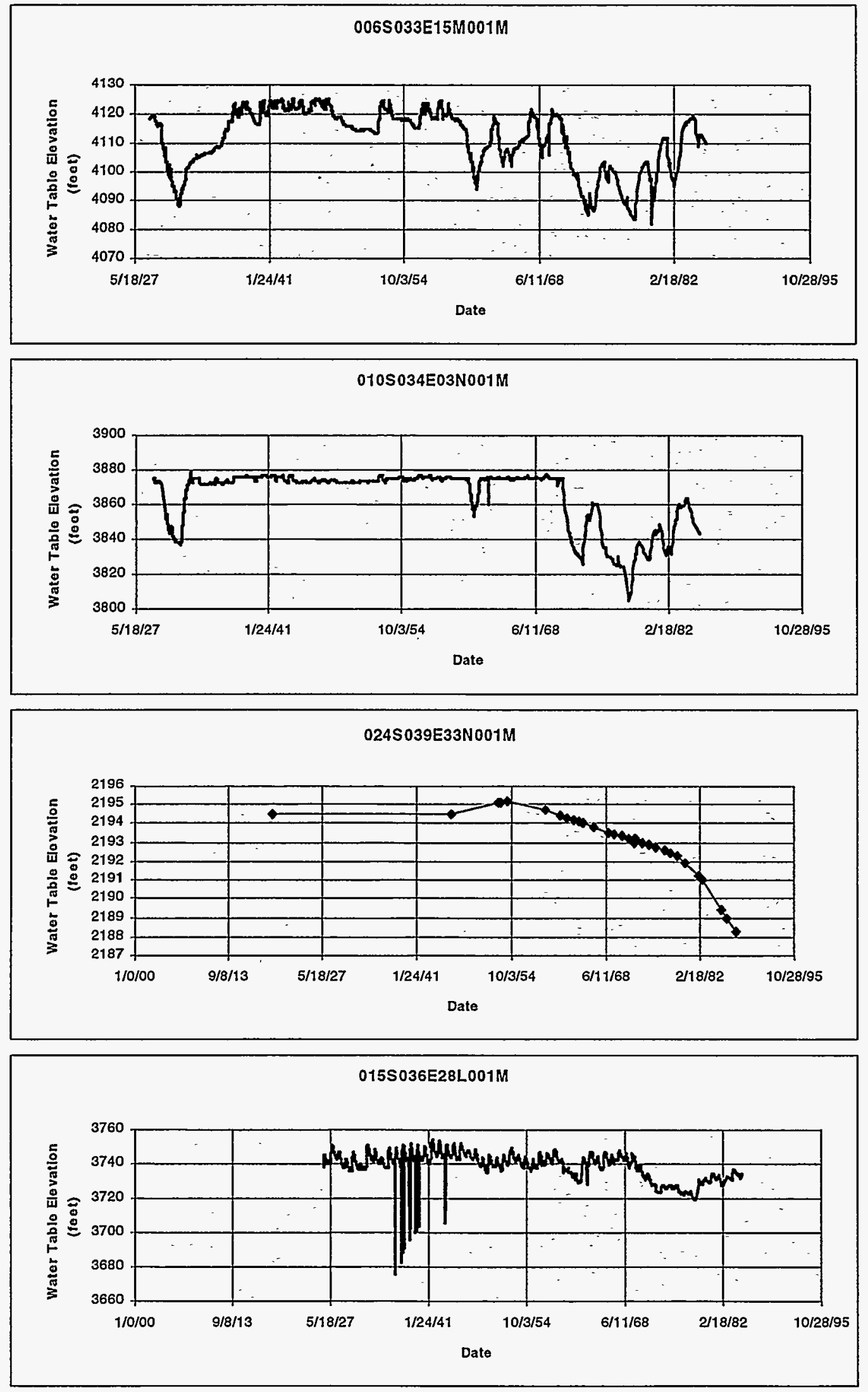

Figure 3-7c Water table elevations of selected wells in Inyo County. 


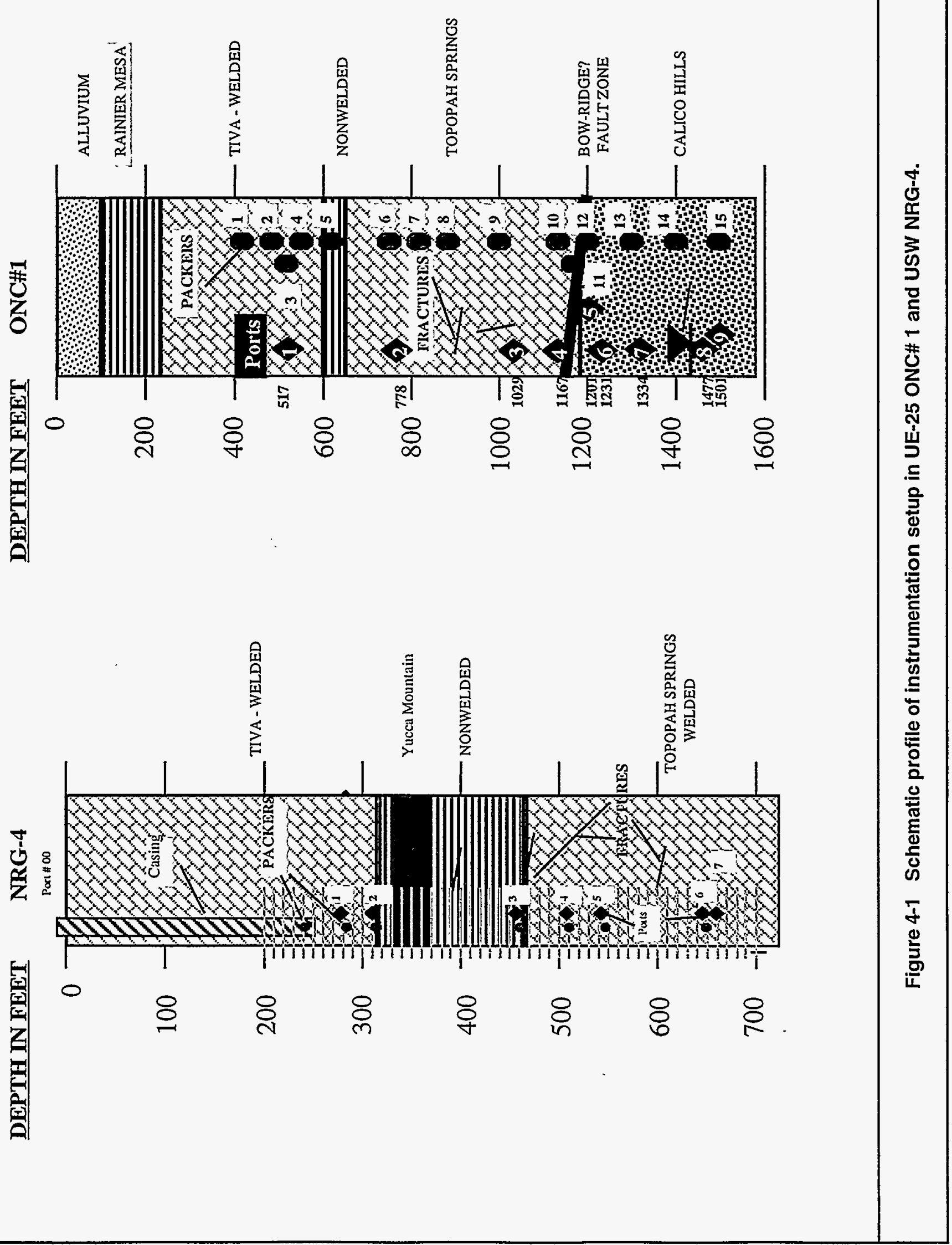




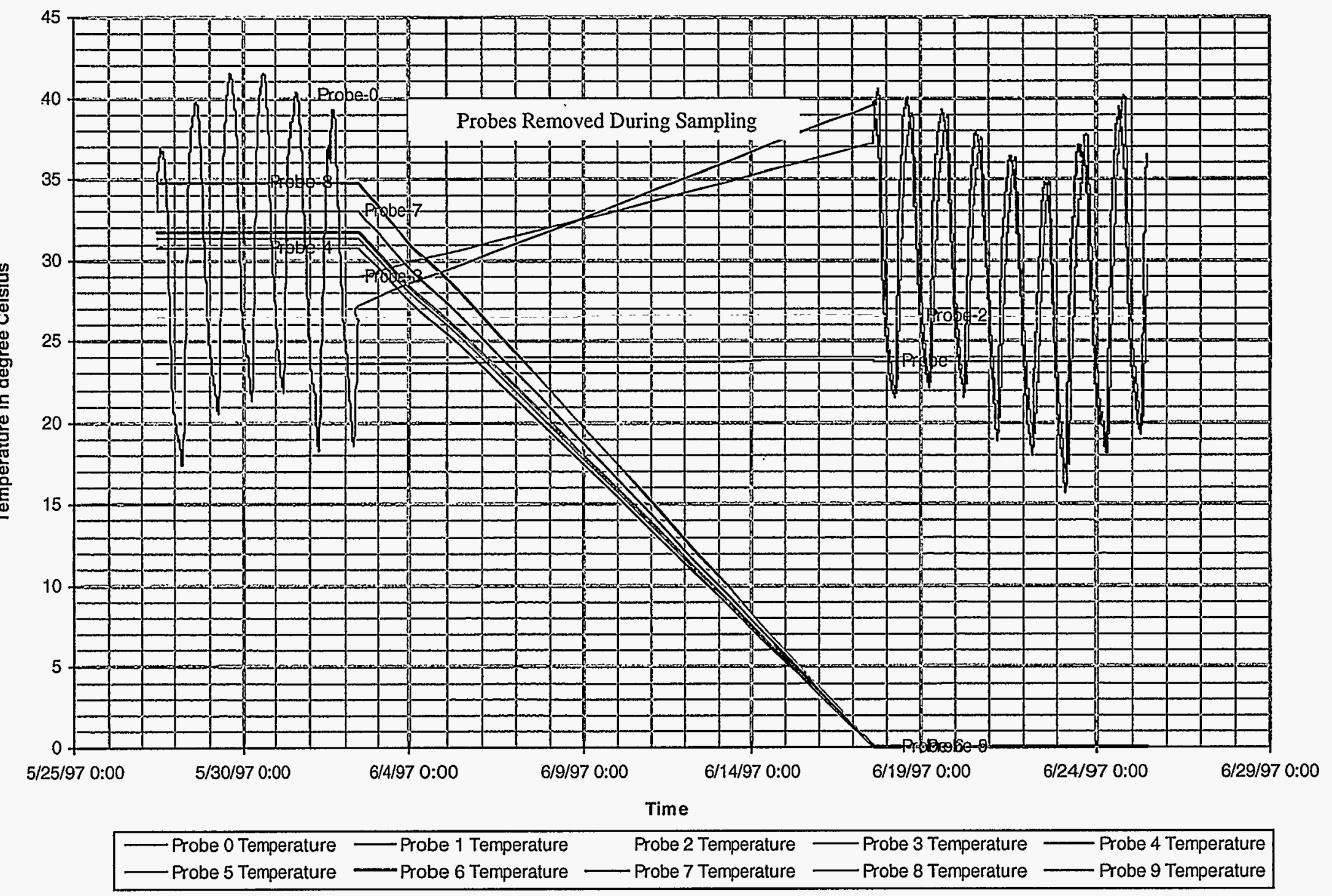




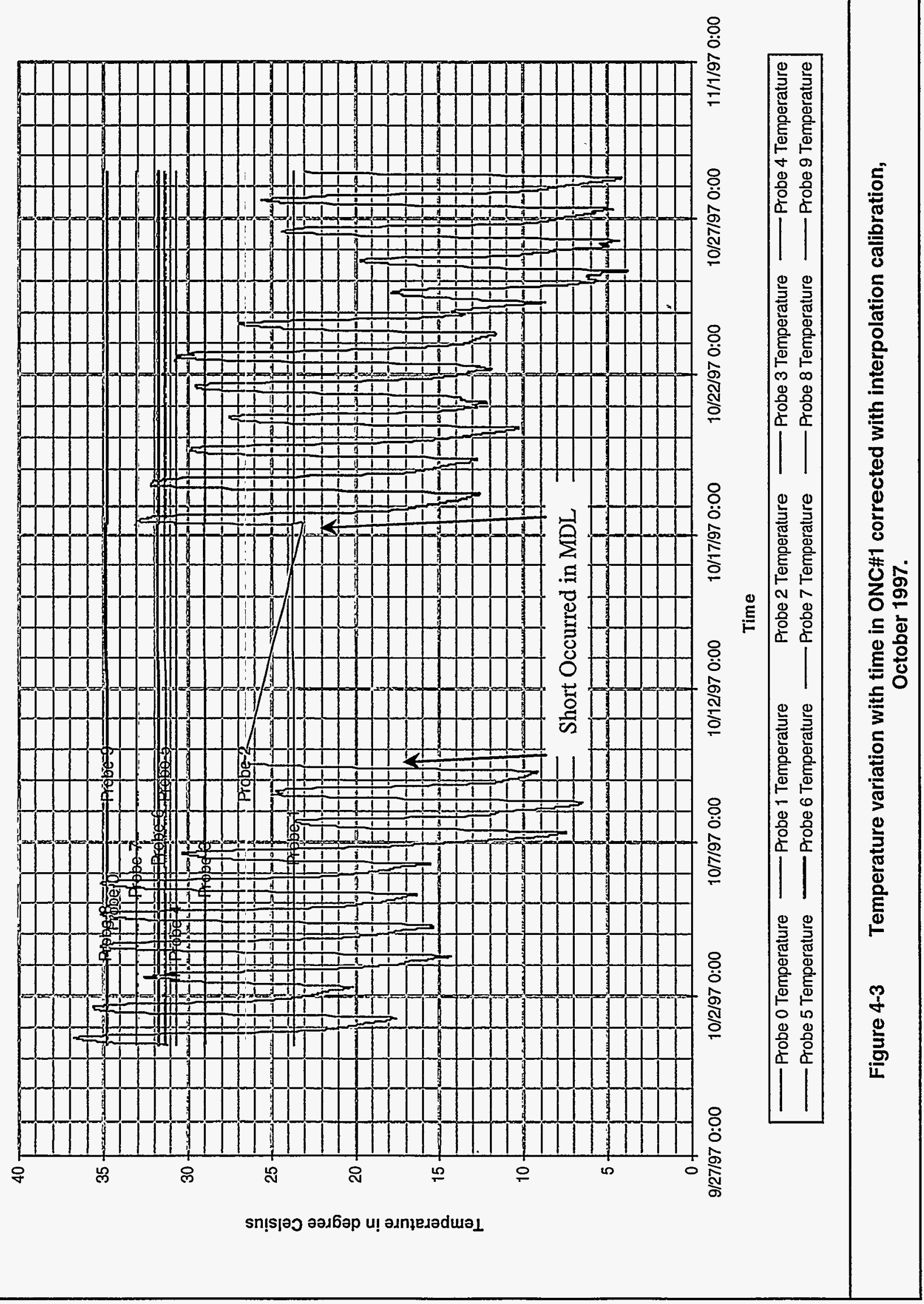




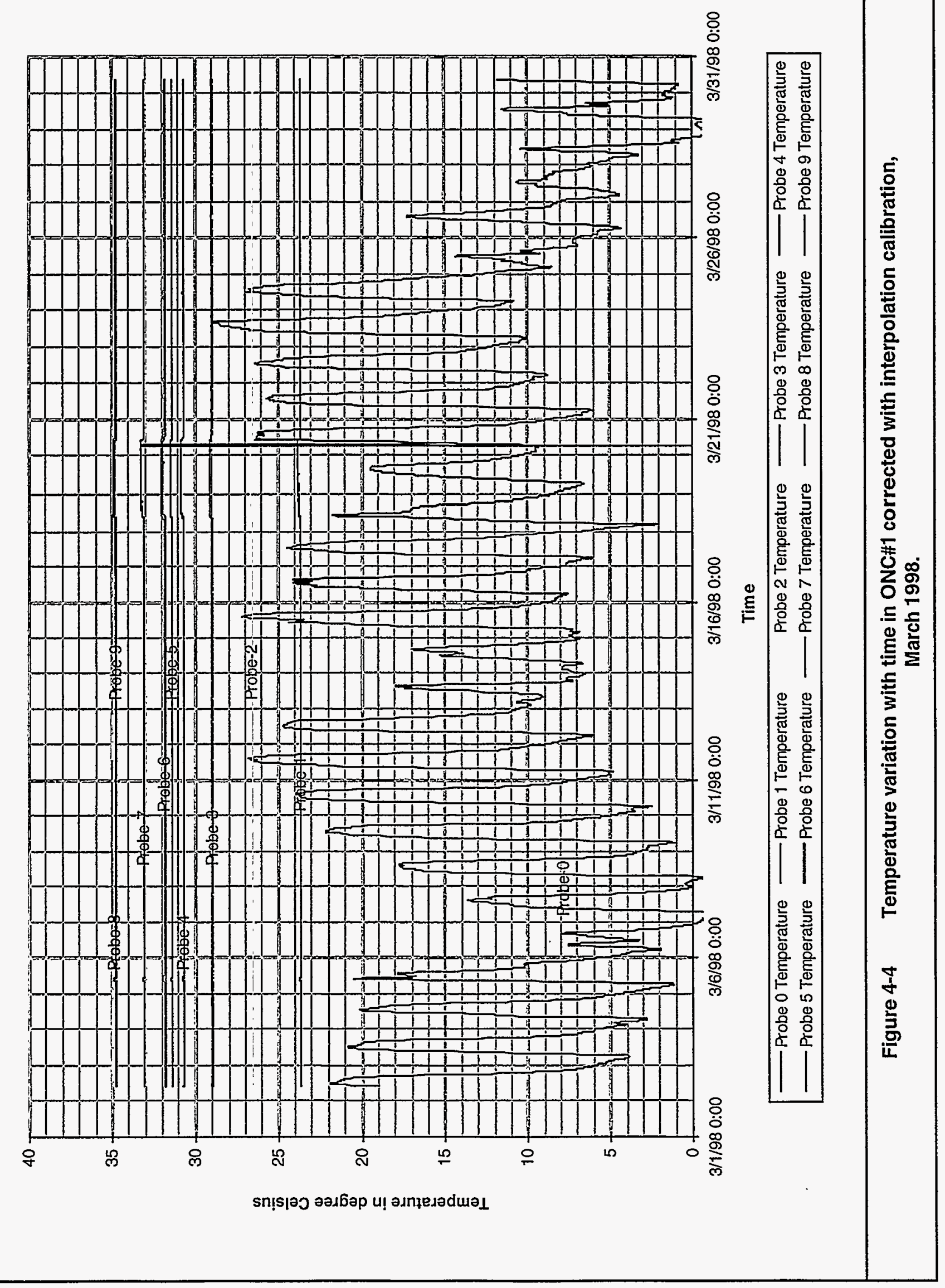




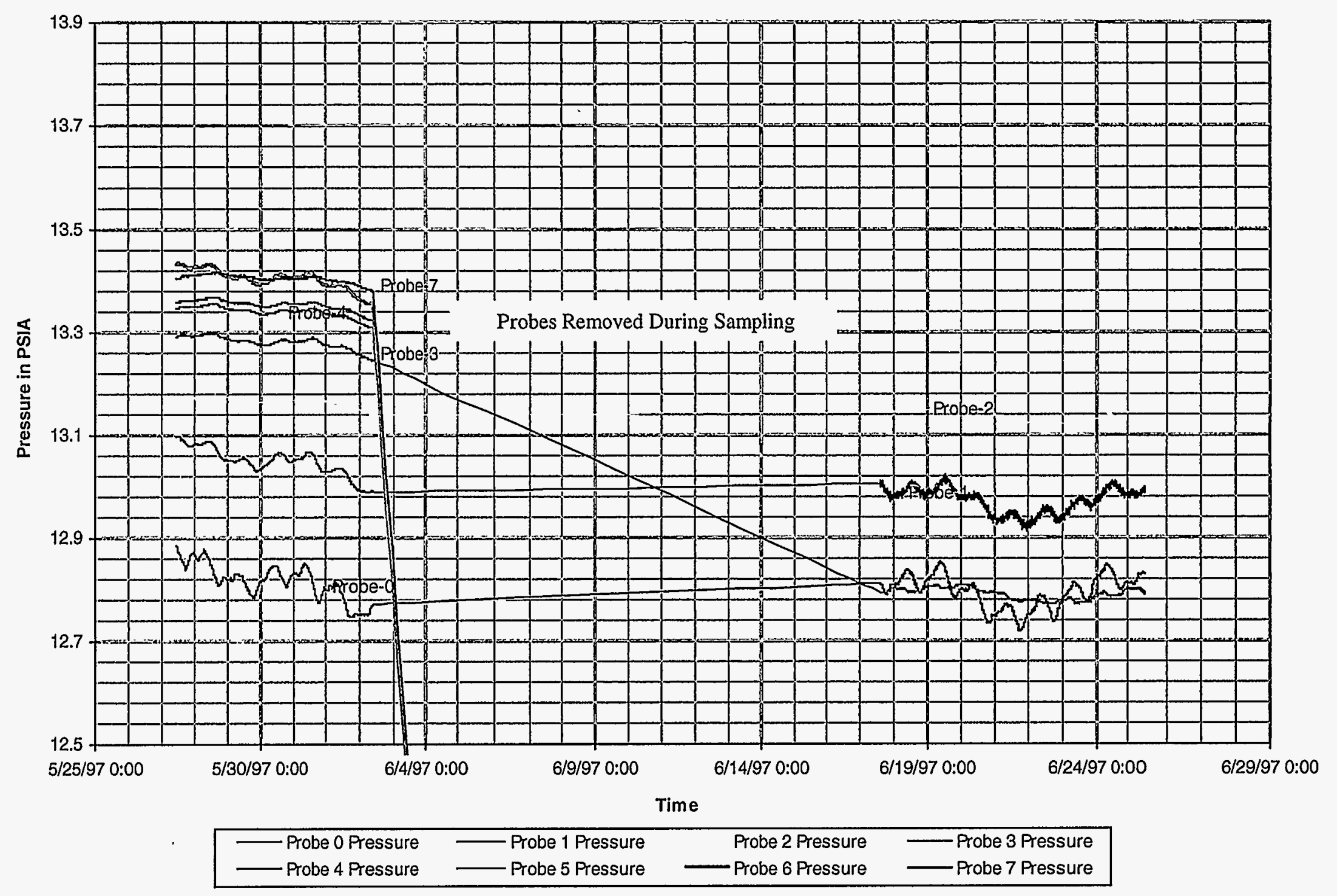

Figure 4-5 Absolute pressure for ONC\#1 corrected with interpolation calibration, June 1997. 


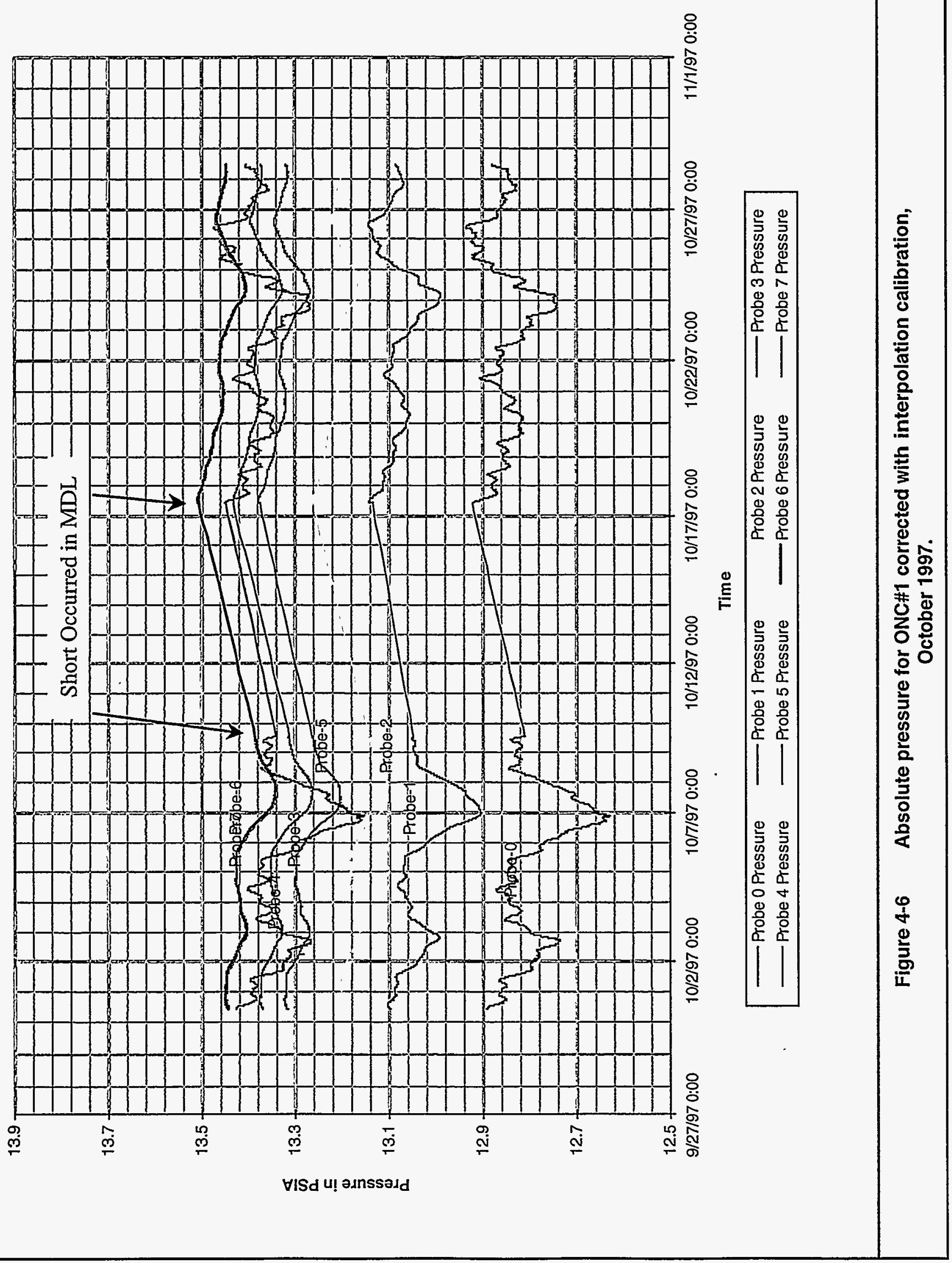




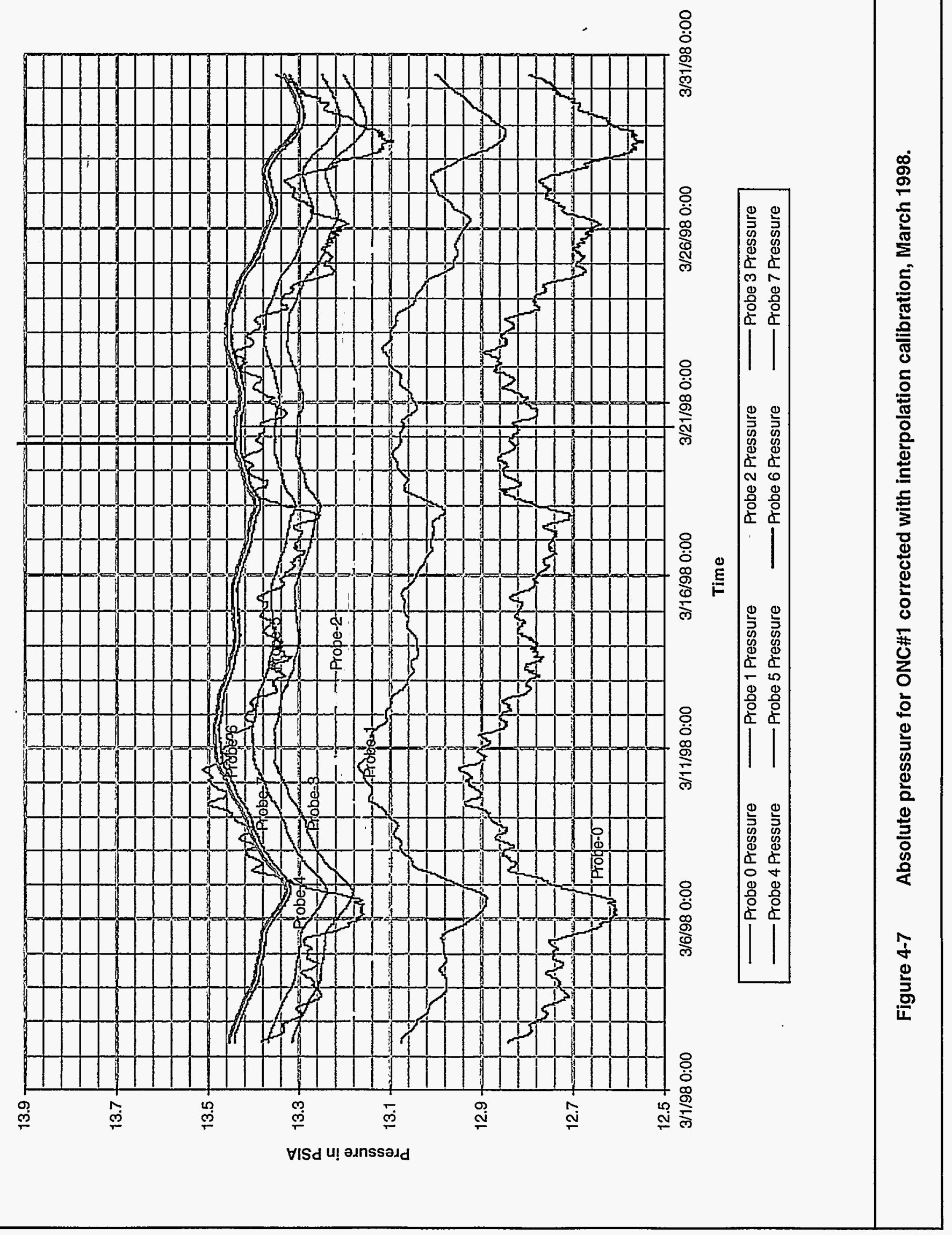




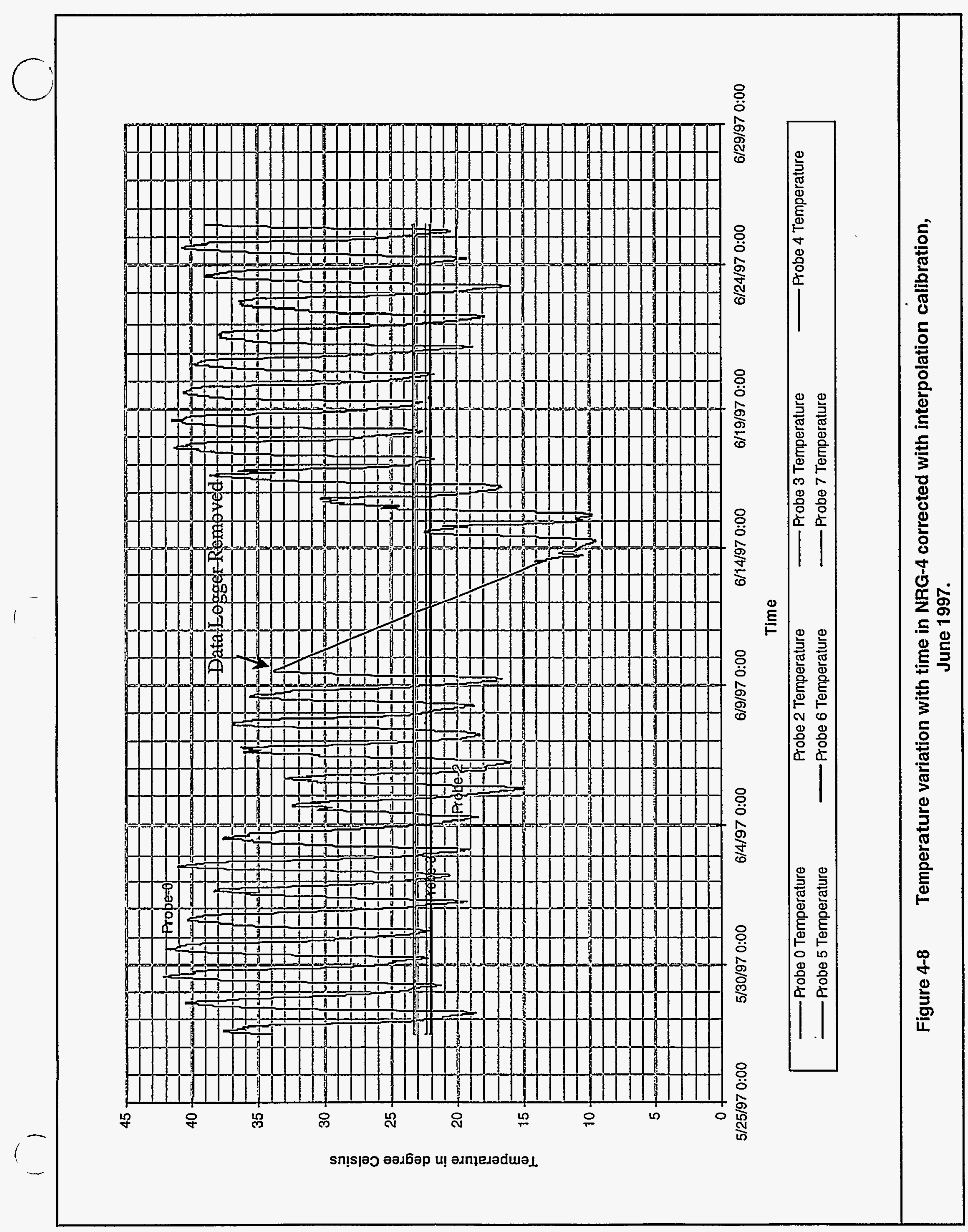




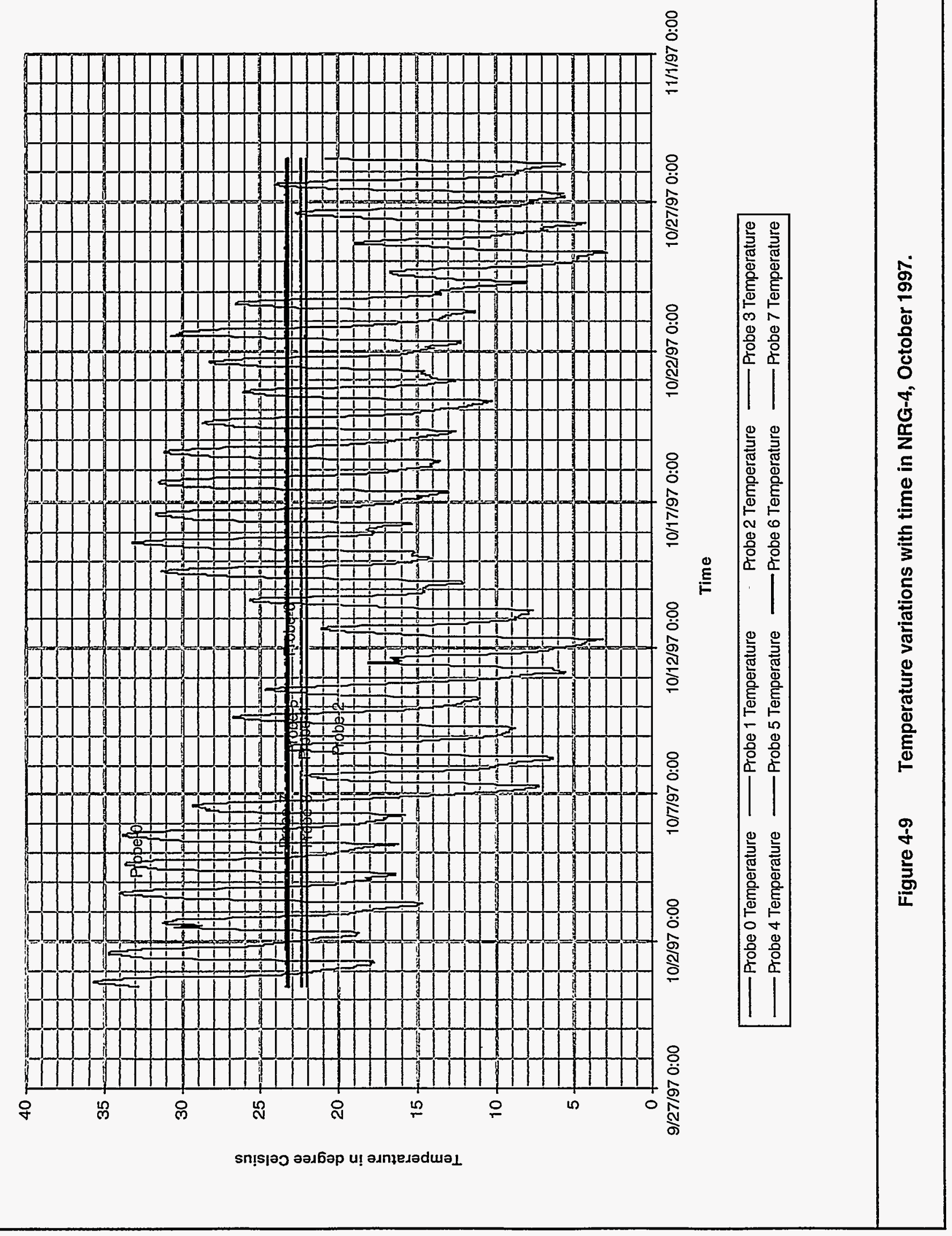




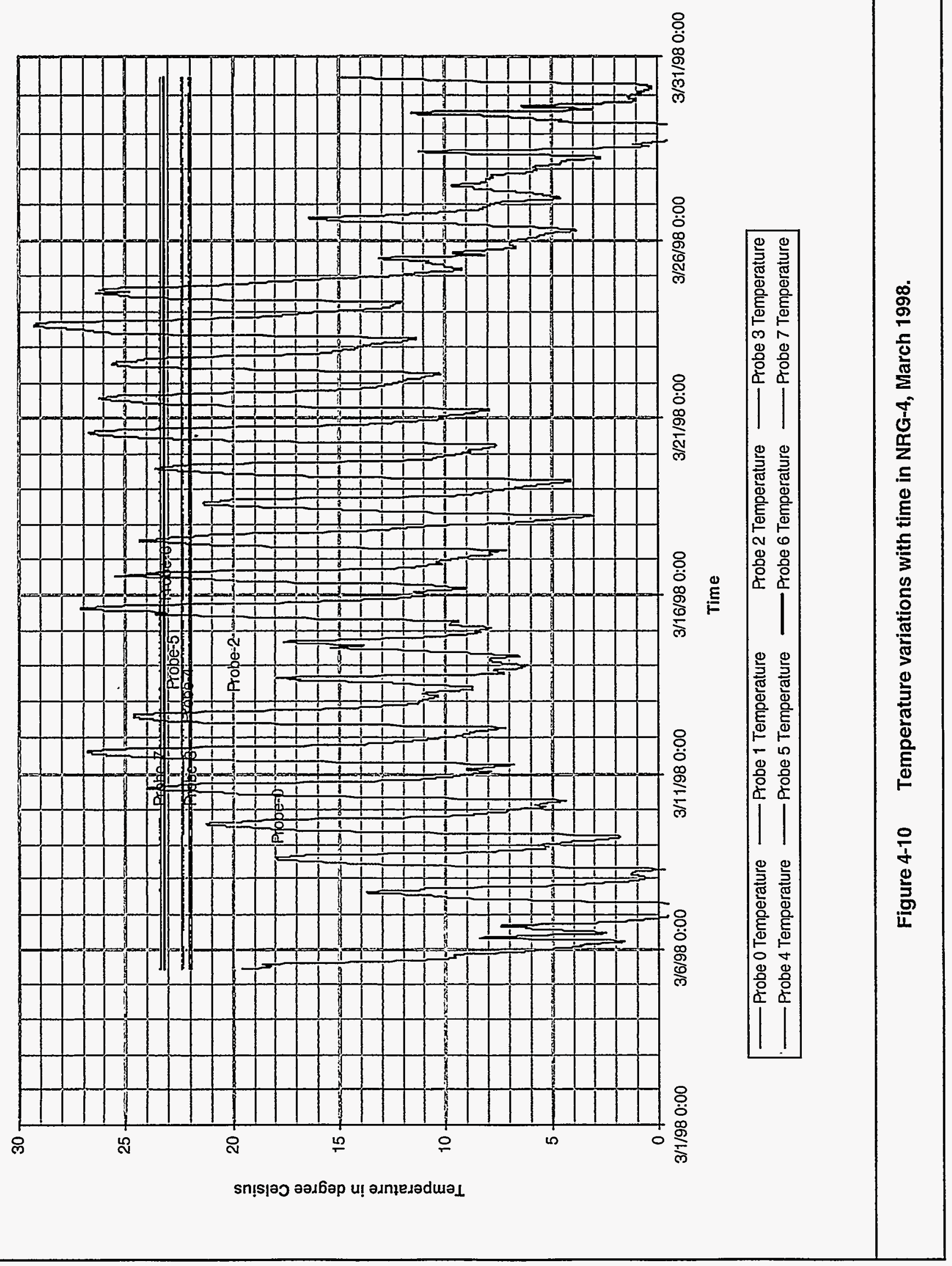




\begin{tabular}{|c|c|c|c|}
\hline adnssadd $\angle$ aqold & aunssald 9 eqold $\longrightarrow$ & əJnssedd G eqold & ədnssodd $\rightarrow$ әqOLd \\
\hline alnssald $\varepsilon$ aqold & 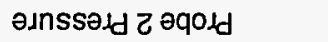 & əunssədd $\vdash$ әqodd & odnssald 0 oqold \\
\hline
\end{tabular}

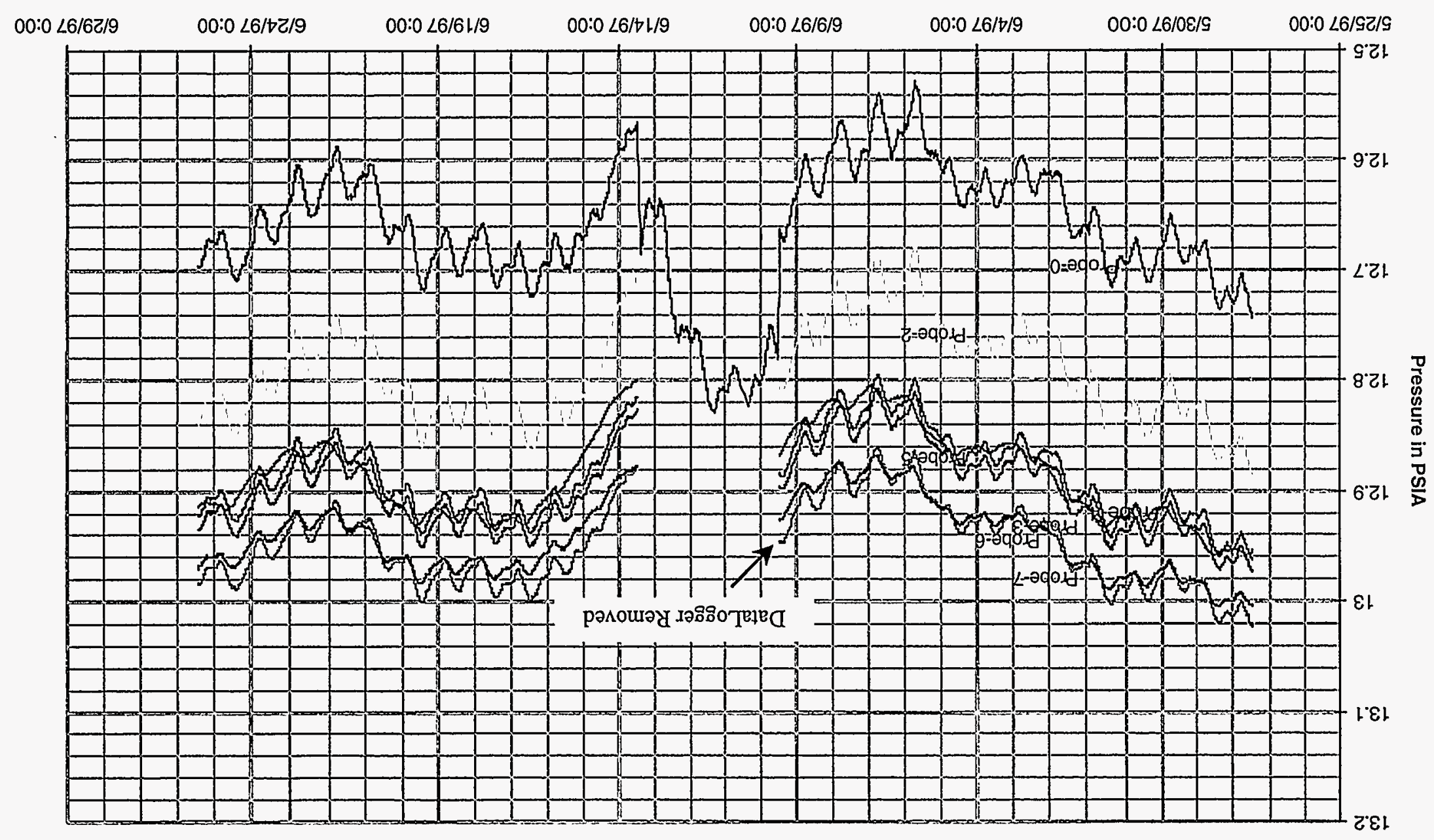




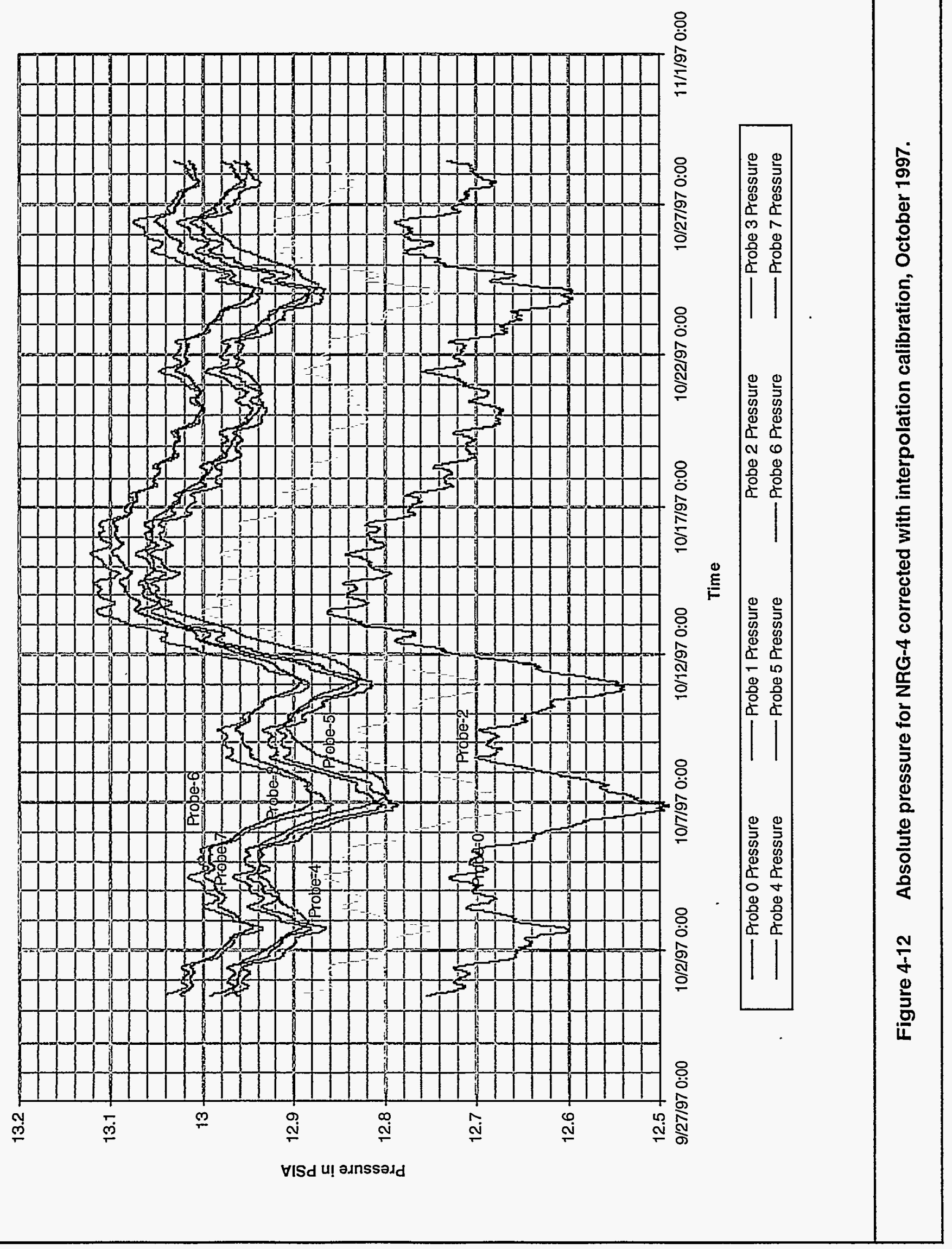




\begin{tabular}{|c|c|c|c|}
\hline asnssədd $\angle$ әqodd & əגnssodd 9 oqold & ə.nssəld $\mathrm{g}$ aqold & 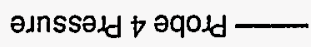 \\
\hline Oגnssold $\varepsilon$ әqOLd - & asnssadd Z әqoגd & əunsseld 1 eqold & alnssedd 0 əqold \\
\hline
\end{tabular}

จแ!

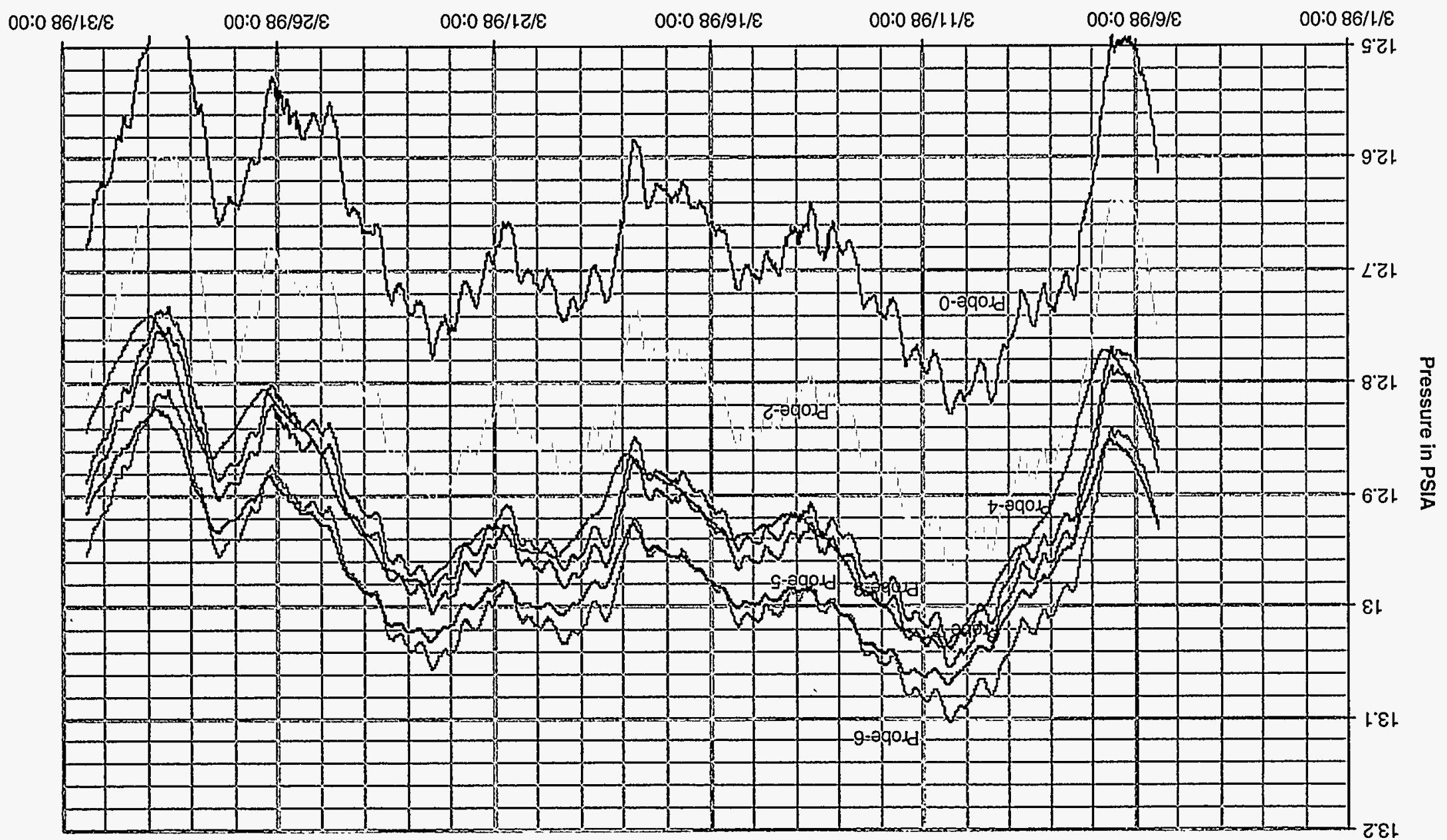




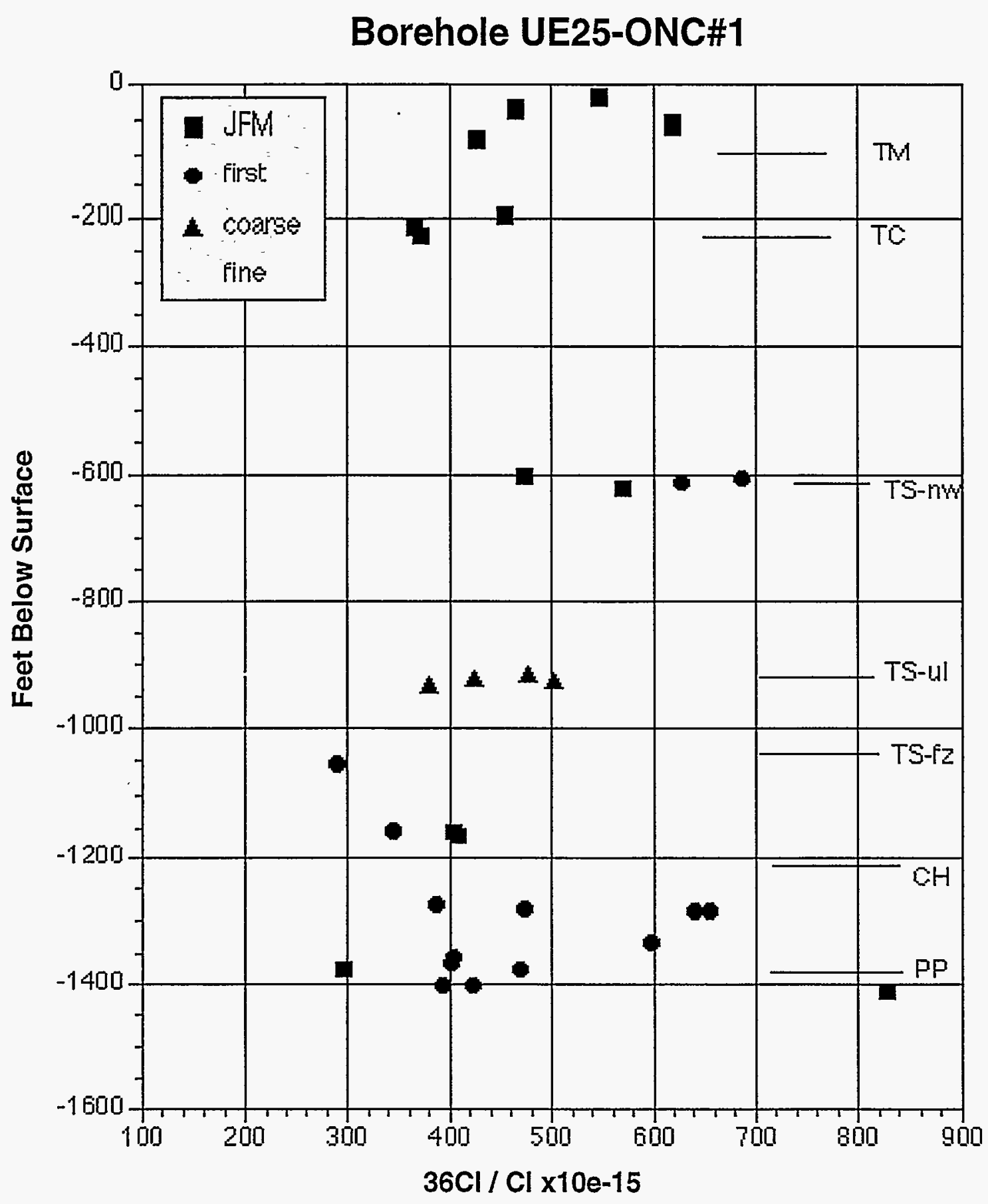

Points plotted at Top of Interval

Figure 5-1 Composite cuttings sample. 


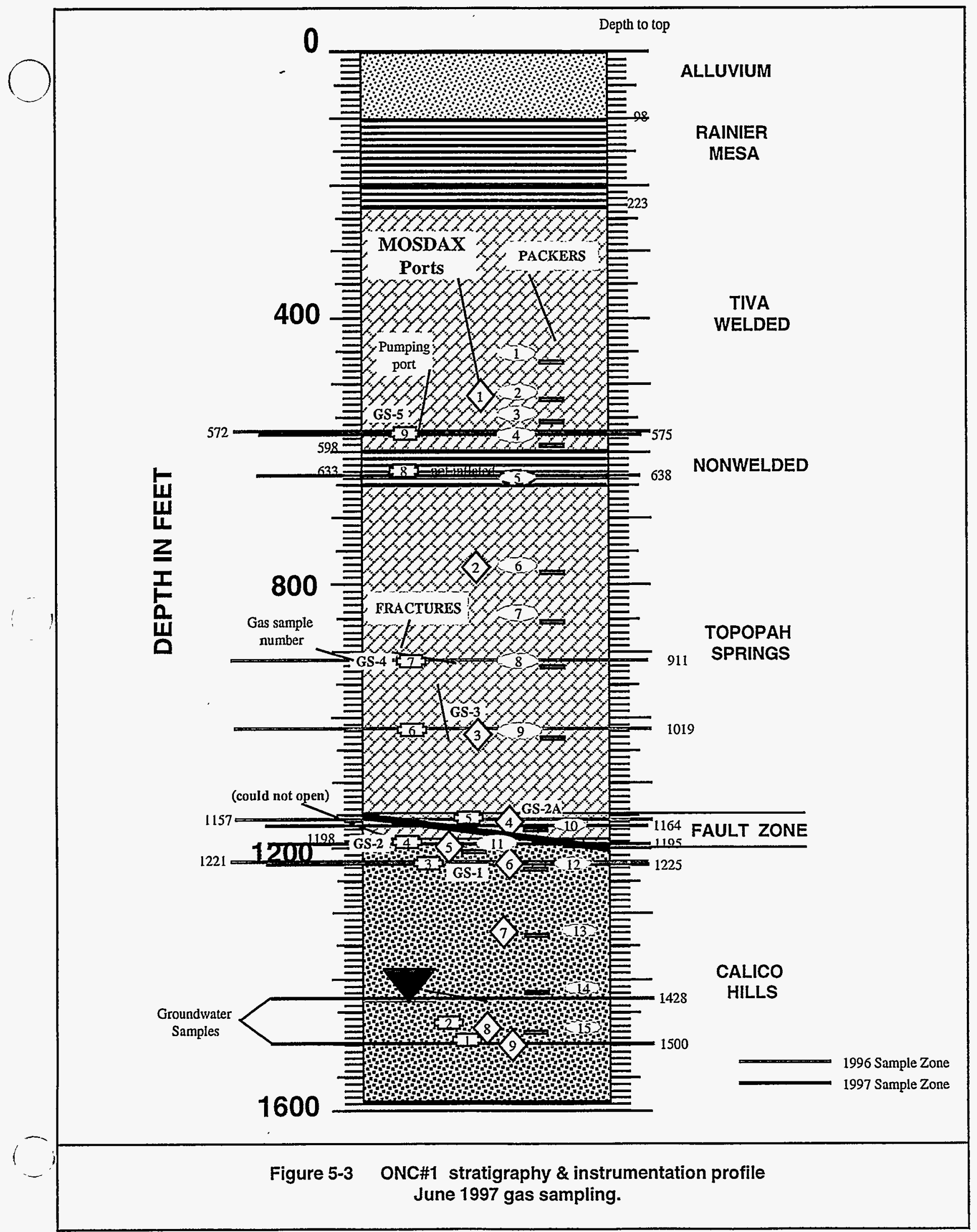




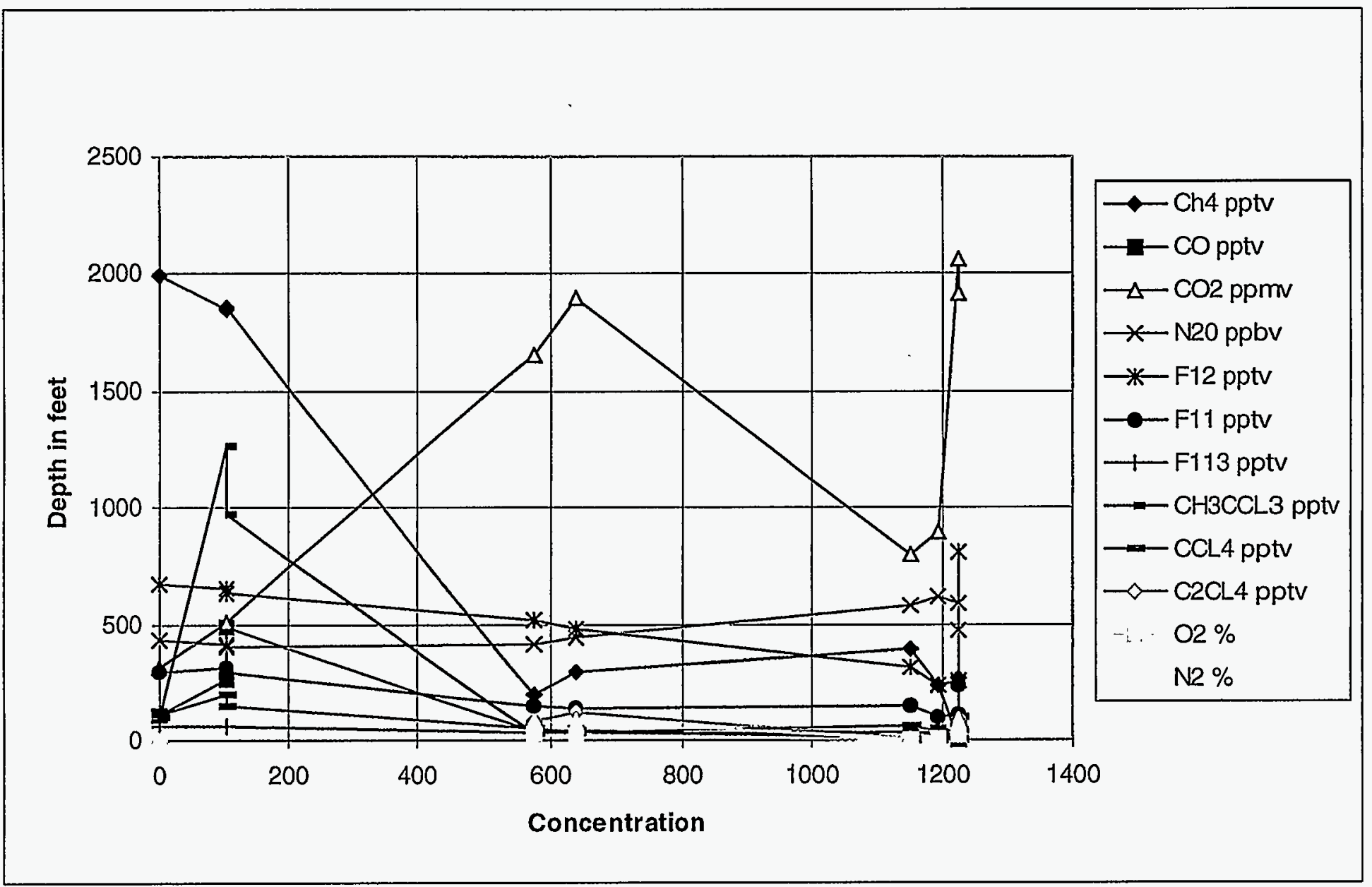

Figure 5-4 Results of all analyses, June 1997. 


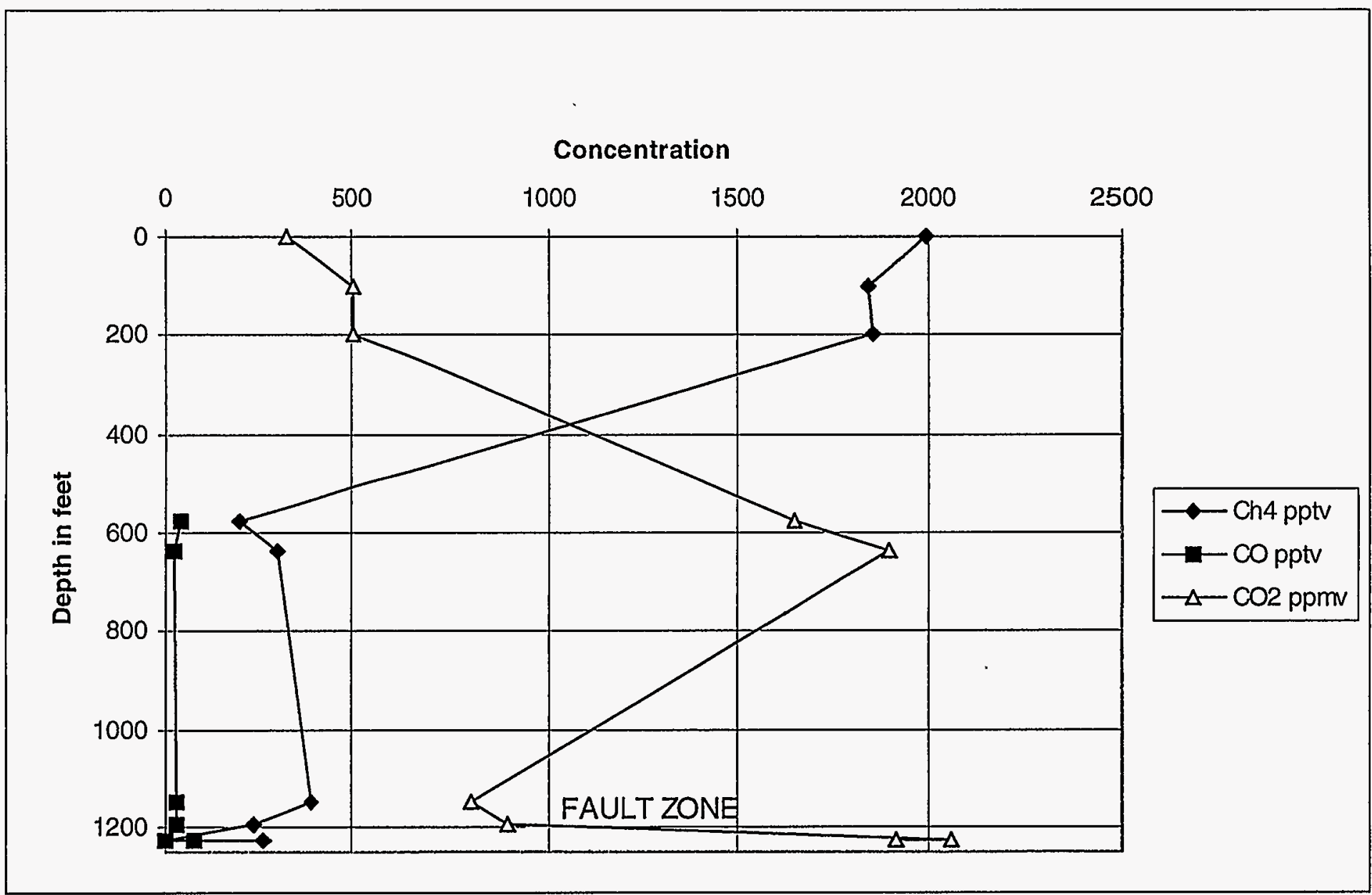

Figure 5-5 Concentration of $\mathrm{CH}_{4}$ with depth at ONC\#1, June 1997. 


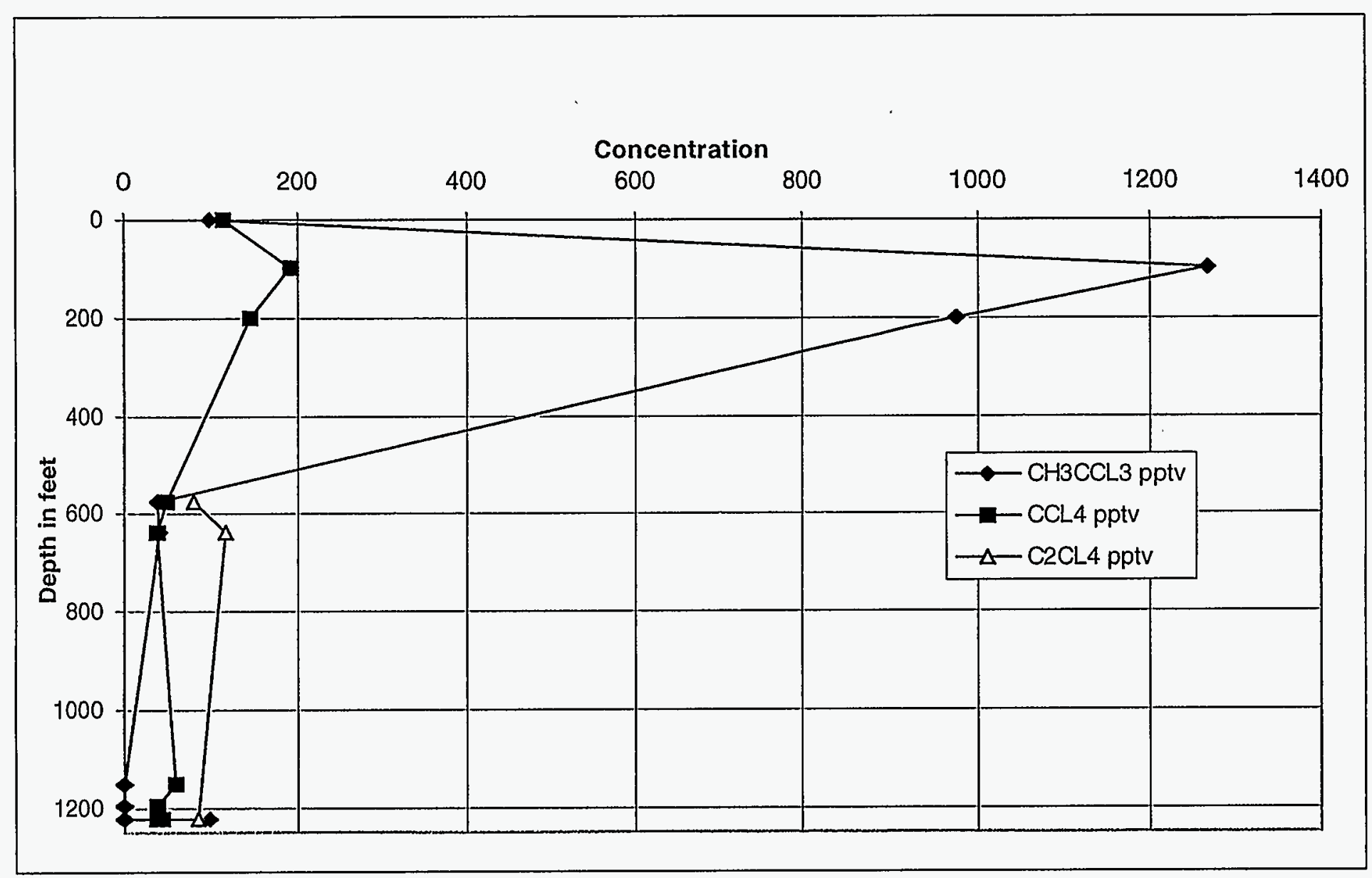

Figure 5-6 Concentration of chlorinated hydrocarbons with depth at ONC\#1, June 1997. 


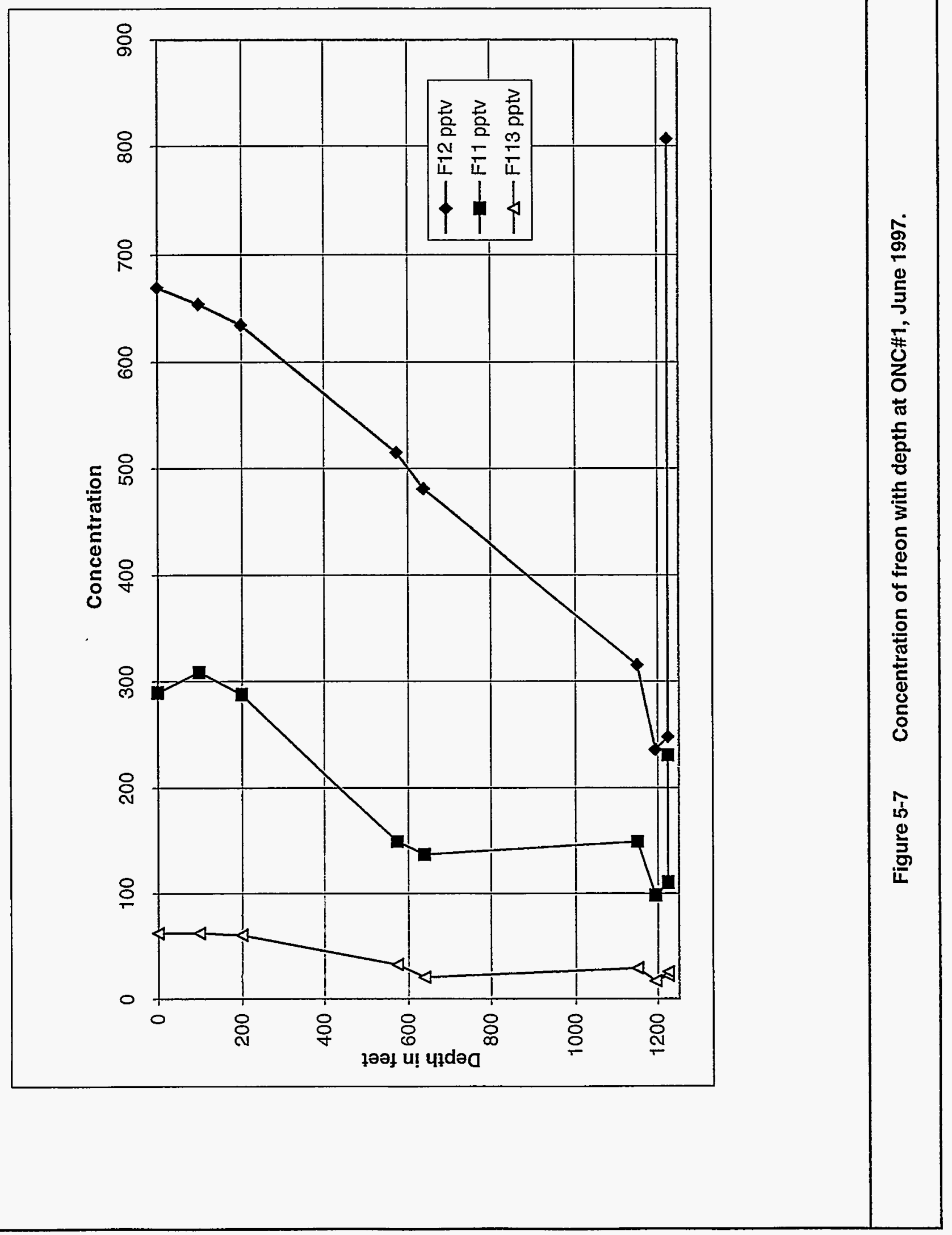




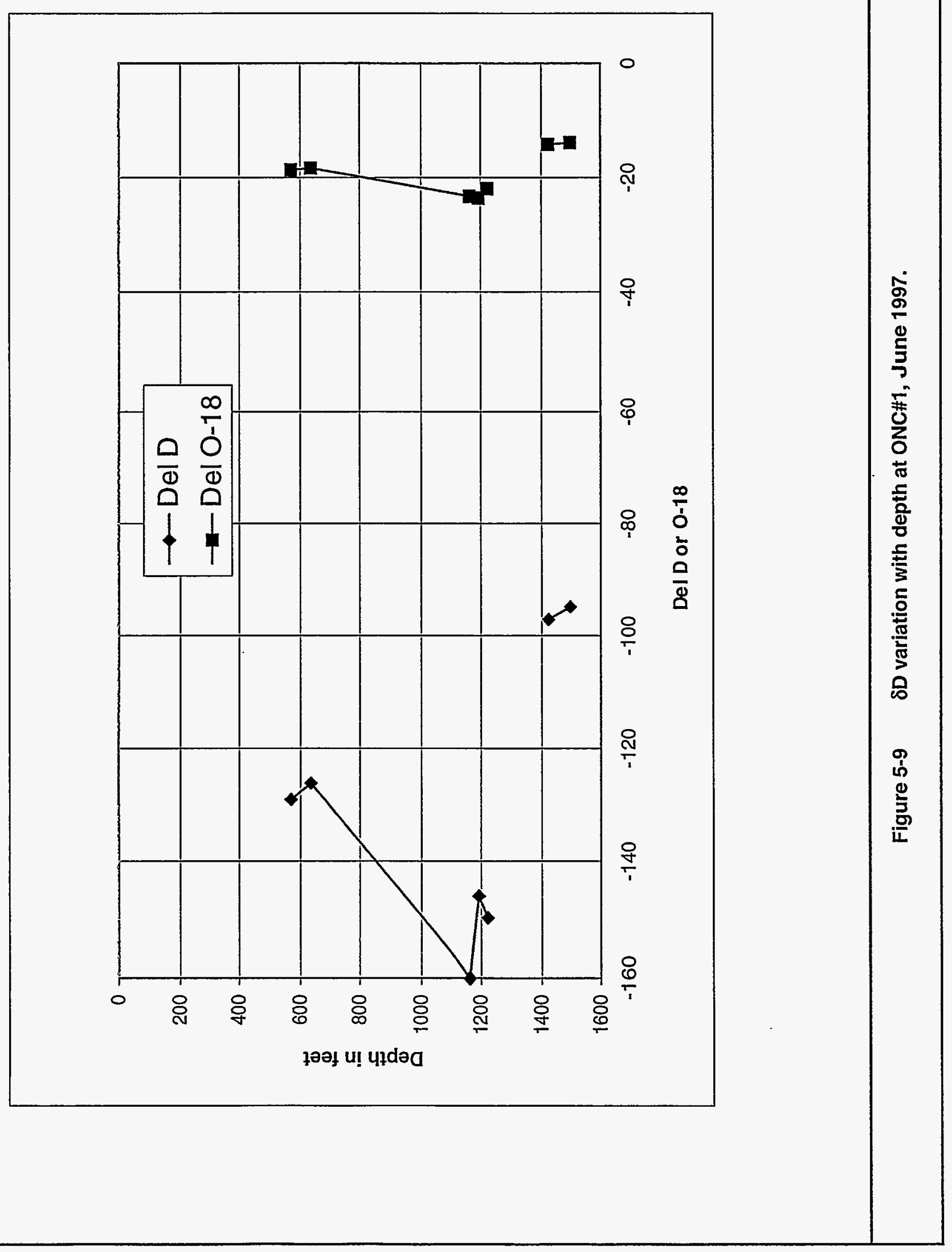




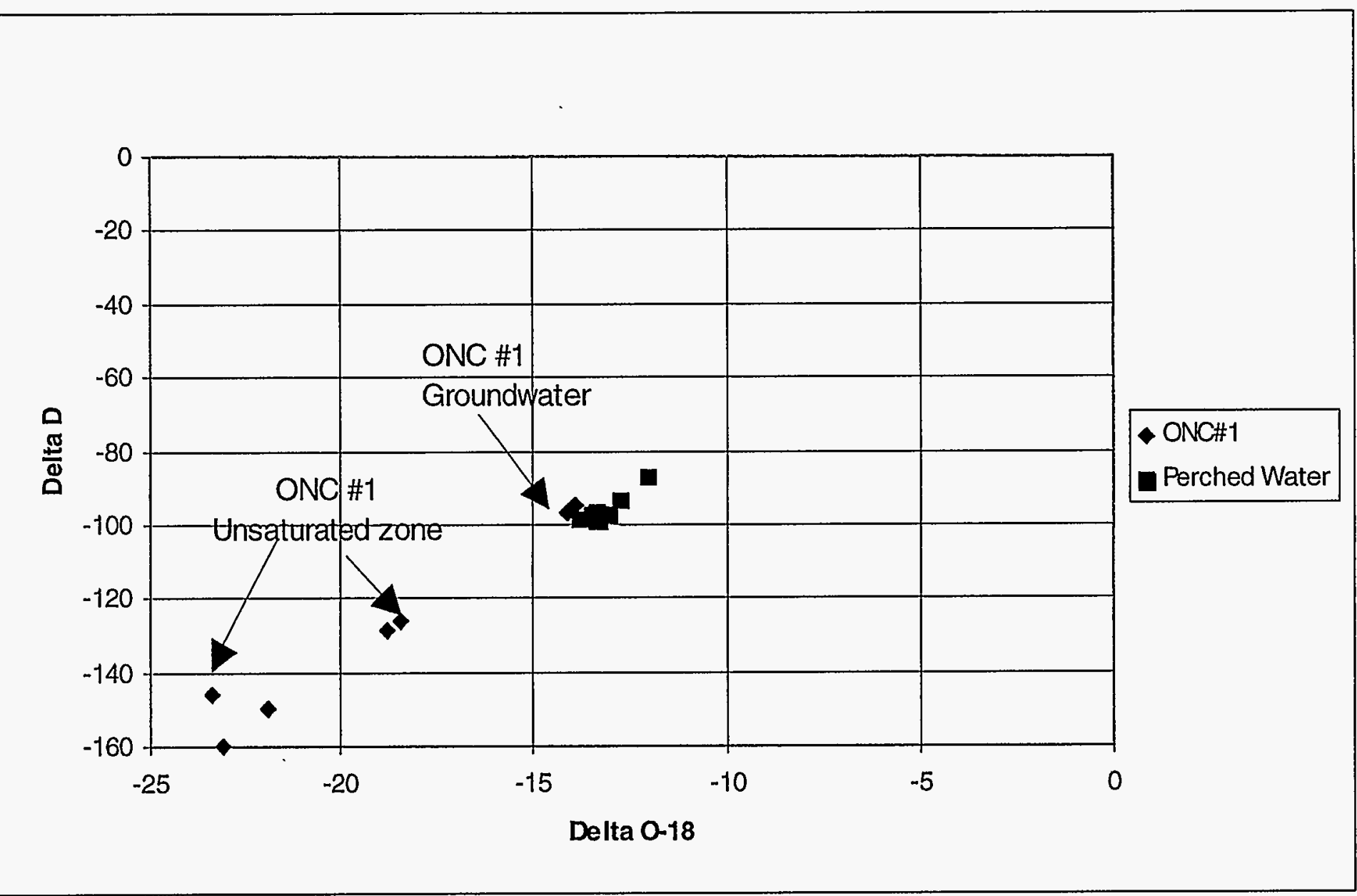

Figure 5-10 $\delta 0^{18}$ versus deuterium plot for ONC\#1, June 1997. 


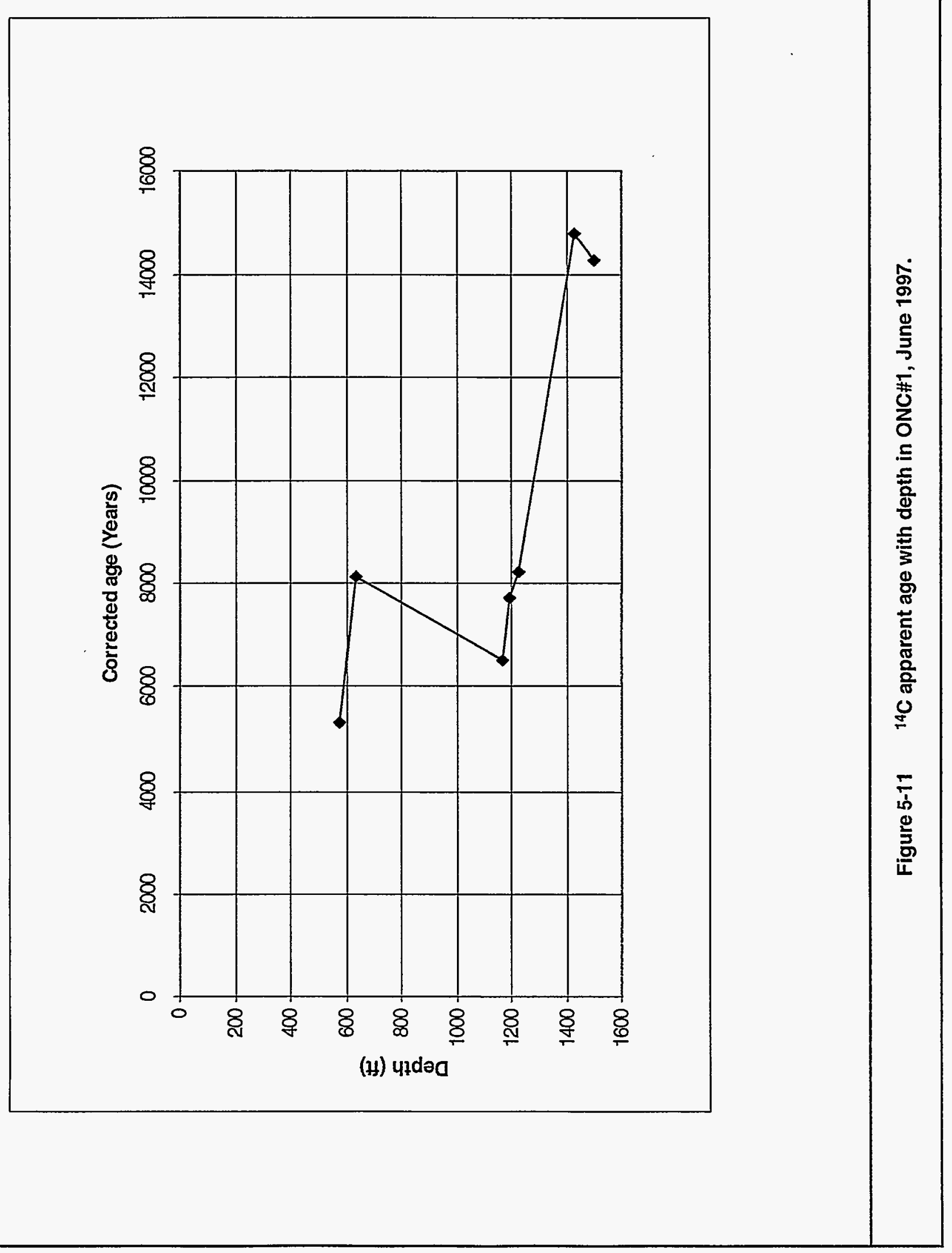


Percent Modern

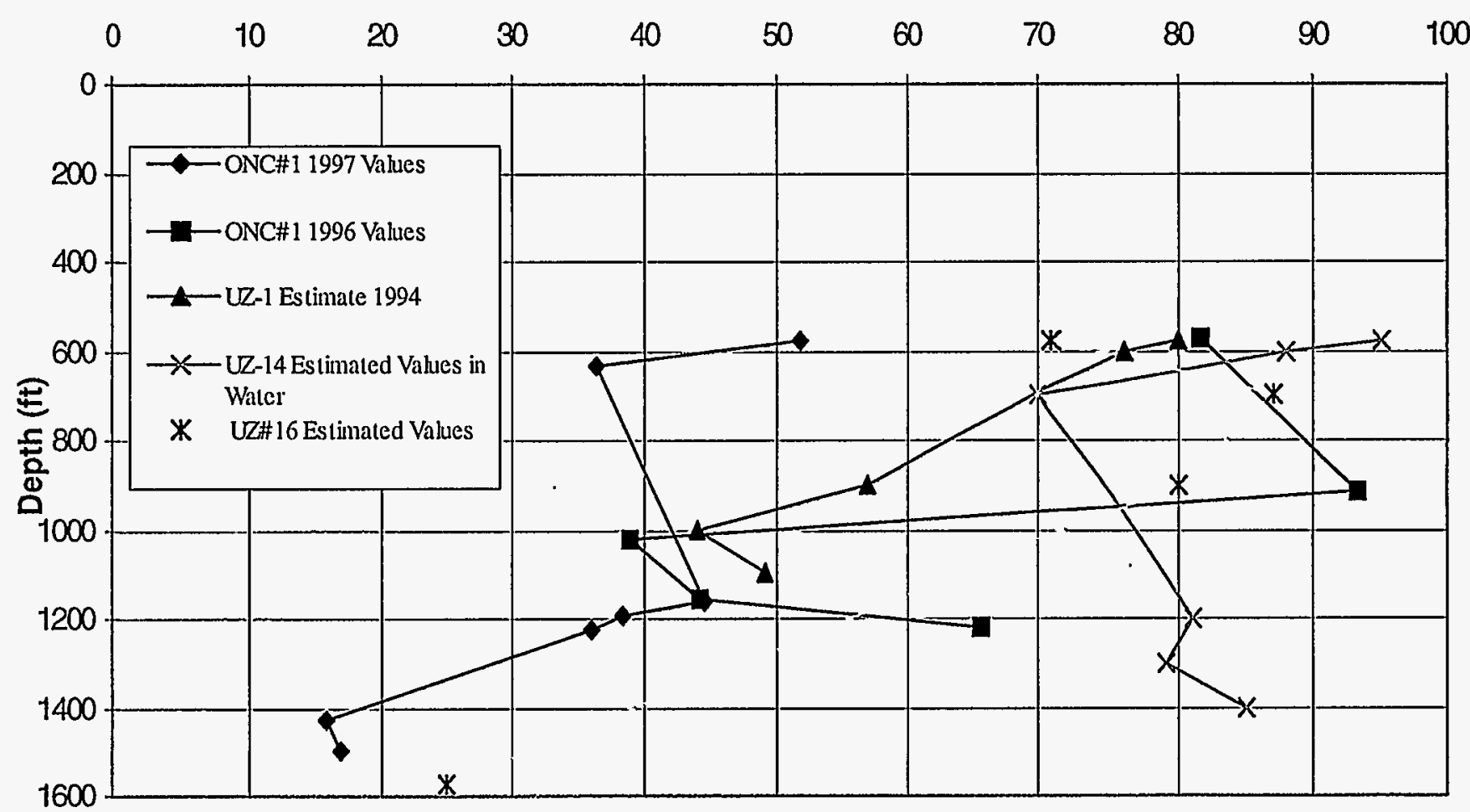

Figure 5-12 ${ }^{14} \mathrm{C}$ activity comparison ONC\#1, UZ-1, UZ-14, UZ\#16, June 1997. 


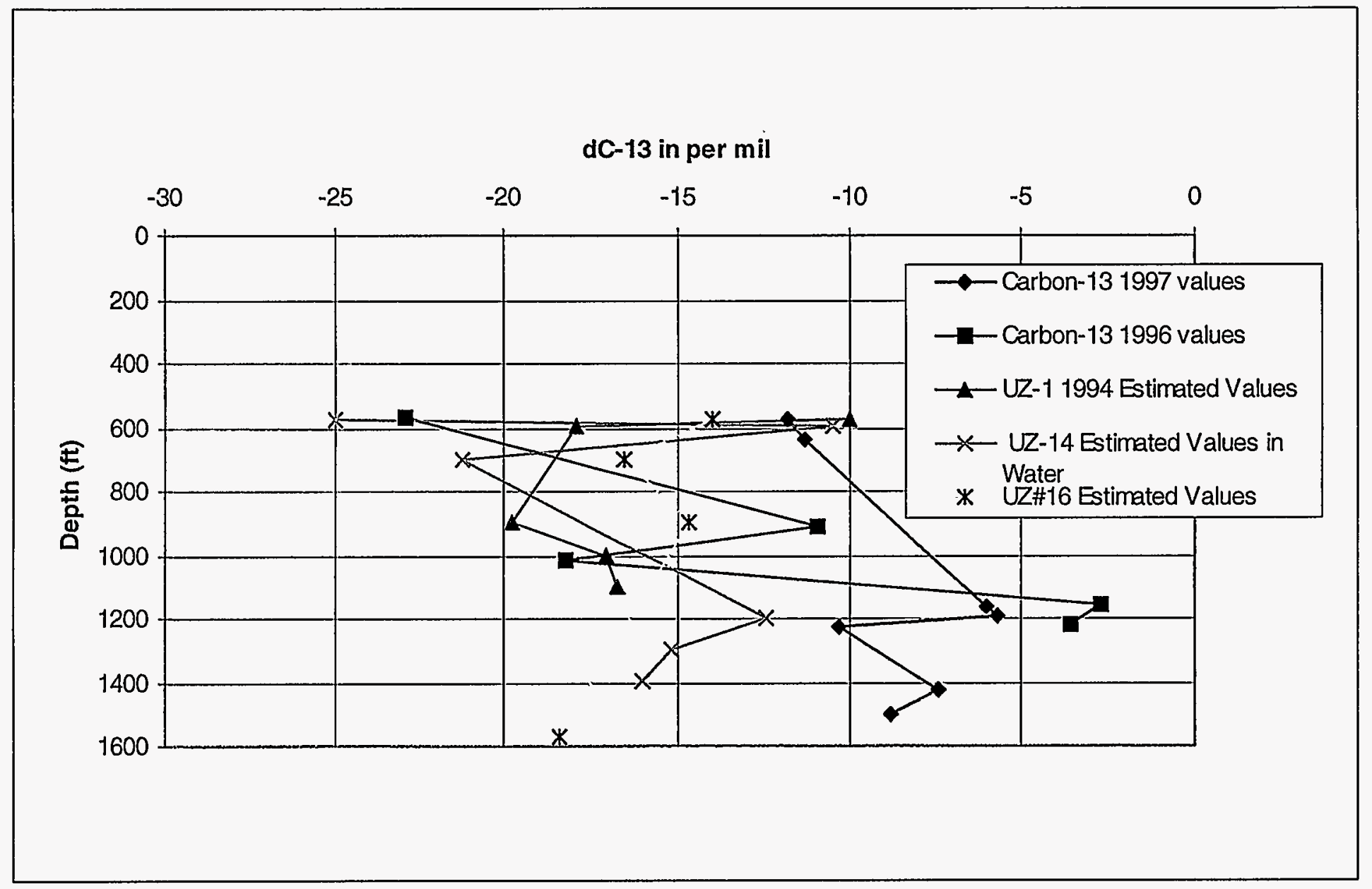

Figure 5-13 $\quad \delta^{13} \mathrm{C}$ with depth in ONC\#1, UZ-1, UZ-14, UZ\#16, June 1997. 


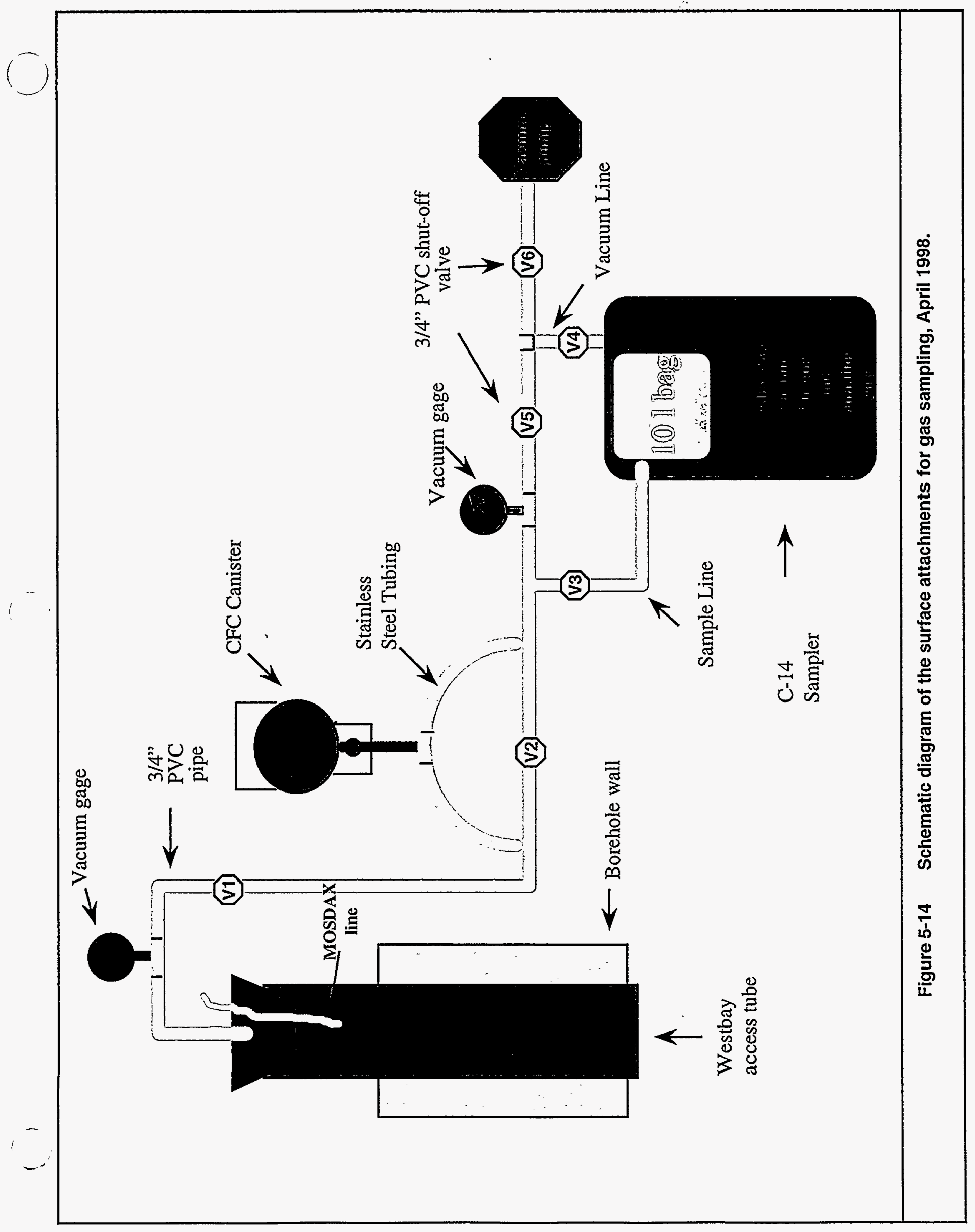




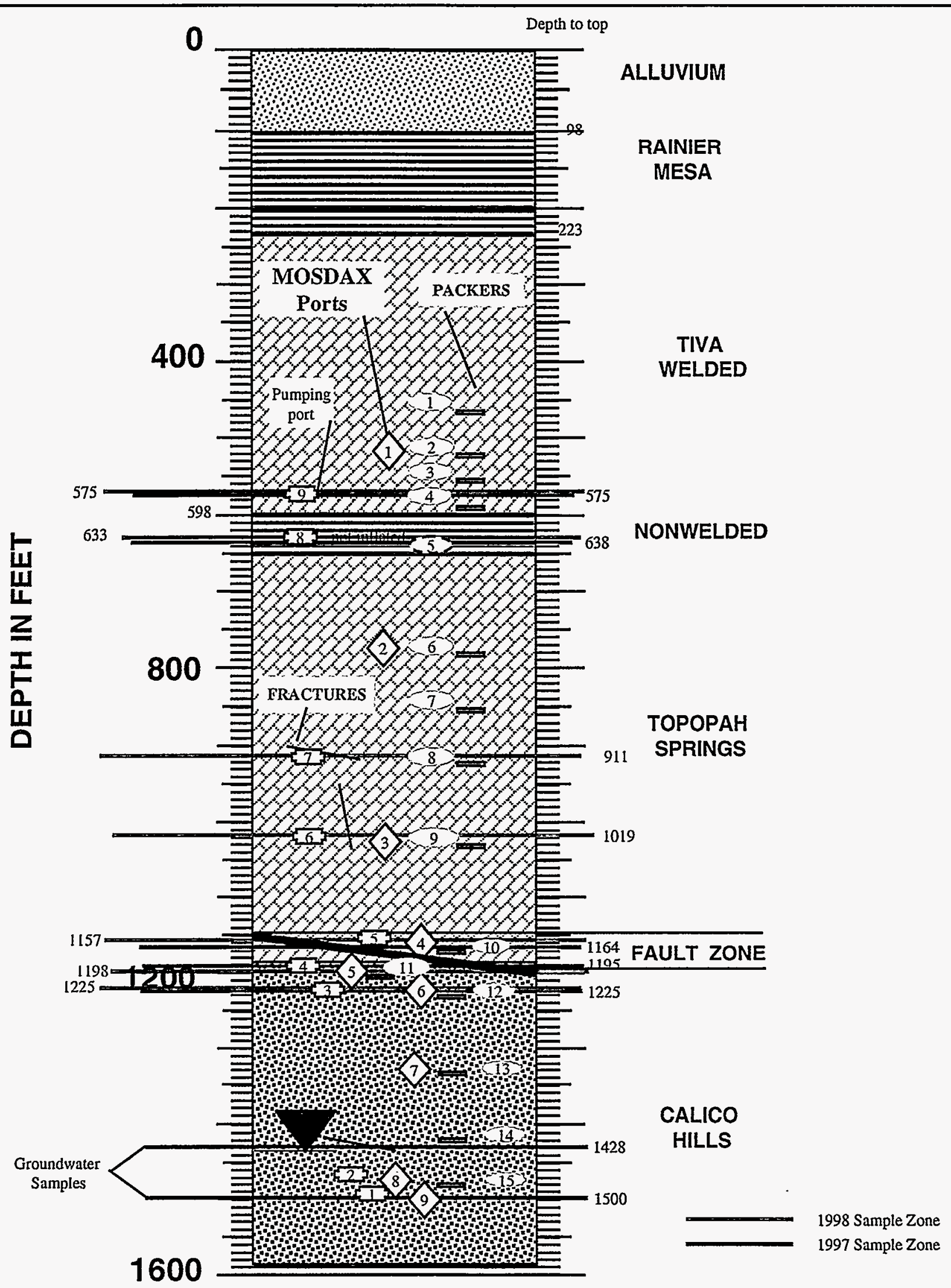

Figure 5-15 ONC\#1 stratigraphy \& instrumentation profile April 1998 gas sampling. 


\section{Photograph 5-1 VIEW AT THE ONC\#1 SAMPLING AND TESTING SETUP.}

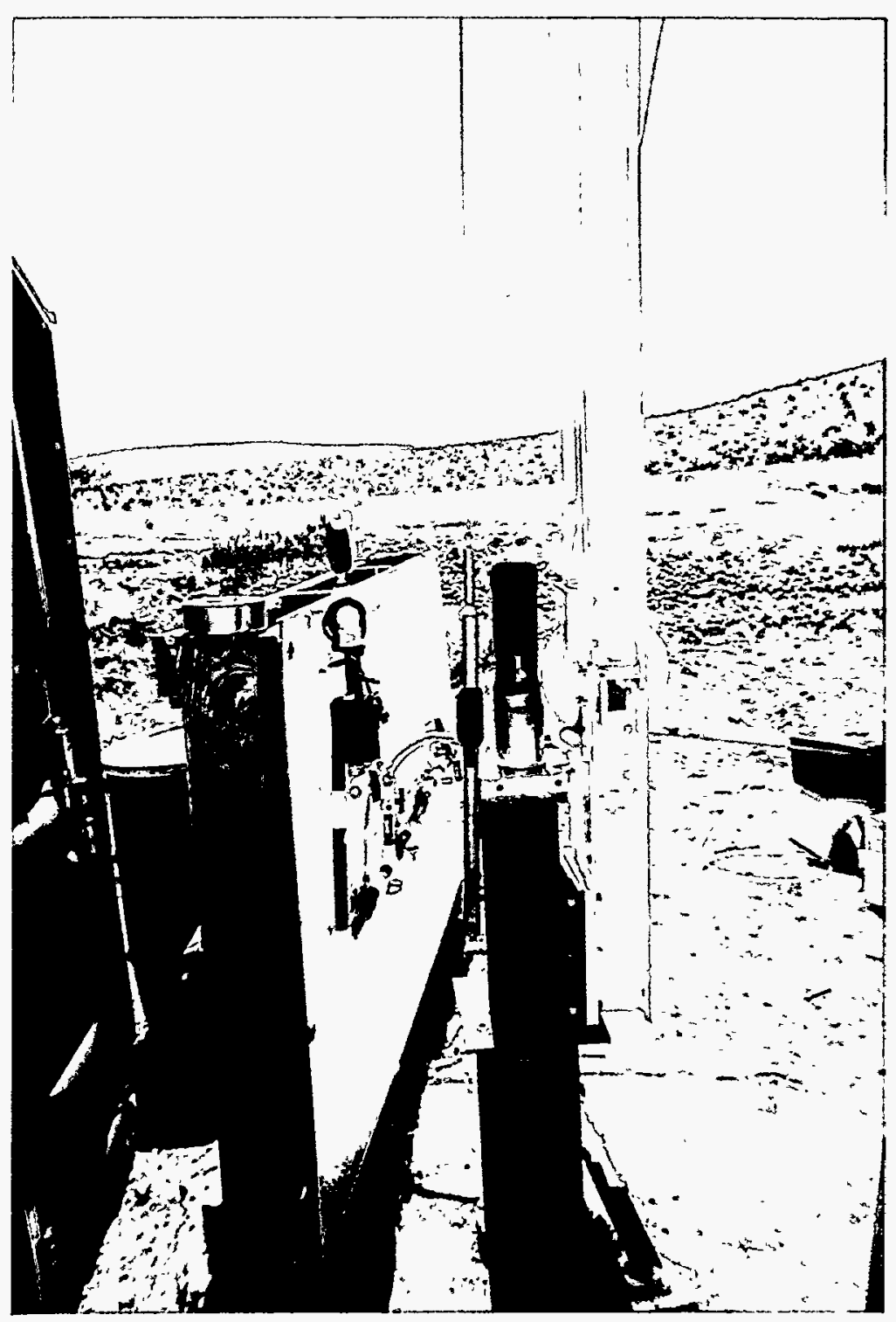




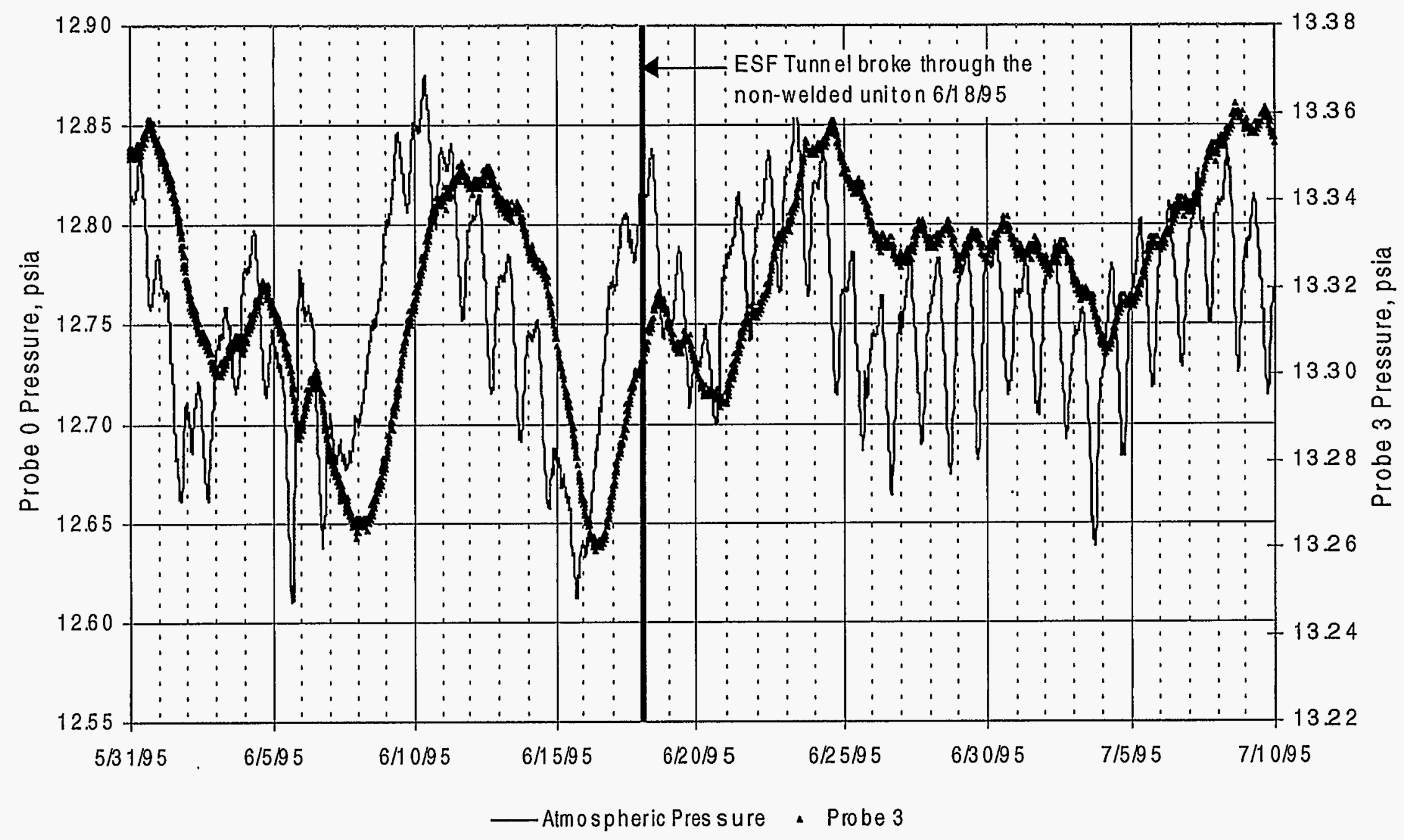

Figure 6-1 Correlation between probes 0 and 3 showing response to ESF breakthrough (ONC\#1 pressure response). 

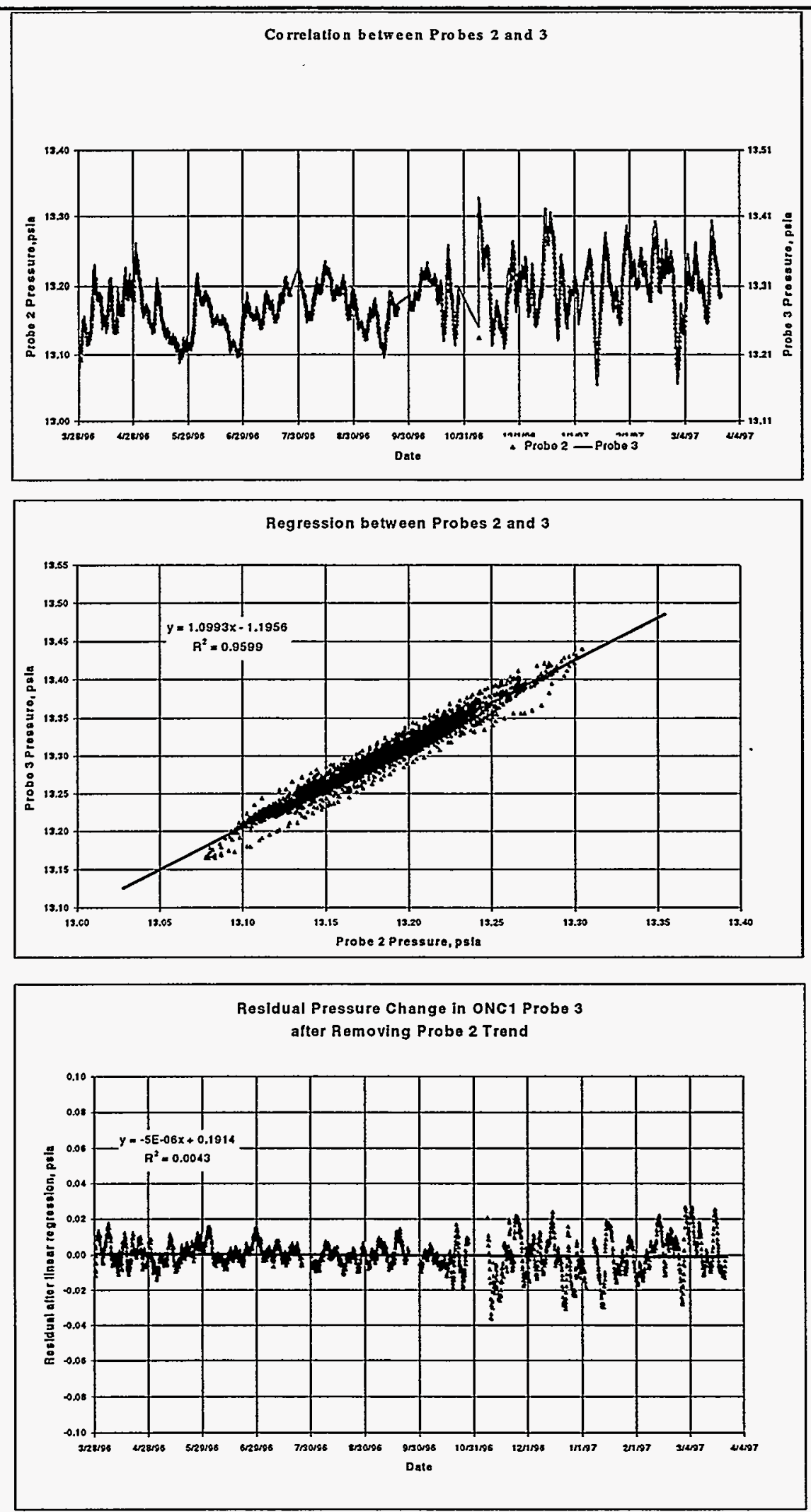

Figure 6-2 Comparison between probes 2 and 3. 


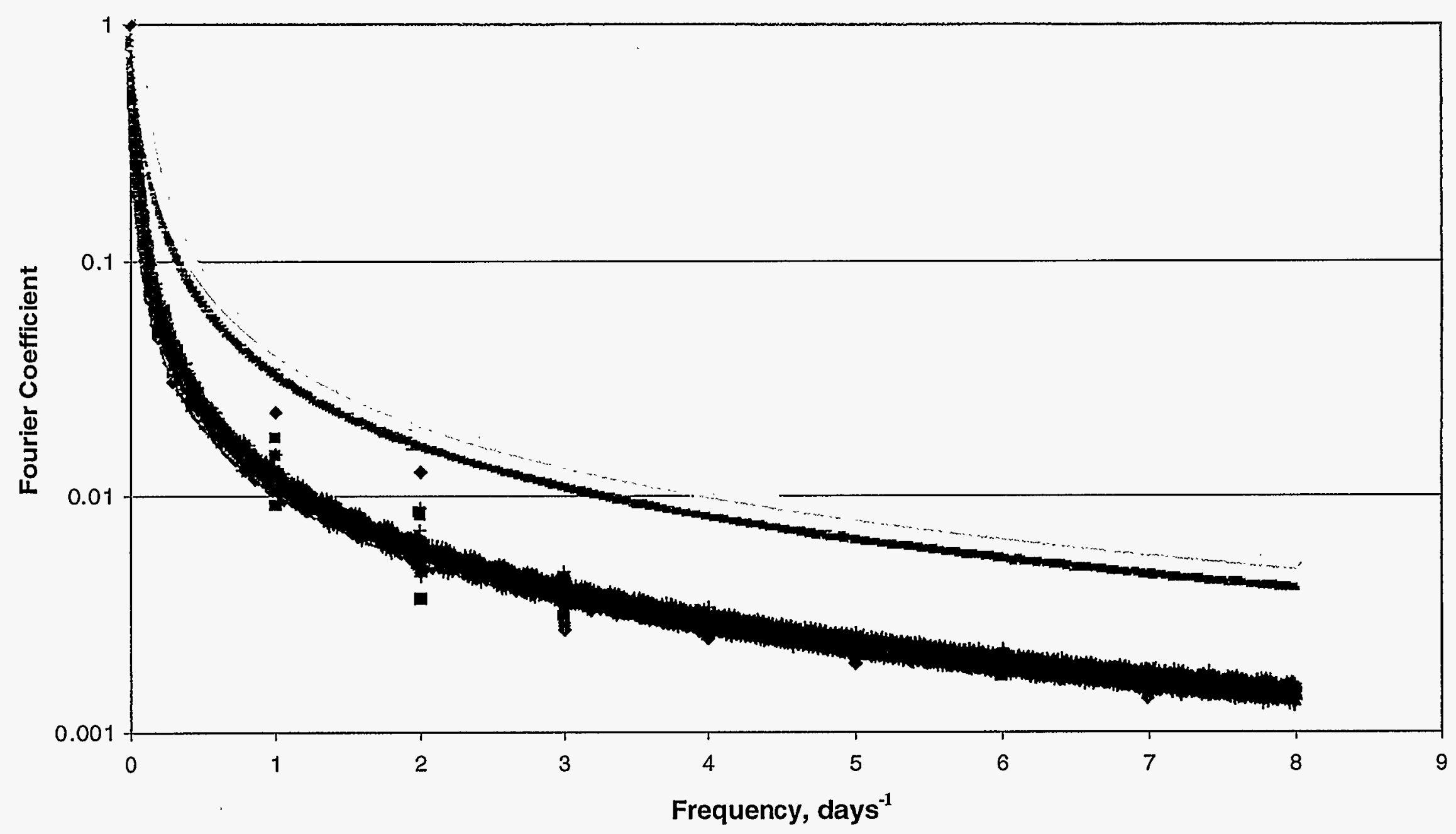

- Probe 0 Probe 1

Probe $2 \times$ Probe $3-x-$ Probe 4 Probe $5+$ Probe 6 - Probe 7 -Probe 8

Probe 9

Figure 6-3 Combined frequency response at ONC\#1. 


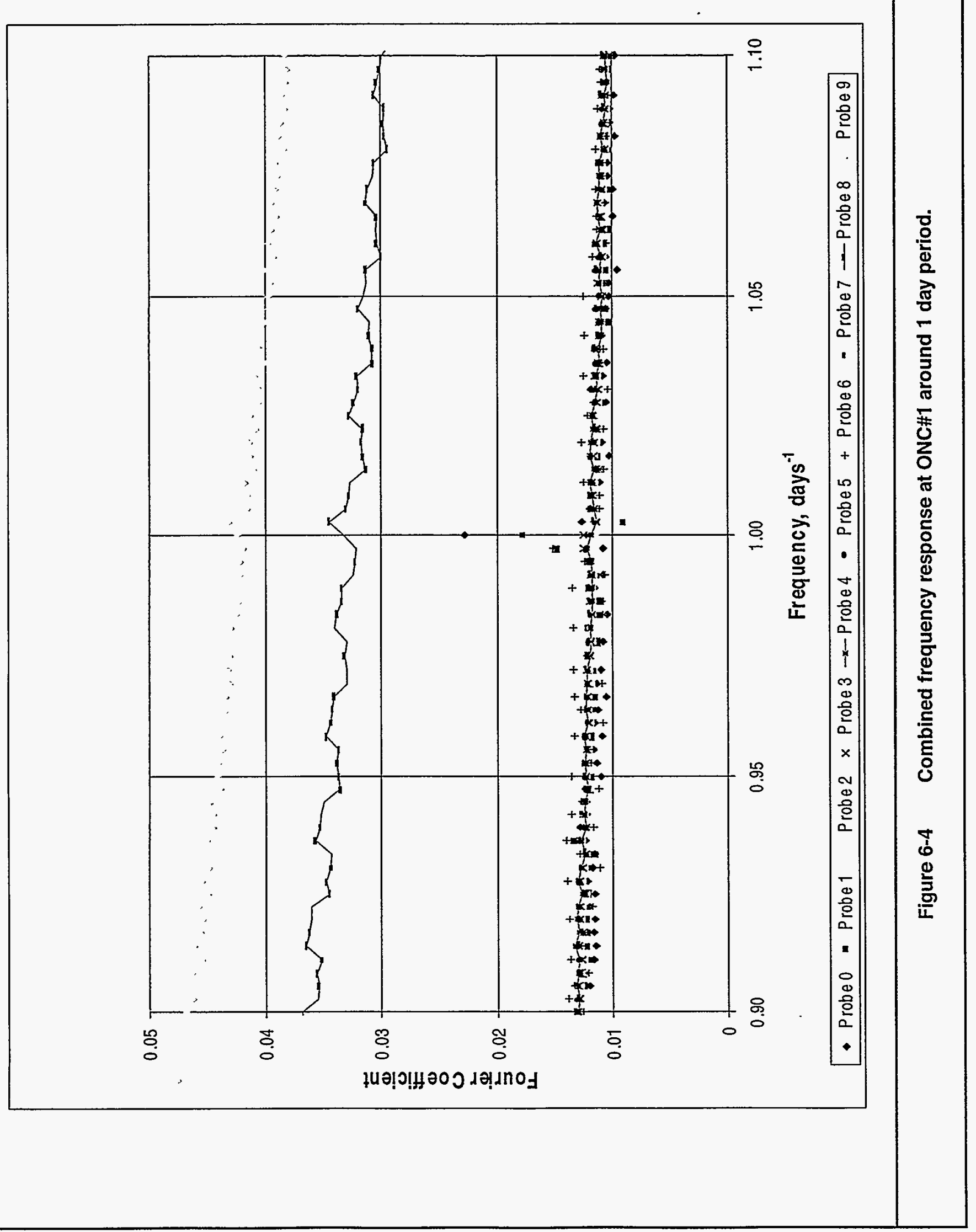




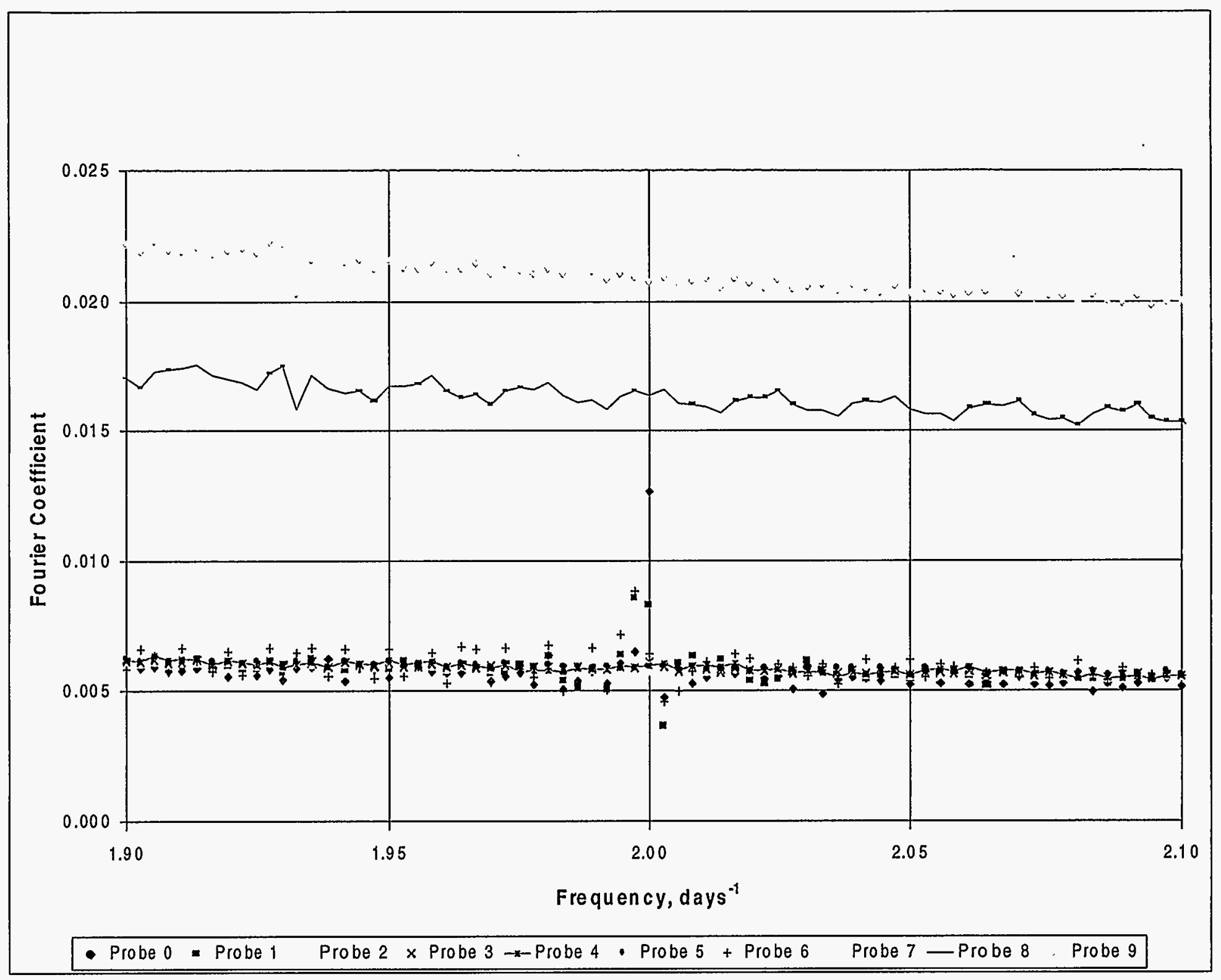

Figure 6-5 Combined frequency response at ONC\#1 around half-day period. 


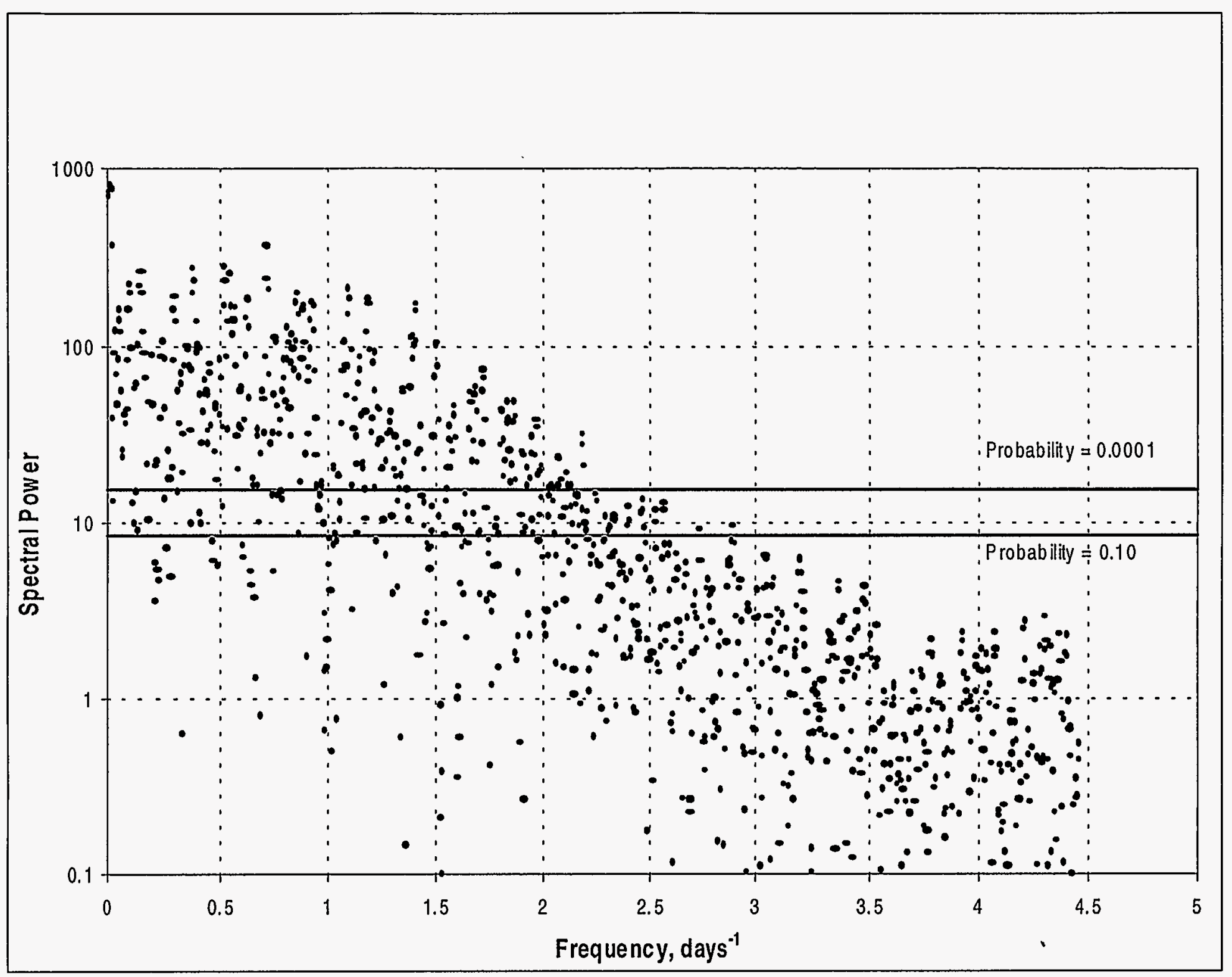

Figure 6-6 Probe 0 response from March 28, 1996 to March 24, 1997 (spectral analysis of ONC\#1 pressure). 


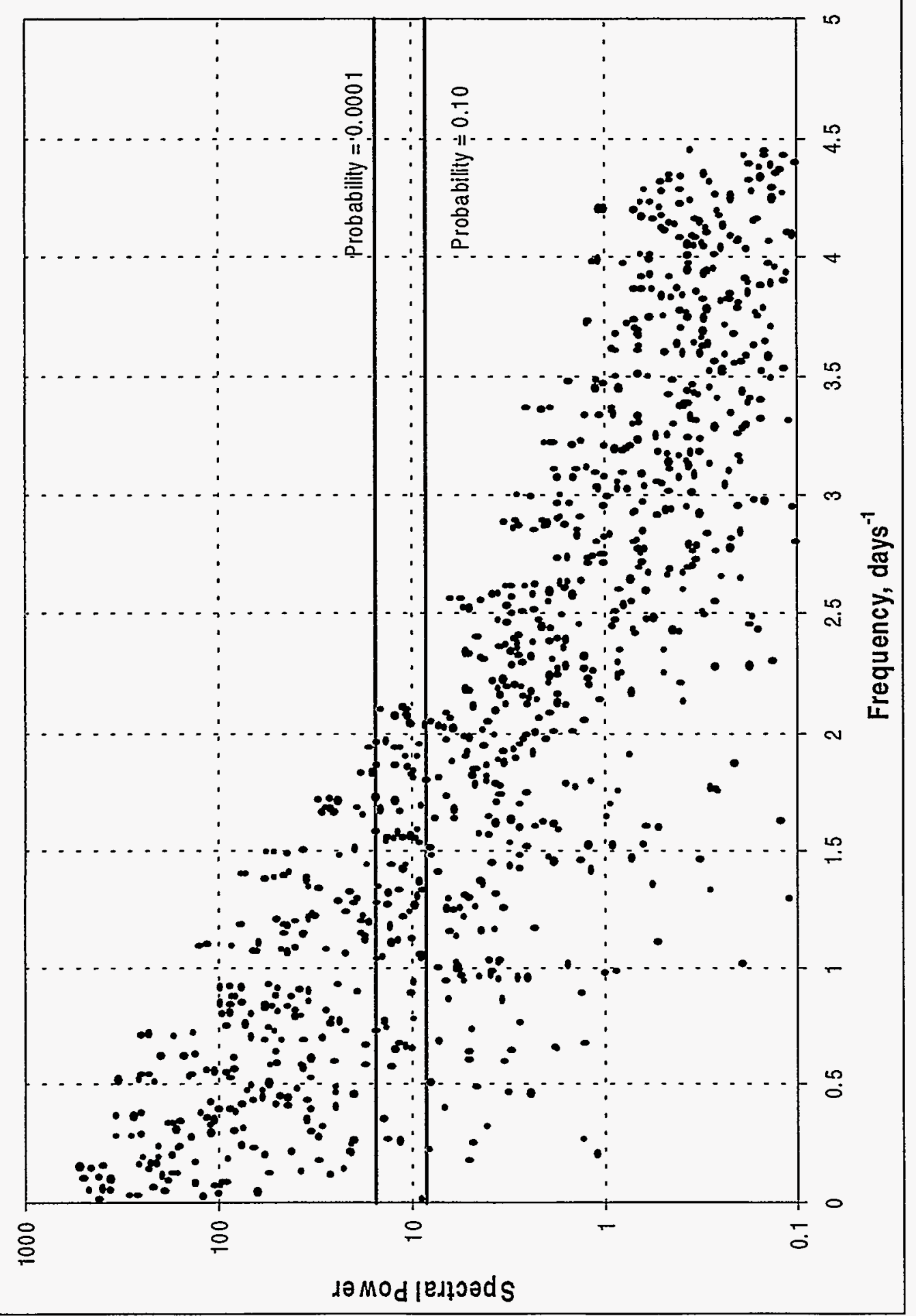

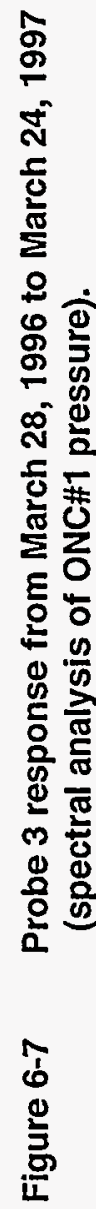




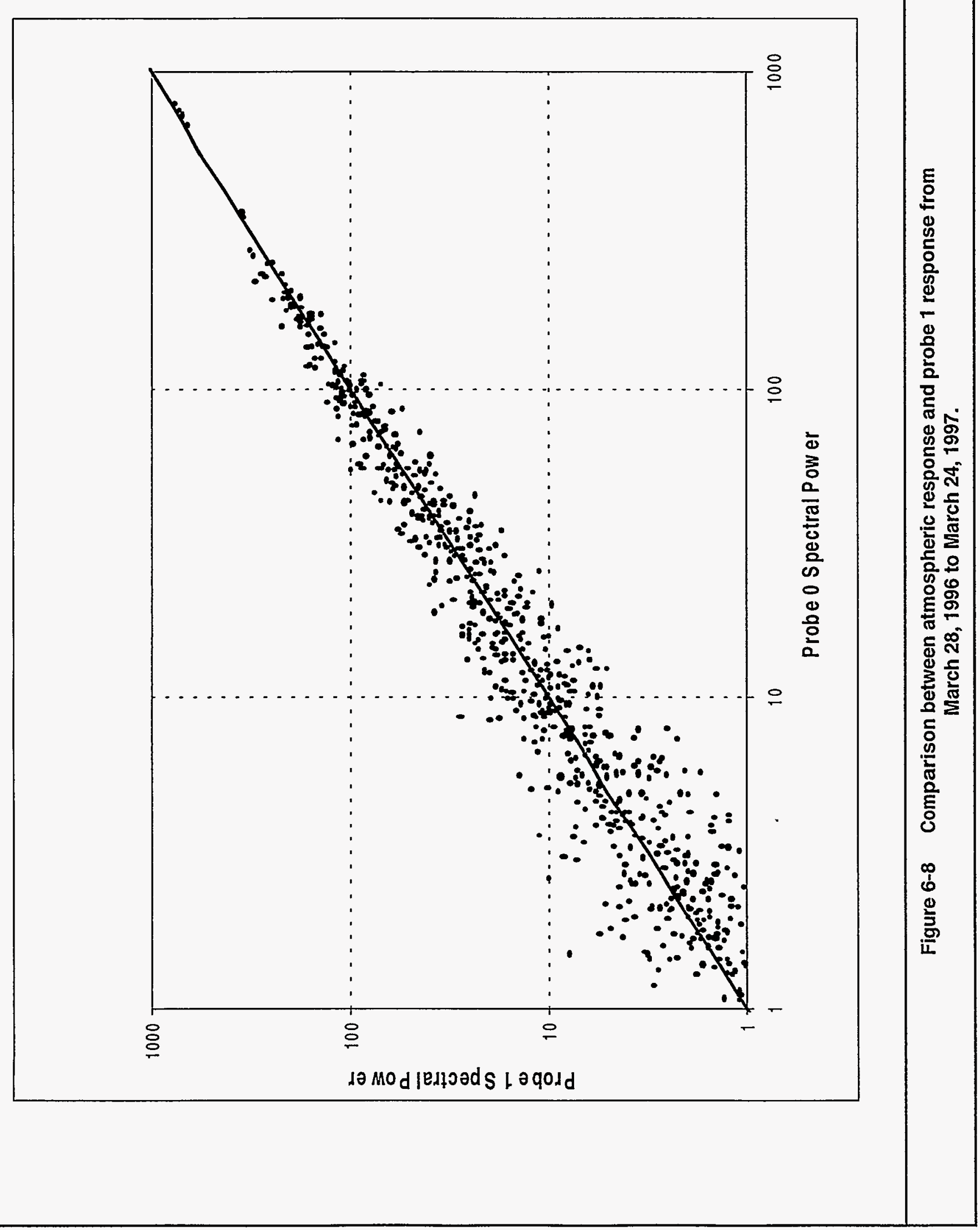




\section{Test Data and Results}

\begin{tabular}{||l|c|c|}
\hline Zone Height & $180 \mathrm{ft}$ & $55 \mathrm{~m}$ \\
Eq. Spherical Wellbore Radius & $15.3 \mathrm{ft}$ & $4.7 \mathrm{~m}$ \\
Production Rate & $0.864 \mathrm{Mcfd}$ & $16.1 \mathrm{slpm}$ \\
Production Flow Time & $18 \mathrm{hrs}$ & $18 \mathrm{hrs}$ \\
Total Pressure Change & $0.75 \mathrm{psi}$ & $5.18 \mathrm{kPa}$ \\
Permeability for S=0 & $19 \mathrm{md}$ & $1.88 \mathrm{E}-14 \mathrm{~m}^{2}$ \\
Permeability (Spherical) & $221 \mathrm{md}$ & $2.18 \mathrm{E}-13 \mathrm{~m}^{2}$ \\
Skin Factor & 10.6 & 10.6 \\
\hline Extrapolated Pressure & $13.073 \mathrm{psi}$ & $90.14 \mathrm{kPa}$ \\
Slope of Line & $-0.00868 \mathrm{psi} / \mathrm{hr}^{1 / 2}$ & $-0.05985 \mathrm{kPa} / \mathrm{hr}^{1 / 2}$ \\
Standard Error & $0.00057 \mathrm{psi} / \mathrm{hr}^{1 / 2}$ & $0.00396 \mathrm{kPa} / \mathrm{hr}^{1 / 2}$ \\
Correlation Coefficient, $\mathrm{r}^{2}$ & 0.9745 & 0.9745 \\
Number of Observations & 30 & 30 \\
\hline
\end{tabular}

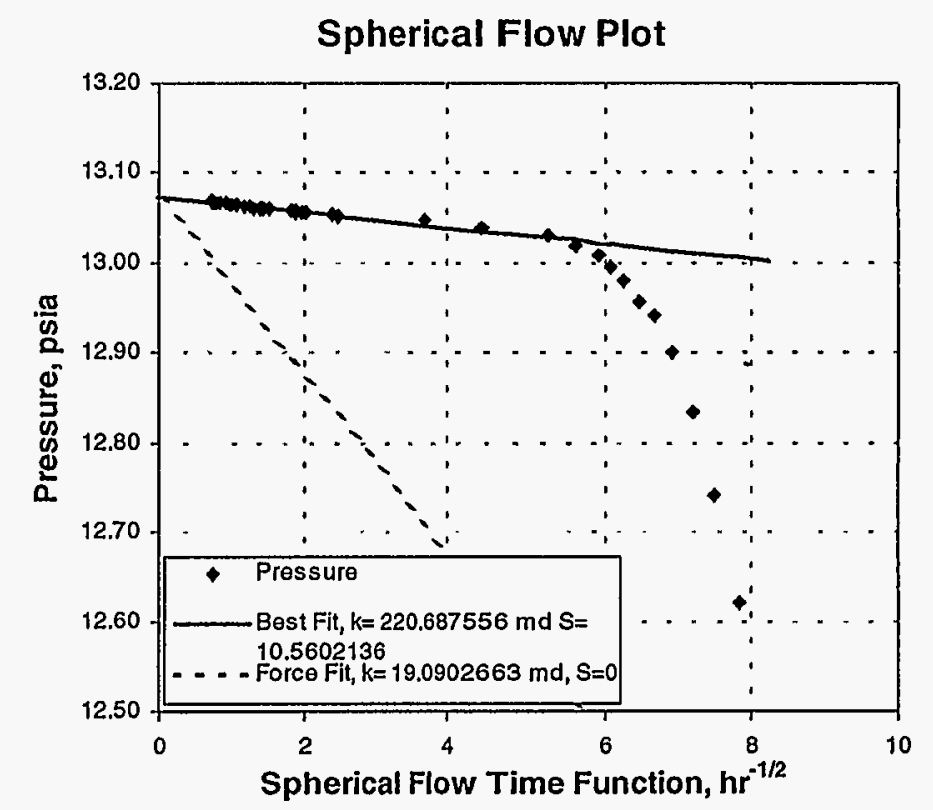

Pressure Response

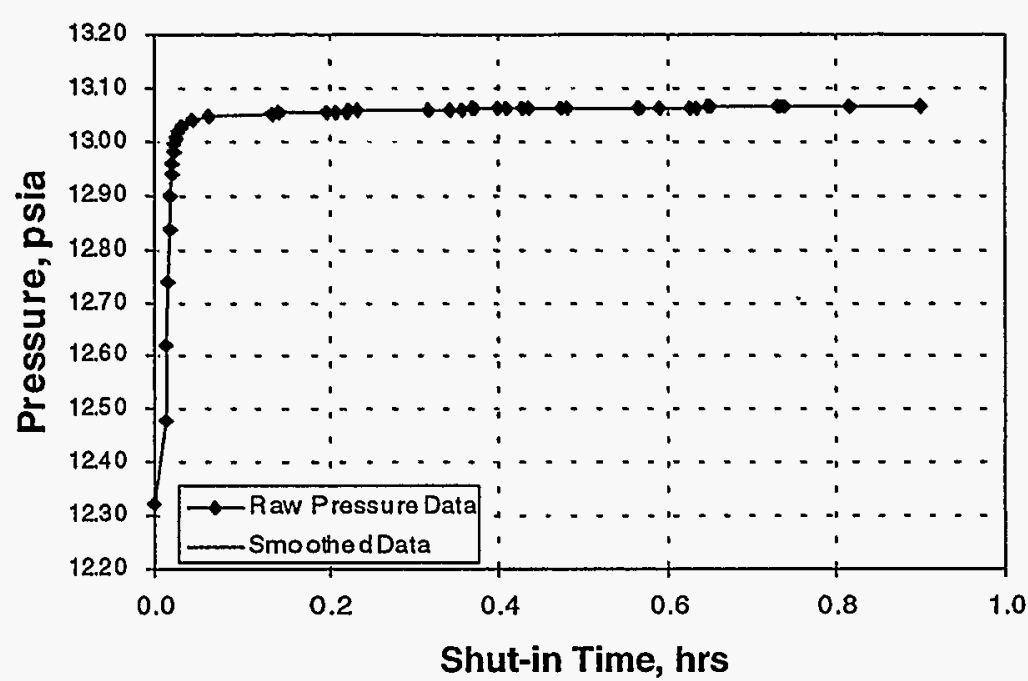

Shut-in Time, hrs

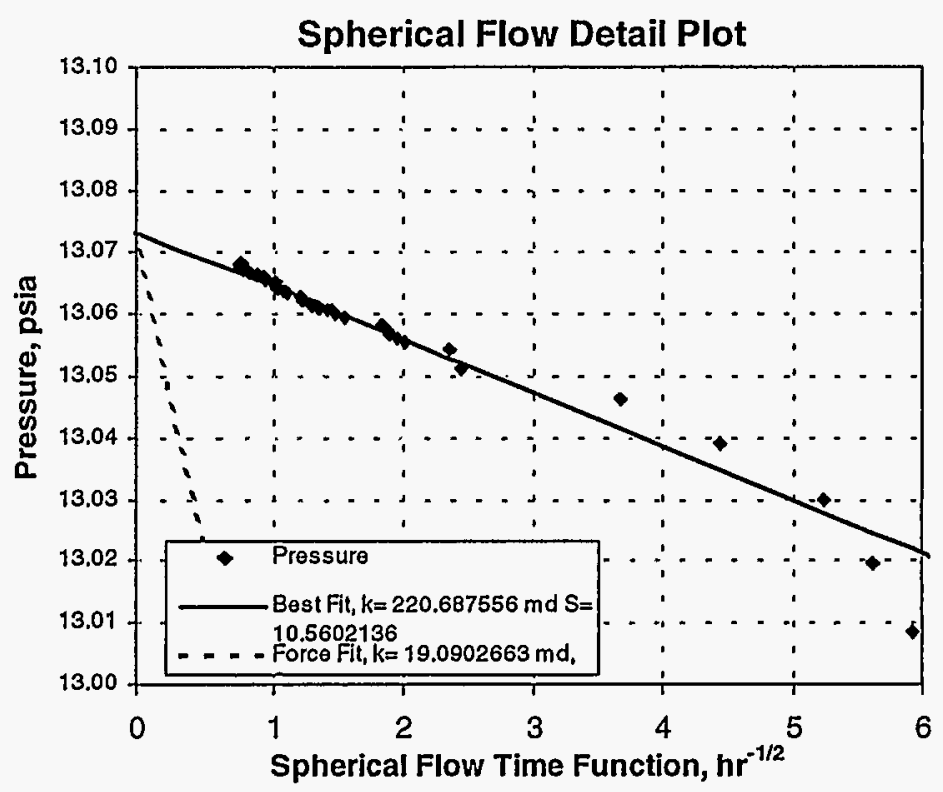

Figure 6-9 ONC\#1 vacuum test \#5. 

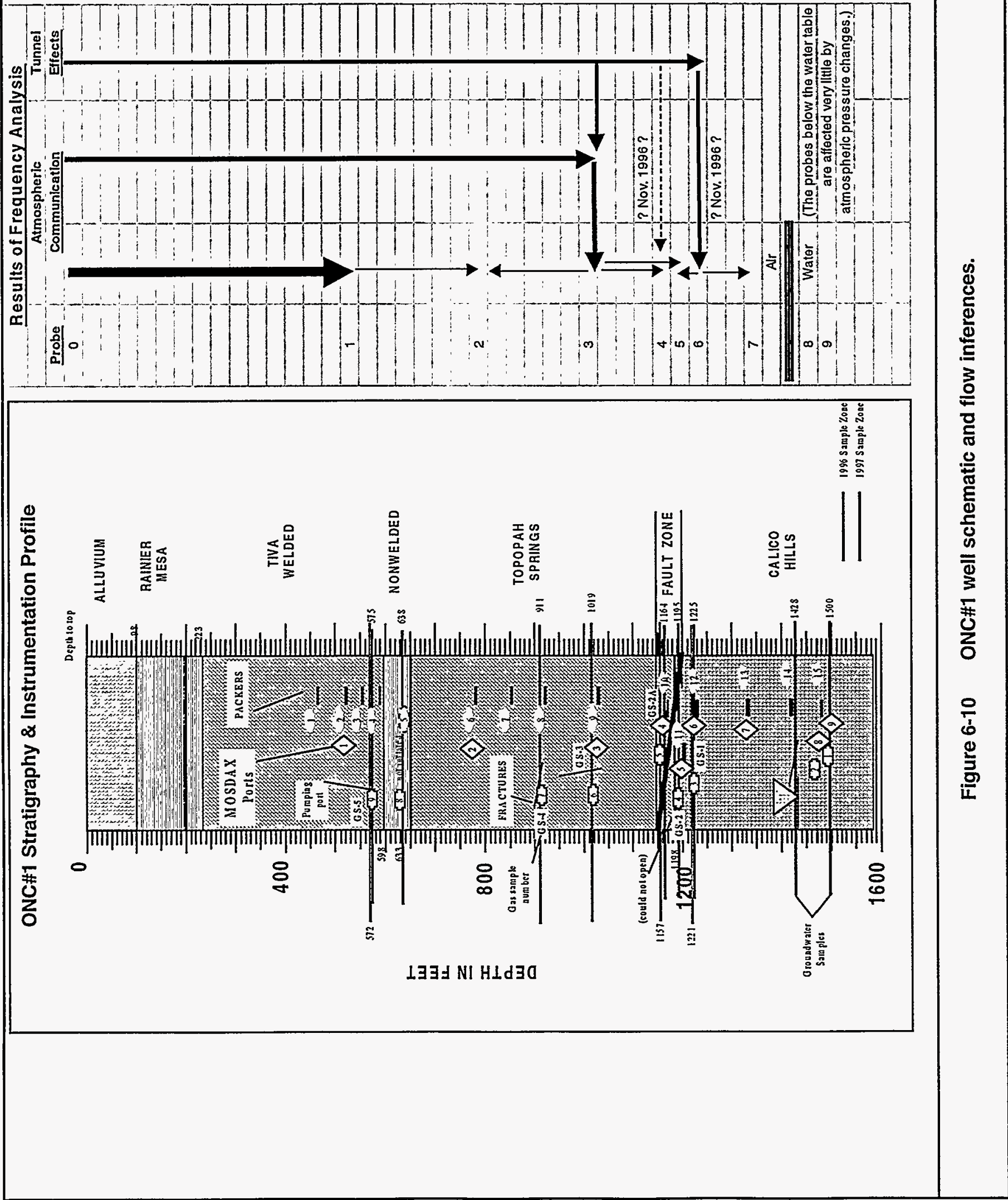


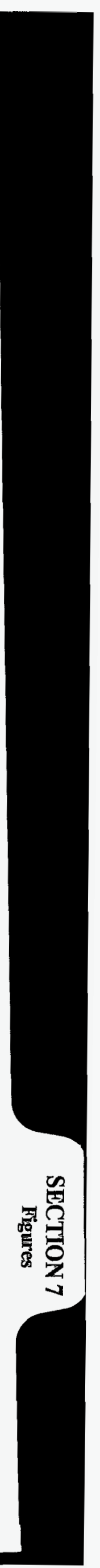




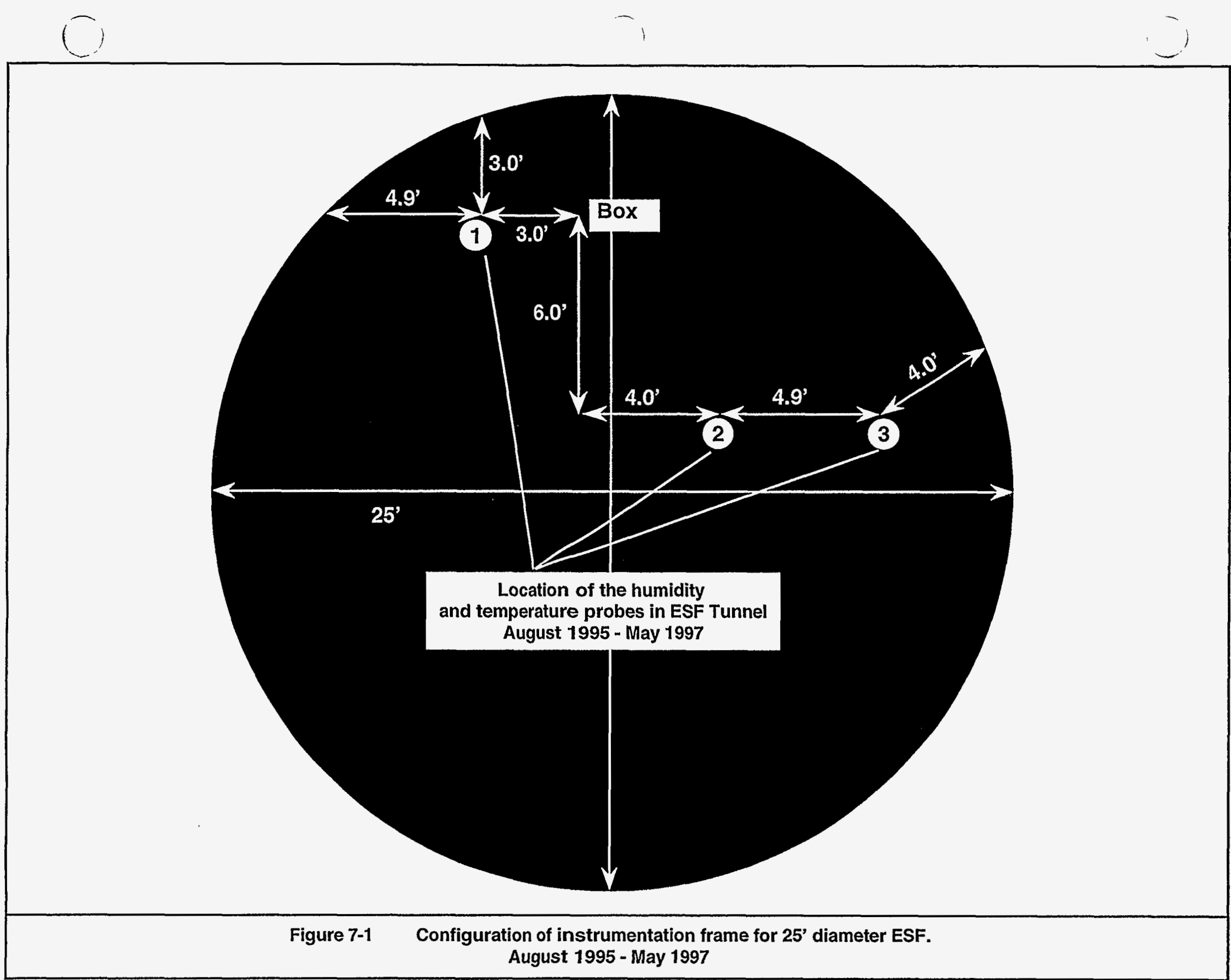




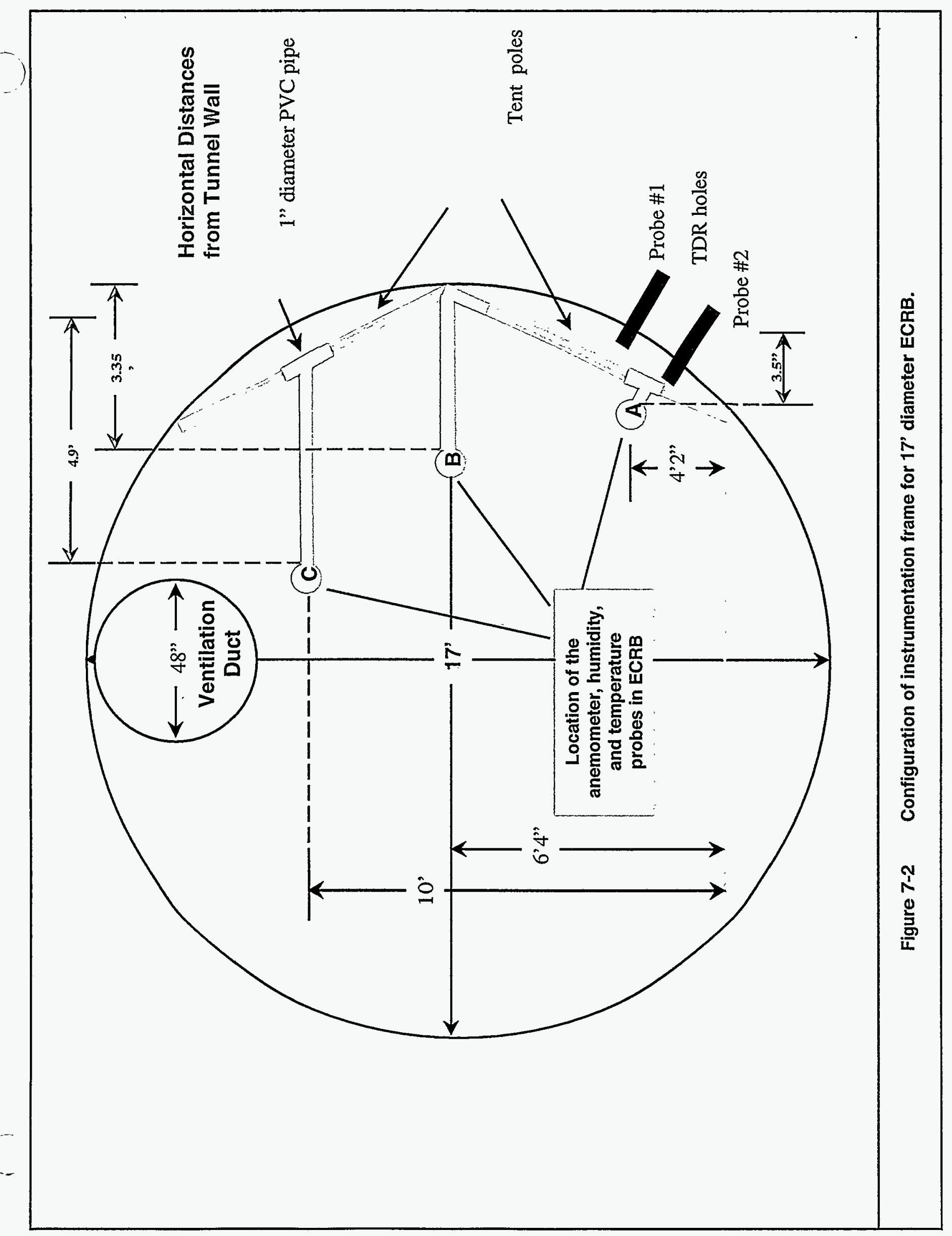




\section{Photograph 7-1 VIEW OF THE CLIMATOLOGICAL MONITORING STATION SETUP IN THE ECRB.}

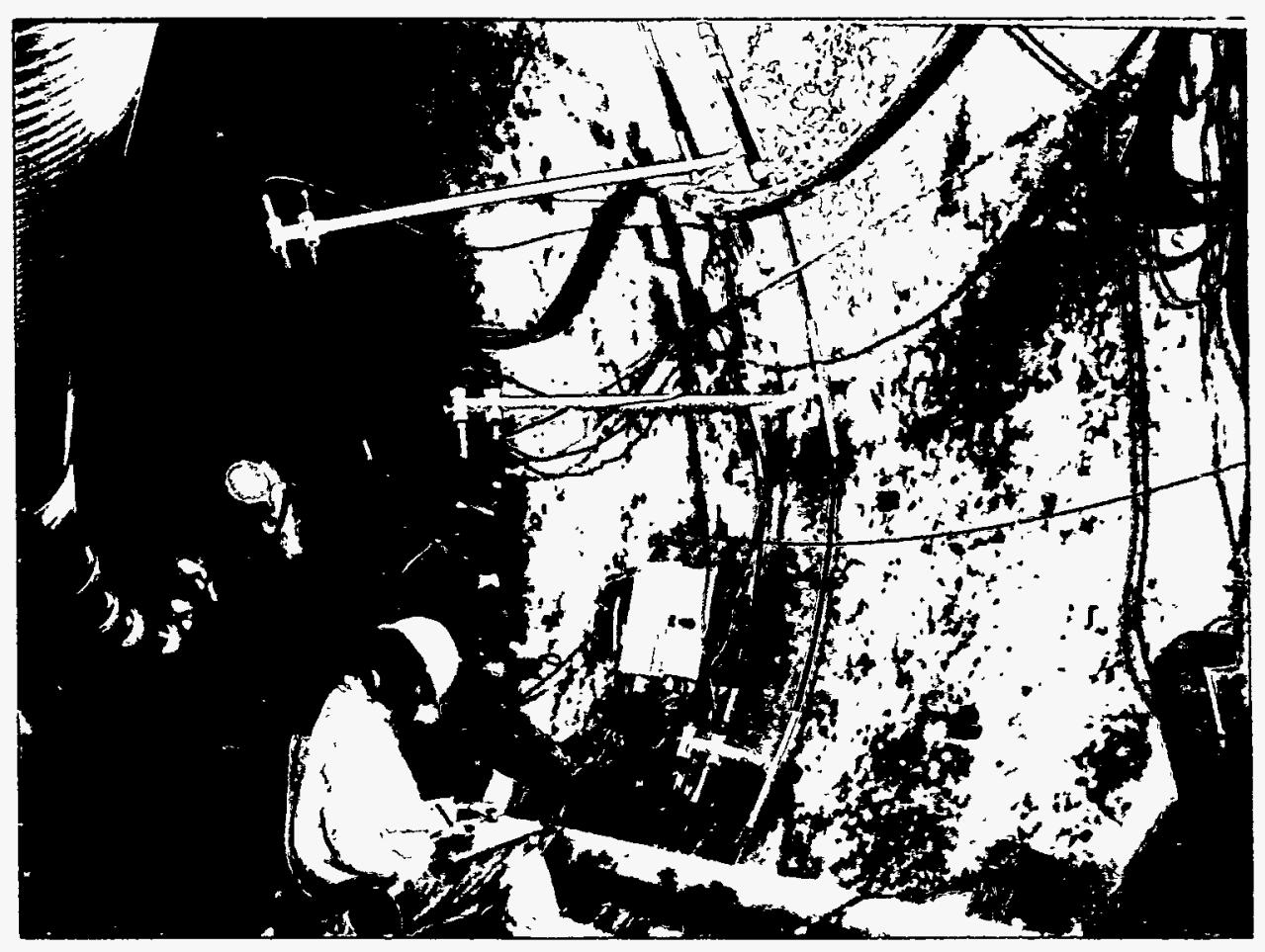




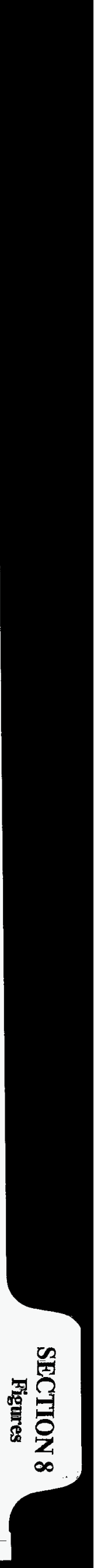




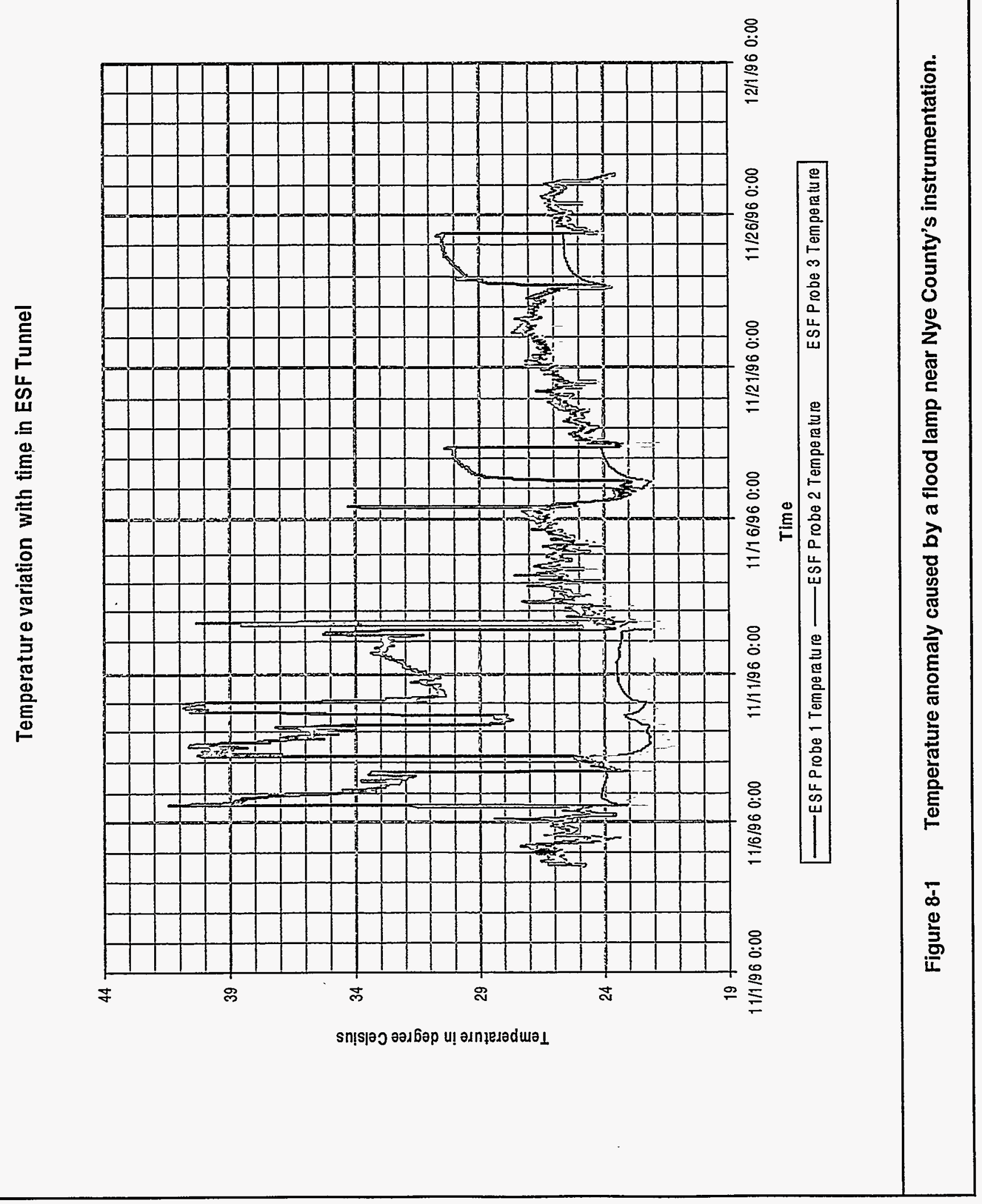




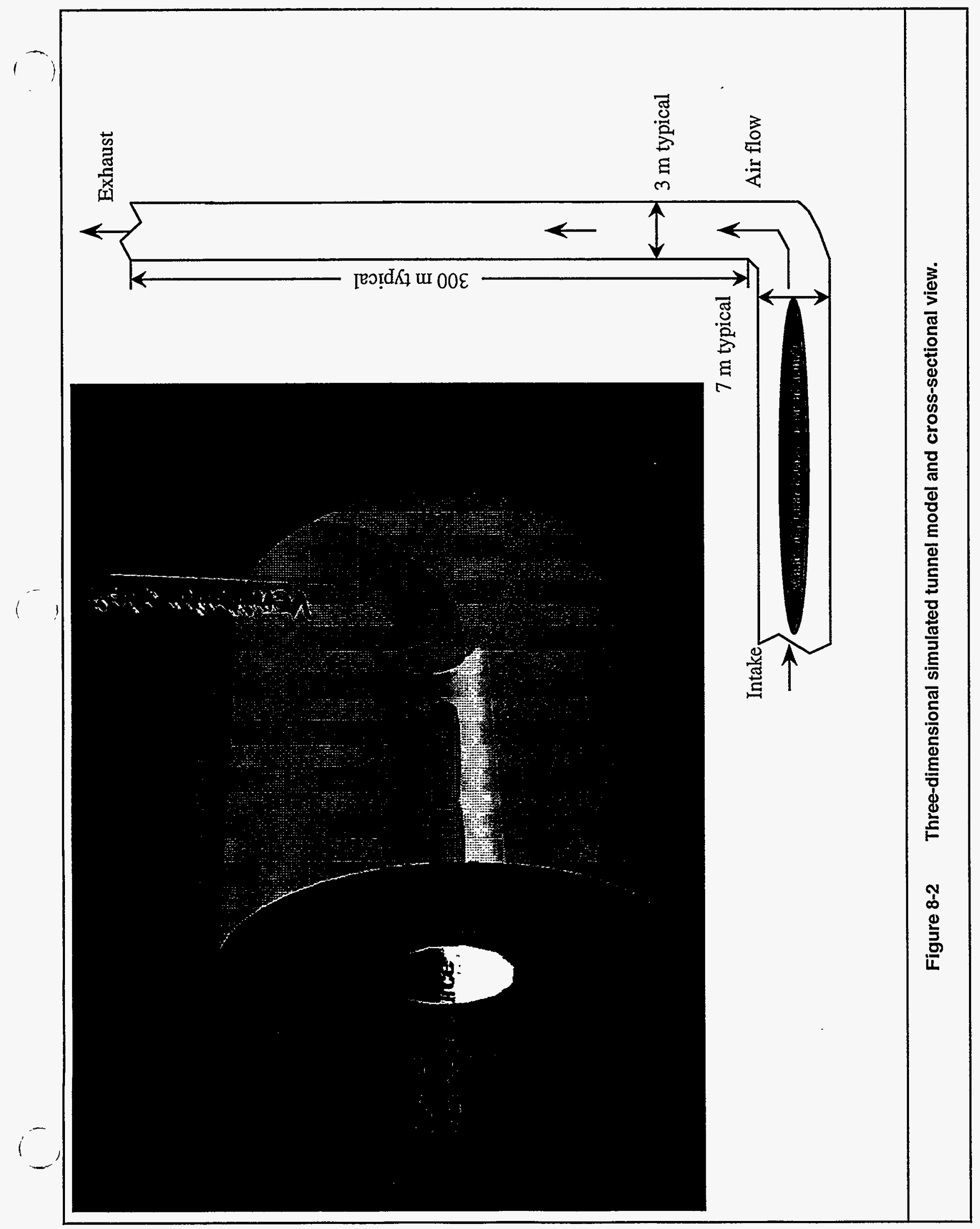




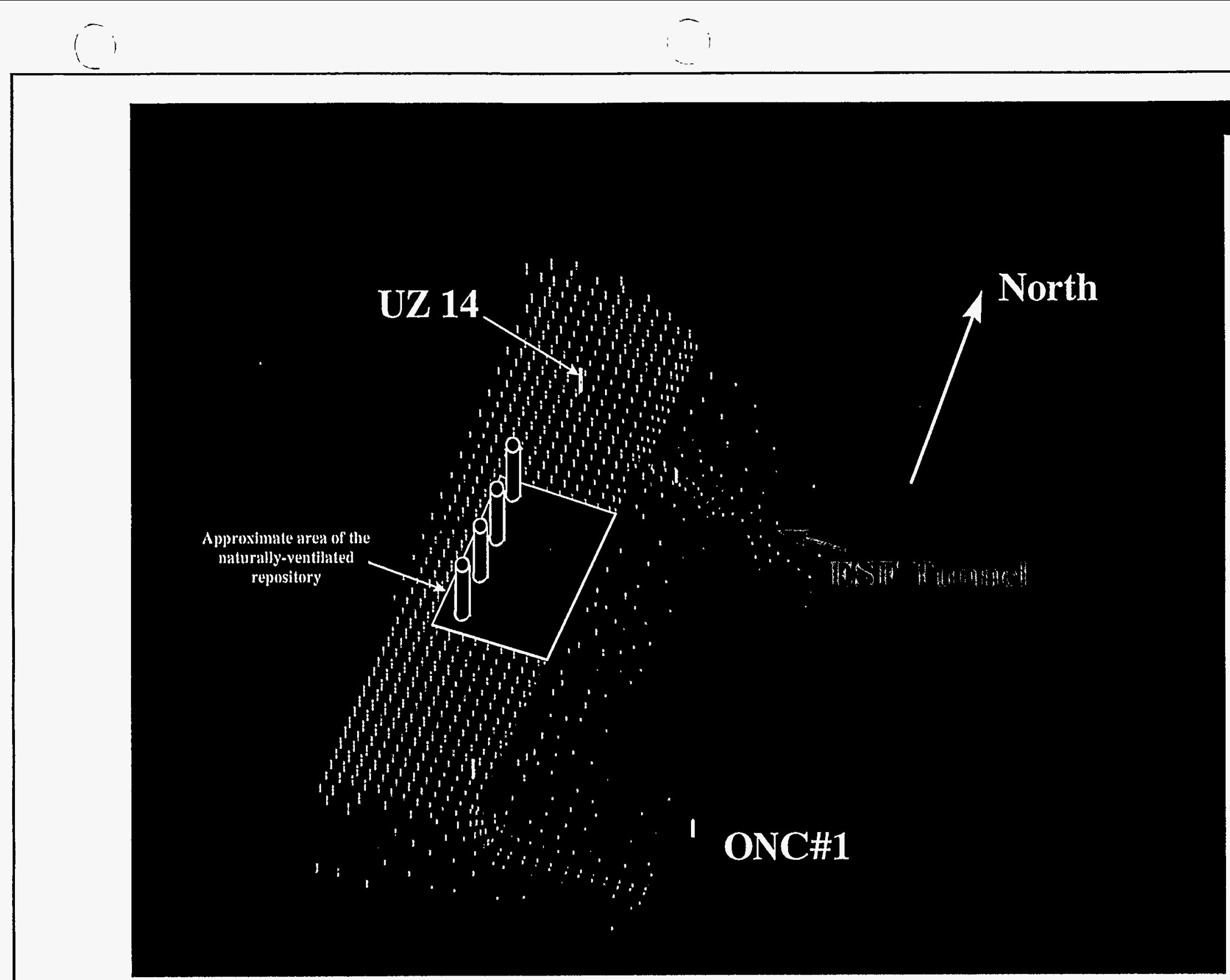




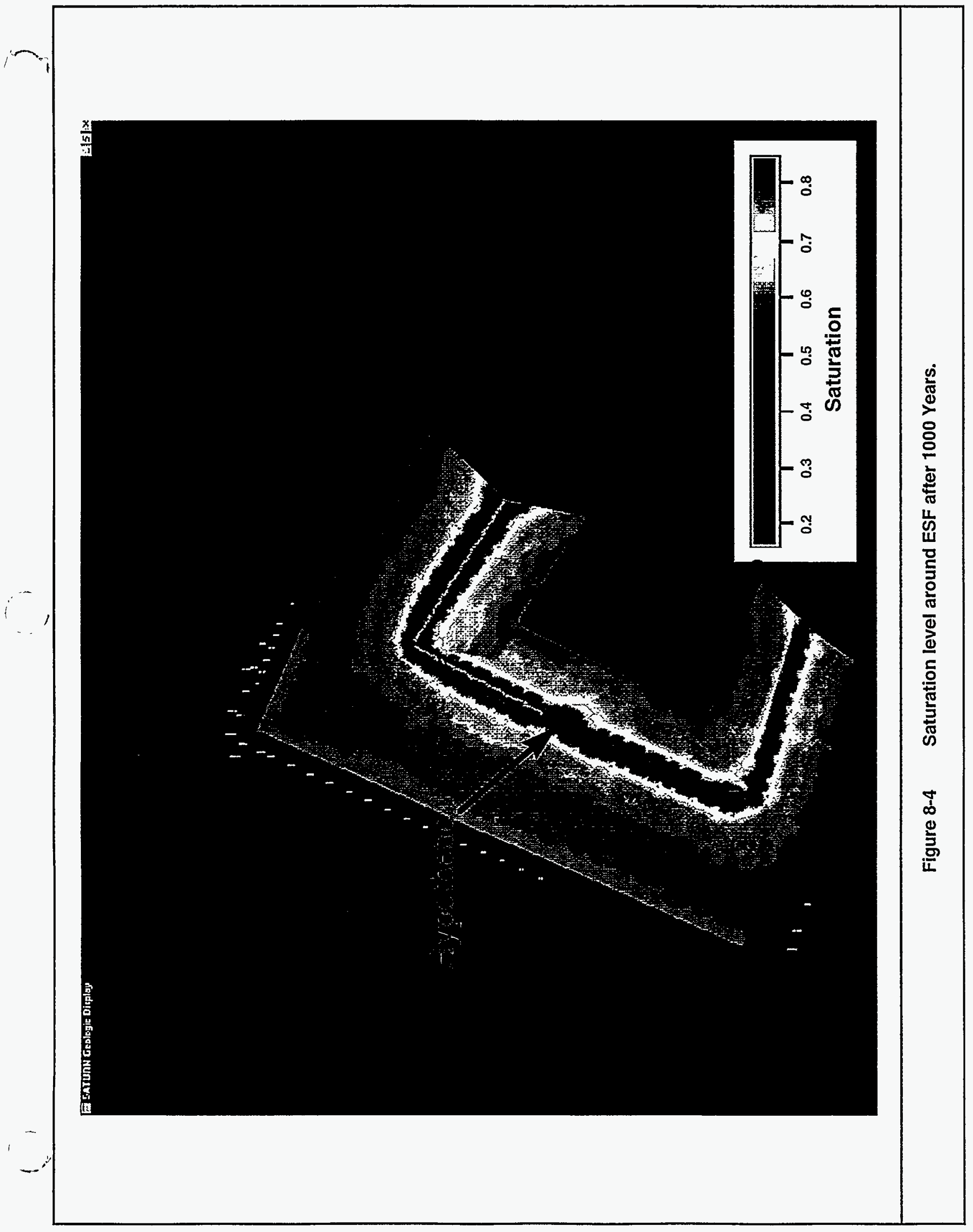




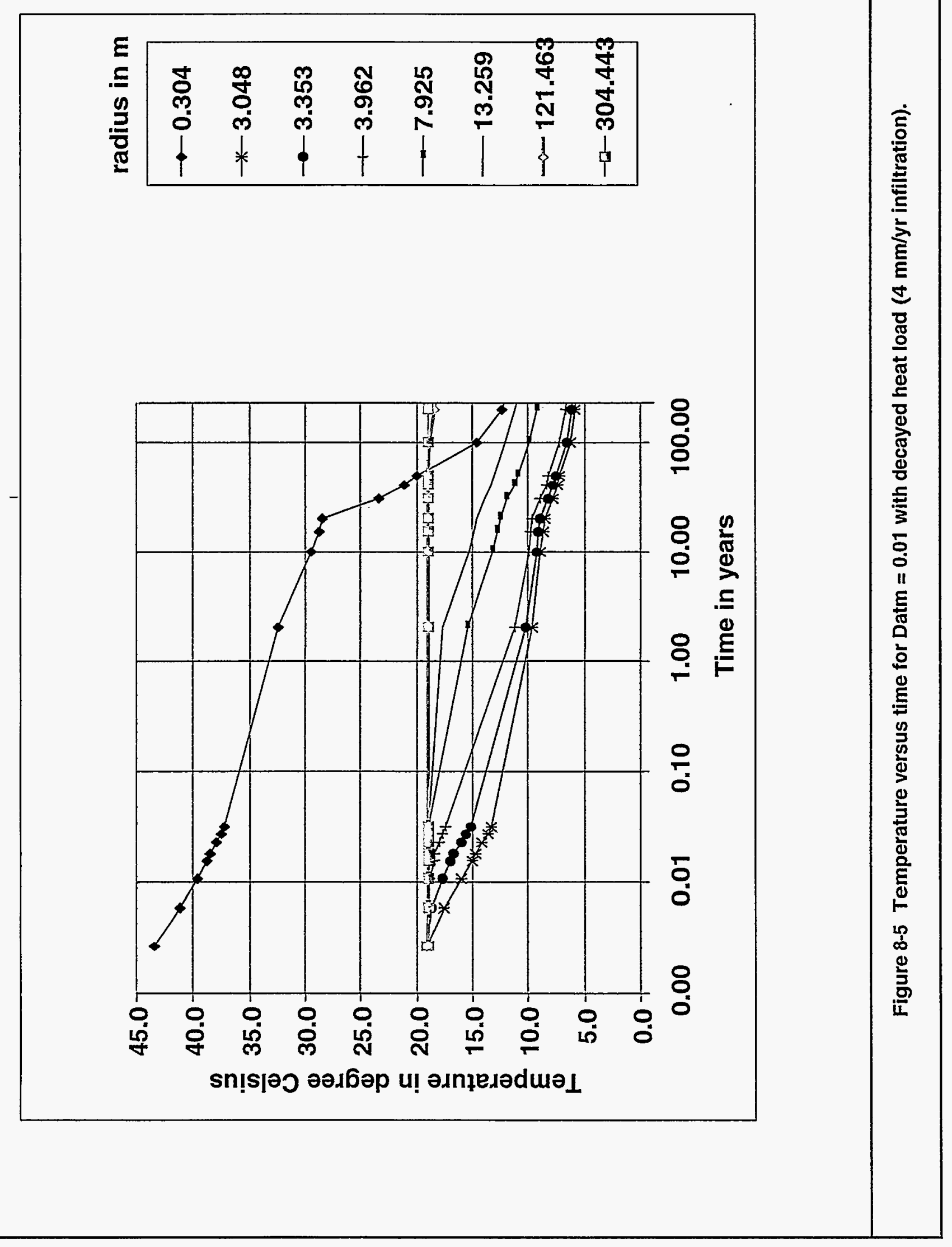




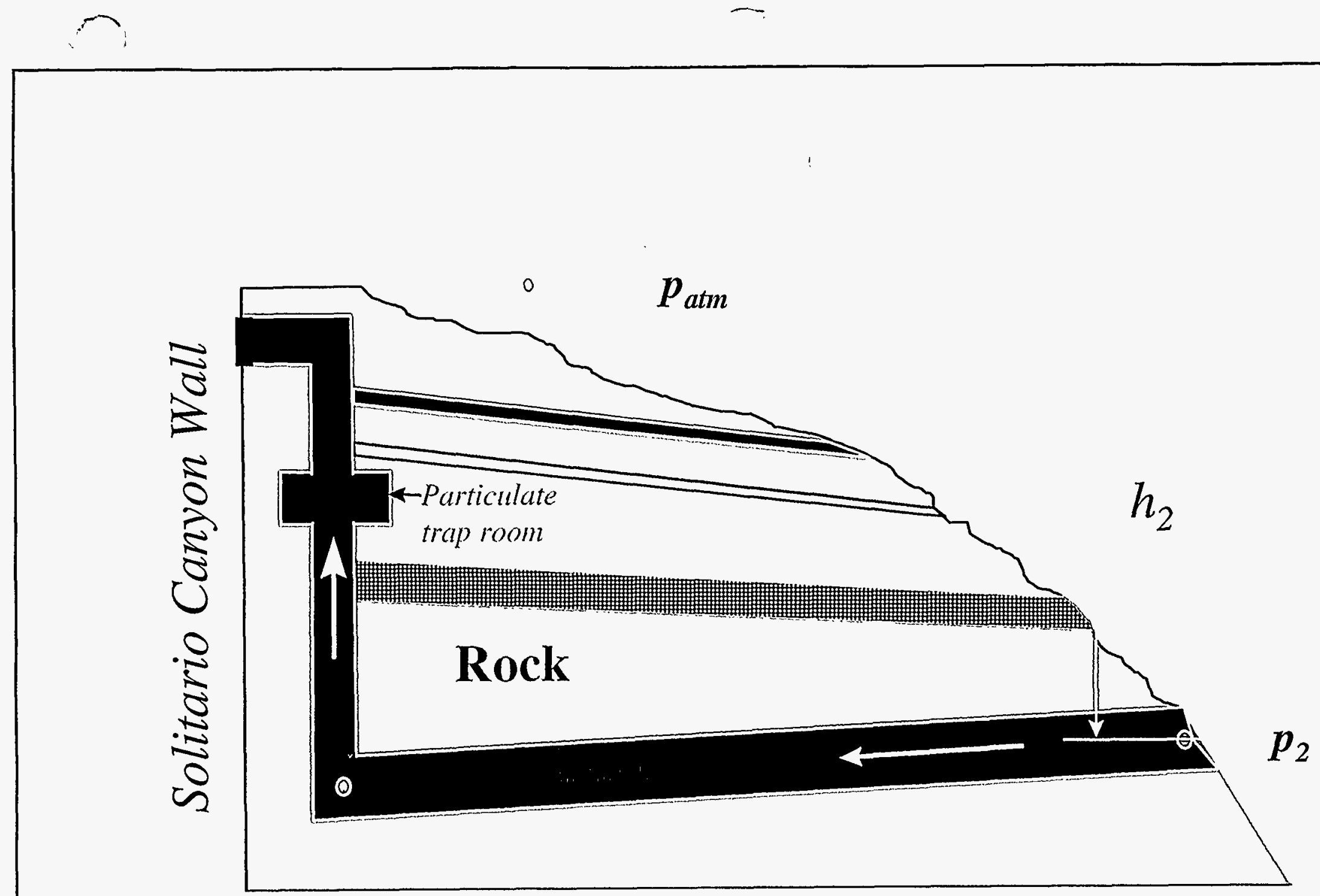

Figure 8-6 Conceptual cross section of a tunnel-shaft configuration for natural ventilation design. 